\author{
UNIVERSIDADE DE SÃO PAULO \\ INSTITUTO DE GEOCIÊNCIAS
}

\title{
CONTAMINAÇÃO POR NITRATO E SUA RELAÇÃO \\ COM O CRESCIMENTO URBANO NO SISTEMA AQUÍFERO BAURU EM PRESIDENTE PRUDENTE (SP)
}

Sandra Procel

Orientador: Prof. Dr. Ricardo César Aoki Hirata

DISSERTAÇÃO DE MESTRADO

Programa de Pós-Graduação em Recursos Minerais e Hidrogeologia

SÃO PAULO

2011 


\title{
UNIVERSIDADE DE SÃO PAULO \\ INSTITUTO DE GEOCIÊNCIAS
}

\section{CONTAMINAÇÃO POR NITRATO E SUA RELAÇÃO COM O CRESCIMENTO} URBANO NO SISTEMA AQUIIFERO BAURU EM PRESIDENTE PRUDENTE (SP)

\author{
SANDRA TERESA PROCEL GUERRA
}

Orientador: Prof. Dr. Ricardo César Aoki Hirata

DISSERTAÇÃO DE MESTRADO

COMISSÃO JULGADORA

Nome

Presidente: Prof. Dr. Ricardo César Aoki Hirata

$\begin{array}{ll}\text { Examinadores: } & \text { Dr. } \\ & \text { Didier Gastmans } \\ & (\text { UNESP) }\end{array}$

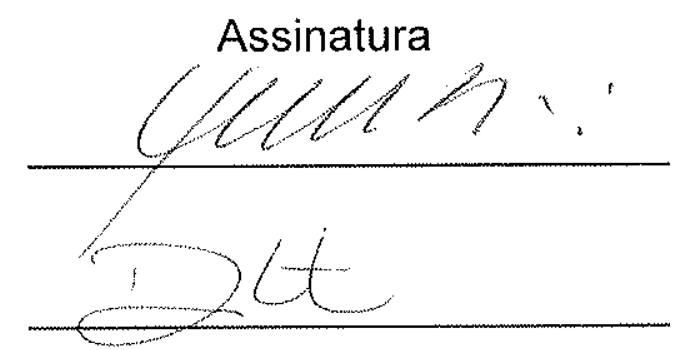

Prof ${ }^{\mathrm{a}}$. Dr ${ }^{\mathrm{a}}$. Veridiana Teixeira de Souza Martins

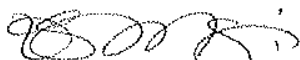

(GSA/Gc/USP) 


\section{UNIVERSIDADE DE SÃO PAULO INSTITUTO DE GEOCIÊNCIAS}

\section{CONTAMINAÇÃO POR NITRATO E SUA RELAÇÃO COM O CRESCIMENTO URBANO NO SISTEMA AQUÍFERO BAURU EM PRESIDENTE PRUDENTE (SP)

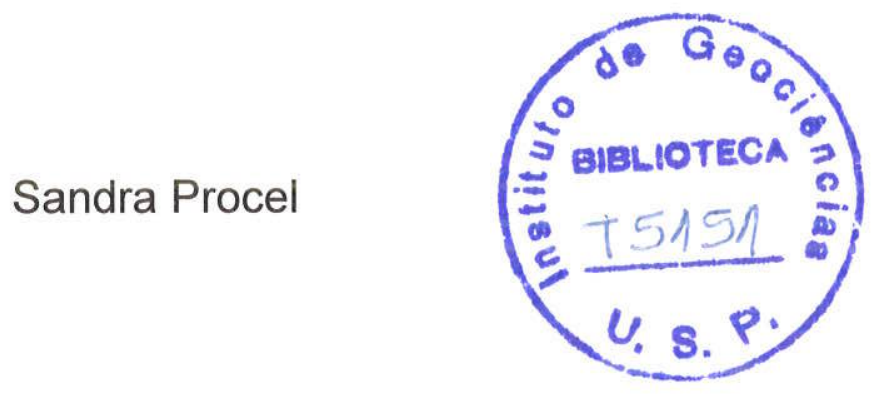

Orientador: Prof. Dr. Ricardo César Aoki Hirata

\section{DISSERTAÇÃO DE MESTRADO}

Programa de Pós-Graduação em Recursos Minerais e Hidrogeologia

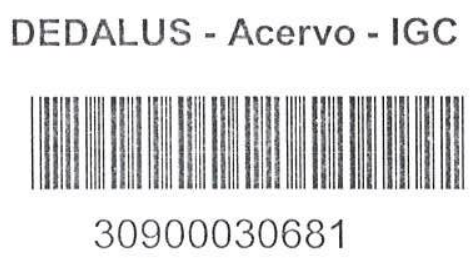

SÃO PAULO 
Autorizo a reprodução e divulgação total e/ou parcial deste trabalho, por qualquer meio para fins de estudo e pesquisa, desde que citada a fonte. 
A meu grande e único amor

Raúl Eduardo (Pichocho) e aos meus amados pais Bolivar e Teresa 


\section{AGRADECIMENTOS}

Agradeço às pessoas que de alguma forma contribuíram com a realização deste trabalho:

\section{Brasil}

Ao Prof. Dr. Ricardo Hirata, pela orientação, apoio, ensino, e paciência.

A Dra. Claudia Varnier, Pesquisadora do Instituto Geológico do Estado de São Paulo co-orientadora do projeto de Mestrado, pela sua imponderável ajuda nas saídas de campo, pelas sugestões e ensino no campo, laboratório, na discussão dos resultados e na escrita desta dissertação. Pelos momentos de relaxamento, as festas latinas e os recorridos pela muito bonita cidade de São Paulo.

Ao Instituto de Geociências da Universidade de São Paulo (IGc-USP), em especial ao Programa de Pós-Graduação em Geologia Sedimentar e Ambiental pela infra-estrutura para a realização deste trabalho.

À Coordenação de Aperfeiçoamento de Pessoal de Nivel Superior-CAPES, pelo apoio financeiro através da conceição da bolsa de Mestrado.

À Fundação de Amparo à Pesquisa do Estado de São Paulo (FAPESP) pelo auxílio à Pesquisa (processo é 2009/05840-1)

Ao Instituto Geológico da Secretaria de Meio Ambiente do Estado de São Paulo, (IG/SMA), em especial ao Núcleo de Hidrogeologia pelo suporte, infra-estrutura e pelo ensino em campo, laboratório assim como no trabalho de escritório. Um agradecimento especial a Mara Akie Iritani, Luciana Martin Rodrigues Ferreira, Sibele Ezaki, Amélia João Frenandez, Mauricio Viotti, que durante todas as etapas do trabalho do mestrado estiveram sempre prontos a colaborar em todo o que precisava.

Ao Departamento de Águas e Energia Elétrica de Presidente Prudente (DAEE), através de seu diretor Osvaldo Sugui e seus funcionários (Sandro, Murilo, André, Emerson, Roberto) por fornecerem todo o suporte técnico e a infra-estrutura para a realização deste projeto. 
À Companhia de Saneamento Básico do Estado de São Paulo (SABESP) através de seus funcionários pelo fornecimento das informações das análises químicas, perfis construtivos dos poços, dados de abastecimento de água e esgoto na área de estudo.

À Vigilância Sanitária Municipal através de seus funcionários (Maura) pelos dados das análises fisico-químicas da área urbana de Presidente Prudente.

À Universidade Estadual de São Paulo-Presidente Prudente através do Professor Leal, e seus alunos de graduação (Milena), mestrado e doutorados pelo fornecimento dos mapas da drenagem, topográfico e urbano e as informações sobre a expansão urbana em Presidente Prudente.

À LEGACY Consultoria Ambiental através de Marcelo e Eduardo Hiroshi Kinoshita pelos dados e informações das análises químicas dos poços.

A meus colegas do Lamo, Leonardo, Diego, Ana, Bruno, Carlos, Tatiana, Bruna, e a toda a equipe LAMO.

A minhas colegas de sala, Martha Edith e Ariana pelas dicas, cafés e risos que diariamente compartíamos.

A meus amigos Sibele, Anabel, Gledison, Thais, Grasiane, Reinaldo, Fernanda, Tatiana, Féderick, Sergio, Emilio, que fizeram de minha vida neste país, uma experiência maravilhosa e inesquecivel.

Às funcionárias do IGc, através de Ana Paula e Magaly pela colaboração e compreensão com uma estrangeira.

\section{Ecuador}

A Dios por bendecirme por todo lo que tengo, por escucharme y mantenerme perseverante.

A mis queridos Padres por el amor y apoyo incondicional en todas las etapas de mi vida. Gracias a ellos pude conocer este país, pude valorar el mío y a los míos.

A mis Hermanas (Ximena y Shadira) y a mis sobrinhas (Mishu, Dany y Dome) por enseñarme a ser perseverante, a ser fuerte lejos de la familia, gracias por ayudarte en los momentos de crisis y por enseñarme a ser valiente. 
A mi gran amor Raúl, por estar siempre a mi lado, por ser mi cómplice, mi amigo, orientador, profesor, todo. Por tenerme paciencia y creer en mí.

A mis jefes Ing. Bernardo Alvarez e Ing. Fernando Tapia, que me ayudaron a decidirme emprender este viaje y aventura de seguir un posgrado. 


\section{RESUMO}

$\mathrm{Na}$ área urbana da cidade de Presidente Prudente foram identificados inúmeros poços tubulares que captam águas do Sistema Aquífero Bauru com concentrações de nitrato acima do padrão de potabilidade (10 mg/L de $\mathrm{NO}_{3}{ }^{-}-\mathrm{N}$ ou $45 \mathrm{mg} / \mathrm{L} \mathrm{NO}_{3}{ }^{\circ}$ ).

O objetivo principal deste trabalho consistiu em avaliar as tendências de distribuição das concentrações de nitrato nas águas subterrâneas, ao longo do tempo e espaço, frente aos padrões de ocupação urbana e do uso do solo.

Os métodos utilizados compreenderam o sistema de informação geográfica (SIG) e métodos estatísticos básicos aplicados aos dados hidrogeoquímicos pré-existentes, provenientes de 60 poços tubulares e os gerados mediante a amostragem semestral de 22 poços, distribuídos na área urbana do município.

A partir dos resultados obtidos, a área urbana foi dividida em três zonas sensiveis à contaminação por nitrato. A zona denominada $(A)$ corresponde às áreas com altas concentrações deste contaminante $\left(>45 \mathrm{mg} / \mathrm{L}\right.$ de $\left.\mathrm{NO}_{3}{ }^{\circ}\right)$ devido ao rápido crescimento populacional, o qual estaria associado, principalmente, à alta densidade de antigos sistemas de saneamento in situ (fossas sépticas e negras). Outras fontes relacionadas aos aumentos nas concentrações constituíram os vazamentos, fugas, redes coletoras de esgoto muito antigas e manutenção inadequada das mesmas. $A$ zona (B) refere-se às áreas com possiveis problemas de nitrato ou áreas denominadas de "alerta", onde a densidade urbana é menor (84 hab/ha) que a zona A (120 hab/ha). As concentrações de nitrato encontram-se entre $23 \mathrm{mg} / \mathrm{L}$ e $45 \mathrm{mg} / \mathrm{L}$. de $\mathrm{NO}_{3}{ }^{-}$. A zona $(\mathrm{C})$ compreende as áreas não contaminadas. Estas áreas têm baixa densidade urbana (20 hab/ha) e concentrações de nitrato inferiores ao valor de alerta definido pela CETESB $\left(23 \mathrm{mg} / \mathrm{L}_{\text {de }} \mathrm{NO}_{3}{ }^{-}\right)$.

O zoneamento proposto neste trabalho servirá como referência para a determinação de medidas preventivas que visam o melhoramento na qualidade das águas subterrâneas na área urbana de Presidente Prudente.

Palavras chaves: nitrato, ocupação urbana, Sistema Aquífero Bauru, Presidente Prudente. 


\section{ABSTRACT}

Concentrations of nitrate, above the drinking water standard $\left(10 \mathrm{mg} / \mathrm{L} \mathrm{NO}_{3}{ }^{-}-\mathrm{N}\right.$ or $45 \mathrm{mg} / \mathrm{L} \mathrm{NO}_{3}{ }^{\circ}$ ), have been detected in several deep drilling wells, located at the urban area of Presidente Prudente city.

The main goal of this work is to evaluate the trends in distribution of nitrate concentrations in groundwater, over time and space, in relation to urban settlement patterns and land use.

In order to perform this, the geographic information systems (GIS) and basic statistical methods were used. These methods were applied on pre-existing hydrogeochemical data of 60 drilling wells, and from new chemical analyses of 22 drilling wells throughout the urban area.

From these results, the urban area was divided in three zones that are sensitive to nitrate contamination. The $\mathrm{A}$ zone corresponds to areas with high nitrate concentrations ( $>45 \mathrm{mg} / \mathrm{L}$ de $\mathrm{NO}_{3}{ }^{-}$) due to the fast population growth, which it could directly be associated to the high density of on-site sanitation systems (latrines and septic tanks). Other sources related to the nitrate increasing concentrations in these areas are the sewer leaks, old sewer as well as their inadequate maintenance. The $B$ zone refers to areas with possible nitrate pollution called "in alert" zones. The population density is low (84 inhabitants. ha $^{-1}$ ) when compared with the A zone (12 inhabitants. ha $\left.{ }^{-1}\right)$. The nitrate concentrations are between $23 \mathrm{mg} / \mathrm{L}$ and $45 \mathrm{mg} / \mathrm{L} \mathrm{NO}_{3}{ }^{\prime \prime}$. The $\mathrm{C}$ zone corresponds to areas without nitrate pollution problem. These areas have low population density ( 20 inhabitants. ha $\left.{ }^{-1}\right)$ and the nitrate concentrations are lower than the alert value defined by CETESB $\left(23 \mathrm{mg} / \mathrm{L} \mathrm{NO}_{3}{ }^{\circ}\right)$.

The proposed zoning in this work will serve as a reference to the establishment of prevent policies in order to improve the groundwater quality within the urban area of Presidente Prudente.

Keywords: nitrate, urban settlement, Bauru Aquifer System, Presidente Prudente. 


\section{SUMÁRIO}

RESUMO

.. V

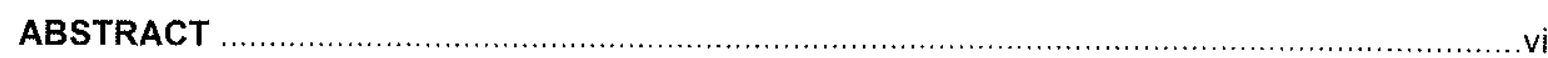

LISTA DE ANEXOS

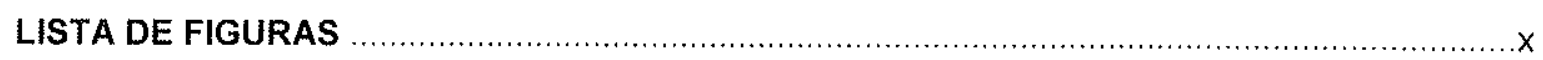

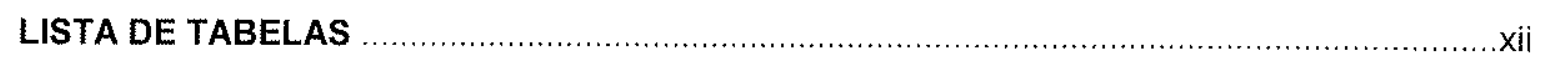

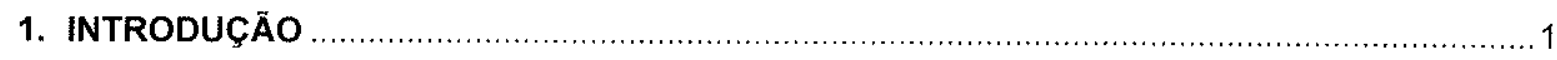

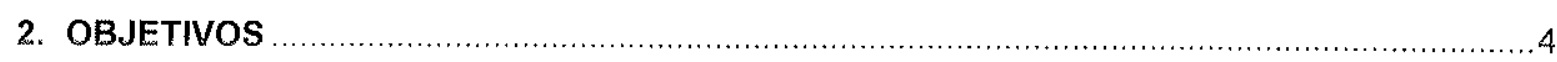

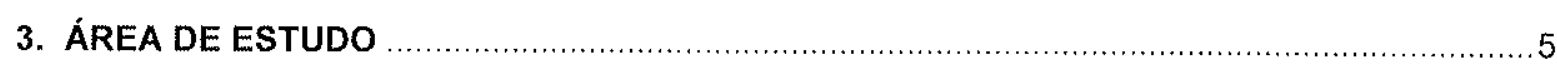

3.1. LOCALIZAÇÃO E CARACTERIZAÇÃO DA ÁREA DE ESTUDO

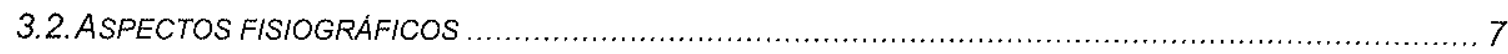

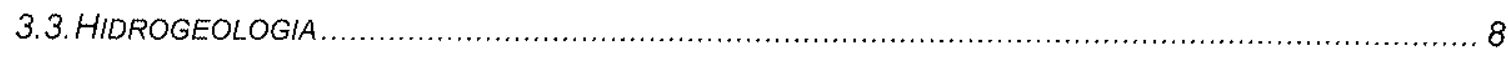

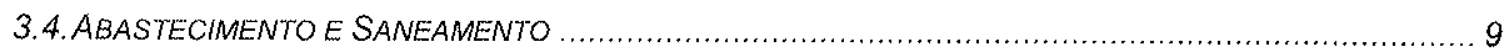

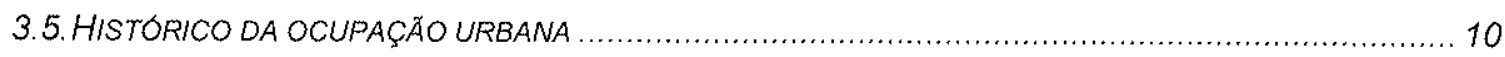

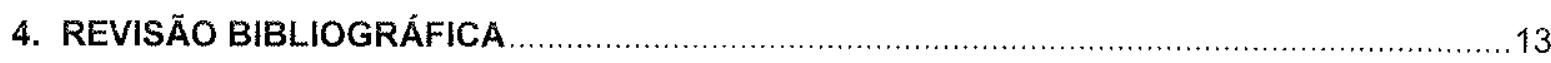

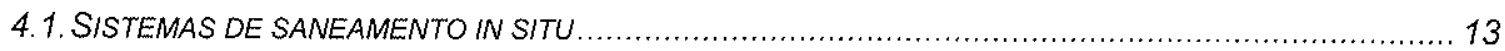

4.2. GEOQUIMICA DOS EFLUENTES GERADOS NOS SISTEMAS DE SANEAMENTO IN SITU ...................... 15

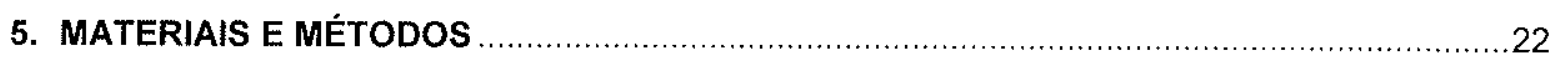

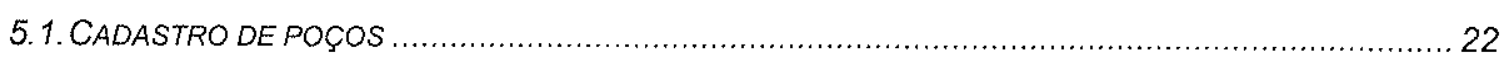

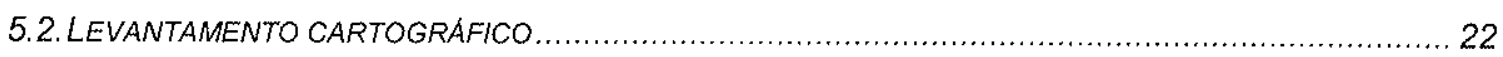

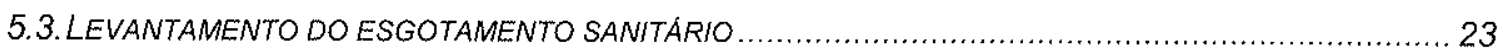

5.4. DETERMINAÇÄO DO MODELO CONCEITUAL DE CIRCULAÇÃO DAS ÁGUAS SUBTERRÂNEAS............. 23

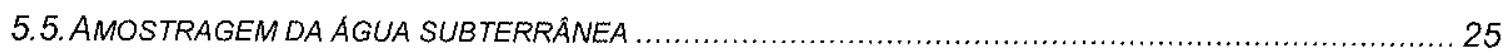

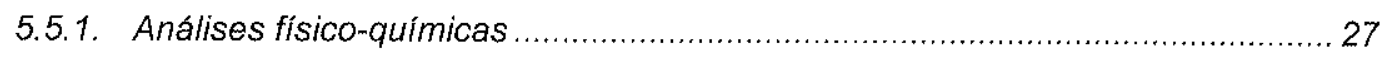

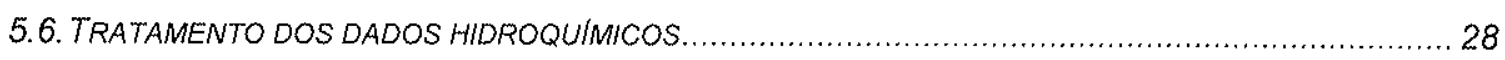

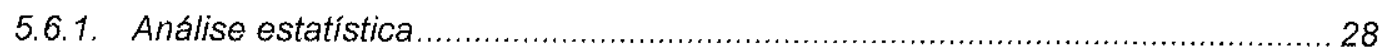

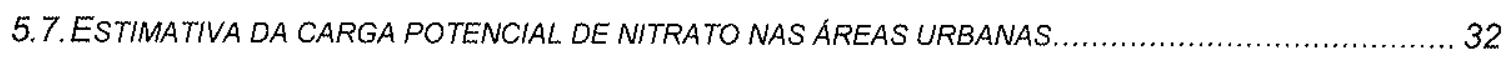

6. RESULTADOS

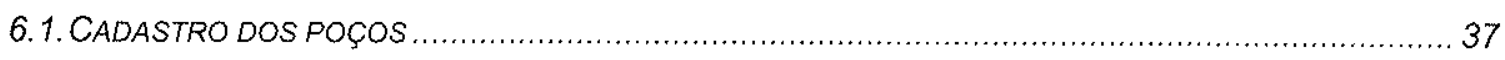

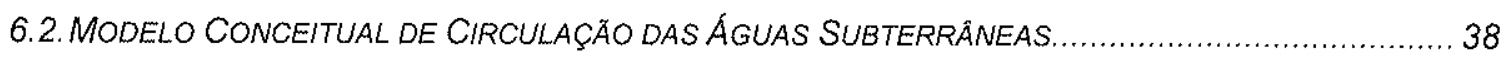

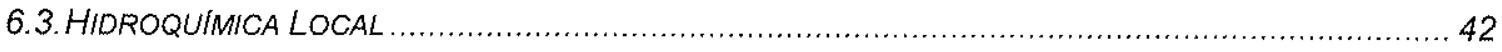

6.3.1. Controle de qualidade dos dados hidroquímicos ......................................... 42

6.3.2. Classificação e Evolução Hidrogeoquímica das Águas Subterrâneas ............. 43

6.3.3. Evoluções temporais e espaciais das concentrą̧ões de nitrato ......................... 56 


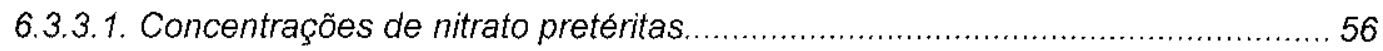

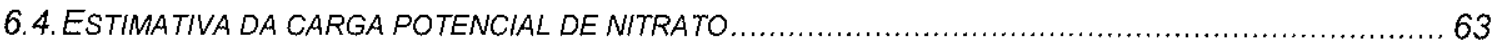

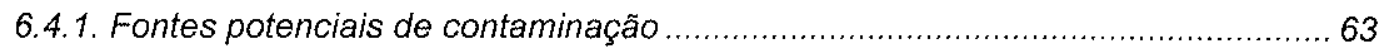

6.4.2. Cálculo semiquantitativo da concentração de nitrato .....................................66 66

6.4.3. Determinação da zona de captura nos poços ........................................... 70

6.5. ZONEAMENTO DAS AREAS POTENCIAIS DE CONTAMINAÇÅO DE NITRATO .............................. 74

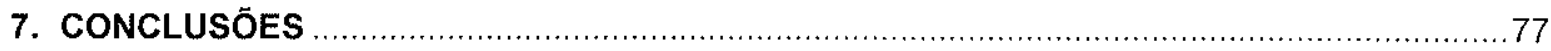

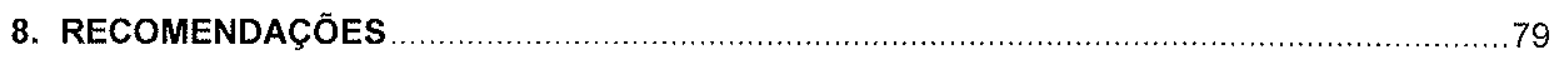

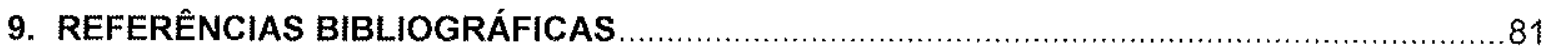




\section{LISTA DE ANEXOS}

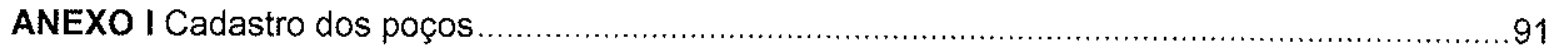

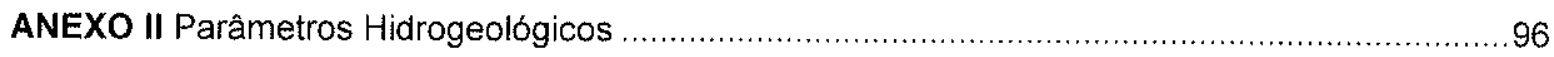

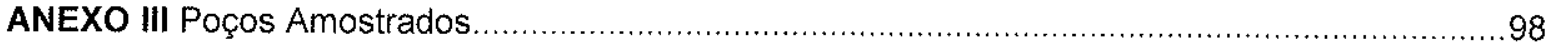

ANEXO IV Resultados dos parâmetros físico-químicos .......................................................100

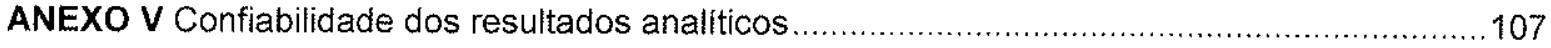

ANEXO VI Análises quimicas de nitrato preexistentes..........................................................113

ANEXO VII Análises químicas separadas por zonas............................................................118

ANEXO VIII Cálculo semiquantivo da concentração de nitrato ...............................................122

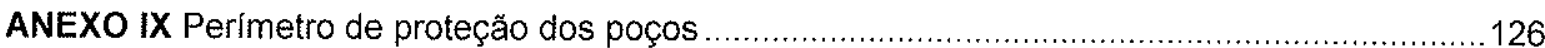




\section{LISTA DE FIGURAS}

Figura 3.1 Localização da área de estudo 6

Figura 3.2 Drenagem na zona urbana de Presidente Prudente

Figura 3.3 Evolução da população de Presidente Prudente (1930-2009). Fonte: SEADE, IBGE/DAEE/Camargo (2007).

Figura 3.4 Taxa de urbanização de Presidente Prudente (1980-2009). Fonte: SEADE, IBGE, DAEE, Camargo (2007)

Figura 4.1a. Esquema dos sistemas de saneamento in situ: a) fossa negra (Fonte: ABNT, 1993) ... 15

Figura 4.2b Esquema dos sistemas de saneamento in situ b) fossa séptica (Fonte:Hydra International L.tda, 2010)

Figura 4.3 Resumo da sequência dos processos na digestão anaeróbia no tanque séptico e fossas negras (os números referem-se às reações químicas), modificado de Van Haandel e Lettinga, 1994 e Wilhelm et al., 1994

Figura 4.4 Espécies químicas no ciclo do nitrogênio (modificado de O' Neil, 1985; in Varnier 2007), 20

Figura 5.1 Localização dos poços amostrados

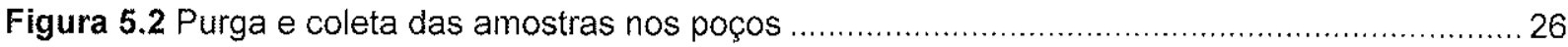

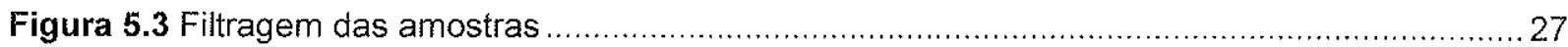

Figura 5.4 Fotografia aérea (1995) à esquerda e imagem do Google Earth (2010) à direita destacando a ferrovia e poços no centro da cidade.

Figura 5.5 Imagem do Google Earth (2011) destacando os critérios de densidade na área urbana de Presidente Prudente.

Figura 5.6. Densidade de ocupação alta $(A)$, média $(M)$ e baixa (B) adotada para Presidente Prudente. Imagem captada do Google Earth (2011).

Figura 6.1 Localização dos poços cadastrados na área urbana de Presidente Prudente. 37

Figura 6.2 Seção geológica do município de Presidente Prudente, a partir dos dados estratigráficos dos poços tubulares situados na área urbana de Presidente Prudente.

Figura 6.3 Potenciometría do SAB, a partir dos valores de níveis estático medidos na época da instalação dos poços tubulares na área de estudo

Figura 6.4 Porcentuais de erro nos balanços iônicos para as duas campanhas de amostragem......43

Figura 6.5a Diagrama de Piper dos poços com concentrações de nitrato inferiores a $45 \mathrm{mg} / \mathrm{L}$, amostrados na primeira (dezembro 2009) e segunda campanha (junhowjulho 2010).

Figura 6.6 Correlação entre nitrato, cloreto e condutividade elétrica para os poços rasos amostrados na primeira campanha de amostragem (dezembro 2009).

Figura 6.7 Correlação entre nitrato, cloreto e condutividade elétrica para os poços rasos amostrados na segunda campanha de amostragem junho - julho/2010.

Figura 6.8 Mapa de isoconcentração de nitrato ( $\mathrm{mg} / \mathrm{L}$ ) para a primeira campanha de amostragem (estação úmida). 
Figura 6.9 Mapa de isoconcentração de nitrato (mg/L) para a segunda campanha de amostragem (estação seca).

Figura 6.10 Mapa de isoconcentração de cloreto (mg/L) para a primeira campanha de amostragem (estação úmida)

Figura 6.11 Mapa de isoconcentração de cloreto ( $\mathrm{mg} / \mathrm{L}$ ) para a segunda campanha de amostragem (estação seca)

Figura 6.12 Localização das zonas urbanas e dos poços com análises pré-existentes (2005-2009. 58

Figura 6.13 Variação temporal nas concentrações de nitrato ao longo do tempo (2005-2009. ........ 58

Figura 6.14 Localização das zonas urbanas, redes de esgoto e poços com análises pretéritas na área

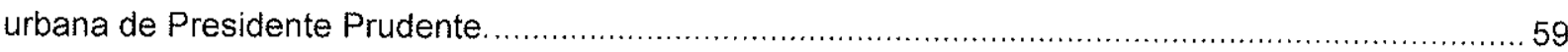

Figura 6.15 Variações do nitrato nas duas campanhas de amostragem ..........................................60 60

Figura 6.16 Variaçăo temporal de nitrato nos poços rasos durante as estações úmida e seca .........60 60

Figura 6.17 Seção dos poços e posicionamento dos filtros. .........................................................62

Figura 6.18 Evolução da malha urbana do município de Presidente Prudente (adaptado de Camargo, 2007)

Figura 6.19 Evolução da rede de esgoto no município de Presidente Prudente (adaptado de SABESP, 1990 e 2006).

Figura 6.20 Correlação entre as concentrações de nitrato medidas em campo e as calculadas semiquantitativamente (Cu) (dezembro 2009).

Figura 6.21 Correlação entre as concentrações medidas em campo e as calculadas semiquantitativamente (Cu) (junho-julho 2010).

Figura 6.22 Correlação entre as concentrações de nitrato medidas em campo e as calculadas semiquantitativamente (Cu), para as análises pretéritas (2007).

Figura 6.23 Concentrações de nitrato: a) medidas em campo (2009), b) medidas em campo (2010); c) calculadas para as duas campanhas (Cu); d) valor médio das análises preexistentes (2007-2009) e) calculadas para as análises pré-existentes (Cu)

Figura 6.24 Vazões dos poços rasos e profundos na área urbana de Presidente Prudente.

Figura 6.25 Raio fixo calculado para os poços amostrados na área urbana de Presidente Prudente.73

Figura 6.26 Raio fixo calculado para os poços da área urbana de Presidente Prudente. 73

Figura 6.27 Expansão urbana e distribuição dos poços amostrados nas zonas A, B e C (adaptado de Camargo, 2007)

Figura 6.28 Zoneamento das áreas potenciais de contaminação por nitrato para a área urbana de Presidente Prudente 


\section{LISTA DE TABELAS}

Tabela 4.1 Resumo dos aquíferos urbanos contaminados pelos sistemas de saneamento in situ

Tabela 4.2 Resumo das principais características hidrogeoquimicas e parâmetros presentes nos sistemas de saneamento in situ (Varnier, 2007 e Wilhelm et al., 1994).

Tabela 5.1 Métodos analíticos adotados para a determinação dos parâmetros em amostras de água.27

Tabela 6.1 Sumário de parâmetros hidrogeológicos na zona de estudo

Tabela 6.2 Estadística dos parâmetros físicos medidos no campo para as amostras de água na primeira campanha de amostragem (dezembro/2009).

Tabela 6.3 Estadística dos parâmetros físicos medidos no campo para as amostras de água na segunda campanha de amostragem (junho-juiho/2010).

Tabela 6.4 Dados estatísticos dos cátions e ânions analisados para amostras de água na primeira campanha de amostragem (dezembro/2009).

Tabela 6.5 Dados estatísticos dos cátions e ânions analisados para amostras de água na segunda campanha de amostragem (junho-julho/2010).

Tabela 6.6 Matriz de correlação das análises químicas dos poços com até $150 \mathrm{~m}$ de profundidade dezembro/2009.

Tabela 6.7 Matriz de correlação das análises quimicas dos poços com até $150 \mathrm{~m}$ de profundidade junho - julho/2010.

Tabela 6.8 e 6.9 Matrizes de correlação das análises químicas dos poços maiores que $150 \mathrm{~m}$ de profundidade dezembro/2009 e junho - julho/2010

Tabela 6.10 Resumo dos números de poços e análises antigas para os anos de 2005 a 2009. 56

Tabela 6.11 Estatística dos valores de nitrato, condutividade elétrica e cloreto analisado em laboratório para as amostras dos poços rasos (dezembro 2009 e junho-julho 2010).

Tabela 6.12 Estatistica dos valores de nitrato, condutividade elétrica e cloreto analisados em laboratório para as amostras dos poços profundos (dezembro 2009 e junho-julho 2010).

Tabela 6.13 Resumo das principais características hidrogeoquímicas das águas subterraneas do $\mathrm{SAB}$ em Presidente Prudente

Tabela 6.14 Estatística básica e comparação dos raios fixos calculados para os poços cadastrados na área urbana de Presidente Prudente

Tabela 6.15 Comparação entre os raios fixos calculados para os poços amostrados na área urbana de Presidente Prudente

Tabela 6.16 Comparação entre os raios fixos calculados para os poços profundos amostrados na área urbana de Presidente Prudente. 


\section{INTRODUÇÃO}

A ocorrência de nitrato em aquíferos tem preocupado administradores dos recursos hídricos em diversos municípios brasileiros, dado que este é o contaminante mais comumente encontrado nas águas subterrâneas. Este parâmetro é utilizado, mundialmente, como indicador da contaminação das águas subterrâneas devido à sua alta mobilidade, podendo atingir extensas áreas.

Uma das fontes potenciais de nitrato são os sistemas de saneamento, dos quais se destacam as fossas sépticas e negras, bem como redes coletoras mal projetadas e executadas que contribuem para a contaminação em áreas urbanas, sobretudo nos locais de grande densidade populacional. Além dos compostos nitrogenados, destaca-se também a presença de contaminantes microbiológicos (bactérias patogênicas e vírus) e, em alguns casos, compostos orgânicos sintéticos.

Altas concentrações de nitrato, muitas vezes excedendo os valores de potabilidade (10 mg/L NO $\mathrm{NO}_{3} \mathrm{~N}$, Portaria $n^{\circ} 518 / 04$ do Ministério da Saúde), foram detectadas em poços tubulares no município de Presidente Prudente, oeste do Estado de São Paulo (Godoy et al., 2004; Varnier et al., 2010).

Este município é parcialmente abastecido pelas águas do Sistema Aquífero Bauru, considerado a maior unidade hidrogeológica em área do Estado de São Paulo, ocupando aproximadamente $47 \%$ do território paulista $\left(96.880 \mathrm{~km}^{2}\right)$. Este aquífero, por comportar-se principalmente como livre e possuir grande área de afloramento, é o que apresenta maior vulnerabilidade à contaminação antrópica, com os mais elevados valores de nitrato nas águas subterrâneas no Estado de São Paulo.

Nos últimos 70 anos, Presidente Prudente sofreu um forte processo de urbanização, inicialmente sem instalação de rede de esgoto, lançando o efluente in natura no solo. Com o processo de urbanização, as fossas foram desativadas e, atualmente, a rede de esgoto cobre aproximadamente 98\% (SABESP, comunicação verbal). 
O processo histórico de ocupação territorial não se restringe somente à Presidente Prudente. Inúmeras cidades do centro-oeste paulista convivem com o mesmo problema, dos quais se destacam São José do Rio Preto (Barcha, 1980), Bauru (Hirata, 2000; Giafferis \& Oliveira, 2006) Marília, Jaú, entre outros.

Mesmo com a considerável extensão de tais redes implantadas nas cidades paulistas, o nitrogênio remanescente no solo continua em grande volume nas zonas não-saturada e saturada do Sistema Aquifero Bauru.

A solução desse problema é complexa e uma pergunta que se coloca refere-se à relação entre urbanização e a evolução deste contaminante nas águas subterrâneas. Adicionalmente, o conhecimento do histórico do uso do solo e padrão de ocupação em áreas urbanas ao longo do tempo, somada à carga de nitrogênio lançada por essas fontes de contaminação, será necessário para definir se o aumento nas concentrações de nitrato no aquífero é resultante deste estilo de ocupação.

Alguns estudos apontaram a relação entre os padrões de concentrações de nitrato nas águas subterrâneas e os de ocupação urbana (Lowe et al., 2000; Cagnon \& Hirata, 2004; Godoy et al., 2004; Drake \& Bauder, 2005; Reynolds-Vargas et al., 2006; Xu et al., 2007) mediante o uso de diferentes ferramentas.

Cagnon \& Hirata (2004) procuraram estabelecer uma relação entre a contaminação das águas subterrâneas do Sistema Aquífero Bauru por nitrato e os padrões de urbanização no município de Urânia (SP) desde 1950 até 2000. Nesta avaliação, realizou-se um levantamento das principais fontes de contaminação bem como estudo do uso e histórico de ocupação do solo por meio de fotografias aéreas de diferentes décadas, imagens de satélite, trabalhos de campo, análises químicas e de $\delta^{15} \mathrm{~N}_{\mathrm{NO} 3}$ em amostras de água. Os resultados obtidos mostraram uma contaminação antrópica e multipontual, do tipo fossas negras, instaladas na área urbana do município desde a década de 50. As maiores concentrações de nitrato foram observadas nas porções mais rasas do aquífero, sobretudo a nordeste da cidade, onde há maior densidade dessas fossas.

Drake \& Bauder (2005) utilizaram sistema de informação geográfica (SIG) e métodos estatísticos para estudar a relação entre os padrões de ocupação 
urbana/uso do solo e as variações espaciais e temporais nas concentrações de nitrato entre os anos de 1971 e 2003 no Estado de Montana (EUA). Os resultados indicaram que houve aumento nas concentrações desse contaminante em áreas com rápido crescimento populacional e que estariam associadas à alta densidade de fossas sépticas irregulares. Segundo estes autores, os métodos estatísticos combinados aos do SIG podem ser utilizados para avaliar amplas áreas indicando, tanto visual como matematicamente, a relação entre as mudanças no uso do solo e a concentração de nitrato ao longo do tempo.

Xu et al. (2007), em estudo similar ao de Drake \& Bauder (2005), verificaram os padrões de concentração de nitrato durante um período de 60 anos, em mais de 200 poços situados em Phoenix e arredores (Arizona, EUA), utilizando SIG. Tais informações, combinadas com aquelas referentes aos mapas de uso do solo, nivel d'água e aspectos construtivos dos poços, foram usadas para avaliar as mudanças nas concentrações de nitrato e sua relação com o uso do solo e padrões de ocupação urbana.

Adicionalmente, Reynolds-Vargas et al. (2006) verificaram os padrões de concentração de nitrato bem como sua origem nas águas subterrâneas do Vale Central (Costa Rica) através de isótopos estáveis $\left({ }^{18} \mathrm{O}_{\mathrm{NO} 3}\right.$ e $\left.{ }^{15} \mathrm{~N}_{\mathrm{NO} 3}\right)$ e dados hidrogeoquimicos. Os resultados obtidos apontaram correspondência entre padrões de ocupação urbana e assinatura isotópica do nitrogênio nas águas subterrâneas. Segundo os autores, os processos de urbanização, com a disposição inadequada dos sistemas sépticos, em substituição às plantações de café, é a provável causa do aumento de até $40 \%$ nas concentrações de nitrato no aquífero estudado.

Diante deste cenário, o estudo propõe avaliar as tendências de incremento nas concentrações de nitrato no Sistema Aquífero Bauru em Presidente Prudente frente ao estilo de ocupação urbana, procurando estabelecer um padrão de causa e efeito entre a fonte e o impacto deste contaminante nas águas subterrâneas. 


\section{OBJETIVOS}

O principal objetivo deste trabalho consiste em avaliar os padrões de ocupação urbana, uso do solo e relacionar com as tendências de distribuição espacial e temporal das concentrações de nitrato nas águas subterrâneas do Sistema Aquífero Bauru na área urbana da cidade de Presidente Prudente.

São objetivos específicos

$\checkmark$ Estabelecer uma relação entre as concentrações de nitrato, crescimento populacional e zonas urbanizadas;

$\checkmark$ Estimar a carga potencial de nitrato nas águas subterrâneas, proveniente de sistemas de saneamento in situ ou de áreas urbanas ocupadas;

$\checkmark$ Propor medidas aos poderes público, municipal e estadual, de modo a minimizar os riscos de contaminação extensiva por nitrato, estabelecendo medidas de atenuação e de proteção dos recursos hídricos subterrâneos. 


\section{3. ÁREA DE ESTUDO}

\subsection{Localização e caracterização da área de estudo}

O local escolhido para o desenvolvimento deste estudo situa-se na área urbana de Presidente Prudente, extremo oeste do Estado de São Paulo. Este possui área territorial de $563,62 \mathrm{~km}^{2}$ e população de 207.625 habitantes (IBGE, 2009). A área específica de estudo abrange um total de $136 \mathrm{~km}^{2}$, entre as coordenadas UTM 7.547,489 e 7.560,450 km e 451,083 e 467,107 km (Figura 3.1).

Presidente Prudente limita-se a norte com os municípios de Adamantina, Flora Rica e Mariápolis, a leste, com Caiabu, Regente Feijó e Indiana, a sul, com Anhumas e Pirapozinho e a oeste, com Álvares Machado e Santo Expedito. O município dista cerca de $570 \mathrm{~km}$ da capital paulista e a principal via de acesso é feita através das rodovias Marechal Castelo Branco (SP 280) até Ourinhos, de onde o trajeto continua pela rodovia Raposo Tavares (SP 270).

A área foi selecionada por apresentar concentrações de nitrato nas águas subterrâneas acima do valor máximo permitido para o consumo humano.

Segundo Strahler (1957), o clima da área de estudo pode ser definido como tropical alternadamente seco e úmido. Segundo Köppen (1948), o mesmo se define como Awa, representado por duas estações do ano bem definidas: um verão quente e chuvoso de outubro a março e um inverno seco, de abril a setembro (Barrios \& Sant'Anna Neto, 1996).

Durante a primavera e verão, as temperaturas diárias oscilam entre os $20^{\circ} \mathrm{C} e$ $32^{\circ} \mathrm{C}$, com máximas próximas aos $40^{\circ} \mathrm{C}$. No outono-inverno, as temperaturas variam entre $15^{\circ} \mathrm{C}$ e $20^{\circ} \mathrm{C}$ (Amorim, 2009). A média anual de precipitação é de $153,1 \mathrm{~mm}$ (2009). Os meses de dezembro a fevereiro são os mais chuvosos e os de junho a agosto, os mais secos. 


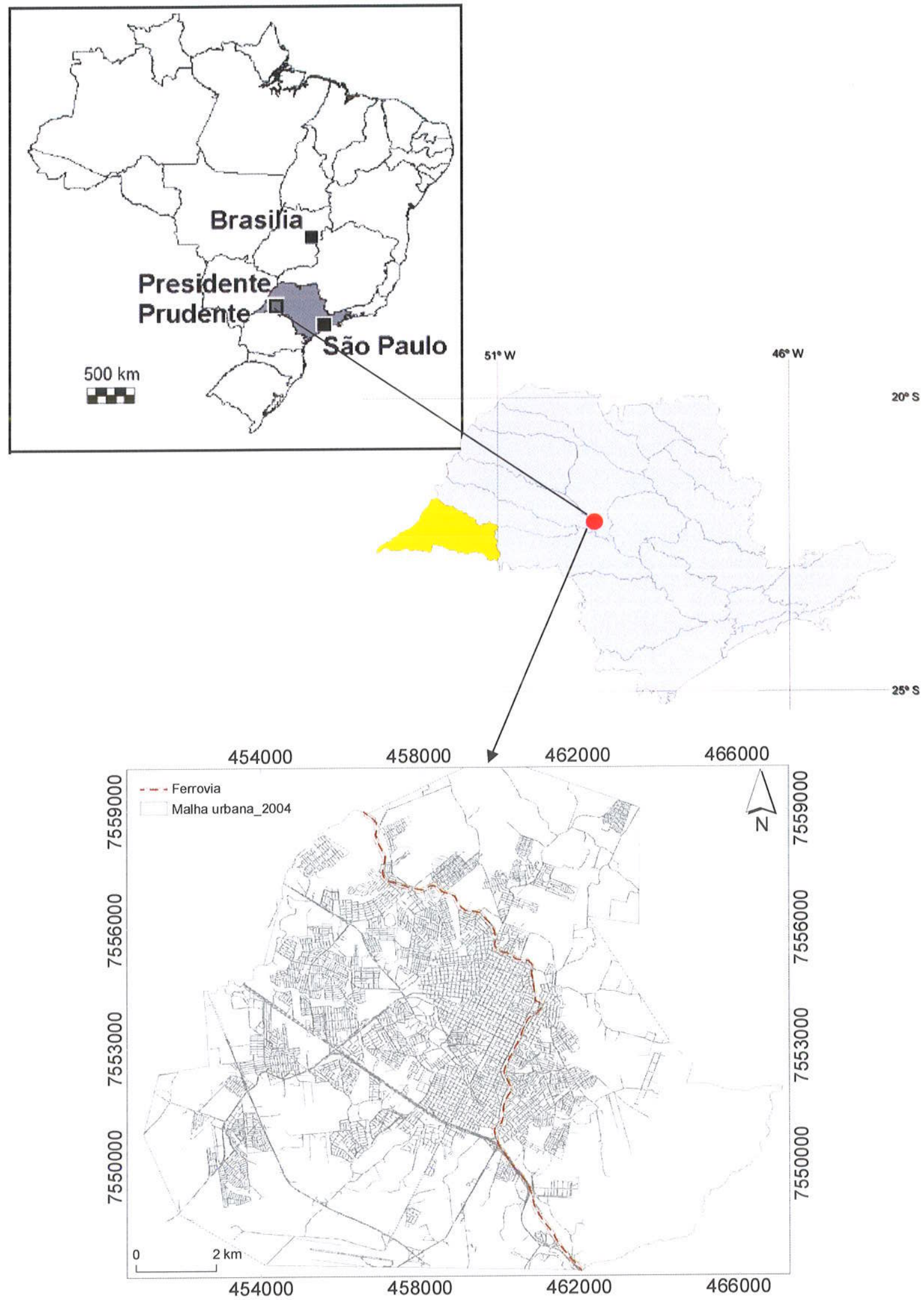

Figura 3.1 Localização da área de estudo 


\subsection{Aspectos fisiográficos}

O município de Presidente Prudente situa-se na unidade geomorfológica denominada Planalto Ocidental Paulista (POP). O POP ocupa cerca de $40 \%$ do Estado de São Paulo (Sant'Anna Neto, 1995) e no município, possui um formato alongado no sentido norte-sul (Amorim, 2000).

O relevo da cidade distingue zonas com diferenciações morfológicas. Na zona leste, predominam colinas de poucas extensões, topos curtos e ondulados, fundos de vales e declividades médias que variam entre $5 \%$ a $20 \%$. Na zona Oeste, o relevo predominante caracteriza-se por colinas médias e baixas, com altitudes que variam entre $300 \mathrm{~m}$ e $600 \mathrm{~m}$ e declividades médias de $10 \%$ a $20 \%$ (Ross, 1991).

A cidade localiza-se sobre um divisor de águas das bacias do rio do Peixe, a norte, e do Paranapanema, a sul, tendo a bacia do rio Santo Anastácio que deságua no rio Paraná, a sul-sudoeste.

A zona urbana possui uma drenagem constituída por pequenos cursos d'água, formadores dos córregos do Cedro e do Limoéiro, ambos afluentes do rio Santo Anastácio, e do Gramado e Cascata, formadores do rio Mandaguari. Este último, por sua vez, é afluente do rio do Peixe, situado no setor leste-nordeste da cidade (figura 3.2).

Segundo Strahler (1957), o clima da área de estudo pode ser definido como tropical alternadamente seco e úmido. Segundo Köppen (1948), o mesmo se define como Awa, representado por duas estações do ano bem definidas: um verão quente e chuvoso de outubro a março e um inverno seco, de abril a setembro (Barrios \& Sant'Anna Neto, 1996).

Durante a primavera e verão, as temperaturas diárias oscilam entre os $20^{\circ} \mathrm{C} \mathrm{e}$ $32^{\circ} \mathrm{C}$, com máximas próximas aos $40^{\circ} \mathrm{C}$. No outono-inverno, as temperaturas variam entre $15^{\circ} \mathrm{C}$ e $20^{\circ} \mathrm{C}$ (Amorim, 2009). A média anual de precipitação é de $153,1 \mathrm{~mm}$ (2009). Os meses de dezembro a fevereiro são os mais chuvosos e os de junho a agosto, os mais secos. 

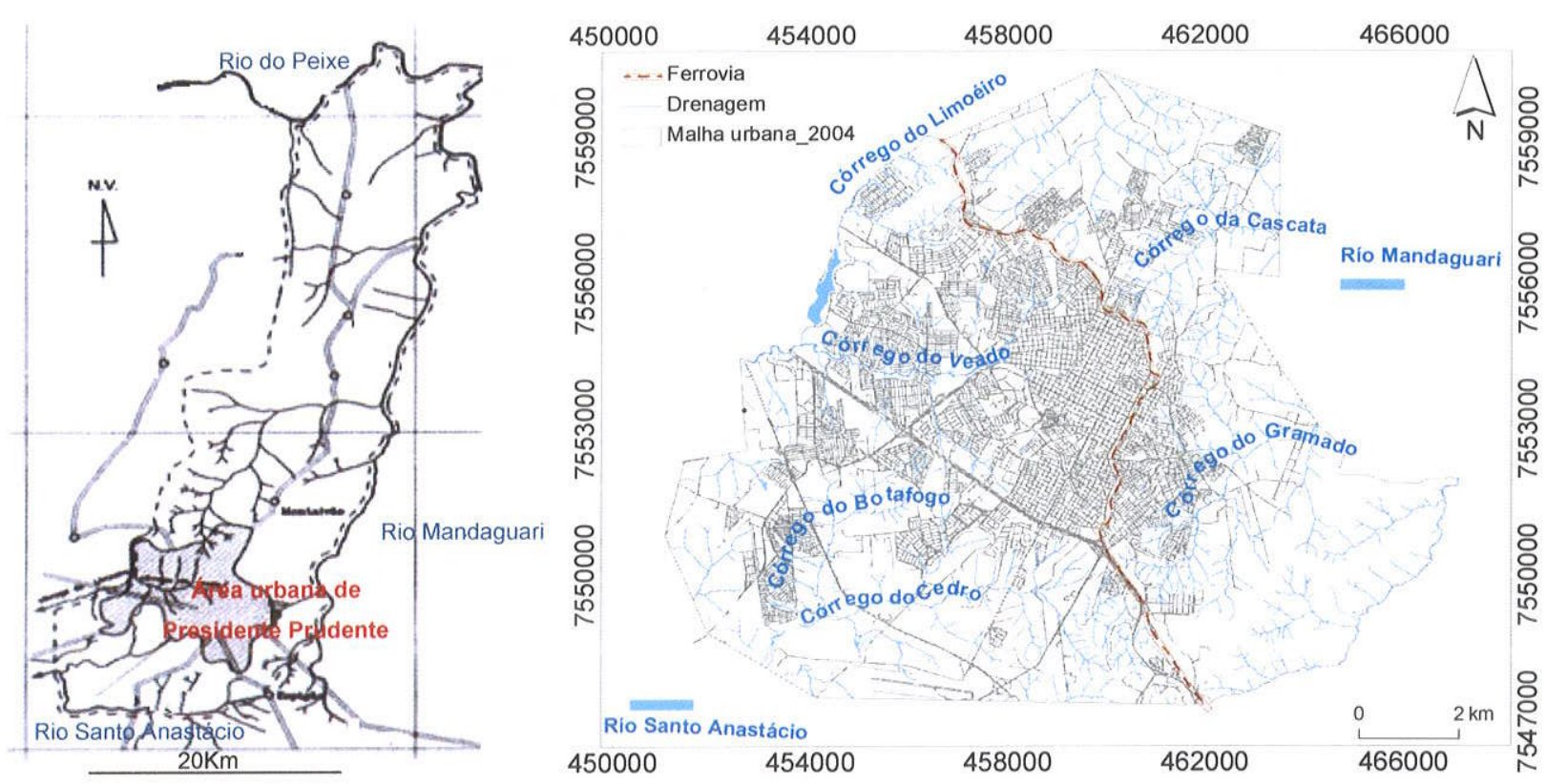

Figura modificada de Godoy, 2004

Figura 3.2 Drenagem na zona urbana de Presidente Prudente

\subsection{Hidrogeologia}

A unidade litoestratigráfica mais intensamente utilizada pelo usuário privado em Presidente Prudente é o Sistema Aquífero Bauru, representado na região pelos aquíferos Adamantina (aflorante) e o Santo Anastácio (subsuperfície).

O Aquífero Adamantina é um aquífero livre, regionalmente semi-confinado, de porosidade primária. Ele é representado na região pela ocorrência de arenitos muito finos a médios, coloração creme a cinza. A profundidade máxima local dos sedimentos desta formação é de $150 \mathrm{~m}$, sendo maiores aquelas localizadas na região nordeste da cidade.

A recarga ocorre pela infiltração da água de chuva em toda a área de exposição dos sedimentos e a descarga local, a oeste do município. As superfícies potenciométricas são fortemente influenciadas pela geomorfologia da 
área, onde os divisores de água subterrânea coincidem com os divisores das bacias hidrográficas.

Sotoposto ao Aquífero Adamantina, encontra-se o Santo Anastácio, constituído por arenitos vermelhos a roxos, granulação fina a média, baixo conteúdo de argila e espessuras uniformes, da ordem de 80 a 100 m (IPT, 1981). Segundo Godoy et al. (2004), os sedimentos deste aquífero apresentam grãos arredondados a subarredondados, cobertos por película limonítica e presença frequente de nódulos carbonáticos ou cavidades preenchidas por carbonato de cálcio. $O$ registro de poços perfurados no município tem mostrado profundidade máxima da ordem de $272 \mathrm{~m}$, conforme atestam os poços tubulares da SABESP.

Quanto ao comportamento hidráulico do Aquífero Adamantina, Rocha et al. (1982) concluíram que os valores médios de capacidade específica, compreendidos no intervalo de 0,5 a $10 \mathrm{~m} 3 / \mathrm{h} / \mathrm{m}$, ocorrem a sudeste do Estado de São Paulo, na região de Rancharia, onde há uma litofácie mais permeável da parte inferior da Formação Adamantina. Áreas com valores abaixo de $0,5 \mathrm{~m} 3 / \mathrm{h} / \mathrm{m}$ ocorrem a sudoeste do Estado, devido à pequena espessura saturada, e ao norte, na margem esquerda do Rio Grande, onde a litofácie da Formação Adamantina é menos permeável.

Posteriormente, CETESB (1997) determinou valores de capacidade específica de 05 a $1 \mathrm{~m}^{3} / \mathrm{h} / \mathrm{m}$, transmissividade de 30 a $50 \mathrm{~m}^{2} /$ dia e permeabilidade aparente de 0,1 a $0,3 \mathrm{~m} / \mathrm{d}$ para o Aquífero Adamantina (CETESB, 2007).

\subsection{Abastecimento e Saneamento}

O abastecimento de água no município de Presidente Prudente e a coleta de esgoto são realizados pela Companhia de Saneamento Básico do Estado de São Paulo (SABESP).

A cobertura da rede dede água abrange $90 \%$ da população, o que corresponde, em média, 65 milhões de litros/dia, sendo $780 \mathrm{~L} / \mathrm{s}$ provenientes dos mananciais superficiais e $140 \mathrm{~L} / \mathrm{s}$, dos subterrâneos (SABESP, 2009). 
O abastecimento pelas águas superficiais na cidade depende de três sistemas produtores: Rio do Peixe $(640 \mathrm{~L} / \mathrm{s})$, a represa no Rio Santo Anastácio $(450 \mathrm{~L} / \mathrm{s})$ e a represa no Balneário da Amizade, esta última utilizada para o abastecimento urbano em razão da seca prolongada, onde o volume reservado total é de $2.066 .000 \mathrm{~m}^{3}$.

Embora o sistema produtor de águas superficiais seja considerado a maior fonte de abastecimento da cidade, a SABESP possui 10 poços com profundidade média de $200 \mathrm{~m}$ que capta água do Aquífero Santo Anastácio. Além disso, estima-se que sejam explorados cerca de $1.710 \mathrm{~m}^{3} / \mathrm{h}$ de águas subterrâneas, considerando apenas os poços cadastrados.

A rede coletora de esgotos atende, atualmente, $97 \%$ da área urbana da cidade. No entanto, de acordo com as informações concedidas pelos funcionários da SABESP, alguns bairros situados na zona leste ainda fazem uso de fossas para o lançamento dos efluentes.

\subsection{Histórico da ocupação urbana}

O processo de urbanização do município de Presidente Prudente teve início em meados da década de 1930, a partir da crise cafeeira e implantação das primeiras indústrias na região. Com o colapso da cultura do café, outros produtos como arroz, milho, feijão e batata ajudaram no fortalecimento do desenvolvimento da atividade agrícola. Esta atividade incentivou a ocupação da região e seu crescimento, orientado principalmente pela ferrovia, por se tratar da principal via de circulação na cidade no sentido norte-sul. Neste período, expandiram-se os seguintes bairros: Centro e Vila Marcondes e os espaços entre os córregos Bacarim, Boscoli e o Córrego do Veado (Amorim 2009).

Durante as décadas de 40 e 50, o aumento das atividades pecuária e industrial tomou conta da cidade. Contudo, a extensão de Presidente Prudente nesta década reduziu-se devido aos sucessivos desmembramentos de outras cidades como Regente Feijó, Presidente Bernandes e Martinópolis (Amorim, 2009). 
Esta expansão prosseguiu nas décadas posteriores para a zona oeste da cidade (Camargo, 2007). A partir da década de 1970, houve uma expressiva ampliação da malha urbana, ocasionada pela proliferação de loteamentos Neste período, a especulação imobiliária tornou-se o motor para a expansão e novos bairros surgiram tais como Vila Liberdade, COHAB, CECAP, entre outros. Essa ocupação gerou quadras irregulares principalmente no centro da cidade. Na zona leste, a ocupação se deu de maneira desordenada, gerando irregularidades na malha urbana, como nos bairros Vilas Brasil, Mendes, Jardim São Pedro (Camargo, 2007).

Nos anos 80, a cidade possuía 129.255 habitantes (SEADE, 2010) e uma taxa de urbanização de $94,74 \%$ (figura 3), em decorrência das áreas residenciais com edificações esparsas, gramado e vegetação arborácea. Nesta época, a expansão territorial urbana atingiu as áreas das bacias de mananciais superficiais utilizados no abastecimento público. O uso do solo urbano foi pouco diversificado predominando domicílios residenciais (87\%), enquanto os usos industriais, comerciais e serviços, respondem por 13\% (Amorim, 2009). O crescimento da zona urbana do município ocorreu no sentido oeste, sul e sudoeste, devido à topografia.

Nos anos 90, o aumento populacional se refletiu na elevada taxa de urbanização, assim como na proliferação da construção dos poços públicos (SABESP) e particulares, principalmente nas regiões centro e norte da cidade. A expansão da malha urbana desenvolveu-se no sentido sudoeste com o surgimento dos bairros Residencial Dahma I e II (Amorim, 2009).

A partir da década de 2000, a expansão da cidade ocorreu em todas as direções, principalmente na zona leste. A demanda habitacional gerou o aumento populacional, conforme apresentado na figura 3.2. Segundo o censo do IBGE (2000), a população distribui-se em 97,91\% (185.229 habitantes) na zona urbana e 2,09\% (3.957 habitantes) na zona rural, demonstrando uma forte concentração urbana (figura 3.3). 


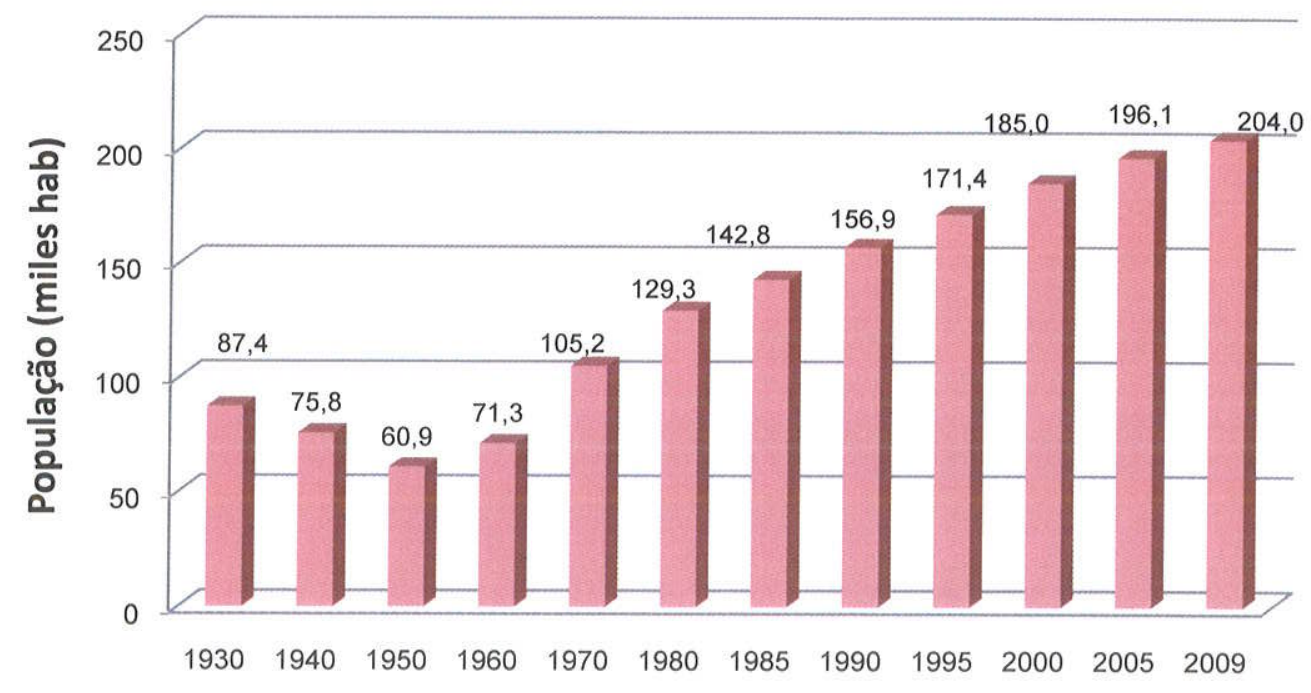

Figura 3.3 Evolução da população de Presidente Prudente (1930-2009). Fonte: SEADE, IBGE/DAEE/Camargo (2007).

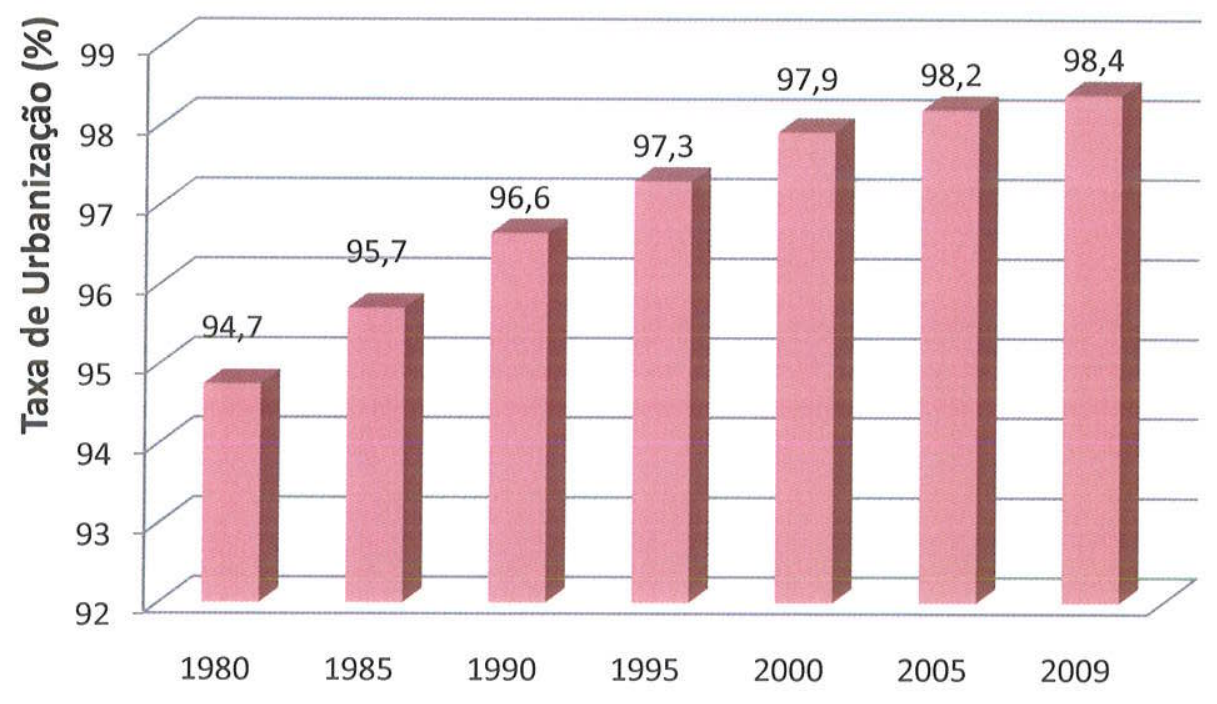

Figura 3.4 Taxa de urbanização de Presidente Prudente (1980-2009). Fonte: SEADE, IBGE, DAEE, Camargo (2007). 


\section{REVISÃO BIBLIOGRÁFICA}

\subsection{Sistemas de saneamento in situ}

A contaminação dos aquíferos nas áreas urbanas está relacionada a inúmeras fontes antrópicas, dos quais se destacam os sistemas de saneamento in situ, (fossas negras e sépticas), vazamento de esgotos e resíduos sólidos (lixões e aterros sanitários). A alta densidade dessas fontes podem geram um grande volume de carga contaminante poluidora para as águas subterrâneas (Foster \& Hirata, 1988).

Os sistemas de saneamento in situ são implantados em zonas urbanas densamente povoadas onde geralmente a rede de esgotamento sanitário é nula ou insuficiente (zonas não planejadas, periferias das cidades). Nesses locais o uso de fossas negras e sépticas para a eliminação dos esgotos é comum e a sua manutenção precária pode constituir uma ameaça para a qualidade das águas subterrâneas (Wakida \& Lerner, 2005).

Os efluentes lançados por esses sistemas são compostos por microorganismos, nutrientes, compostos orgânicos sintéticos, sais, além de nitrato e cloreto (Foster \& Hirata, 1988). Estes últimos são considerados como bons parâmetros químicos indicadores de contaminação, devido à alta mobilidade e persistência (APHA, 1998; Varnier 2007). 
Tabela 4.1 Resumo dos aquíferos urbanos contaminados pelos sistemas de saneamento in situ

\begin{tabular}{|c|c|c|}
\hline Autor & País & Comentário \\
\hline $\begin{array}{c}\text { Jeon et al., } \\
(2001)\end{array}$ & Coréia do Sul & $\begin{array}{l}\text { Estudaram o efeito do uso do solo e da urbanização na quimica e contaminação da água subterrânea. As maiores fontes de } \\
\text { contaminação são os vazamentos na rede de esgoto e antigas fossas, além de aterros. }\end{array}$ \\
\hline $\begin{array}{c}\text { Yintao Lu, et. } \\
\text { al., (2007) }\end{array}$ & China & $\begin{array}{l}\text { Estudaram os efeitos do desenvolvimento urbano no fluxo das águas subterâneas em Fengcun, (litoral sul da China). Através da } \\
\text { amostragem de poços em março } 2005 \text { e julho } 2006 \text {, determinaram que a área de estudo encontram-se contaminada por nitrato. } \\
\text { As análises químicas revelaram que as concentrações do ion aumentaram com o tempo (de } 20 \mathrm{mg} / \mathrm{L} \text { de } \mathrm{NO}_{3}{ }^{-} \text {no } 2005 \text { até } 120 \\
\text { mg/L no } 2006 \text { ), o que evidencia uma rápida propagação da contaminação.Segundo os autores as fontes da contaminação são os } \\
\text { sistemas de saneamento in situ (fossas negras e sépticas). }\end{array}$ \\
\hline $\begin{array}{c}\text { Muchimbane } \\
\text { (2010) }\end{array}$ & Moçambique & $\begin{array}{l}\text { Relaciona a falta de esgotamento sanitário, presença de sistemas de saneamento in situ e alta densidade populacional gerado } \\
\text { pelo crescimento urbano irregular com a contaminação por nitrato e coliformes fecais das águas subterrâneas. Todos os poços } \\
\text { cacimbas (até } 20 \mathrm{~m} \text { de profundidade) contêm concentrações de nitrato de até } 178 \mathrm{mg} / \mathrm{L} \text { de } \mathrm{NO}_{3}^{-} \text {. }\end{array}$ \\
\hline $\begin{array}{c}\text { Cavalcante et } \\
\text { al., }\{2003)\end{array}$ & & $\begin{array}{l}\text { Determinaram que no bairro do Farol, em Maceió (Alagoas), a presença de compostos nitrogenados é uma resposta à grande } \\
\text { densidade de sistemas de saneamento in situ, o uso do sistema fossa-poço e à precária manutenção das redes coletoras de } \\
\text { esgoto. }\end{array}$ \\
\hline $\begin{array}{l}\text { Alves de Lima } \\
\text { et al. (2008) }\end{array}$ & Brasil & $\begin{array}{l}\text { Constaram que em Porto Velho }(\mathrm{RO}) \text { as maiores concentrações de nitrato, ocorrem nas áreas com maiores densidades } \\
\text { populacionais e, consequentemente, maiores quantidades de fossas sépticas e negras, uma vez que os locais não dispöem de } \\
\text { rede de esgoto. }\end{array}$ \\
\hline $\begin{array}{c}\text { Bernice \& } \\
\text { Hirata (2010) }\end{array}$ & & $\begin{array}{l}\text { Avaliaram os impactos potenciais do saneamento urbano no Aquifero Adamantina em Urânia (SP), através da simulação de } \\
\text { diferentes cenários de usos do solo. Mostraram que a contaminação por nitrato proveniente de uma fonte constante prevalece no } \\
\text { tempo. Considerando a construção de uma rede de esgoto totalmente eficiente, o tempo de recuperação das porçōes rasa e } \\
\text { intermediária do aquífero é de } 10 \text { anos. Já na porção mais profunda, a contaminação perduraria por um período de } 90 \text { anos após } \\
\text { o encerramento da fonte. }\end{array}$ \\
\hline
\end{tabular}




\subsection{Geoquímica dos efluentes gerados nos sistemas de saneamento in situ.}

As fossas negras e sépticas são sistemas individuais de disposição de esgotos domésticos ou águas residuais domésticas. A diferença entre ambas consiste no tipo de construção. As fossas negras compreendem uma escavação sem revestimento interno, onde os efluentes são lançados diretamente no solo (Carvalho, 1981). As fossas sépticas, por sua vez, podem ser definidas como uma unidade de sedimentação fotação e digestão de esgotamento horizontal e contínuo (CETESB, 1989). Nelas são feitas a separação de duas fases físicas (escuma e lodo) e a transformação físico-química da parte líquida (efluente) como ilustrado na figura 4.1.

A escuma é formada por uma mistura de gases, gordura e sólidos que flutuam no líquido em tratamento. O lodo é um material acumulado na base do tanque (zona de digestão), por sedimentação de partículas sólidas suspensas no esgoto (ABNT, 1993).

a)

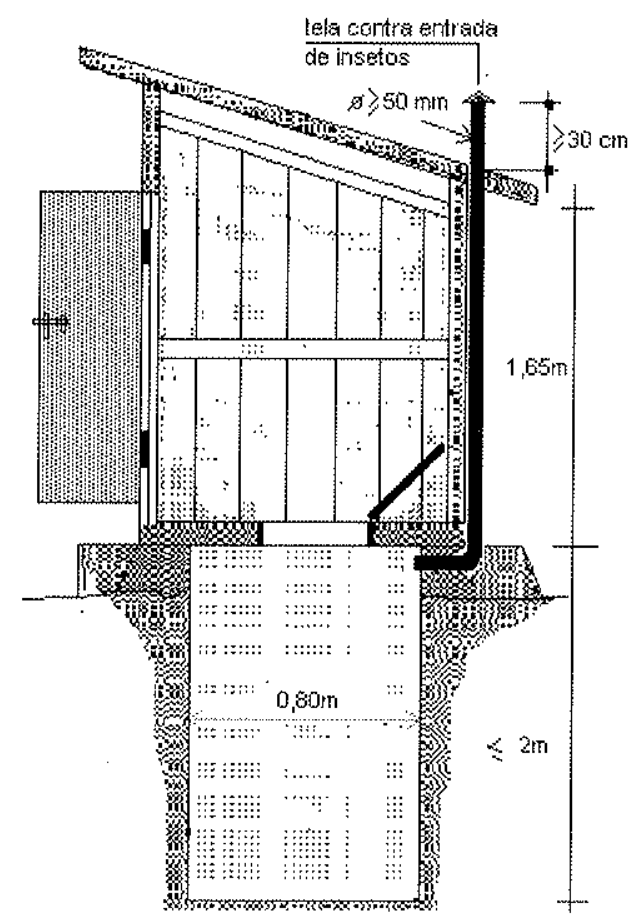

Figura 4. 1a. Esquema dos sistemas de saneamento in situ: a) fossa negra (Fonte: ABNT, 1993) 
b)

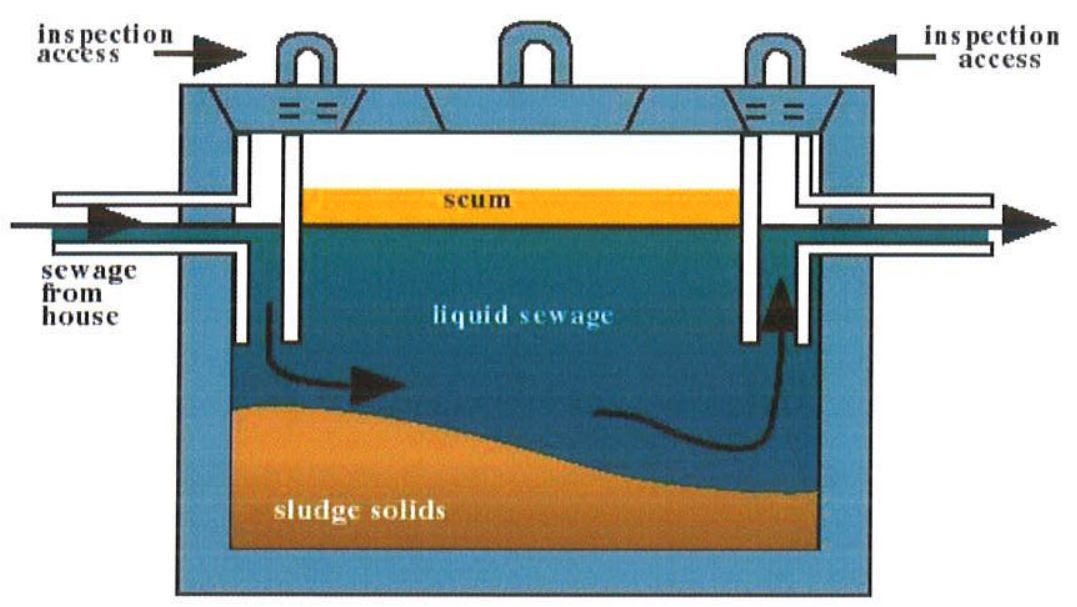

Figura 4. 2b Esquema dos sistemas de saneamento in situ b) fossa séptica (Fonte:Hydra International Ltda, 2010).

Os sistemas de saneamento in situ (fossas negras e sépticas) recebem o efluente com uma carga contaminante que é uma mistura de nutrientes (nitrato e fosfato), sais, microorganismos patogênicos, como bactérias, vírus e nitrato, além de dejetos alimentícios (proteínas, carboidratos, gorduras) e dejetos humanos (com alta concentração de uréia). As proteínas e uréia constituem mais de 97\% dos 20-70 $\mathrm{mg} / \mathrm{L}$ do nitrogênio tipicamente encontrado nos esgotos (Tchobanouglos et al. 1991, in Wilhelm et al., 1994).

Segundo Wilhelm et al., (1994), o nitrogênio orgânico junto com o carbono são os responsáveis pela maior demanda de oxigênio no esgoto. $\mathrm{O} \mathrm{pH}$ do efluente normalmente encontra-se entre 6,5 a 8,0 e sua alcalinidade é superior à da água original de abastecimento (100 a $200 \mathrm{mg} / \mathrm{L} \mathrm{de} \mathrm{CaCO}_{3}$ ).

Varnier (2007) identificou uma série de processos químicos que nas zonas não saturada e saturada do aquífero, proveniente de uma fossa negra desativada. Segundo a autora, destacam-se as principais reações: i) oxidação da matéria orgânica, ii) amonificação, iii) nitrificação, iv) metanogênese e v) desnitrificação. $O$ resumo dos principais processos detectados pela autora são apresentados na tabela 4.2.

Ainda segundo Varnier (2007), no interior da fossa negra ocorrem os processos de transformação do nitrogênio, gerando reações predominantes, possíveis e improváveis descritas na figura 4.3. 
Nas fossas sépticas, Wilhelm et al, (1994) determinaram que os principais processos compreendem a hidrólise, fermentação, oxidação anaeróbica, redução de sulfato e metalogênese na zona anaeróbica (tanque séptico). A oxidação da matéria orgânica, nitrificação, oxidação de sulfato e tampão de carbonato surgem na zona aeróbica (área desnifiltração), enquanto que na segunda zona anaeróbica (zona saturada), há o processo de desnitrificação. (figura 4.2).

Tanto nas fossas negras como nas sépticas o processo de conversão da matéria orgânica (tabela 4.2) é caracterizado pelas condições de baixas concentrações de oxigênio dissolvido. A digestão anaeróbica é mediada pela ação de microorganismos que usam aceptores de elétrons como $\mathrm{C}_{\text {organico, }} \mathrm{H}^{+}$e $\mathrm{CO}_{2}$ para oxidar a matéria orgânica e produzir $\mathrm{H}_{2}, \mathrm{CO}_{2}$. A maior parte do nitrogênio é liberado pelas moléculas orgânicas na forma reduzida de amônio (Wilhelm et al., 1994, in Suhogusoff ,2010).

- A digestão anaeróbia é normalmente considerada um processo de dois estágios, com o aumento ou decréscimo da alcalinidade do efluente (Wilhelm et al., 1994, in Suhogusoff ,2010). No primeiro estágio, um grupo de bactérias anaeróbicas convertem os orgânicos complexos como proteínas, carboidratos, gorduras, uréia e aminoácidos em compostos mais simples, propiciando a formação de $\mathrm{H}_{2} \mathrm{e}$ diminuição da alcalinidade. Dentre os processos mais comuns, destacam-se a hidrolise, fermentação e oxidação. No segundo estágio, os despejos que contém compostos de enxofre são submetidos à redução de sulfato e formação de sulfetos. Os compostos a base de enxofre são utilizados como aceptores de elétrons durante a oxidação de compostos orgânicos. Durante este processo, sulfato, sulfito e outros compostos sulfurosos são reduzidos a sulfeto, através da ação de bactérias redutoras de sulfato (figura 4.2 ).

Adicionalmente, ocorre a conversão dos ácidos orgânicos, gás carbônico e hidrogênio em produtos finais gasosos, como o metano e gás carbônico sob a ação das bactérias metanogênicas. A redução do sulfato e o consumo metanogênico aumentam a alcalinidade do efluente.

A sequência dos processos e principais reações da digestão anaeróbica nos sistemas de saneamento in situ são apresentadas na figura 4.2. 
$\mathrm{Na}$ zona saturada (zona anaeróbica), onde as concentrações de $\mathrm{O}_{2}$ são limitadas, o processo que predomina numa fossa séptica é a desnitrificação (Wilhelm et al., 1994, in Suhogusoff ,2010), desde que haja quantidade suficiente de carbono que não é consumido pela nitrificação ou digestão anaeróbica. A natureza da fonte de carbono e a presencia das espécies microbianas, são fatores que afetam a razão C/N, necessária para a completa redução de nitrato (Payne, 1973; Rijn et al., 2006).

Se o fluxo de carbono para o aquífero aumenta a razão $\mathrm{C} / \mathrm{N}$, pode-se promover a transformação de nitrato em $\mathrm{NH}_{3}$ ao invés de $\mathrm{N}_{2}$ (Rehr \& Klemme, 1989, in Gillham \& Cherry, 1978). Porem, geralmente nestes processos, o fator limitante nos aquíferos é a baixa concentração de carbono (Starr \& Gilham, 1993).

Embora os sistemas de saneamento in situ representem um problema para as águas subterrâneas, é possivel minimizar os impactos causados ao construir uma fossa alternativa melhorada com uso de barreiras reativas, que possibilitassem a degradação mais eficiente de nitrato e de microorganismos patogênicos, como a proposta por Suhogusoff (2010).

As avaliações feitas nesta fossa alternativa melhorada demonstraram que na zona anaeróbica do tanque séptico o $\mathrm{pH}$ é quase neutro com o cálcio e amônio como cátions dominantes, e o fosfato e cloreto como os ânions, tendo como processo a hidrólise. $\mathrm{Na}$ zona aeróbica (área de infiltração), onde se localizou a primeira barreira reativa denominada como BOF (Basic Oxygen Furnace) e utilizada para a degradação de microorganismos, evidenciou-se uma variação da alcalinidade com $\mathrm{pH}$ muito maiores que 7. O cátion predominante continuou sendo o cálcio, com diminuição nas concentrações de magnésio, sódio e amônio. Os possíveis processos, identificados pela autora, correspondem a: oxidação da matéria orgânica, troca catiônica, absorção e nitrificação. Já na segunda zona anaeróbica onde se encontra a barreira de serragem, o processo de desnitrificação se inicia, chegando a $62 \%$ de sua eficácia. O pH torna-se quase neutro com presencia predominante de amônio e diminuição de cálcio, magnésio, sódio nitrato e cloreto. Isto torna esta fossa uma alternativa para a prevenção da contaminação do solo e da água subterrânea. 


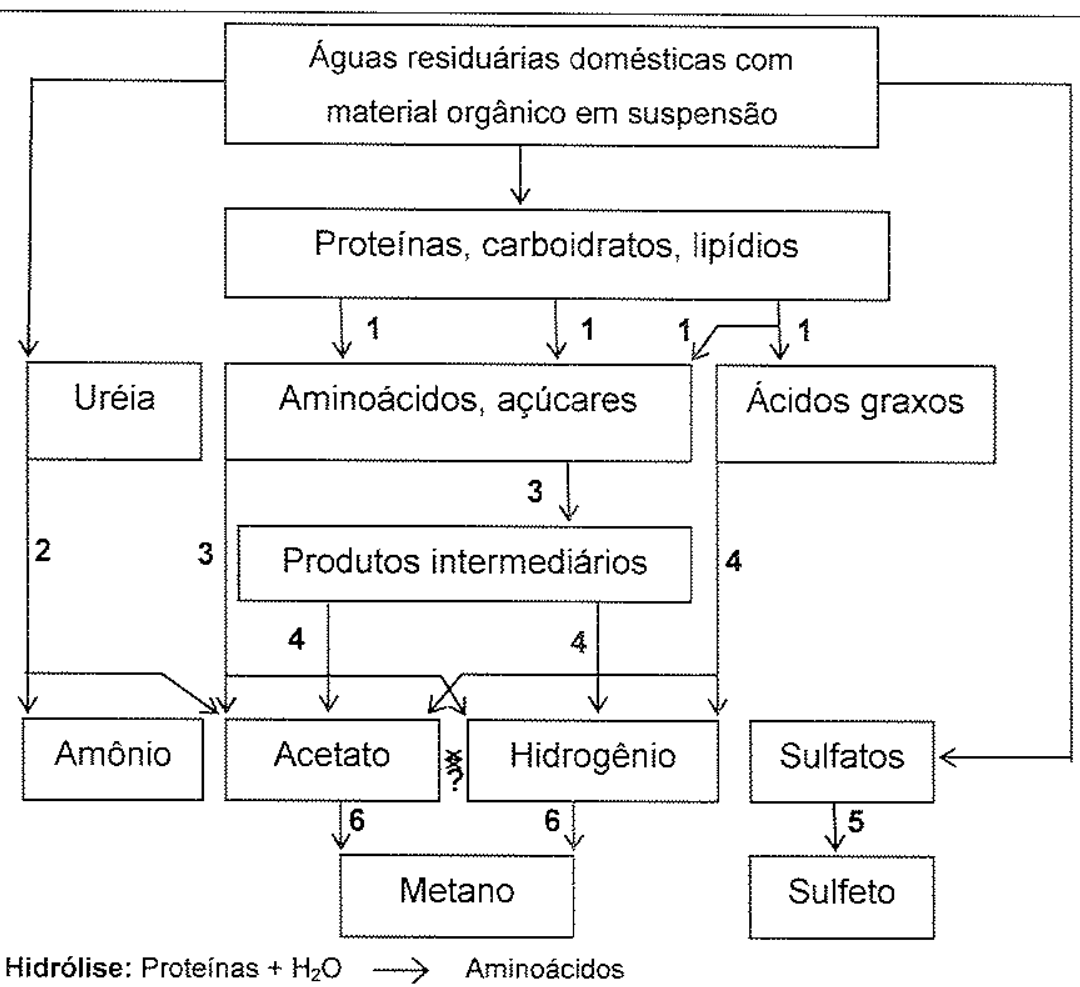

1. Hidrólise: Proteinas $+\mathrm{H}_{2} \mathrm{O} \longrightarrow$ Aminoácidos

2. Amônio*: Uréia $+\mathrm{H}_{2} \mathrm{O} \longrightarrow 2 \mathrm{NH}_{4}^{+}+$compostos orgânicos

Fossas sépticas

3. Fermentação: Aminoácidos $\longrightarrow \overbrace{2},\left(\mathrm{CH}_{3} \mathrm{OO}\right)$, outros ácidos

Zona não saturada

4. Oxidação anaeróbica: Ácidos graxos $+\mathrm{H}_{2} \mathrm{O} \quad\left(\mathrm{CH}_{3} \mathrm{OO}\right)$

Zona anaeróbica

5. Redução de sulfato: $\mathrm{SO}_{4}{ }^{2-}+2 \mathrm{CH}_{2} \mathrm{O}+2 \mathrm{H} \rightarrow \mathrm{H}_{2} \mathrm{~S}+2 \mathrm{CO}_{2}+\mathrm{H}_{2} \mathrm{O}$

6. Metalogênese ${ }^{*}: \mathrm{CH}_{3} \mathrm{OO}^{-}+\mathrm{H}^{+} \longrightarrow \mathrm{CH}_{4}+2 \mathrm{CO}_{2} ; \mathrm{CO}_{2}+4 \mathrm{H}_{2} \rightarrow \mathrm{H}_{4}+2 \mathrm{H}_{2} \mathrm{O}$

Figura 4. 3 Resumo da sequência dos processos na digestão anaeróbia no tanque séptico e fossas negras (os números referem-se às reações químicas), modificado de Van Haandel e Lettinga, 1994 e Wilhelm et al., 1994. 


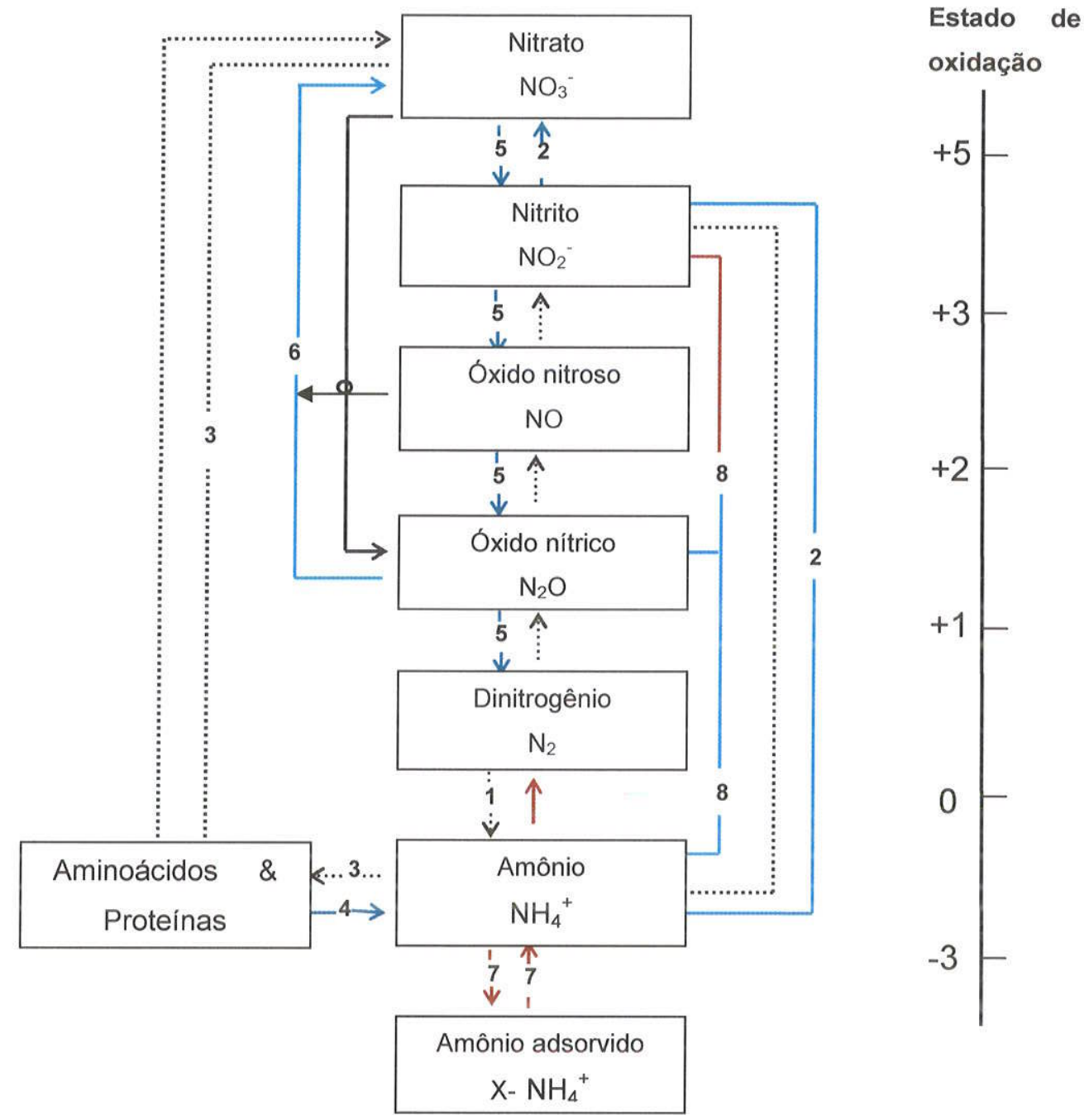

\section{Reações}

1. Fixação

2. Nitrificação

3. Assimilação pelas plantas

4. Mineralização*

5. Desnitrificação

6. Nitrato precipitado (como $\mathrm{HNO}_{3}$ )

7. Adsorção e desorção

8. Anamox*

* Processos mediados por microorganismos

Figura 4.4 Espécies químicas no ciclo do nitrogênio (modificado de O' Neil, 1985; in Varnier 2007), 
Tabela 4.2 Resumo das principais características hidrogeoquímicas e parâmetros presentes nos sistemas de saneamento in situ (Varnier, 2007 e Wilhelm et al., 1994).

\begin{tabular}{|c|c|c|c|c|c|c|c|}
\hline $\begin{array}{l}\text { Sistema de } \\
\text { saneamento }\end{array}$ & $\begin{array}{c}\text { Zonas definidas no } \\
\text { sistema }\end{array}$ & Possiveis processos & $\begin{array}{l}\text { Parâmetros } \\
\text { físicos }\end{array}$ & Cátions & Ânions & $\begin{array}{c}\text { Outros } \\
\text { Parâmetros e gases }\end{array}$ & Observaçōes \\
\hline \multirow{4}{*}{$\begin{array}{l}\text { (Varnier, 2007) } \\
\text { Fossa negra } \\
\text { desativada } \\
\text { instalação de uma } \\
\text { estação } \\
\text { experimental, } \\
\text { situada a } 1 \mathrm{~m} \text { de } \\
\text { uma fossa } \\
\text { desativada por } \\
\text { cinco anos }\end{array}$} & $\begin{array}{c}\text { Zona não saturada } \\
(\text { ZNS })<1 \mathrm{~m}\end{array}$ & Infiltração efluente & $\uparrow C E ; \downarrow p H<<6$ & $\begin{array}{c}\uparrow \mathrm{NH}_{4}^{+} ; \uparrow \mathrm{Ca}^{2+} \\
\uparrow \mathrm{K}^{+}: \uparrow \mathrm{Na}^{+}>\mathrm{Mg}^{2+}\end{array}$ & $\begin{array}{l}\mathrm{NOO}_{3}^{-} ; \mathrm{\uparrow Cl}^{-} \\
; \uparrow \mathrm{HCO}_{3}^{-}\end{array}$ & $\begin{array}{c}\uparrow C O D ; \downarrow N_{\text {org }} ; \uparrow \mathrm{CH}_{4} \\
; \uparrow \mathrm{N}_{2} \mathrm{O} ; \uparrow \mathrm{O}_{2}\end{array}$ & \multirow{4}{*}{$\begin{array}{l}\text { Desnitrificação } \\
\text { ocorre nos } \\
\text { poros dos } \\
\text { sedimentos } \\
\text { situados dentro } \\
\text { de meio } \\
\text { aeróbico. }\end{array}$} \\
\hline & $\begin{array}{c}\text { ZNS } \\
\text { Fossa }(1-5 \mathrm{~m})\end{array}$ & $\begin{array}{c}\text { Oxidação } \\
\text { (Materia orgânica) } \\
\text { Amonificação } \\
\text { Nitrificação } \\
\text { Metalogênese } \\
\text { Desnitrificaçāo }\end{array}$ & $\uparrow C E ; \downarrow \mathrm{pH}<<6$ & $\downarrow \mathrm{Ca}^{2+}$ & $\downarrow \mathrm{HCO}_{3}^{-} \uparrow \mathrm{NO}_{3}^{-}$ & $\uparrow C O D: \uparrow \mathrm{CH}_{4}: \uparrow \mathrm{O}_{2}$ & \\
\hline & ZNS $(5-9 m)$ & & $\uparrow C E ; \downarrow p H<<6$ & $\begin{array}{c}\uparrow \mathrm{Ca}^{2+} ; \uparrow \mathrm{K}^{+}: \uparrow \mathrm{Na}^{+}: \\
\uparrow \mathrm{Mg}^{2+}\end{array}$ & ${ }^{-} \mathrm{NO}_{3}: \uparrow \mathrm{Cl}^{-}$ & $\uparrow \mathrm{O}_{2} ; \downarrow \mathrm{CH}_{4}$ & \\
\hline & $\begin{array}{l}\text { Zona Saturada } \\
\text { (ZS) entre 9-11 m }\end{array}$ & Diluiçāo & $\downarrow \mathrm{CE} ; \mathrm{pH} \approx 6$ & 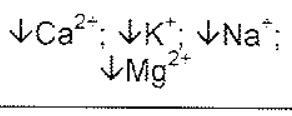 & $\begin{array}{l}\downarrow \mathrm{NO}_{3}^{-} ; \downarrow \mathrm{Cl} \\
; \uparrow \mathrm{HCO}_{3}^{-} \\
\end{array}$ & $\downarrow \mathrm{COD} ; \downarrow \mathrm{CH}_{4} ; \downarrow \mathrm{O}_{2}$ & \\
\hline \multirow{3}{*}{$\begin{array}{l}\text { Wilhelm et al., } \\
\qquad(1994) \\
\text { Modelo conceitual } \\
\text { para evolução } \\
\text { química de esgoto } \\
\text { doméstico gerado } \\
\text { por sistemas de } \\
\text { saneamento in situ }\end{array}$} & $\begin{array}{l}\text { Zona Anaeróbica } \\
\text { (tanque séptico) }\end{array}$ & $\begin{array}{c}\text { Hidrólise } \\
\text { Amônio } \\
\text { Fermentação } \\
\text { Oxidaçāo anaeróbica } \\
\text { Redução de sulfato } \\
\text { Metalogênese }\end{array}$ & $\downarrow \mathrm{CE}$ pH<7 & $\uparrow \mathrm{NH}_{4}{ }^{*}$ & $\downarrow \mathrm{NO}_{3}^{-}$ & $\downarrow \mathrm{COD} ; \uparrow \mathrm{CO}_{2} ; \uparrow \mathrm{CH}_{4}$ & \\
\hline & $\begin{array}{l}\text { Zona Aeróbia } \\
\text { (área de infiltração) }\end{array}$ & $\begin{array}{c}\text { Oxidação } \\
\text { (Materia orgânica) } \\
\text { Nitrificação } \\
\text { Oxidaçāo de sulfato } \\
\text { Tampão de carbonato }\end{array}$ & $\downarrow C E \mathrm{pH}<7$ & $\mathrm{NNH}_{4}^{+}$ & $\begin{array}{c}\text { 个NO}{ }_{3}^{-} ; \downarrow \mathrm{HCO}_{3}^{-} \\
; \uparrow \mathrm{SO}_{4}^{-}\end{array}$ & $\downarrow \mathrm{O}_{2} ; \uparrow \mathrm{CO}_{2} ; \downarrow N_{\mathrm{org}}$ & \\
\hline & $\begin{array}{c}\text { Segunda zona } \\
\text { Anaeróbia } \\
\text { (ZS) }\end{array}$ & Desnitificação & $\downarrow C E p H<7$ & $\uparrow \mathrm{NH}_{4}{ }^{*}$ & $\downarrow \mathrm{NO}_{3}^{-}$ & $\downarrow C O D ; \uparrow N_{2}$ & \\
\hline
\end{tabular}

ZNS: zona não saturada: ZS: zona saturada 


\section{MATERIAIS E MÉTODOS}

\subsection{Cadastro de poços}

O cadastro de poços tubulares existentes na área de estudo foi realizado através da consulta ao arquivo do Sistema de Informação de Águas Subterrâneas (SIDAS) do Departamento de Águas e Energia Elétrica (DAEE), bem à base de dados da Companhia de Saneamento Básico do Estado de São Paulo (SABESP), Vigilância Sanitária Municipal, empresas de consultoria e demais órgãos competentes.

Com base nestes levantamentos, uma análise criteriosa foi adotada para a interpretação e reavaliação das informações disponiveis dando especial atenção aos poços que continham as seguintes informações: coordenadas de localização, cota, dados construtivos, parâmetros hidráulicos, descrição litológica, aquífero explorado e análises pretéritas das concentrações de nitrato (anexo 1).

Foram levantados, no total, 212 poços dos quais selecionaram-se 195 poços que atenderam ao conjunto de informações necessárias, mencionadas anteriormente (inserir mapa com a localização dos poços).

\subsection{Levantamento cartográfico}

O levantamento cartográfico foi feito mediante a pesquisa das informações presentes nos mapas topográficos, de drenagem, uso e ocupação do solo, cartas de densidade de edificações, mapas de cobertura vegetal, agrupados na publicação Carta de Qualidade Ambiental (Camargo, 2007) e demais publicações (Sposito, 1983; Ikuta, 2003; Mileski, 2006; Cavaleiro, 2008)

As informações supracitadas foram compiladas, integradas e homogeneizadas numa base digital à mesma escala (1:25.000) através do software Arcgis 9.2. 
A partir da base cartográfica digital e fotointerpretação das fotografias do municipio (anos 1972, 1978 e 1995), em escala 1:25.000, e das imagens adquiridas no site do Google Earth (2009) e Google Maps (2009), foram delimitados s os perímetros urbanos para cada década.

\subsection{Levantamento do esgotamento sanitário}

Os dados sobre a captação e tratamento do esgoto de Presidente Prudente foram adquiridas junto à SABESP. Na ocasião, foram consideradas as seguintes informações: i) números de ligações (conjunto de tabulações e dispositivos que integram a rede de distribuição); ii) economias de esgoto (prédios ou subdivisões de um prédio com ocupações comprovadamente independentes entre si que utilizam uma única instalação de abastecimento).

Adicionalmente, foram concedidos mapas da rede de esgoto para os anos de 1990 e 2006. Estes mapas foram digitalizados e homogenizados em escala 1:25.000, de modo a proporcionar a localização dos bairros com e sem saneamento básico, com presença potencial de fossas sépticas e/ou negras.

Cabe assinalar que os dados sobre o tratamento do esgoto na única estação de tratamento (Estação do Córrego Limoeiro) não foram analisados neste estudo, devido à falta de informação da SABESP, sobre os volumes captados e tratados na referida estação.

5.4. Determinação do modelo conceitual de circulação das águas subterrâneas.

O modelo conceitual de circulação das águas subterrâneas do $S A B$ na área de estudo foi estabelecido a partir da análise dos perfis construtivos, geológicos e geofísicos dos poços selecionados. Adicionalmente, foram determinados dados 
hidráulicos mediante ensaios de bombeamento existentes (níveis estáticos, dinâmicos, vazão e condutividade hidráulica).

As análises resultaram na elaboração dos mapas potenciométricos, seções hidrogeológicas e cálculo dos parâmetros hidráulicos, o que permitiu ter a visão em planta e perfil do modelo de circulação das águas subterrâneas no local. Os mapas potenciométricos e as seções hidrogeológicas foram elaborados a partir dos mapas topográficos e hidrográficos fornecidos e digitalizados pela UNESP, escala 1:25.000, com curvas de nivel com equidistância de $10 \mathrm{~m}$. Nesses mapas distinguiram-se os principais feições morfológicas, divisores de água, e principais córregos da cidade.

Os mapas potenciométricos foram confeccionados a partir dos valores das cargas hidráulicas dos poços cadastrados, localizados na área urbana. Estas cargas foram calculadas subtraindo-se os valores de cota do terreno e níveis de água estáticos registrados na época da instalação dos poços. A partir destes mapas, procurou-se determinar as direções preferenciais de fluxo da água subterrânea no aquifero, gradiente hidráulico e a velocidade de fluxo da água, calculada através da equação de Darcy levando em conta a porosidade efetiva de $5 \%$ e $15 \%$, conforme proposto por Hirata (1999).

As seções hidrogeológicas foram elaboradas a partir dos perfis construtivos, litológicos e geofísicos dos poços, obtidos através dos arquivos do SIDAS e da SABESP. Os dados foram correlacionados entre os poços, obtendo, assim, os possiveis contatos e espessuras dos aquiferos Adamantina e Santo Anastácio no município.

Os valores de condutividade hidráulica e transmissividade foram determinados por meio de testes de bombeamento em nove poços tubulares (anexo II). Esses parâmetros hidráulicos foram calculados segundo a metodologia de Yazvin \& Bochevier (Constantino de Miguel Fernandez, 1999).

Por fim, os parâmetros de gradiente hidráulico e velocidade de fluxo da água calcularam-se através da equação de Darcy levando em conta a porosidade efetiva de $5 \%$ e $15 \%$ determinada para o Grupo Bauru (Hirata, 1999). 


\subsection{Amostragem da água subterrânea}

Um total de 60 amostras de água foi coletado na área urbana de Presidente Prudente em 22 poços selecionados através de duas campanhas de amostragem (dezembro/2009 e junho/2010 (incluir uma figura com os pontos selecionados para a amostragem).

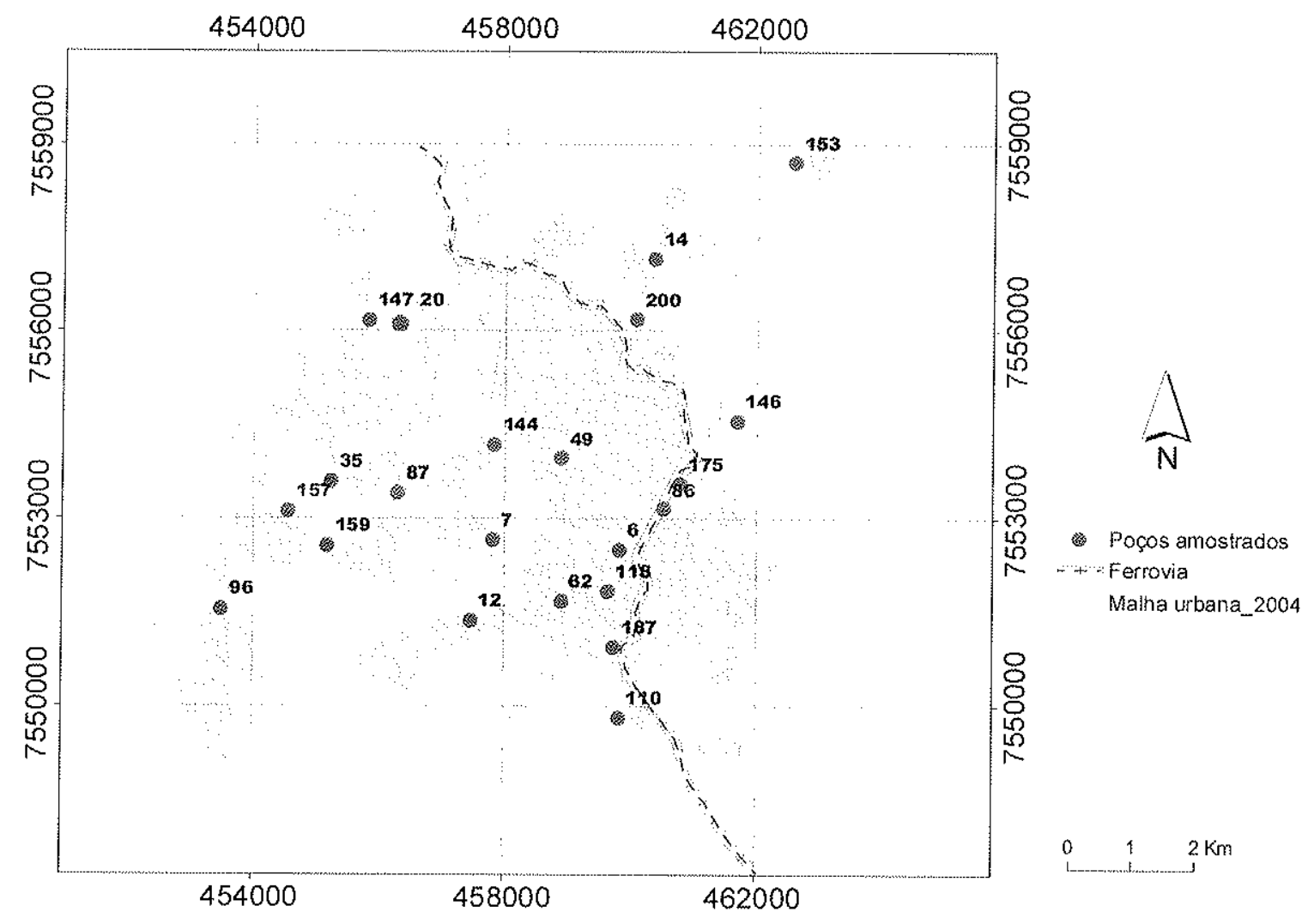

Figura 5.1 Localização dos poços amostrados

Os critérios adotados para a seleção dos poços foram os seguintes: i) distribuição espacial dos mesmos de forma a obter-se um conjunto de dados representativos de toda a área urbana, ii) concentração anômala de nitrato; iii) aspectos construtivos e possibilidade de coleta, quando possivel, direto da boca; iv) localização geográfica de acordo com a expansão urbana. 
A primeira campanha de amostragem, entre 14 e 19 de dezembro de 2009, contemplou os 22 poços com um total de 30 amostras que incluíram duas duplicatas (157-1 e 175-1 correspondentes aos poços 157 e 175) e quatro amostras em diferentes tempos de bombeamento ( $t=0 \mathrm{~h}, \mathrm{t}=6 \mathrm{~h}$ e $\mathrm{t}=24 \mathrm{~h}$ para os poços 175 e 146). A segunda campanha, realizada entre e 28 de junho e 3 de julho de 2010, contemplou os 22 poços com um total de 30 amostras que incluíram três duplicatas $(85,486,310)$ pertencentes aos poços $(85,86$ e 110) e cinco amostras coletadas em diferentes tempos $(t=0 h, t=6 h$ e $t=24 h$ para o poço 175 , e $t=6 h$ e $t=24 h$ para o poço $6)$.

A amostragem foi feita através das próprias bombas instaladas nos poços com purga prévia para remoção de água estagnada, equivalente a um volume de poço, conforme os procedimentos descritos pela USEPA (1985). Após a coleta, as amostras foram filtradas em membranas de acetato celulose $(0,45 \mu \mathrm{m})$, com o auxílio de bomba a vácuo manual e, em alguns casos uma de bancada. A bomba estava conectada a porta-filtros de $500 \mathrm{~mL}$. As amostras foram acondicionadas em frascos de polietileno, acidificadas (cátions e série nitrogenada), conservadas em geladeira a $4^{\circ} \mathrm{C}$ e encaminhadas ao laboratório para análise química.
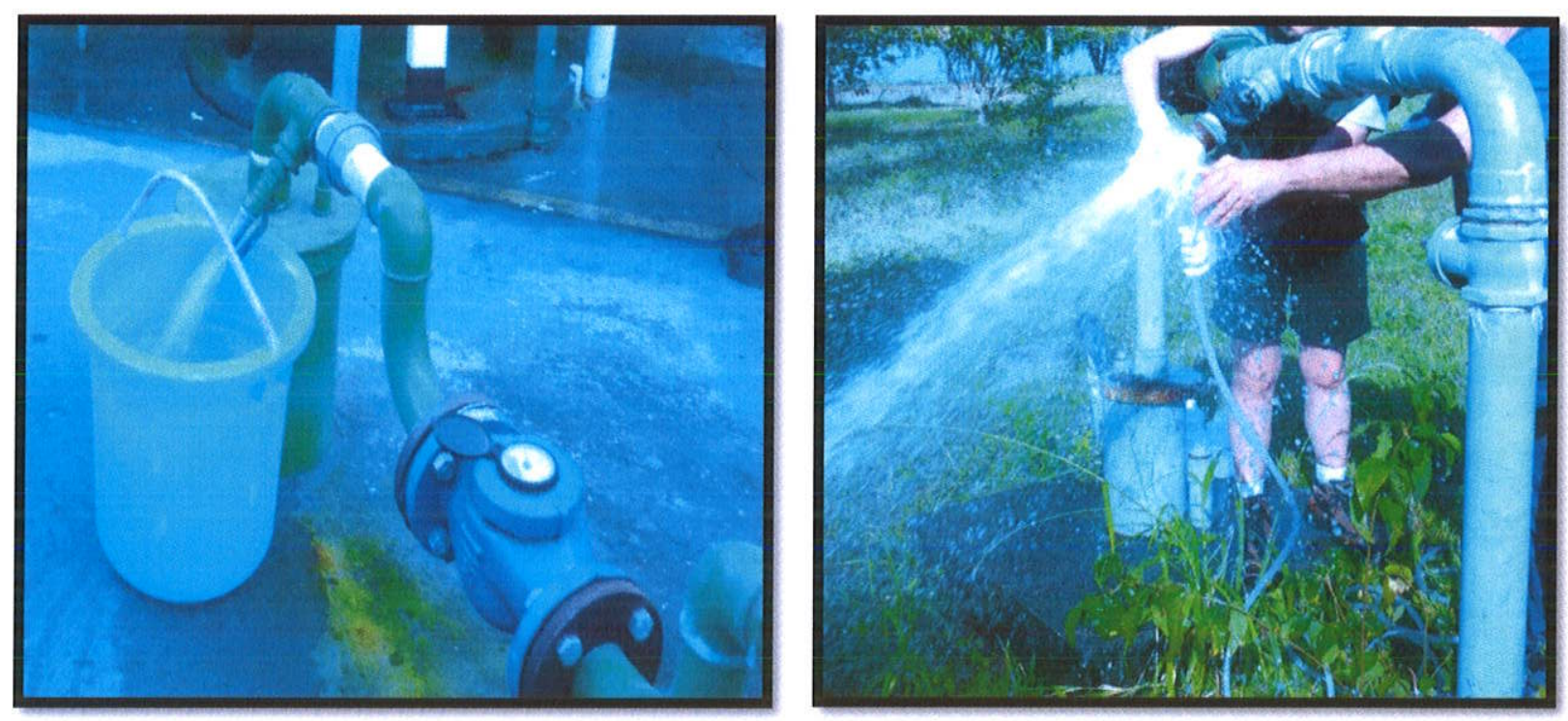

Figura 5.2 Purga e coleta das amostras nos poços 

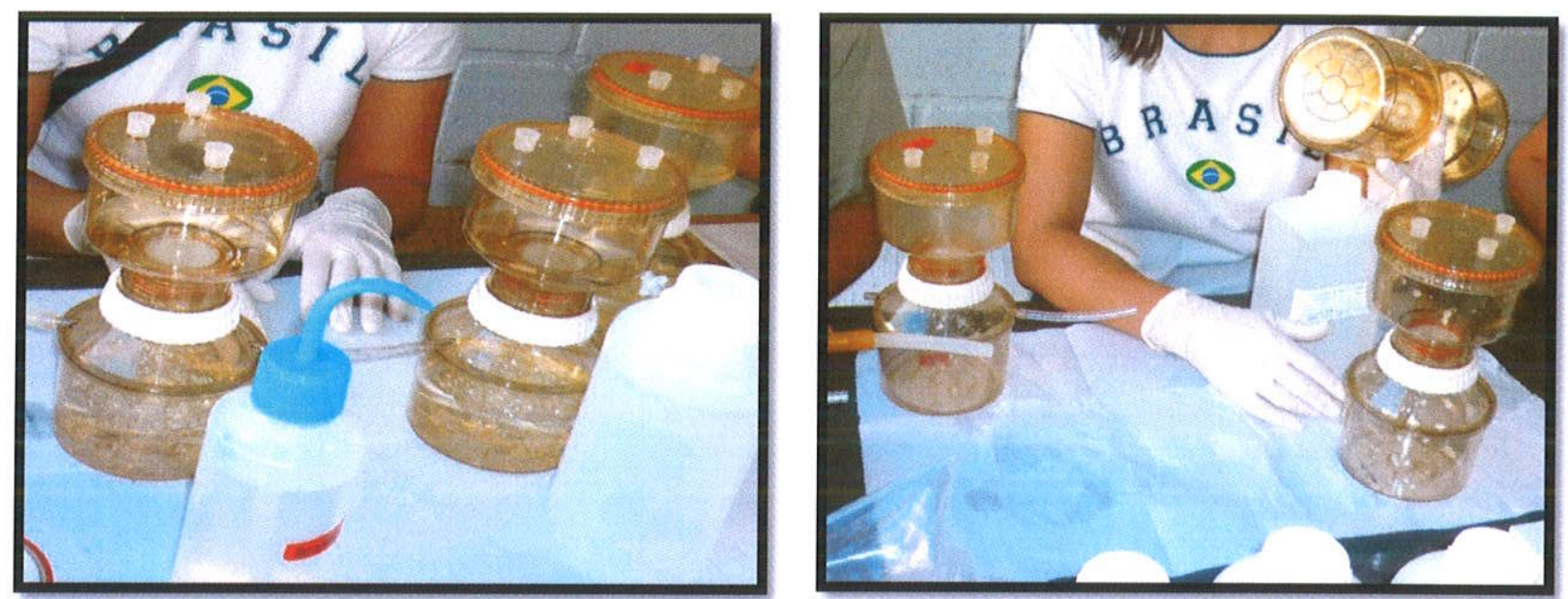

Figura 5.3 Filtragem das amostras

\subsubsection{Análises físico-químicas}

Os parâmetros analisados incluíram os compostos nitrogenados $\left(\mathrm{N}_{\text {total }}, \mathrm{N}_{\text {org }}, \mathrm{NH}_{4}^{+}\right.$, $\mathrm{NO}_{2}{ }^{-}$e $\left.\mathrm{NO}_{3}{ }^{-}\right)$, sílica, cátions e ânions $\left(\mathrm{Ca}^{2+}, \mathrm{Cl}^{-}, \mathrm{Mg}^{2+}, \mathrm{K}^{+}, \mathrm{Na}^{+}\right.$e $\left.\mathrm{SO}_{4}{ }^{2-}\right)$. Estas análises foram efetuadas no laboratório CTQ, em São Paulo. Os procedimentos de preservação da amostra, metodologias analíticas e técnicas são expressas na tabela 5.1 .

Tabela 5.1 Métodos analíticos adotados para a determinação dos parâmetros em amostras de água.

\begin{tabular}{|c|c|c|c|}
\hline Parâmetro & Preservação & Técnica & Metodologia \\
\hline Nitrogênio total & $\mathrm{H}_{2} \mathrm{SO}_{4}$ & Quimiofluorescência & Tekmar 14-900N-074 Rev. B \\
\hline Nitrogênio orgânico & $\mathrm{H}_{2} \mathrm{SO}_{4}$ & $\begin{array}{l}\text { Digestão/Eletrodo } \\
\text { seletivo }\end{array}$ & SMWWE 21th ed-4500 Norg B \\
\hline Nitrogênio amoniacal & $\mathrm{H}_{2} \mathrm{SO}_{4}$ & Eletrodo seletivo & $\begin{array}{c}\text { SMWWE 21th ed-4500 NH3 B e } \\
\text { G }\end{array}$ \\
\hline Nitrato e Nitrito & resfriamento & Cromatografia iônica & EPA 300.1 R. 1 \\
\hline $\begin{array}{l}\text { Cátions }\left(\mathrm{Na}^{+}, \mathrm{K}^{+},\right. \\
\left.\mathrm{Ca}^{2+}, \mathrm{Mg}^{2+}, \mathrm{Fe}^{\text {total }}\right)\end{array}$ & $\mathrm{HNO}_{3}$ & $\mathrm{ICP}$ & SMWW $21^{\mathrm{a}} \mathrm{Ed} 3120 \mathrm{~B}$ \\
\hline Ânions $\left(\mathrm{SO}_{4}{ }^{2-} \mathrm{e} \mathrm{Cl}\right)$ & resfriamento & Cromatografia iônica & EPA 300.1 R. 1 \\
\hline Sílica & resfriamento & ICP & SMWW $21^{\mathrm{a} E d} 3120 \mathrm{~B}$ \\
\hline
\end{tabular}


Além dessas espécies químicas, foram determinados, in situ, pH, Eh, condutividade elétrica e temperatura da água através de equipamentos portáteis da marca WTW (Eh/pH: 330/SET1, condutividade elétrica: LF330/SET) e Digimed (Eh/pH: DM-2, condutividade elétrica: DM-32). Aos valores de potencial redox, acrescentou-se o fator de correção de $250 \mathrm{mV}$, a título de obtenção do Eh.

Outro parâmetro medido em campo foi a alcalinidade (total e parcial), expressa em mg/L de $\mathrm{CaCO}_{3}$. A técnica adotada foi a titulação volumétrica, utilizando-se de ácido sulfúrico 0,01 e $0,010 \mathrm{~N}$, padronizado previamente em laboratório com $\mathrm{Na}_{2} \mathrm{CO}_{3}$, indicadores misto e fenolftaleína e de uma bureta digital, da marca Optilab, com aproximadamente $0,1 \%$ de precisão.

\subsection{Tratamento dos dados hidroquímicos}

\subsubsection{Análise estatística}

De acordo com a profundidade dos poços e o tipo de material reportado nos perfis de perfuração, foram definidos dois grupos: poços tubulares rasos (menores que 150 $\mathrm{m}$ ) e poços tubulares profundos (maiores que $150 \mathrm{~m}$ ). Nesses grupos procedeu-se o seguinte tratamento estatístico: análises descritivas convencionais e estatística multivariada. Tal tratamento foi feito com o intuito de avaliar o comportamento relativo entre os diferentes compostos presentes na água e suas possíveis correlações.

A análise estatística convencional baseou-se na determinação da média aritmética simples $(x)$ e do desvio padrão $(\mathrm{s})$, dos parâmetros físico-químicos $(\mathrm{pH}$, Eh, temperatura, condutividade elétrica), além dos cátions, ânions e série nitrogenada.

As determinações destas variáveis definiram os valores médios de cada parâmetro nos poços rasos e profundos para as duas campanhas de amostragem. Além dos dados das campanhas 2009 e 2010 , este tratamento foi efetuado com os 
dados das análises pré-existentes, compilados das fichas de outorga do SIDAS. Especial atenção foi dada às concentrações de nitrato; estes dados foram previamente separados por anos, entre 2005 e 2008, para a verificação da evolução temporal deste parâmetro na área urbana (anexo VI).

Tanto os poços com resultados dos parâmetros físico-químicos das duas etapas de amostragem quanto aqueles com concentrações pretéritas de nitrato foram separados em quatro zonas geográficas, de acordo com as coordenadas e posições dos poços em relação ao divisor de águas e ferrovia (já que segundo Abreu, 1972, ao longo das ferrovias multiplicam-se os núcleos urbanos). Desta forma, as zonas consideradas foram as seguintes: nordeste, centro, sudoeste e oeste.

Em cada zona determinou-se também a média aritmética simples e desvio padrão dos parâmetros determinados no campo, laboratório e análises de nitrato pré. existentes.

Com o intuito de caracterizar a dispersão ou variabilidade dos dados em termos relativos a seu valor médio, calculou-se o coeficiente de variação de Pearson (CVP) O coeficiente é dado pela razão entre o desvio padrão e a média referente a cada um dos parâmetros analisados.

Seguindo com o tratamento estatístico convencional dos dados, foram confeccionados gráficos das concentrações de nitrato versus $\mathrm{pH}$, condutividade elétrica em função do tempo, levando em consideração os grupos de poços e as zonas definidas segundo a localização geográfica (nordeste, centro, sudeste e oeste), com intuito de verificar a o comportamento dos parâmetros no contexto temporal

A análise estatística multivariada, por sua vez, avaliou o grau de correlação entre os parâmetros determinados em campo ( $\left.\mathrm{pH}, \mathrm{T}, \mathrm{CE}, \mathrm{Eh}, \mathrm{HCO}_{3}{ }^{*}, \mathrm{NH}_{4}{ }^{+}\right)$e no laboratório $\left(\mathrm{Na}^{+}, \mathrm{K}^{+}, \mathrm{Mg}^{2+}, \mathrm{Ca}^{2+}, \mathrm{Cl}^{-}, \mathrm{SO}_{4}{ }^{2-}\right.$ e $\left.\mathrm{NO}_{3}{ }^{-}\right)$, através do teste da correlação linear de Pearson. Tal tratamento foi feito com o intuito de avaliar o comportamento relativo entre os diferentes compostos presentes na água e suas possiveis correlações. A fim de melhor visualizar estas relações, utilizou-se também de um teste de correlação linear onde foi adotado um nível de significância de 5\% (Davis, 1986). Neste caso, aceita-se a hipótese da existência de correlação entre dois 
parâmetros, com $5 \%$ de significância, se o coeficiente de correlação (r) entre eles for tal que $T(r)>1,96$ ou $T(r) \leq-1,96$, conforme ilustrado na equação 5.1

$$
T(r)=\frac{\sqrt{N-3}}{2} \ln \frac{(1+r)}{1-r}
$$

Onde: $\mathrm{N}$ é número de pares e r é o coeficiente de correlação de Pearson

Foram considerados os pares cuja hipótese de existência de correlação apresentassem valores de $T(r)$ dentro deste intervalo, sendo desconsiderados aqueles pares cujos valores eram excedentes. Para o cálculo desta correlação foi utilizado o software estatístico Statistica versão 9.0 da StatSoft South America.

Complementando as análises de correlação, foram também gerados gráficos que relacionam as concentrações de nitrato, condutividade elétrica, $\mathrm{pH}$, cloreto e sódio. O objetivo foi verificar o grau de dependência destes parâmetros.

\subsubsection{Controle de Qualidade, Classificação e Evolução Hidroquímica das Águas Subterrâneas}

Os resultados das análises químicas foram submetidos a dois tipos de controle de qualidade: cálculo do balanço iônico e amostras duplicatas.

O cálculo do balanço iônico e o envio de amostras duplicatas consistem em procedimentos mais comuns adotados para avaliar a reprodutibilidade dos resultados, além de quantificar possíveis erros durante a execução das análises. $O$ balanço iônico foi efetuado em todas as amostras coletadas em campo de modo a assegurar se o erro estava dentro do limite permitido, geralmente entre $\pm 10 \%$.

A porcentagem do erro do balanço înico para todas as amostras totais foi calculada a partir dos valores em miliequivalentes dos ânions e cátions. 
Com o intuito de caracterizar quimicamente as águas subterrâneas e estabelecer uma evolução hidroquímica da área utilizou-se o diagrama triangular de Piper através do software Aquachem, versão 5.1, da Schlumberger Water Services. As concentraçôes dos ions maiores na água $\left(\mathrm{Ca}^{2+}, \mathrm{Mg}^{2+}, \mathrm{Na}^{+}, \mathrm{K}^{+}, \mathrm{HCO}_{3}{ }^{2}, \mathrm{SO}_{4}{ }^{2-}, \mathrm{Cl}^{\sim} \mathrm{e}\right.$ $\mathrm{NO}_{3}{ }^{-}$) foram convertidas em meq/L e dispostas no diagrama, calculando-se as porcentagens em relação à soma de cátions e ânions de cada amostra. Os resultados das análises plotedas consideraram as duas campanhas de amostragem, levando-se em conta os poços rasos e profundos.

\subsubsection{Distribuições espacial e temporal dos parâmetros}

A análise das correlações temporal e espacial foram realizadas através dos seguintes procedimentos:

a) Mapa de localização dos poços que tiveram dados das concentrações de nitrato preexistentes. Os critérios considerados para a confecção de dito mapa baseou-se nas informações de localização geográfica dos poços, endereço, nomes dos bairros, localização do divisor de águas e da ferrovia. Os poços foram ploteados sobre a malha urbana mais nova, correspondente ao ano 2004.

b) Mapas de isoconcentrações para o nitrato e cloreto, correspondentes à primeira e à segunda campanha (estação úmida e estação seca respectivamente). Nos mapas foi utilizado o método de interpolação kriging ordinário, do software Surfer, versão 8.0 da Golden Softwares, Inc e Arcgis 9.0. A partir deles foi feita a análise dos padrões de distribuição dos referidos compostos e suas concentrações na área urbana de Presidente Prudente. 


\subsection{Estimativa da carga potencial de nitrato nas áreas urbanas}

A análise da carga potencial de nitrato na área de estudo foi realizada conforme a Identificação das áreas urbanas respeito ao adensamento urbano. O adensamento urbano ou densidade de ocupação foi avaliado a partir do conjunto de fotografias aéreas da cidade, escala 1:25.000 (1995), bem como as imagens captadas do Google Earth 2010 para comparar e constatar mudanças no uso e ocupação no solo e espacialização das áreas de expansão urbana e demográfica. A comparação entre ambas permitiu também a identificação de características principais da cidade tais como a ferrovia, bairros (antigos e novos) e poços (figura 5.4).
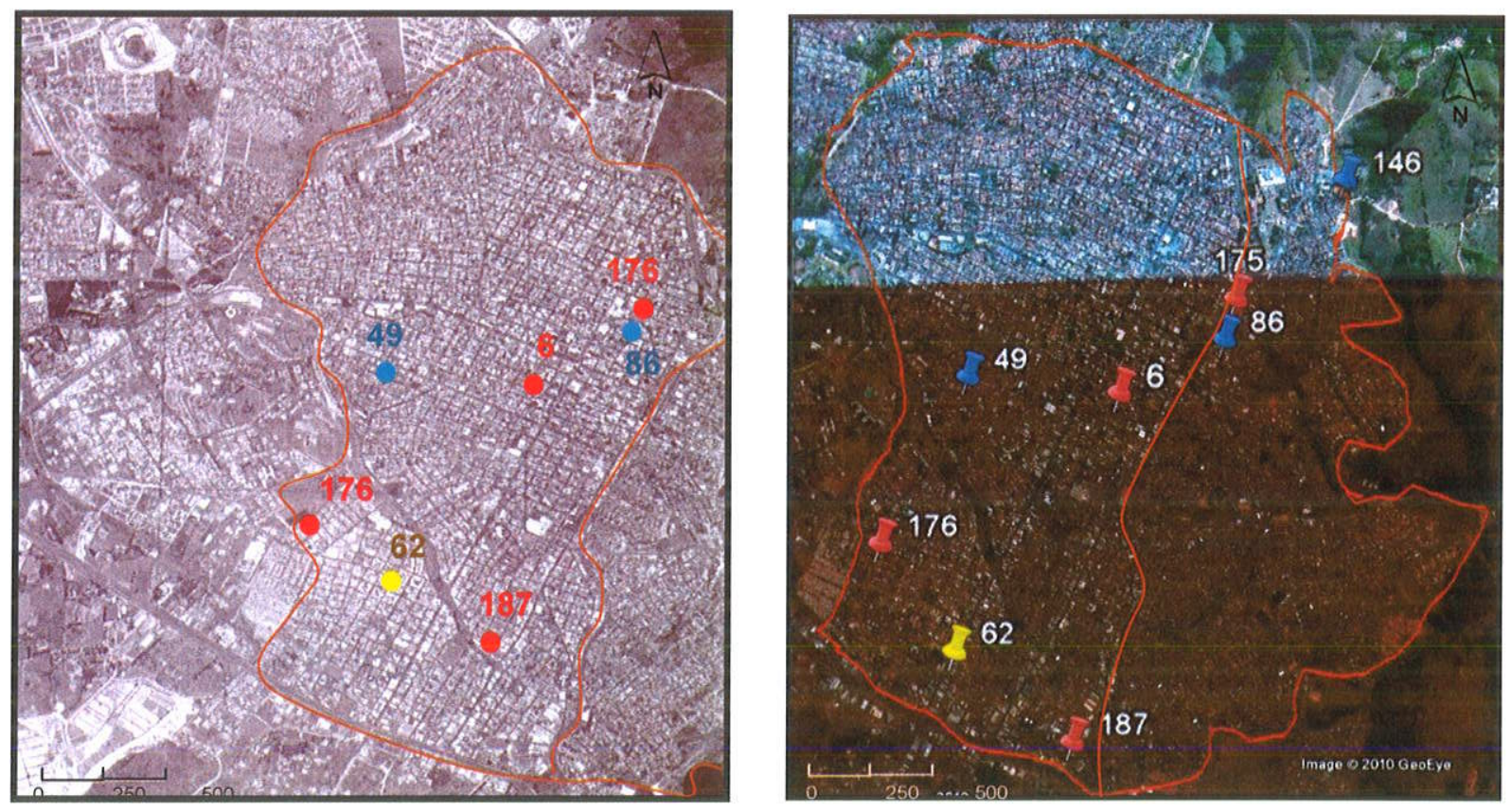

Figura 5.4 Fotografia aérea (1995) à esquerda e imagem do Google Earth (2010) à direita destacando a ferrovia e poços no centro da cidade.

Posteriormente, selecionou-se uma mesma área (1ha) em diferentes zonas da cidade, onde foram quantificadas as moradias, considerando três tipos de densidade: alta (A), média $(\mathrm{M})$ e baixa (B). As áreas $\mathrm{s}$ com alta densidade de ocupação apresentaram maior quantidade de residências ou prédios e poucos 
espaços livres (praças, parques e gramados) (figuras 5.5 e 5.6). Nestas circunstâncias, a quantificação determinou que 1hectare (ha) corresponde, em média, a 40 residências.

As áreas de média densidade apresentaram maior ocorrência de espaços livres, em relação às de alta densidade (figuras 5.5 e 5.6). Neste caso, 1ha, em média, compreende 21 residências.

Por fim, nas áreas de baixa densidade, 1(ha) possui aproximadamente cinco residências. Esse tipo de densidade foi registrado somente em bairros mais novos que ainda estão em processo de ocupação (figuras 5.5 e 5.6).

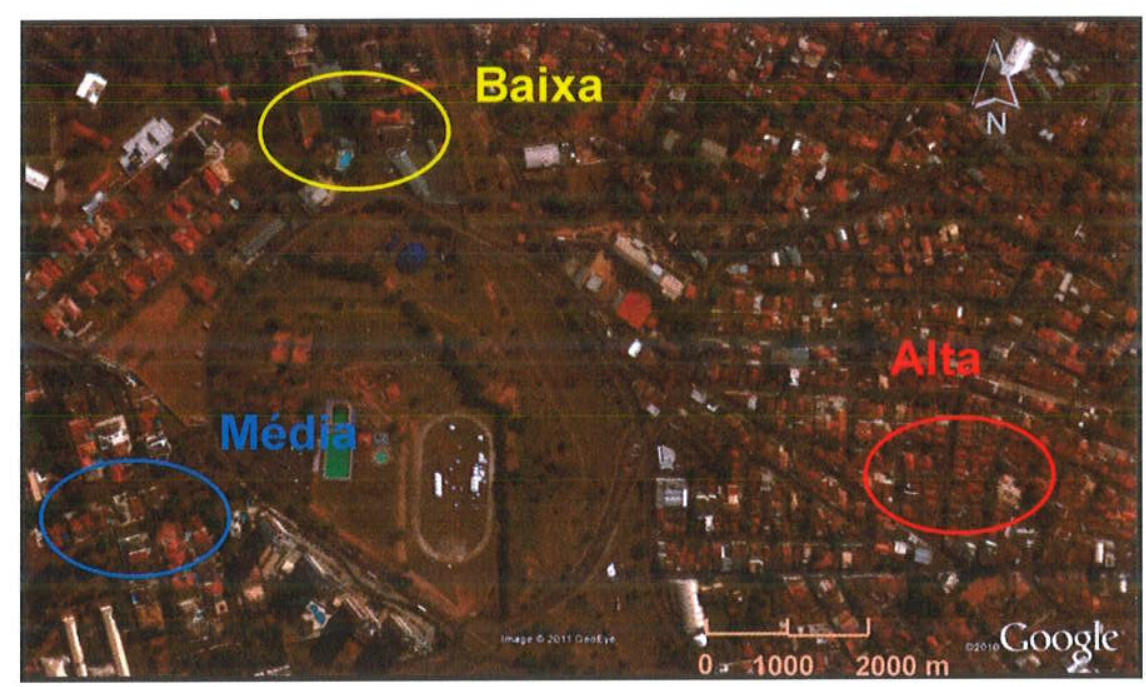

Figura 5.5 Imagem do Google Earth (2011) destacando os critérios de densidade na área urbana de Presidente Prudente.

A partir da relação da densidade e número de residências, procedeu-se a quantificar a relação número de pessoas por hectare. Considerando que, segundo Bertolo (2001) uma moradia geralmente abriga quatro habitantes, obteve-se as seguintes relações: (A) densidade de ocupação alta: 160hab/ha; (M) media: 84hab/ha e (B) baixa: 20hab/ha. 

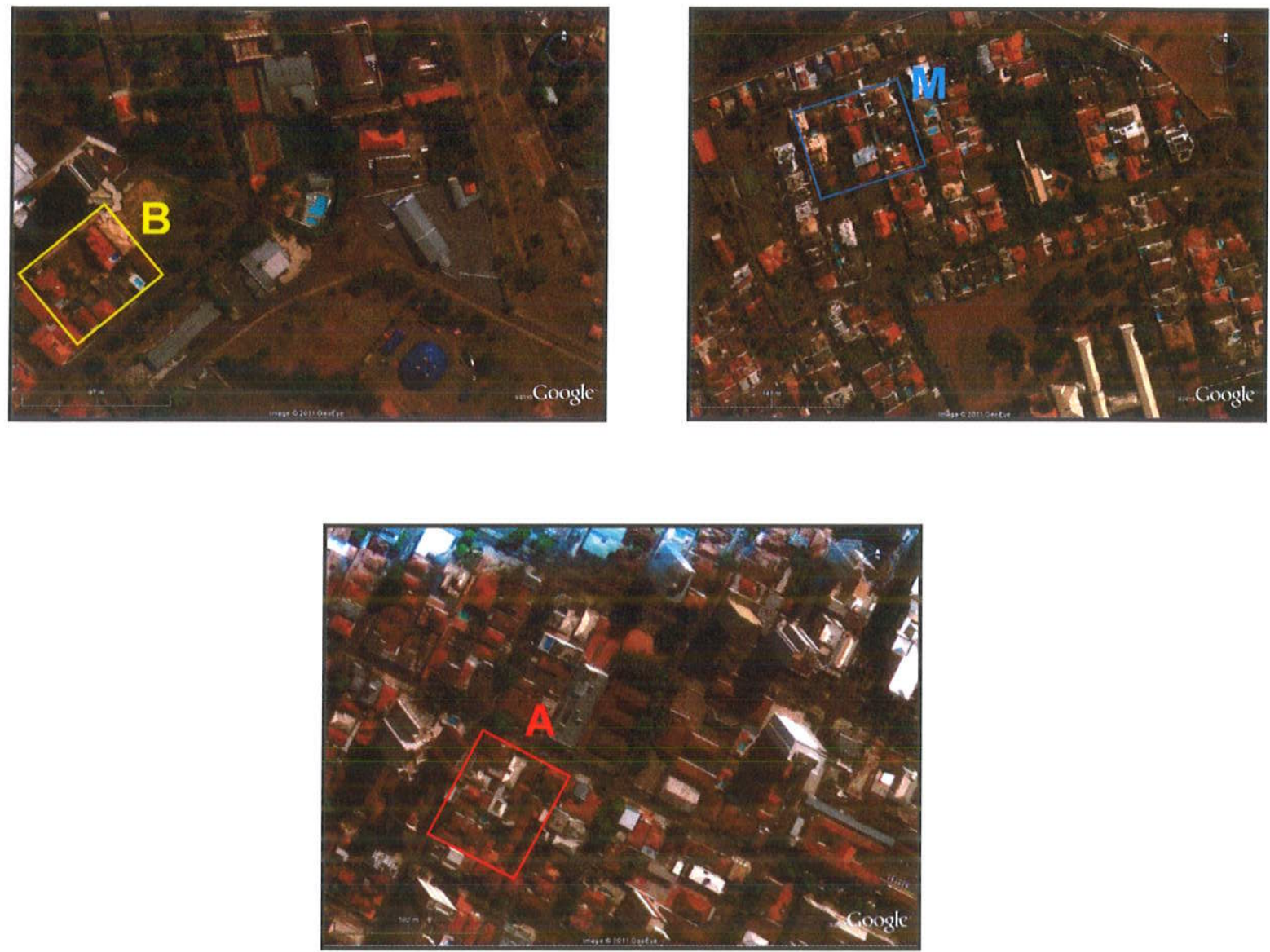

Figura 5.6. Densidade de ocupação alta (A), média (M) e baixa (B) adotada para Presidente Prudente. Imagem captada do Google Earth (2011).

As quantificações da densidade urbana foram consideradas na estimativa da concentração de nitrato que pode ser lixiviado para o aquífero na área urbana de Presidente Prudente. Esta estimativa foi determinada através da equação proposta por Foster \& Hirata (1988):

$$
C_{u}=\left(\mathrm{mg} / \mathrm{L} \mathrm{NO}{ }_{3}-\mathrm{N}\right)=\left(1000 * a^{*} A^{*} f_{u}\right)\left(0.36 * A^{*} \mathrm{U}+10 \mathrm{I}\right)^{-1}
$$

Onde: a (Kg/cap/ano) representa o peso por unidade de $\mathrm{NO}_{3}{ }^{-} \mathrm{N}$ da excreta; $A$ (hab/ha) é a densidade de ocupação; / ( $\mathrm{mm} / \mathrm{ano}$ ) é a taxa de infiltração ou excesso de precipitação; $U$ (L/hab/dia) porção não consumível do uso da água total e $f_{u}$ (adimensional), a proporção de nitrogênio lixiviado para as águas subterrâneas. 
As cargas potenciais de nitrato $C_{u}\left(\mathrm{mg} / \mathrm{L} \mathrm{NO}_{3}-\mathrm{N}\right)$, determinadas pela equação 5.2 , foram comparadas com as concentrações de nitrato obtidas nas duas campanhas de amostragem, com o objetivo de avaliar o grau de ajuste entre os dados medidos e os calculados.

Da mesma forma, as cargas de nitrato $\left(C_{u}\right)$ nos poços amostrados foram estabelecidas semi-quantitativamente a partir dos dados das concentrações de nitrato pré-existentes. Assim, também foi feito o mesmo tratamento comparativo entre os valores das concentraçōes calculadas e as reportadas nas análises dos poços não amostrados, considerando-se os valores médios nos casos onde os poços possuem mais de uma análise. Os gráficos para a análise das informações de ocupação ou adensamento urbano, profundidade dos poços, malha urbana, concentrações de nitrato, e idade das redes coletoras de esgoto foram feitos de acordo com o software Idl, versão 6.4, e no Arcgis 9.3. De acordo com estes critérios, a análise de dependência desses dados foi feita através de diagramas cúbicos e mapas da distribuição espacial das concentrações de nitrato na área urbana. Os diagramas cúbicos mostram em um triedro a dependência de quatro parâmetros (ocupação ou adensamento, profundidade dos poços, malha urbana, concentrações de nitrato).

Por se tratar de um aquífero livre e vuinerável à contaminação pelas cargas potencialmente poluidoras, $\mathrm{SAB}$, da superfície do terreno foi necessário determinar a zona de captura dos poços (ZOC).

A zona de captura de poço (ZOC) representa a área em superfície que pode contribuir de qualquer forma à captação (Cadernos do Projeto Ambiental Estratégico Aquíferos, 2010). A delimitação da ZOC neste trabalho foi realizada através de duas metodologías: a) raio fixo calculado (RFC) e b) método de Wyssling (Merino et al., 1991).

Posteriormente, foram comparados os raios calculados pelos métodos mencionados com intuito de estabelecer semelhanças ou diferencias na determinação da área de contribuição à captação e as suas possíveis correlações o entre as concentrações de nitrato nos poços e as áreas delimitadas na ZOC. 
Por último, foi determinado o zoneamento da área urbana da cidade, levando em conta a quantidade (número de poços rasos, profundos, privados e públicos) e a qualidade dos poços analisados (dados da estimativa da carga potencial de nitrato, concentrações determinadas no campo e laboratório, concentrações pré-existentes) além de dados de densidade de ocupação urbana. 


\section{RESULTADOS}

\subsection{Cadastro dos poços}

Com base nas informações coletadas no DAEE, na zona urbana de Presidente Prudente, existem 212 poços, dos quais, 198 (93\%) estão ativos e 14 (7\%) estão fora de operação ou tamponados (anexo I). A figura 6.1 ilustra a localização de todos os poços cadastrados na área estudada.

Dentre os poços ativos, 95\% são privados, com profundidades entre 60 e $242 \mathrm{~m}$ e $5 \%$ são de abastecimento público, com profundidades entre 200 e 272 m. Estes últimos pertencem à Companhia de Saneamento Básico do Estado de São Paulo (SABESP).

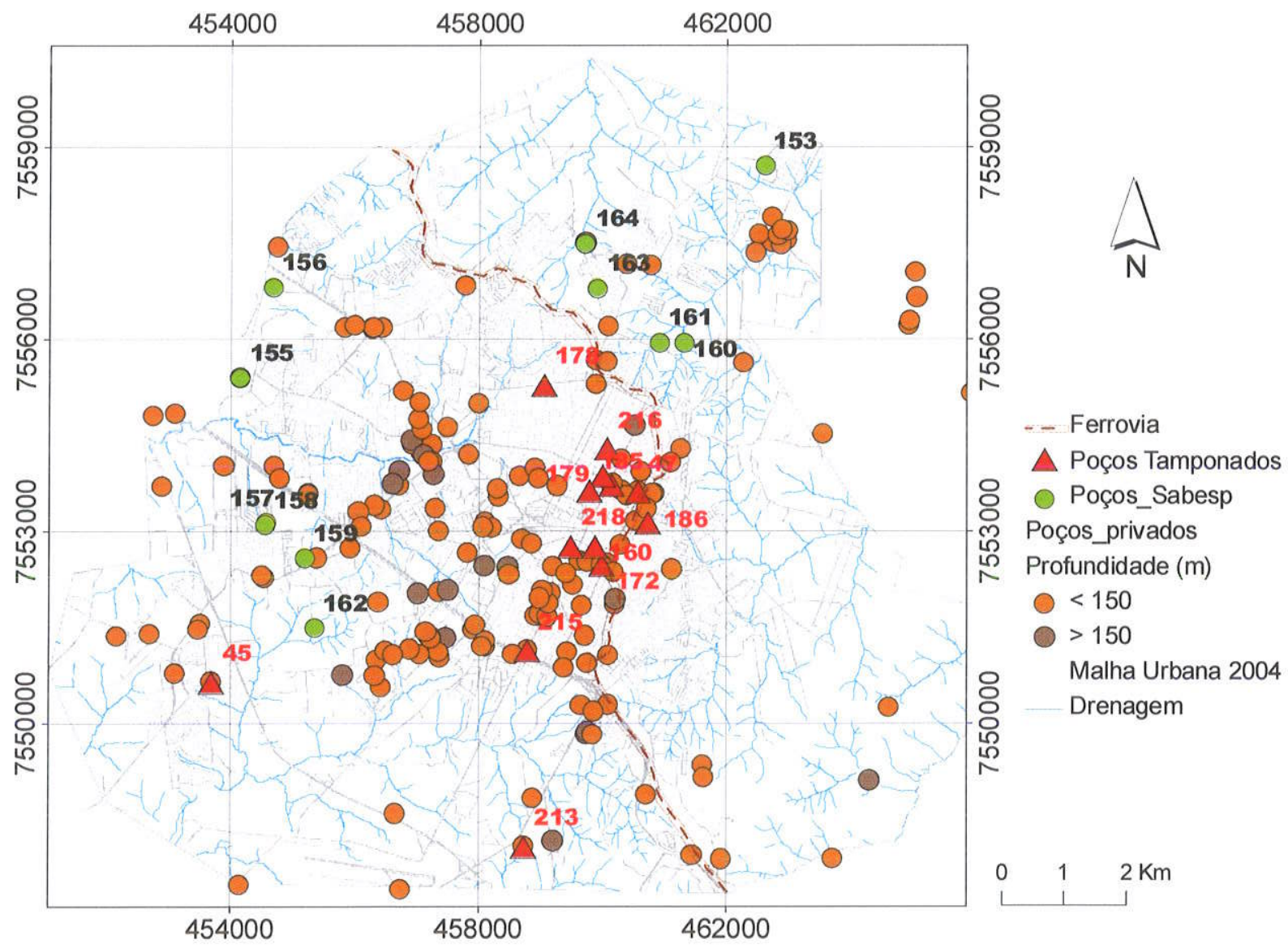

Figura 6.1 Localização dos poços cadastrados na área urbana de Presidente Prudente. 


\subsection{Modelo Conceitual de Circulação das Águas Subterrâneas}

A unidade litoestratigráfica mais intensamente utilizada pelo usuário privado em Presidente Prudente é o Sistema Aquífero Bauru, representado na região pelos aquíferos Adamantina (aflorante) e o Santo Anastácio (subsuperfície).

O Aquífero Adamantina é do tipo livre, regionalmente semi-confinado, de porosidade primária. Ele é representado, na área, pela ocorrência de arenitos muito finos a médios, cremes a cinzas, bem selecionados e espessura local média de 130 m (figura 6.2).

Sotoposto ao Aquífero Adamantina encontra-se o Santo Anastácio, que é constituído por arenitos vermelhos a roxos, granulação de fina a média, baixo conteúdo de argila. Segundo Godoy et al. (2004), estes sedimentos apresentam grãos arredondados a sub-arredondados, cobertos por uma película limonítica com presença frequente de nódulos carbonáticos ou cavidades preenchidas por carbonato de cálcio. Os poços tubulares que captam o Aquífero Santo Anastácio correspondem principalmente aos da SABESP, que o penetram de forma parcial com espessura média de 93m (figura 6.2).

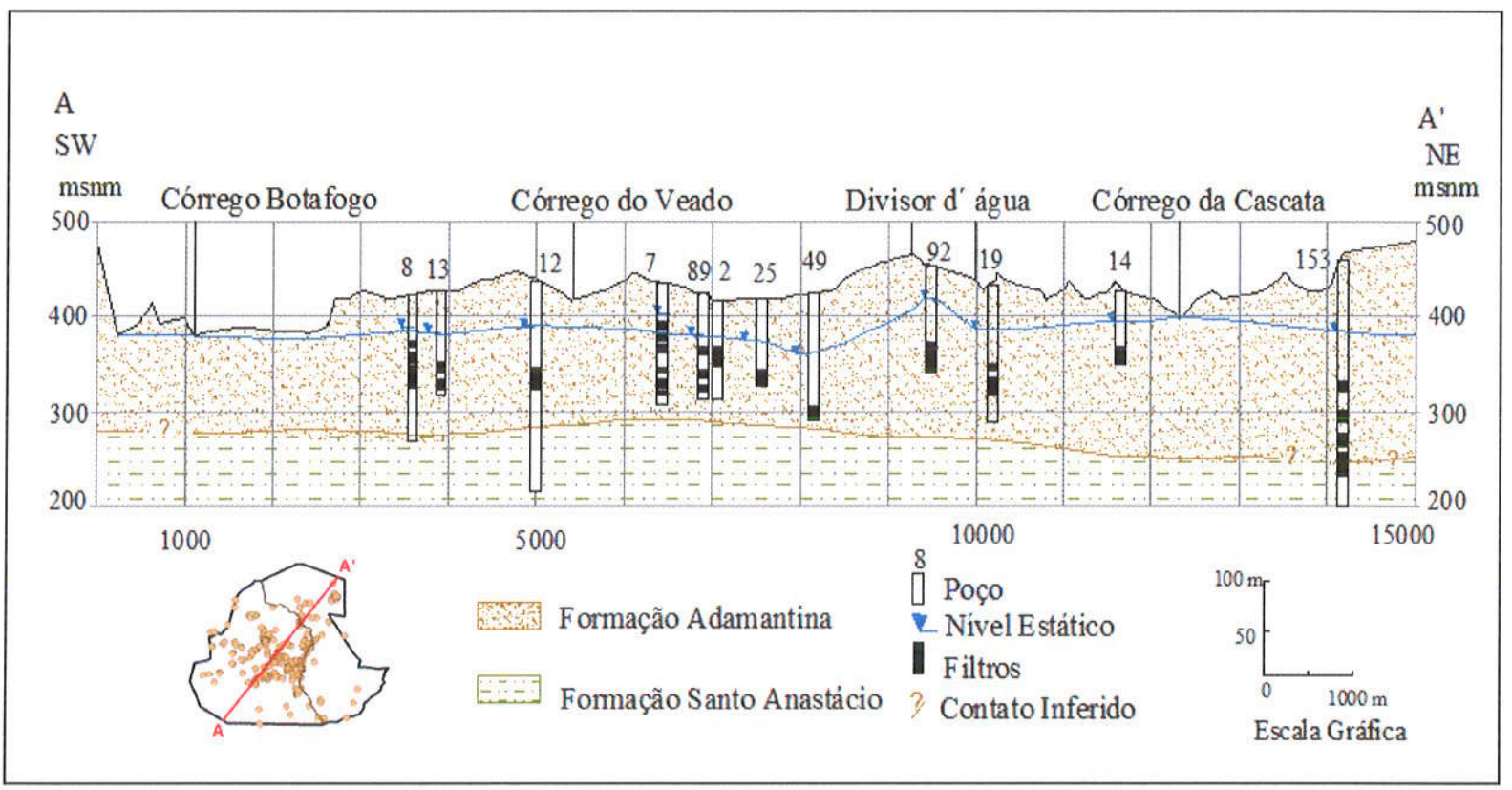

Figura 6.2 Seção geológica do município de Presidente Prudente, a partir dos dados estratigráficos dos poços tubulares situados na área urbana de Presidente Prudente. 
Os perfis construtivos dos poços mostram que, na maioria, os filtros distribuem-se em toda sua extensão e não necessariamente em um nivel aquífero determinado (figura 6.2). Assim, o nivel potenciométrico dos poços de produção pode corresponder à mescla de vários níveis aquíferos.

A partir da análise dos poços tubulares mais rasos (até $150 \mathrm{~m}$ ), confeccionou-se um mapa potenciométrico, para o Aquífero Adamantina. A partir deste, foi possível estabelecer as direções principais de fluxo das águas subterrâneas bem como determinar o gradiente hidráulico. As maiores cotas são de $469 \mathrm{msnm}$ (metros sobre o nível do mar; poço 14) e um mínimo, junto ao Córrego do Veado de $310 \mathrm{msnm}$ (poço 55; figura 6.3).

De acordo com este mapa, a direção preferencial das águas subterrâneas ocorre nas porções oeste e sudeste da cidade.

A recarga do aquífero ocorre pela infiltração natural da água de chuva em toda a área de exposição dos sedimentos. A morfologia da área influencia as superfícies potenciométricas e os divisores das micro-bacias hidrográficas são coincidentes com os das águas subterrâneas (figura 6.3). As descargas locais encontram-se na direção dos principais córregos: Veado, Cascata, Botafogo e Cedro, estes últimos afluentes do Rio Santo Anastácio.

A partir dos dados dos testes de bombeamento realizados no momento da construção dos poços tubulares na área urbana de Presidente Prudente (34 poços), calcularam-se os parâmetros hidrogeológicos para o Aquífero Adamantina na área. Já para o Santo Anastácio, estes parâmetros foram determinados através de sete poços profundos, três de propriedade da SABESP. A tabela 6.1 apresenta um sumário dos parâmetros hidrogeológicos para os aquíferos Adamantina e Santo Anastácio.

De acordo com a tabela 6.1 , os valores médios de condutividade hidráulica e transmissividade do Aquífero Adamantina são, respectivamente, $0,77 \mathrm{~m} /$ dia e 100,1 $\mathrm{m}^{2} /$ dia (espessura média de $130 \mathrm{~m}$ ). O gradiente hidráulico varia de 0,01 a 0,03 $(1,91 \%$ a $3,5 \%)$ e a velocidade de fluxo das águas subterrâneas de 0,15 a $0,46 \mathrm{~m} / \mathrm{dia}$ (porosidade efetiva de $5 \%$ ) e de 0,05 a $0,15 \mathrm{~m} /$ dia (porosidade efetiva de $15 \%$ ). 
O Aquífero Santo Anastácio, por sua vez, apresenta parâmetros similares aos determinados para o Aquífero Adamantina. Com base nos valores de espessura saturada média de $93 \mathrm{~m}$, obtiveram-se os parâmetros hidrogeológicos que estão descritos na tabela 6.1

Tabela 6.1 Sumário de parâmetros hidrogeológicos na zona de estudo

\begin{tabular}{cccccc}
\hline Aquiferos & $\begin{array}{c}\text { Cond. } \\
\text { Hidráulica } \\
(\mathrm{m} / \text { dia) }\end{array}$ & $\begin{array}{c}\text { Gradiente } \\
\text { Hidráulico }\end{array}$ & $\begin{array}{c}\text { Velocidade de fluxo } \\
\text { (m/dia) }\end{array}$ & $\begin{array}{c}\text { Transmissividade } \\
\left(\mathrm{m}^{2} / \mathrm{dia}\right)\end{array}$ \\
$\begin{array}{c}\text { Adamantina } \\
\text { Santo }\end{array}$ & 0,77 & 0,01 a 0,03 & 0,15 a 0,46 & 0,05 a 0,15 & 100,1 \\
Anastácio & 0,71 & 0,01 a 0,02 & 0,14 a 0,15 & 0,05 a 0,09 & 65,78 \\
\hline
\end{tabular}



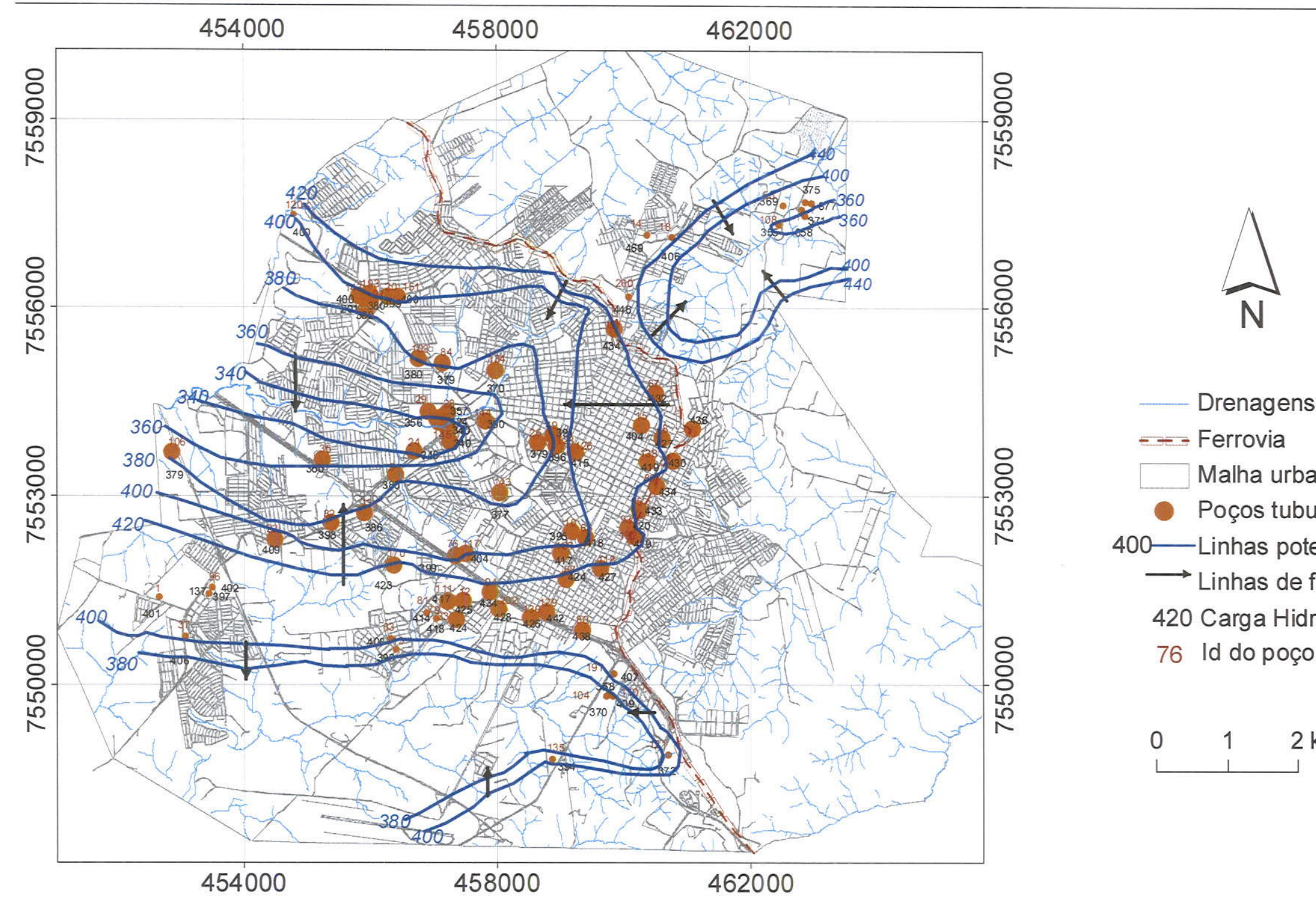

$\square$ Malha urbana 2004

Poços tubulares

400 _Linhas potenciométri

$\longrightarrow$ Linhas de fluxo

420 Carga Hidráulica (m)

76 Id do poço

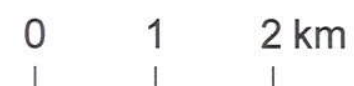

Figura 6.3 Potenciometría do SAB, a partir dos valores de níveis estático medidos na época da instalação dos poços tubulares na área de estudo 


\subsection{Hidroquímica Local}

\subsubsection{Controle de qualidade dos dados hidroquímicos}

Para a avaliação da qualidade e confiabilidade dos dados das análises químicas, foram adotados dois critérios: i) cálculo do balanço iônico e ii) amostras duplicatas.

A figura 6.4 apresenta a porcentagem dos erros calculados para as campanhas de amostragem. O balanço iônico fol determinado calculado duas vezes para cada campanha: a primeira utilizou os dados obtidos em laboratório e a segunda, os resultados de amônio, nitrito, nitrato e ferro obtidos no campo.

As amostras da primeira campanha apresentaram balanços iônicos com maiores percentagens de erro quando são considerados os valores de alcalinidade determinada em campo (figura 6.4). Em contrapartida, o erro é maior nos balanços que consideram os valores de alcalinidades de laboratório na segunda campanha de amostragem. Assim, os dados de alcalinidade nas duas campanhas de amostragem foram utilizados com cautela, pois segundo Custodio \& LLamas (1976) a determinação da alcalinidade é uma das maiores fontes de erros.

$\mathrm{Na}$ primeira campanha foram considerados os resultados das análises de laboratório para todos os parâmetros, incluindo a alcalinidade. Já para a segunda etapa, consideraram-se os valores de alcalinidade determinado em campo obtendose, assim, melhores resultados.

Nota-se que $48 \%$ das amostras se restringiram a erros inferiores que $10 \%$ na primeira campanha de amostragem sem consideramos a alcalinidade determinada em laboratório e 95 \% na segunda campanha ao considerar a alcalinidade de campo, o que mostra uma confiabilidade maior para os resultados obtidos na segunda campanha de amostragem (anexo V). 


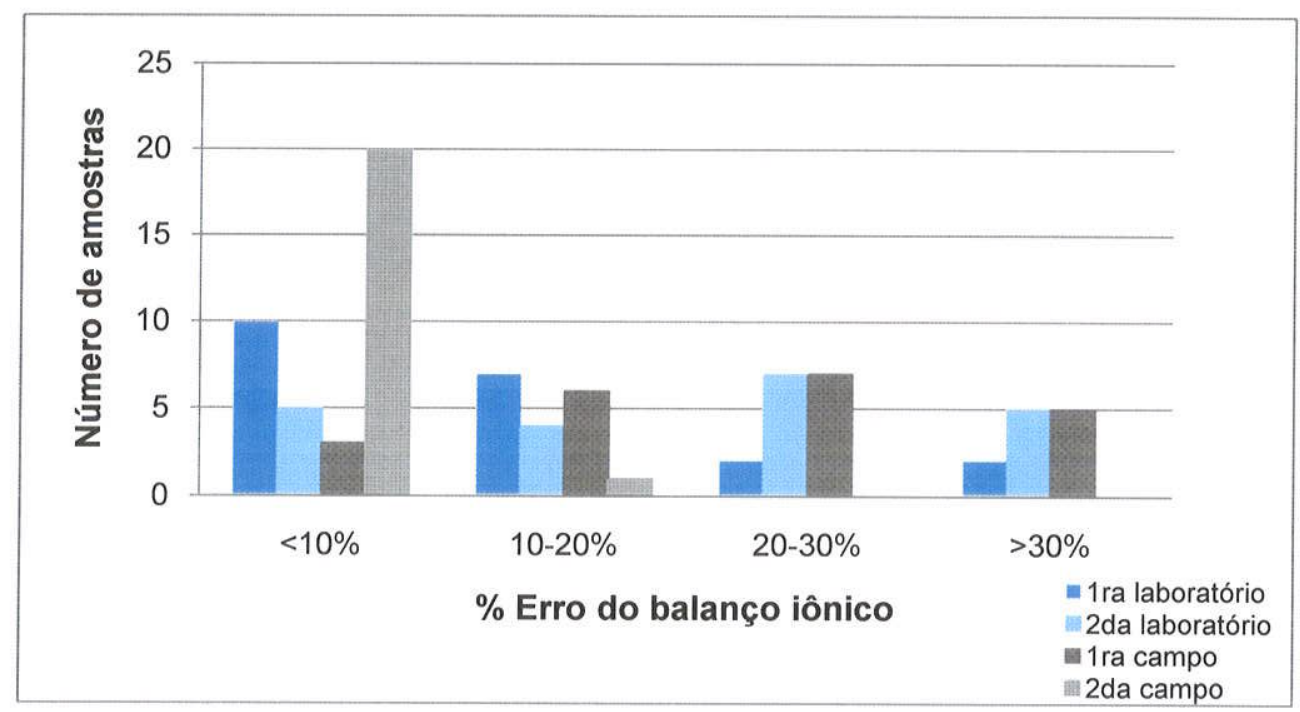

Figura 6.4 Porcentuais de erro nos balanços iônicos para as duas campanhas de amostragem.

Um segundo critério para verificar a precisão dos resultados obtidos em laboratório consistiu-se na coleta de amostras duplicatas para as duas campanhas de amostragem (anexo V). Coletaram-se, no total, quatro amostras: duas na primeira campanha $(157-1,175-1)$ e duas na segunda (310 e 486) em poços escolhidos aleatoriamente $(86,110,157$, e 175). Os resultados não mostraram diferença estatisticamente significantiva entre os valores obtidos. As porcentagens de erro foram menores que $30 \%$ em $88 \%$ dos compostos analisados, menor do que o admitido pela USEPA (1995) para amostras duplicatas, o que confere a estas análises uma boa precisão.

\subsubsection{Classificação e Evolução Hidrogeoquímica das Águas Subterrâneas}

As análises dos parâmetros físico-químicos e químicos das amostras de água, coletadas em dezembro/2009 e junho de 2010, são apresentados no anexo IV.

As variações nos resultados dos parâmetros físicos medidos em campo e os analisados em laboratório, em relação à profundidade, confirmaram a existência de 
águas com composições distintas na área de estudo (tabelas 6.2 e 6.3). Os resultados estatísticos (valor mínimo, máximo, média, desvio padrão) (anexo IV) indicam que as águas do $\mathrm{SAB}$, na área de estudo, apresentam temperaturas homogêneas cujo valor médio é de $25^{\circ} \mathrm{C}$. Os valores de $\mathrm{pH}$ indicam águas ligeiramente ácidas (média de 6,53 e 6,44 para a primeira e segunda campanha respectivamente) nas águas rasas e alcalinas nas águas profundas (média de 8,17 e 7,44 para a primeira e segunda campanha respectivamente). Os valores de Eh mostram que as águas profundas perdem a capacidade de agente oxidante comparadas às águas mais rasas. Os resultados de condutividade elétrica são variáveis, tanto nos poços rasos como nos profundos, no entanto, indicam que as águas mais rasas contêm mais sais iônicos que as profundas.

Tabela 6.2 Estadística dos parâmetros físicos medidos no campo para as amostras de água na primeira campanha de amostragem (dezembro/2009).

\begin{tabular}{|c|c|c|c|c|}
\hline $\begin{array}{c}\text { Poços } \\
\text { rasos } \\
16 \text { poços }\end{array}$ & $\mathrm{pH}$ & $\left({ }^{0} \mathrm{C}\right)$ & $\begin{array}{c}C E \\
(\mu S / \mathrm{cm})\end{array}$ & $\underset{(m V)}{E h}$ \\
\hline Min. & 5,64 & 24,30 & 110,50 & 394,50 \\
\hline Máx. & 8,14 & 26,60 & 750,00 & 575,60 \\
\hline Média & 6,53 & 25,06 & 348,66 & 466,93 \\
\hline D.P. & 0,65 & 0,67 & 158,68 & 50,34 \\
\hline $\begin{array}{l}\text { Poços } \\
\text { profundos } \\
5 \text { poços }\end{array}$ & $\mathrm{pH}$ & $T\left({ }^{\circ} \mathrm{C}\right)$ & $\begin{array}{c}C E \\
(\mu S / \mathrm{cm})\end{array}$ & $\begin{array}{c}\text { Eh } \\
(\mathrm{mV})\end{array}$ \\
\hline Min. & 6,02 & 24,20 & 151,50 & 323,90 \\
\hline Máx. & 9,53 & 26,60 & 413,00 & 505,60 \\
\hline Média & 8,17 & 25,08 & 295,50 & 405,86 \\
\hline D.P. & 1,61 & 0,95 & 98,21 & 65,51 \\
\hline
\end{tabular}

Tabela 6.3 Estadística dos parâmetros físicos medidos no campo para as amostras de água na segunda campanha de amostragem (junho-julho/2010).

\begin{tabular}{|c|c|c|c|c|}
\hline $\begin{array}{c}\text { Poços } \\
\text { rasos } \\
16 \text { poços }\end{array}$ & $\mathrm{pH}$ & $\begin{array}{c}\mathrm{T} \\
\left({ }^{\circ} \mathrm{C}\right)\end{array}$ & $\underset{(\mu S / \mathrm{cm})}{C E}$ & $\begin{array}{c}E h \\
(m V)\end{array}$ \\
\hline Min. & 5,54 & 21,70 & 101,10 & 400,00 \\
\hline Máx. & 8,39 & 27,20 & 701,00 & 543,00 \\
\hline Média & 6,44 & 24,42 & 324,18 & 485,96 \\
\hline D. P. & 0,77 & 1,36 & 159,58 & 41,38 \\
\hline $\begin{array}{l}\text { Poços } \\
\text { profundos } \\
5 \text { poços }\end{array}$ & $\mathrm{pH}$ & $\left({ }^{\mathrm{T}} \mathrm{C}\right)$ & $\begin{array}{c}C E \\
(\mu \mathrm{S} / \mathrm{cm})\end{array}$ & $\begin{array}{c}\text { Eh } \\
(\mathrm{mV})\end{array}$ \\
\hline Min. & 6,75 & 24,90 & 218,00 & 430,20 \\
\hline Máx. & 9,18 & 25,00 & 370,00 & 507,60 \\
\hline Média & 7,44 & 24,98 & 294,75 & 463,05 \\
\hline D. P. & 1,17 & 0,05 & 86,33 & 32,32 \\
\hline
\end{tabular}


Na classificação hidrogeoquímica das águas subterrâneas, considerou-se, primeiramente, sete poços amostrados nas duas campanhas $(14,62,144,49,35$, $159,153)$, cujas concentrações de nitrato são inferiores a $45 \mathrm{mg} / \mathrm{L}$ de $\mathrm{NO}_{3}{ }^{-}$. Esses poços, segundo os critérios expostos acima, indicam as condições naturais do SAB na área. Através dos diagramas de Piper (figura 6.5a) foi possível distinguir dois tipos hidroquímicos predominantes. O primeiro tipo é composto por águas bicarbonatadas cálcicas nas porções mais rasas do aquífero (até 150m) e o segundo, corresponde às águas bicarbonatadas sódicas, localizadas em maior profundidade (>150 m) (figura 6.5a).

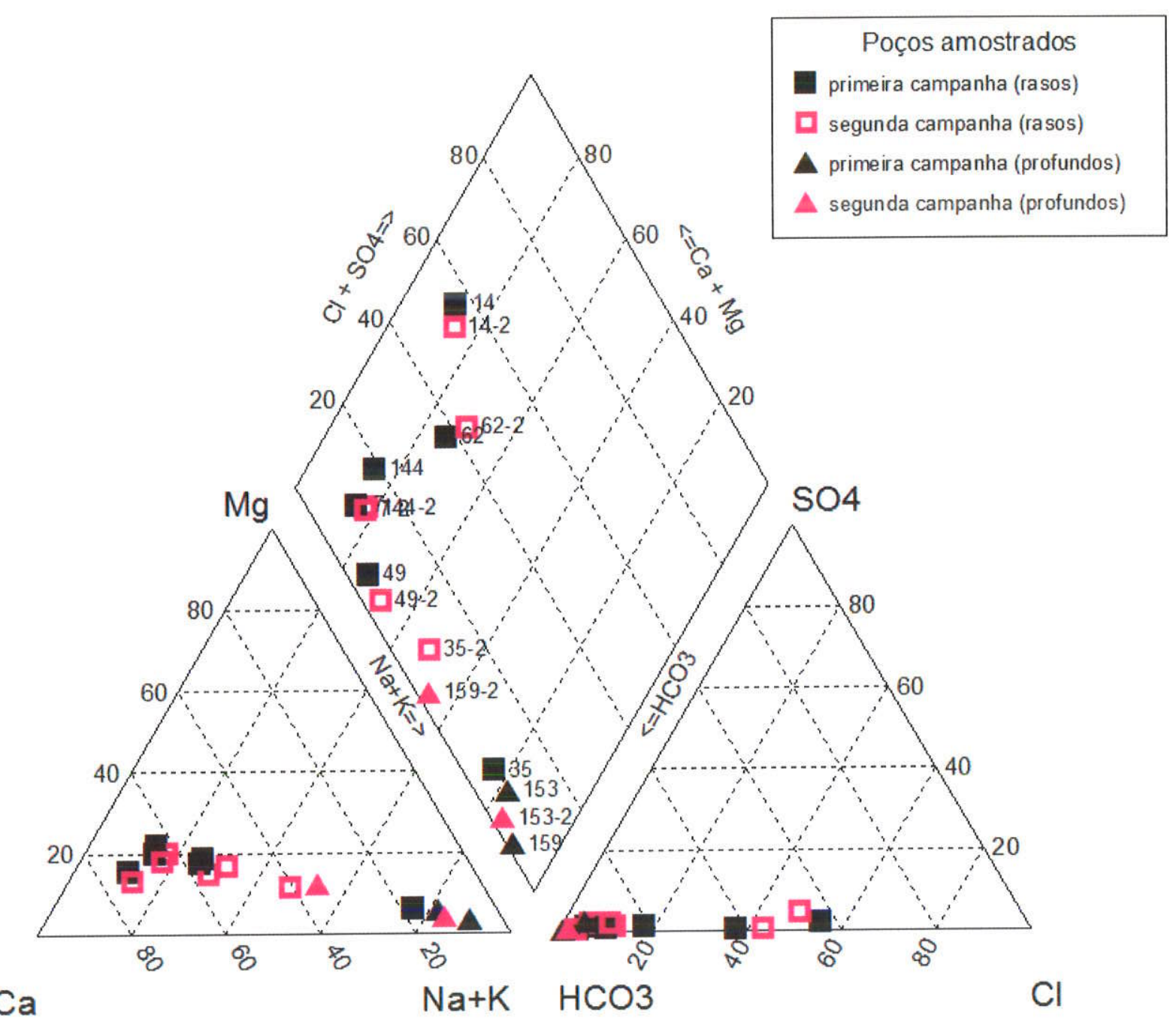

Figura 6.5a Diagrama de Piper dos poços com concentrações de nitrato inferiores a 45mg/L, amostrados na primeira (dezembro 2009) e segunda campanha (junho-julho 2010). 
Ao levar em conta os poços com concentrações de nitrato superiores a 23mg/L (6, $86,175,176,187,200)$, observa-se que as águas adquirem uma composição que varia desde bicarbonatadas-cálcicas a cloro-nitratadas nas porções mais rasas do aquífero (figura 6.5b). O mesmo é observado em dois poços profundos (12 e 146).

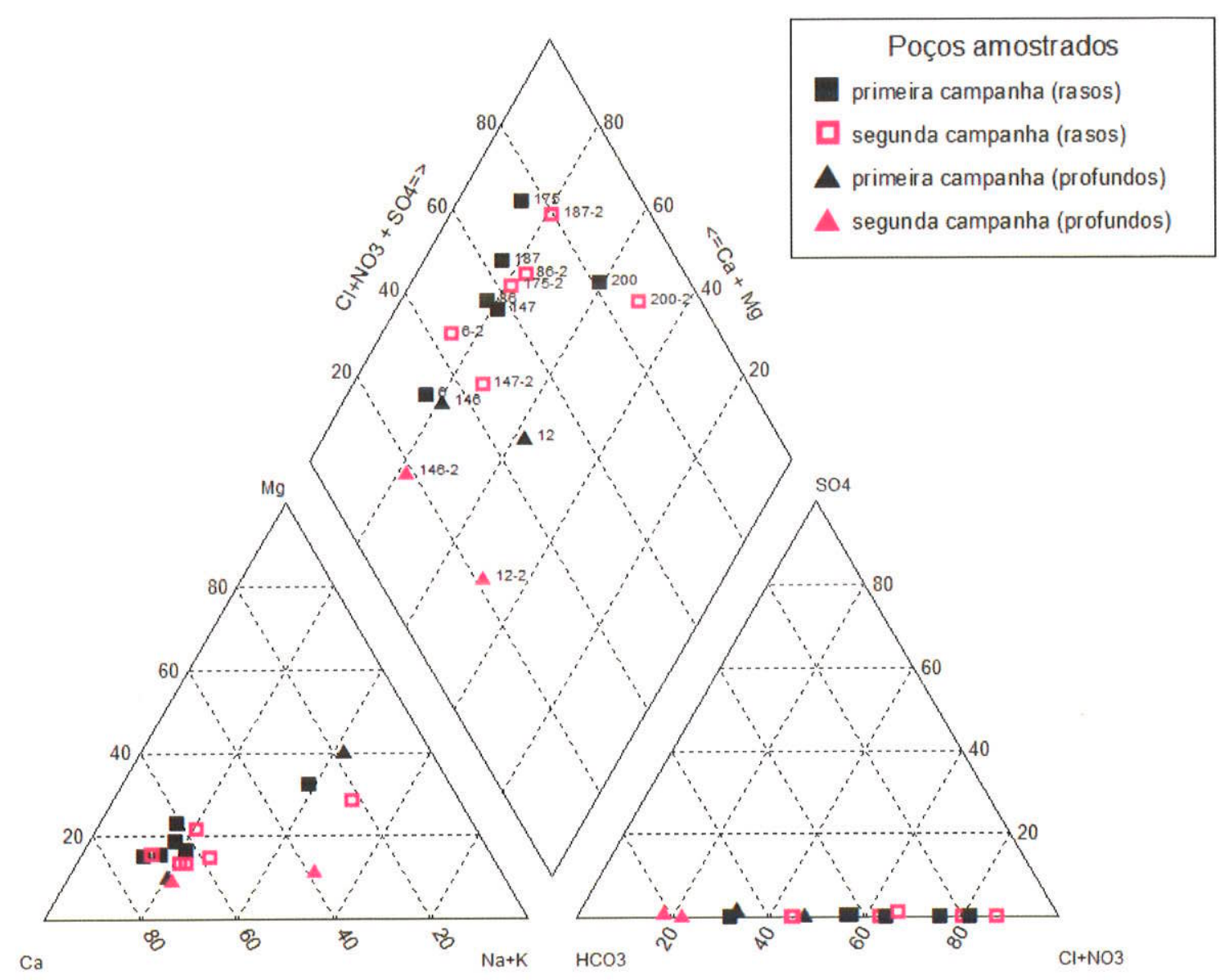

Figura 6.5b Diagrama de Piper dos poços com concentrações de nitrato maiores a 23mg/L, amostrados na primeira (dezembro 2009) e segunda campanha (junho-julho 2010).

As águas bicarbonatadas a cloro-nitratadas cálcicas são, em geral, ligeiramente ácidas com valores de $\mathrm{pH}$ entre 5,54 e 8,39 (tabelas 6.2 e 6.3). Os íons predominantes são o cálcio, sódio, bicarbonato, cloreto e nitrato (tabelas 6.4 e 6.5).

As águas bicarbonatadas sódicas apresentaram valores de $\mathrm{pH}$ neutro a alcalino. Dentre os íons predominantes, destacam-se o sódio e o bicarbonato. A diminuição nas concentrações de cálcio e magnésio sugere a possível ocorrência de reações de troca catiônica nas porções mais profundas do aquífero. Segundo Bertolo et al. (2009) \& Bourotte et al. (2009), as reações de troca catiônica $\left(\mathrm{Ca}^{2+}, \mathrm{Na}^{+}\right)$propiciam a 
diminuição das concentrações de cálcio e parecem controlar a dissolução de minerais carbonáticos presentes nos sedimentos, elevando o $\mathrm{pH}$ e as concentrações de bicarbonato, como foi observado pelos autores na Aquífero Adamantina na cidade de Urânia. A queda nas concentrações de cloreto e nitrato nas porções mais rasas para as mais profundas (tabela 6.4 e 6.5) provavelmente é ocasionada por processos de dispersão e diluição.

Tabela 6.4 Dados estatísticos dos cátions e ânions analisados para amostras de água na primeira campanha de amostragem (dezembro/2009).

\begin{tabular}{|c|c|c|c|c|c|c|c|}
\hline $\begin{array}{c}\text { Poços } \\
\text { rasos } \\
16 \text { poços }\end{array}$ & $\mathrm{Ca}^{2+}$ & $\mathrm{Mg}^{2+}$ & $\mathrm{K}^{+}$ & $\mathrm{Na}^{+}$ & $\mathrm{HCO}_{3}$ & $\mathrm{NO}_{3}{ }^{-}$ & $\mathrm{Cl}^{-}$ \\
\hline Min. & 8,10 & 1,80 & 1,10 & 3,80 & 16,27 & 6,80 & 0,02 \\
\hline Máx. & 93,00 & 26,00 & 11,00 & 173,00 & 471,70 & 204,00 & 65,00 \\
\hline Média & 36,51 & 7,39 & 4,43 & 21,53 & 132,83 & 58,49 & 23,12 \\
\hline D. P. & 23,18 & 5,54 & 2,56 & 41,49 & 117,84 & 54,32 & 20,65 \\
\hline $\begin{array}{c}\text { Poços } \\
\text { profundos } \\
5 \text { pocos }\end{array}$ & $\mathrm{Ca}^{2+}$ & $\mathrm{Mg}^{2+}$ & $\mathrm{K}^{+}$ & $\mathrm{Na}^{+}$ & $\mathrm{HCO}_{3}^{-}$ & $\mathrm{NO}_{3}^{-}$ & $\mathrm{Cl}^{-}$ \\
\hline Min. & 0,88 & 0,09 & 0,10 & 5,50 & 3,40 & 0,55 & 1,40 \\
\hline Máx. & 55,00 & 4,80 & 3,80 & 67,00 & 80,15 & 32,00 & 46,00 \\
\hline Média & 13,84 & 2,32 & 1,53 & 40,10 & 47,69 & 13,20 & 12,12 \\
\hline D. P. & 23,09 & 1,96 & 1,77 & 28,06 & 28,15 & 14,49 & 19,10 \\
\hline
\end{tabular}

Tabela 6.5 Dados estatísticos dos cátions e ânions analisados para amostras de água na segunda campanha de amostragem (junho-julho/2010).

\begin{tabular}{|c|c|c|c|c|c|c|c|}
\hline $\begin{array}{l}\text { Poços } \\
\text { rasos } \\
16 \text { poços }\end{array}$ & $\mathrm{Ca}^{2+}$ & $\mathrm{Mg}^{2+}$ & $\mathrm{K}^{+}$ & $\mathrm{Na}^{+}$ & $\mathrm{HCO}_{3}^{-}$ & $\mathrm{NO}_{3}^{-}$ & $\mathrm{Cl}^{-}$ \\
\hline Min. & 7,60 & 2,10 & 2,40 & 5,50 & 17,81 & 7,10 & 2,50 \\
\hline Máx. & 88,00 & 14,00 & 14,00 & 28,00 & 391,77 & 111,00 & 57,00 \\
\hline Média & 33,10 & 5,55 & 4,83 & 13,20 & 108,42 & 42,89 & 22,55 \\
\hline D. P. & 20,79 & 2,84 & 3,02 & 6,35 & 88,47 & 33,00 & 17,88 \\
\hline $\begin{array}{l}\text { Poços } \\
\text { profundos } \\
5 \text { pocos }\end{array}$ & $\mathrm{Ca}^{2+}$ & $\mathrm{Mg}^{2+}$ & $\mathrm{K}^{+}$ & $\mathrm{Na}^{+}$ & $\mathrm{HCO}^{\circ}$ & $\mathrm{NO}_{3}{ }^{-}$ & $\mathrm{Cl}^{\circ}$ \\
\hline Min. & 6,20 & 1,20 & 0,43 & 17,00 & 101,74 & 1,50 & 1,50 \\
\hline Máx. & 52,00 & 6,10 & 3,20 & 52,00 & 271,70 & 23,00 & 21,00 \\
\hline Média & 25,80 & 3,55 & 2,06 & 35,25 & 179,39 & 9,30 & 7,30 \\
\hline D. P. & 20,04 & 2,10 & 1,26 & 18,84 & 75,52 & 9,88 & 9,17 \\
\hline
\end{tabular}


Ressaltam-se ainda as correlações positivas entre as concentrações de nitrato $x$ cloreto, nitrato $\mathrm{x}$ condutividade elétrica e condutividade elétrica $\mathrm{x}$ cloreto para as águas mais rasas (tabelas 6.6 e 6.7; figuras 6.6 e 6.7).

Tabela 6.6 Matriz de correlação das análises químicas dos poços com até $150 \mathrm{~m}$ de profundidade dezembro/2009.

\begin{tabular}{|c|c|c|c|c|c|c|c|c|c|c|c|}
\hline & $\mathrm{pH}$ & $\mathrm{T}$ & $C E$ & Eh & $\mathrm{HCO}_{3}$ & $\mathrm{Na}^{+}$ & $K^{+}$ & $\mathrm{Mg}^{2+}$ & $\mathrm{Ca}^{2+}$ & $\mathrm{Cl}^{-}$ & $\mathrm{NO}_{3}$ \\
\hline $\mathrm{pH}$ & 1.00 & 0.01 & -0.08 & -0.44 & 0.73 & 0.75 & -0.58 & -0.25 & -0.01 & -0.28 & -0.44 \\
\hline $\mathrm{T}$ & & 1.00 & -0.53 & -0.08 & -0.01 & 0.22 & -0.01 & -0.27 & -0.64 & -0.37 & -0.44 \\
\hline CE & & & 1.00 & -0.30 & 0.16 & -0.05 & 0.22 & 0.65 & 0.72 & 0.85 & 0.76 \\
\hline Eh & & & & 1.00 & -0.40 & -0.42 & 0.11 & -0.06 & -0.33 & -0.35 & -0.14 \\
\hline $\mathrm{HCO}_{3}^{-}$ & & & & & 1.00 & 0.40 & -0.51 & 0.16 & 0.34 & -0.08 & -0.26 \\
\hline $\mathrm{Na}^{+}$ & & & & & & 1.00 & -0.24 & -0.26 & -0.20 & -0.20 & -0.21 \\
\hline $\mathrm{K}^{+}$ & & & & & & & 1.00 & 0.62 & 0.25 & 0.17 & 0.45 \\
\hline $\mathrm{Mg}^{2+}$ & & & & & & & & 1.00 & 0.73 & 0.43 & 0.51 \\
\hline $\mathrm{Ca}^{2+4}$ & & & & & & & & & 1.00 & 0.47 & 0.53 \\
\hline $\mathrm{Cl}^{\circ}$ & & & & & & & & & & 1.00 & 0.71 \\
\hline $\mathrm{NO}_{3}^{-}$ & & & & & & & & & & & 1.00 \\
\hline
\end{tabular}

Tabela 6.7 Matriz de correlação das análises químicas dos poços com até 150 $m$ de profundidade junho - julho/2010.

\begin{tabular}{|c|c|c|c|c|c|c|c|c|c|c|c|}
\hline & $\mathrm{pH}$ & $\mathrm{T}$ & CE & Eh & $\mathrm{HCO}_{3}{ }^{\prime \prime}$ & $\mathrm{Na}^{+}$ & $\mathrm{K}^{+}$ & $\mathrm{Mg}^{2+}$ & $\mathrm{Ca}^{2+}$ & $\mathrm{Cl}^{-}$ & $\mathrm{NO}_{3}{ }^{-}$ \\
\hline $\mathrm{pH}$ & 1.00 & 0.48 & -0.04 & -0.19 & 0.52 & 0.06 & -0.69 & 0.06 & 0.16 & -0.59 & -0.63 \\
\hline$T$ & & 1.00 & -0.26 & -0.38 & 0.28 & 0.42 & -0.37 & -0.22 & -0.11 & -0.38 & -0.70 \\
\hline$C E$ & & & 1.00 & 0.07 & 0.65 & 0.33 & 0.13 & 0.85 & 0.91 & 0.59 & 0.30 \\
\hline Eh & & & & 1.00 & -0.11 & -0.48 & 0.38 & 0.29 & 0.02 & 0.18 & 0.23 \\
\hline $\mathrm{HCO}_{3}^{-}$ & & & & & 1.00 & 0.41 & -0.38 & 0.75 & 0.76 & -0.08 & -0.51 \\
\hline $\mathrm{Na}^{+}$ & & & & & & 1.00 & 0.12 & 0.23 & 0.15 & -0.09 & -0.10 \\
\hline $\mathrm{K}^{+}$ & & & & & & & 1.00 & 0.22 & -0.22 & 0.43 & 0.60 \\
\hline $\mathrm{Mg}^{2+}$ & & & & & & & & 1.00 & 0.76 & 0.35 & -0.01 \\
\hline $\mathrm{Ca}^{2+}$ & & & & & & & & & 1.00 & 0.51 & 0.04 \\
\hline $\mathrm{Cl}^{-}$ & & & & & & & & & & 1.00 & 0.64 \\
\hline $\mathrm{NO}_{3}{ }^{-}$ & & & & & & & & & & & 1.00 \\
\hline
\end{tabular}

Os valores em negrito indicam correlaçôes com intervalo de significância de $95 \%$, sendo considerados 17 dados de cada parâmetro. $T=$ temperatura $\left({ }^{\circ} \mathrm{C}\right) ; \mathrm{CE}=$ condutividade elétrica $(\mathrm{uS} / \mathrm{cm})$; $\mathrm{Eh}=(\mathrm{mV})$; ions ( $\mathrm{mg} / \mathrm{L}$ ) 


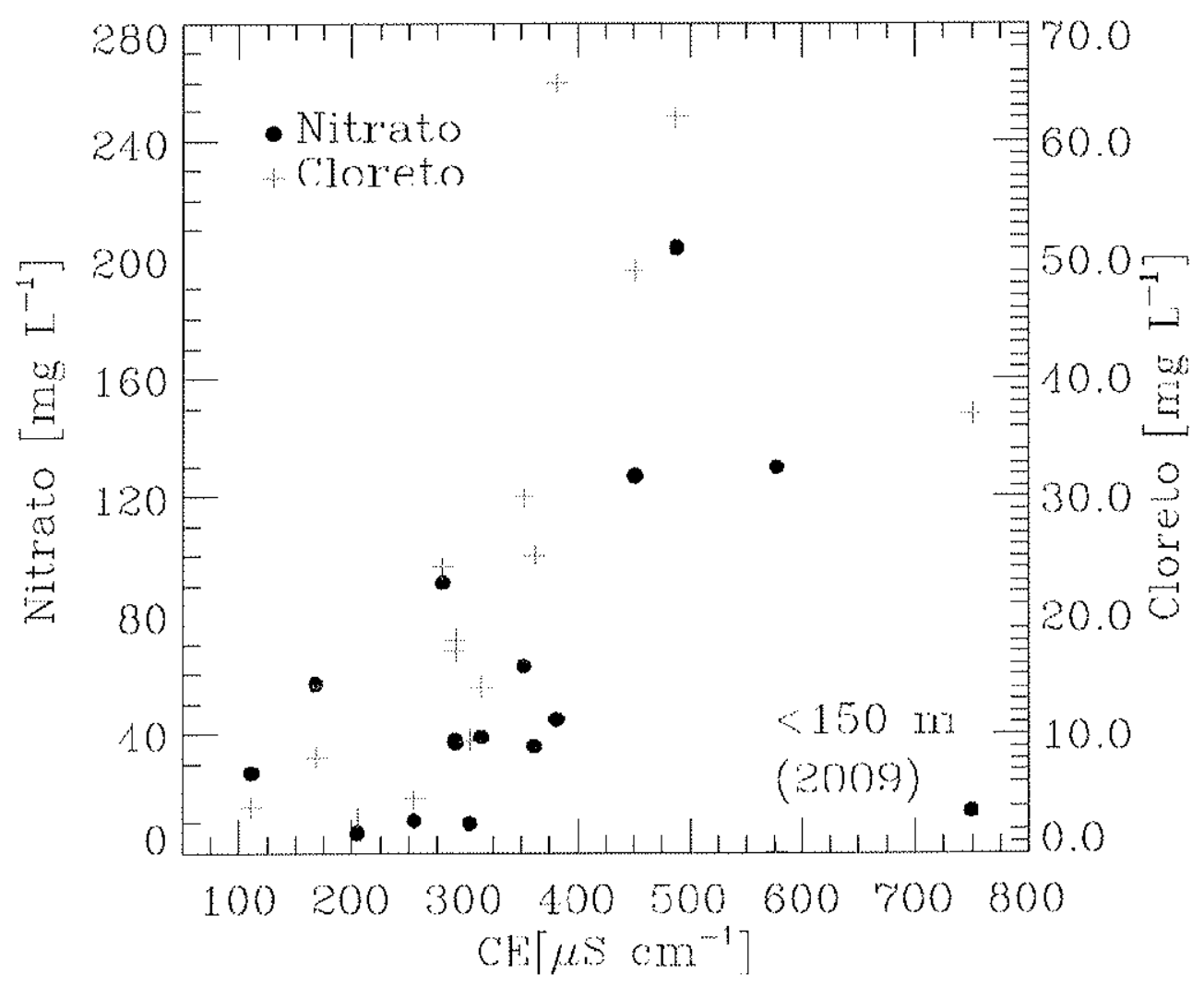

Figura 6.6 Correlação entre nitrato, cloreto e condutividade elétrica para os poços rasos amostrados na primeira campanha de amostragem (dezembro 2009).

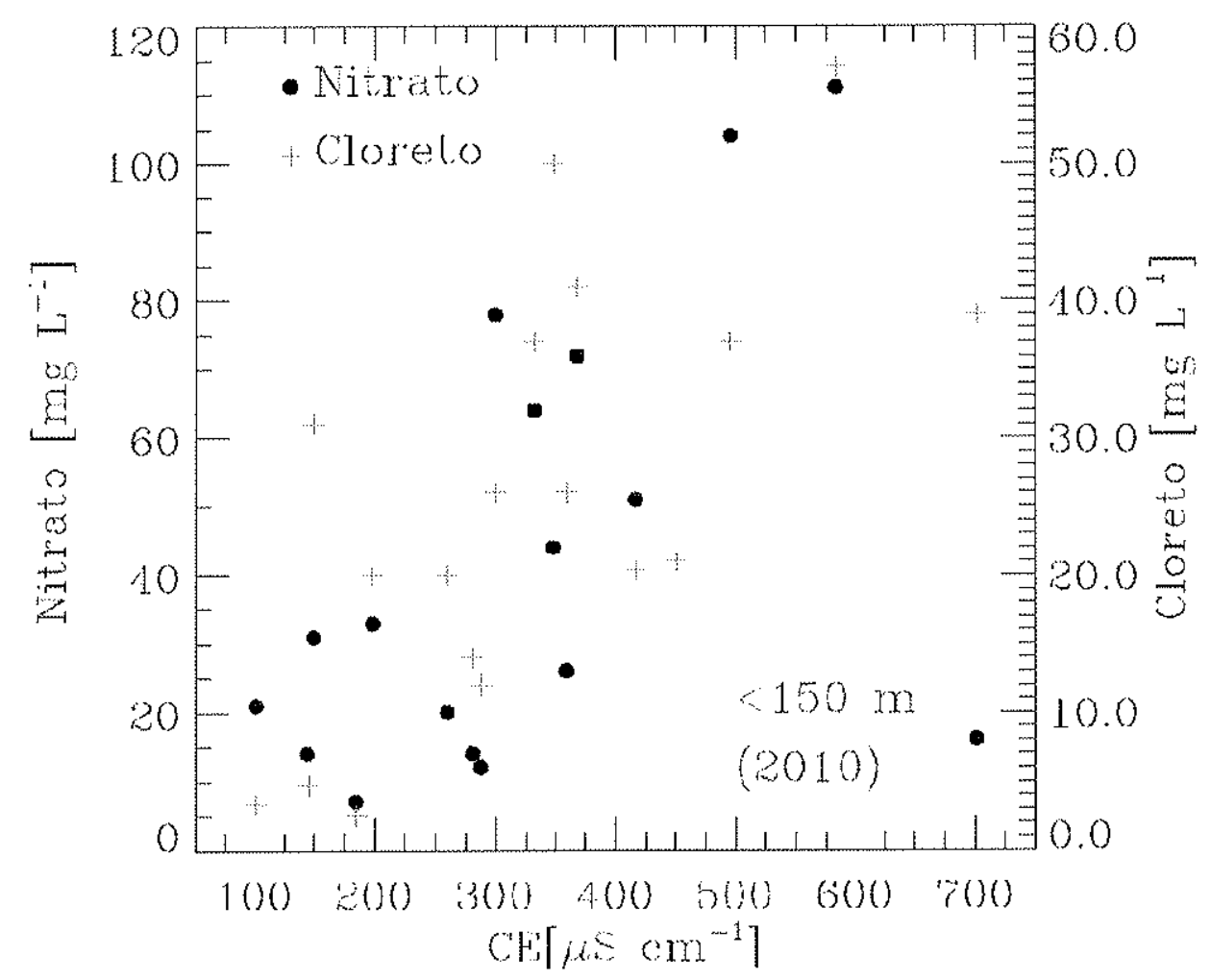

Figura 6.7 Correlação entre nitrato, cloreto e condutividade elétrica para os poços rasos amostrados na segunda campanha de amostragem junho - julho/2010. 
Salienta-se, ainda, que nas águas mais profundas se observam correlações negativas entre cloreto, sódio, cálcio e $\mathrm{pH}$, indicando a diminuição da contaminação e o aumento relativo da dissolução de minerais carbonáticos presentes na matriz dos sedimentos (tabelas 6.8 e 6.9 ).

Tabela 6.8 e 6.9 Matrizes de correlação das análises químicas dos poços maiores que $150 \mathrm{~m}$ de profundidade dezembro/2009 e junho - julho/2010.

\begin{tabular}{|c|c|c|c|c|c|c|c|c|c|c|c|}
\hline & $\mathrm{pH}$ & $\mathrm{T}$ & $\mathrm{CE}$ & Eh & $\mathrm{HCO}_{3}$ & $\mathrm{Na}^{+}$ & $\mathrm{K}^{+}$ & $\mathrm{Mg}^{2+}$ & $\mathrm{Ca}^{2+}$ & $\mathrm{Cl}^{-}$ & $\mathrm{NO}_{3}$ \\
\hline $\mathrm{pH}$ & 1.00 & 0.26 & 0.93 & 0.97 & -0.49 & 0.96 & -1.00 & -1.00 & 0.88 & -0.90 & -0.99 \\
\hline$T$ & & 1.00 & 0.58 & 0.47 & 0.72 & 0.51 & -0.21 & -0.32 & -0.24 & -0.65 & -0.40 \\
\hline$C E$ & & & 1.00 & 0.99 & -0.14 & 1.00 & -0.92 & -0.96 & 0.65 & -1.00 & -0.98 \\
\hline Eh & & & & 1.00 & 0.27 & 1.00 & -0.96 & -0.99 & 0.74 & -0.98 & -1.00 \\
\hline $\mathrm{HCO}_{3}$ & & & & & 1.00 & -0.22 & 0.53 & 0.42 & -0.84 & 0.05 & 0.35 \\
\hline $\mathrm{Na}^{+}$ & & & & & & 1.00 & -0.95 & -0.98 & 0.71 & -0.98 & -0.99 \\
\hline $\mathrm{K}^{+}$ & & & & & & & 1.00 & 0.99 & -0.90 & 0.88 & 0.98 \\
\hline $\mathrm{Mg}^{2 \cdot 1}$ & & & & & & & & 1.00 & -0.84 & 0.93 & 1.00 \\
\hline $\mathrm{Ca}^{2+}$ & & & & & & & & & 1.00 & -0.58 & .0 .80 \\
\hline $\mathrm{Cl}^{-}$ & & & & & & & & & & 1.00 & 0.95 \\
\hline \multirow[t]{2}{*}{$\mathrm{NO}_{3}$} & & & & & & & & & & & 1.00 \\
\hline & $\mathrm{pH}$ & $\mathrm{T}$ & $C E$ & Eh & $\mathrm{HCO}_{3}$ & $\mathrm{Na}^{+}$ & $K^{*}$ & $\mathrm{Mg}^{2+}$ & $\mathrm{Ca}^{2+}$ & $\mathrm{Cl}^{+}$ & $\mathrm{NO}_{3}^{-}$ \\
\hline $\mathrm{pH}$ & 1.00 & 0.57 & -0.41 & -1.00 & -0.24 & 0.55 & -0.91 & -0.68 & -0.73 & -1.00 & -0.53 \\
\hline $\mathrm{T}$ & & 1.00 & 0.52 & -0.54 & 0.66 & 1.00 & -0.86 & 0.22 & 0.15 & -0.54 & -1.00 \\
\hline$C E$ & & & 1.00 & 0.43 & 0.98 & 0.54 & -0.01 & 0.95 & 0.92 & 0.44 & -0.56 \\
\hline Eh & & & & 1.00 & 0.27 & -0.52 & 0.90 & 0.70 & 0.75 & 1.00 & 0.50 \\
\hline $\mathrm{HCO} 3-$ & & & & & 1.00 & 0.68 & -0.18 & 0.88 & 0.84 & 0.28 & -0.70 \\
\hline $\mathrm{Na}+$ & & & & & & 1.00 & -0.84 & 0.25 & 0.18 & -0.52 & -1.00 \\
\hline $\mathrm{K}+$ & & & & & & & 1.00 & 0.31 & 0.38 & 0.90 & 0.83 \\
\hline $\mathrm{Mg}_{2+}+$ & & & & & & & & 1.00 & 1.00 & 0.70 & -0.27 \\
\hline $\mathrm{Ca} 2+$ & & & & & & & & & 1.00 & 0.75 & -0.20 \\
\hline $\mathrm{Cl}-$ & & & & & & & & & & 1.00 & 0.50 \\
\hline NO3- & & & & & & & & & & & 1.00 \\
\hline
\end{tabular}

O nitrato ocorre em altas concentrações, acima do padrão de potabilidade (Portaria 518/04 do Ministério de Saúde), em 39\% das amostras analisadas, atingindo valores de até $204 \mathrm{mg} / \mathrm{L} \mathrm{NO}_{3}{ }^{-}$(tabelas 6.4 e 6.5). As concentrações deste ion estão relacionadas provavelmente à contaminação de origem antrópica (antigas fossas e vazamentos na rede de esgoto) que, por sua vez, é responsável pelos altos conteúdos de cloreto na água (até $65 \mathrm{mg} / \mathrm{L}$ ) (tabelas 6.4 e 6.5). Esses altos teores foram observados em locais onde os filtros dos poços estão posicionados mais 
próximos à superfície do terreno e na porção central da área urbana, onde se encontram os bairros mais antigos e com maior densidade populacional da cidade (poços 6, 86, 175, 176, 187).

Assim, considerando os parâmetros nitrato e cloreto nas duas campanhas de amostragem, nota-se que as concentrações apresentam altos picos nos poços rasos 6, 86, 175, 187 e 200 (figuras 6.8 e 6.9). Estes poços estão distribuídos principalmente na zona central da cidade, mostrando uma tendência similar entre os dos parâmetros (figuras 6.10 e 6.11). Salienta-se que as concentrações médias do cloreto para os poços rasos $(23,12 \mathrm{mg} / \mathrm{L}$ na primeira campanha e $24,99 \mathrm{mg} / \mathrm{L}$ na segunda) são maiores que $15 \mathrm{mg} / \mathrm{L}$, valores similares aos apresentados pelos esgotos (World Health Organization, 2009).

Quanto aos demais compostos da série nitrogenada (nitrogênio orgânico, amônio, nitrito), ambos estiveram abaixo do limite de deteç̧ão, denotando um ambiente oxidante para toda a área de estudo, que propicia a existência de nitrato de forma abundante e estável. 


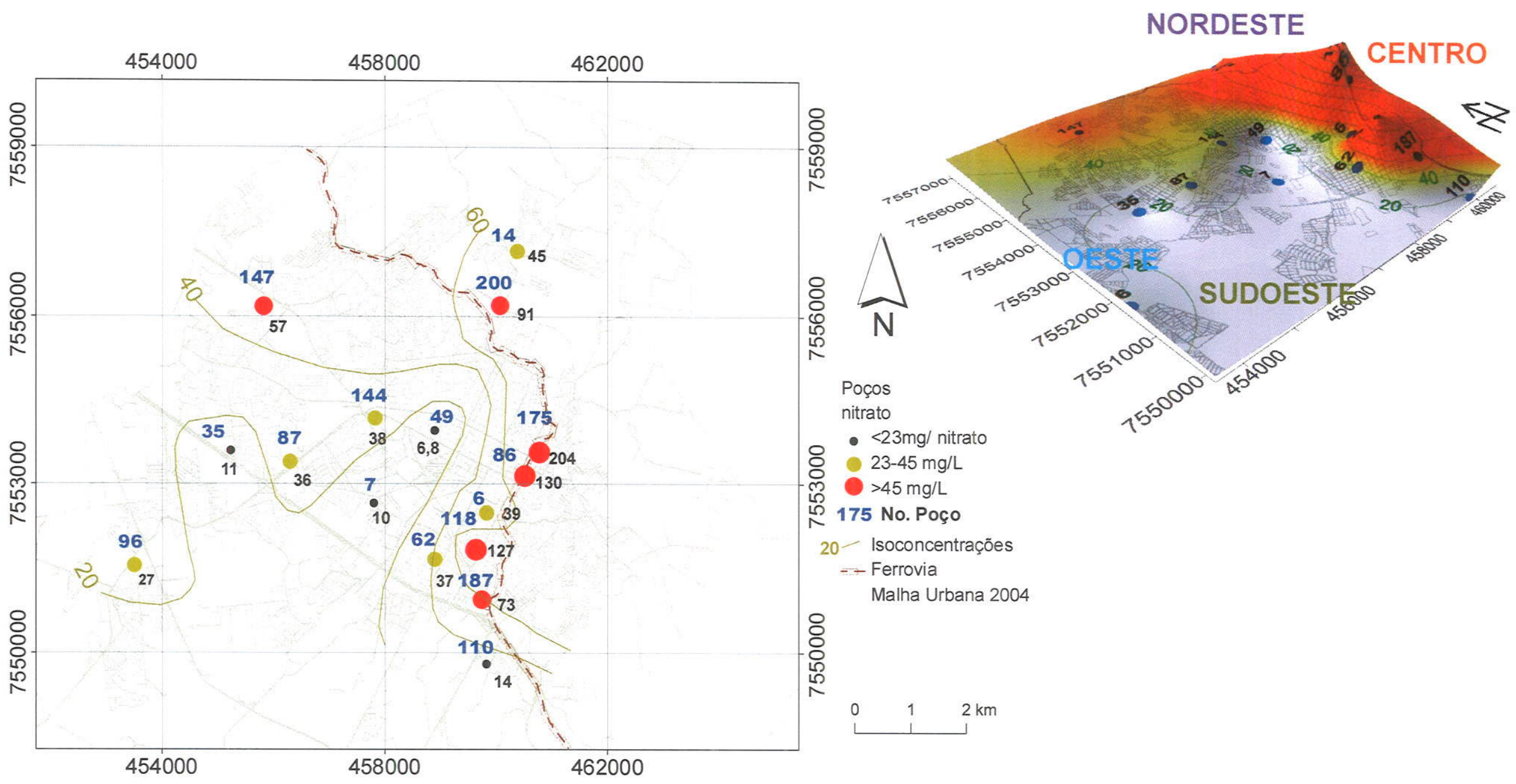

Figura 6.8 Mapa de isoconcentração de nitrato (mg/L) para a primeira campanha de amostragem (estação úmida). 


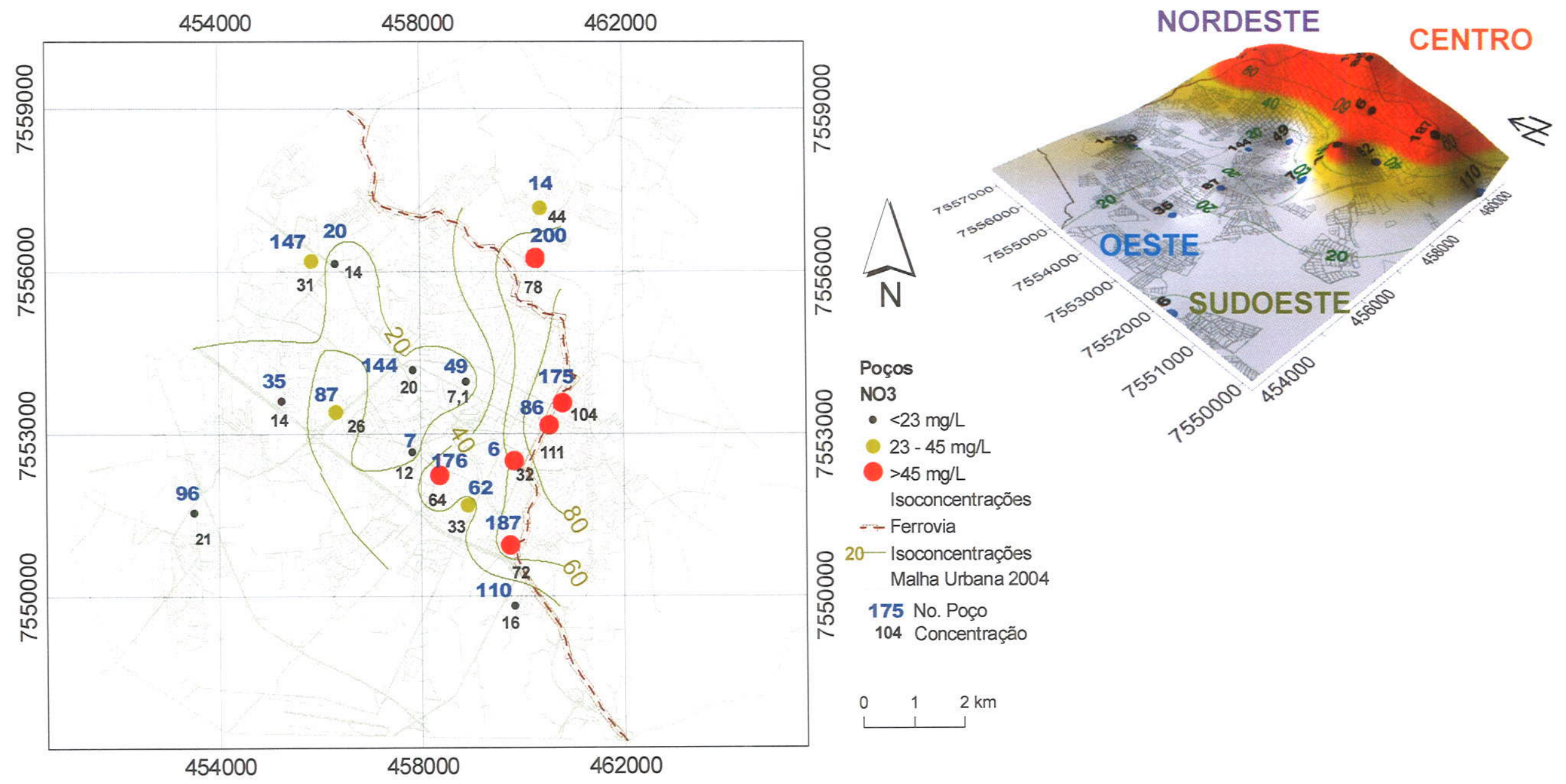

Figura 6.9 Mapa de isoconcentração de nitrato (mg/L) para a segunda campanha de amostragem (estação seca). 


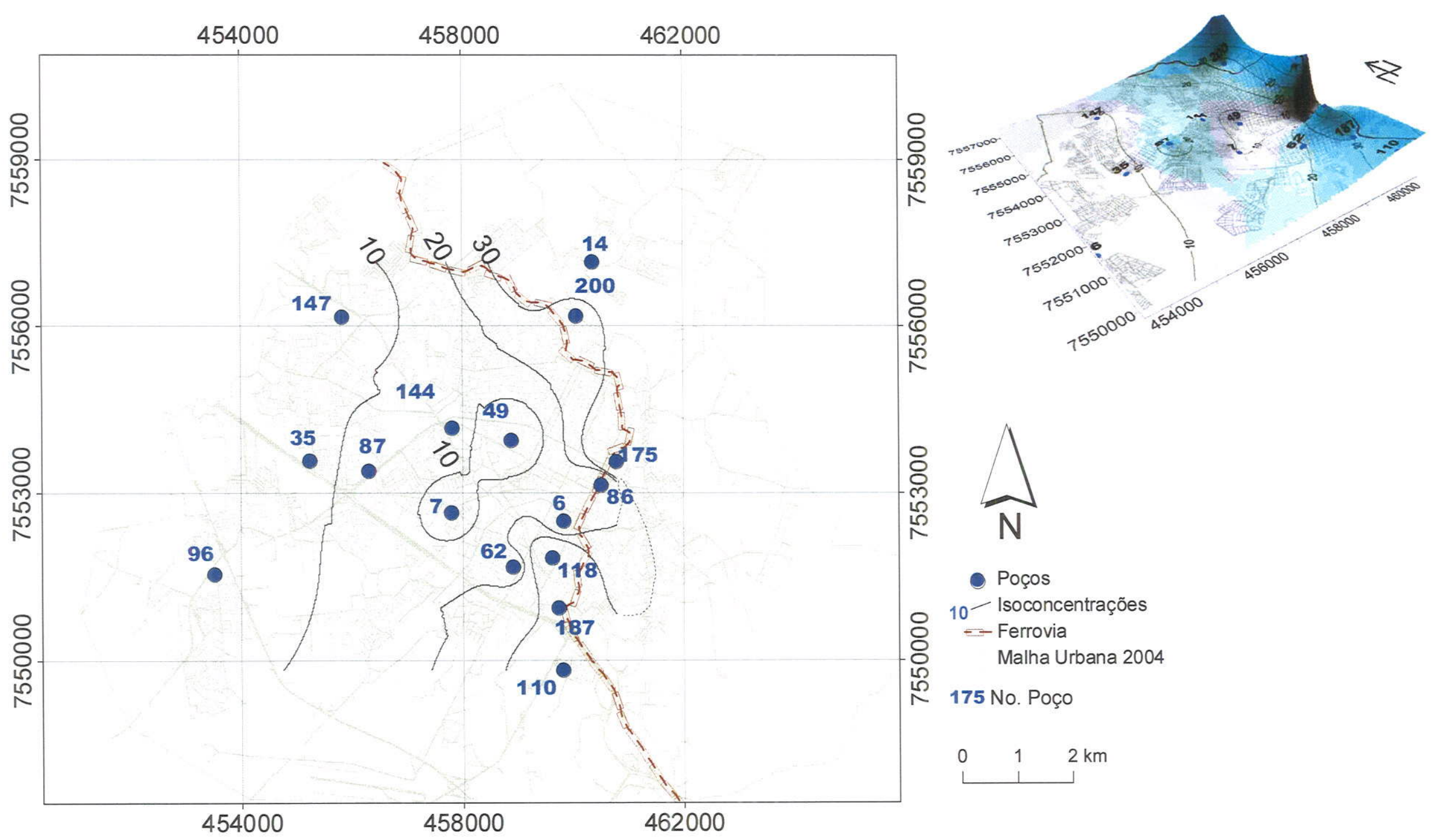

Figura 6.10 Mapa de isoconcentração de cloreto (mg/L) para a primeira campanha de amostragem (estação úmida) 


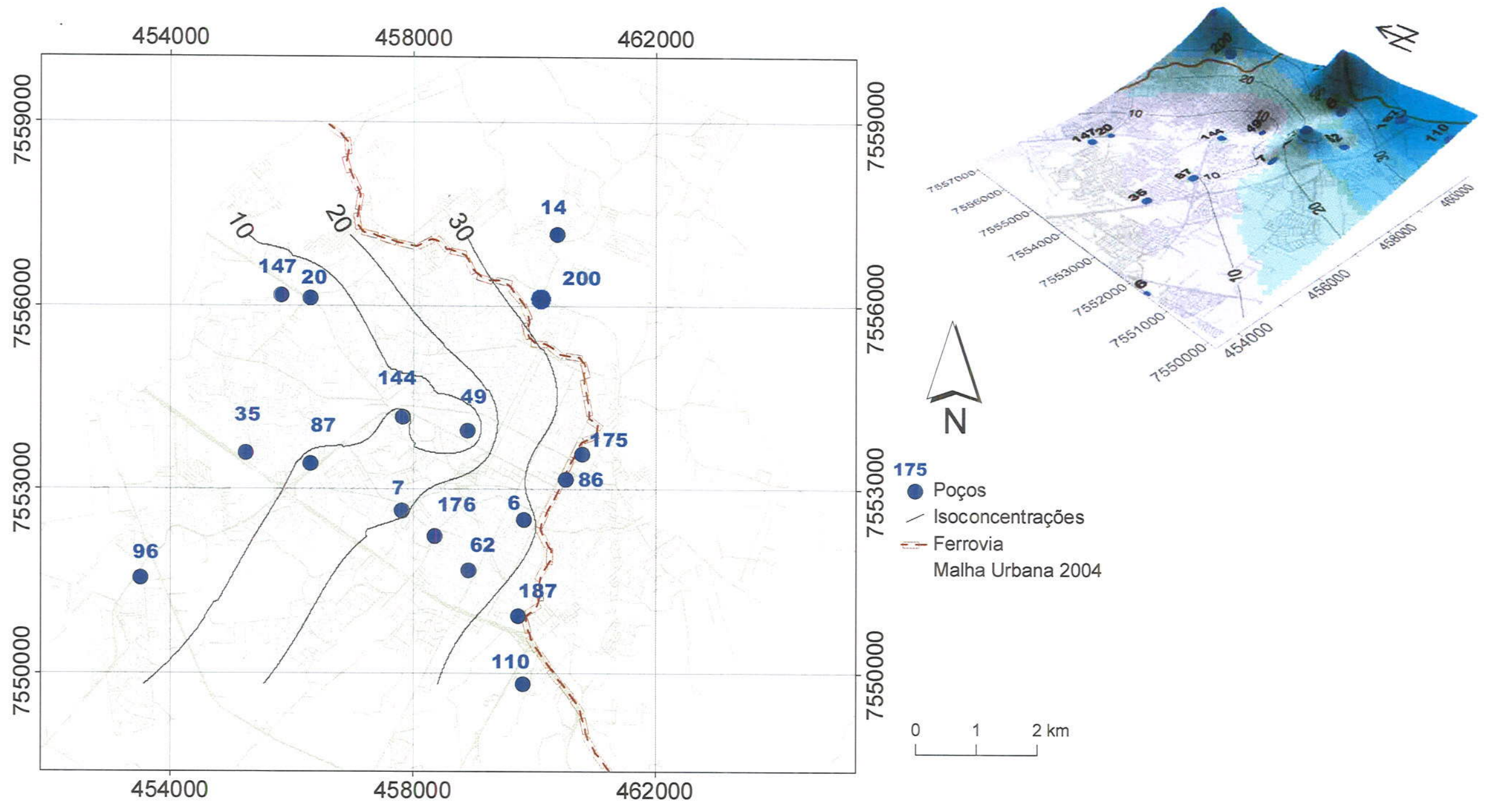

Figura 6.11 Mapa de isoconcentração de cloreto (mg/L) para a segunda campanha de amostragem (estação seca) 


\subsubsection{Evoluções temporais e espaciais das concentrações de nitrato}

\subsubsection{Concentrações de nitrato pretéritas}

A evolução temporal do nitrato, a longo prazo, nas quatro zonas definidas na item 5.6 (nordeste, centro, sudoeste e oeste) se baseou em dados de análises químicas pré-existentes, entre 2005 a 2009, na zona urbana de Presidente Prudente (tabela $6.10)$.

Tabela 6.10 Resumo dos números de poços e análises antigas para os anos de 2005 a 2009.

\begin{tabular}{|c|c|c|c|c|c|c|c|}
\hline Zonas & Número de poços & $\begin{array}{c}\text { Total } \\
\text { poços } \\
\text { por } \\
\text { zona }\end{array}$ & $\begin{array}{l}N^{\circ} \\
\text { Análises }\end{array}$ & $\begin{array}{l}\text { Poços } \\
\text { mas } \\
\text { uma } \\
\text { análise }\end{array}$ & $\begin{array}{c}\mathrm{N}^{\circ} \text { poços } \\
\text { com relaçãoo } \\
\dot{a} \\
\text { profundidade }\end{array}$ & $\begin{array}{c}\text { Ano } \\
\text { análise }\end{array}$ & $\begin{array}{c}\text { Média } \\
\text { zona }\end{array}$ \\
\hline Nordeste & $7(39,57,78,112,136,149,108)$ & 8 & 8 & 0 & $\begin{array}{l}7<150 \mathrm{~m} ; 1 \\
\text { igual a } 150 \mathrm{~m}\end{array}$ & 2006 & 13,75 \\
\hline \multirow{6}{*}{ Central } & $1(52)$ & & & & $\begin{array}{c}18<150 \mathrm{~m} ; 2 \\
\text { iguais a } \\
150 \mathrm{~m} ;\end{array}$ & 2008 & 12,24 \\
\hline & $3(65,80,188)$ & 2.1 & 29 & 6 & $1>150 \mathrm{~m}$ & 2005 & 54,8 \\
\hline & $3(71,171,142)$ & & & & & 2006 & 54,90 \\
\hline & $10(6,15,50,86,93,129,138,175,177,187)$ & & & & & 2007 & 68,73 \\
\hline & $5(10,86,118,130,196)$ & & & & & 2008 & 70,48 \\
\hline & $7(6,80,86,110,118,171,187)$ & & & & & 2009 & 79,69 \\
\hline \multirow[t]{2}{*}{ Oeste } & $6(26,28,29,30,119,101)$ & 23 & 39 & 4 & $\begin{array}{c}17<150 \mathrm{~m} ; 1 \\
\text { igual a } \\
150 \mathrm{~m} ; \\
5>150 \mathrm{~m}\end{array}$ & 2005 & 8,27 \\
\hline & $\begin{array}{l}2(134,144) \\
11 \\
(9,15,20,9091117119.124,139147,198)\end{array}$ & & & & & 2006 & 12,55 \\
\hline \multirow{8}{*}{ Sudeste } & $5(20,76,131,145,151)$ & & & & & 2008 & 8,47 \\
\hline & $4(35,119,144,147)$ & & & & & 2009 & 30,49 \\
\hline & & & & & $\begin{array}{c}5<150 \mathrm{~m} ; 1 \\
\text { igual a } \\
150 \mathrm{~m} ;\end{array}$ & & \\
\hline & $2(12,13)$ & 8 & 19 & 3 & $2>150 \mathrm{~m}$ & 2005 & 12,55 \\
\hline & $4(12,13,69,105)$ & & & & & 2006 & 12,54 \\
\hline & $5(12,16,75,79,81)$ & & & & & 2007 & 18,05 \\
\hline & $2(13,137)$ & & & & & 2008 & 15,47 \\
\hline & $1(12)$ & & & & & 2009 & 32,00 \\
\hline
\end{tabular}


Os dados apresentados na tabela 6.10 mostram que $24 \%$ das captações apresentam valores acima dos limites de potabilidade. Em $21 \%$ dos poços, os valores de nitrato ultrapassam os valores de alerta $\left(>23 \mathrm{mg} / \mathrm{L}\right.$ de $\mathrm{NO}_{3}{ }^{\circ}, \mathrm{CETESB}$, 1994) refletindo condições sanitárias inadequadas nas águas subterrâneas.

Adicionalmente, se observou uma tendência de aumento nas concentrações deste ânion para o periodo reportado (figuras 6.12 e 6.13). Os maiores valores encontram-se na região central da cidade (zona central). Neste local, as médias anuais variam de 55 a $80 \mathrm{mg} / \mathrm{L}$ de $\mathrm{NO}_{3}{ }^{\circ}$, tanto nos poços rasos como nos profundos (figuras 6.12 e 6.13). Em outras zonas, contudo, o aumento das concentrações é cinco vezes menor (figura 6.13).

Dos 22 poços localizados no centro, $55 \%$ estão contaminados e $27 \%$, com concentrações superiores ao valor de alerta. Desta forma, pode-se dizer que quase toda a zona central está impactada por nitrato. A contaminação atribui-se, provavelmente, à presença de antigas fossas sépticas ou negras bem como ao vazamento das tubulações antigas de esgoto, já que essa zona abrange os bairros mais antigos da cidade.

Nas demais zonas da cidade (nordeste, sudeste e oeste), para o mesmo periodo, foram detectadas concentrações intermediárias e baixas (figura 6.13). As concentrações intermediárias, maiores que $23 \mathrm{mg} / \mathrm{L}$ de $\mathrm{NO}_{3}{ }^{-}$, foram encontradas nos poços rasos localizados em bairros relativamente novos (p.e. Damha I e II, Bosque, Parque Brasil Novo, criados a partir da década dos 90), onde as redes de esgoto não foram totalmente implantadas (figura 6.14). 


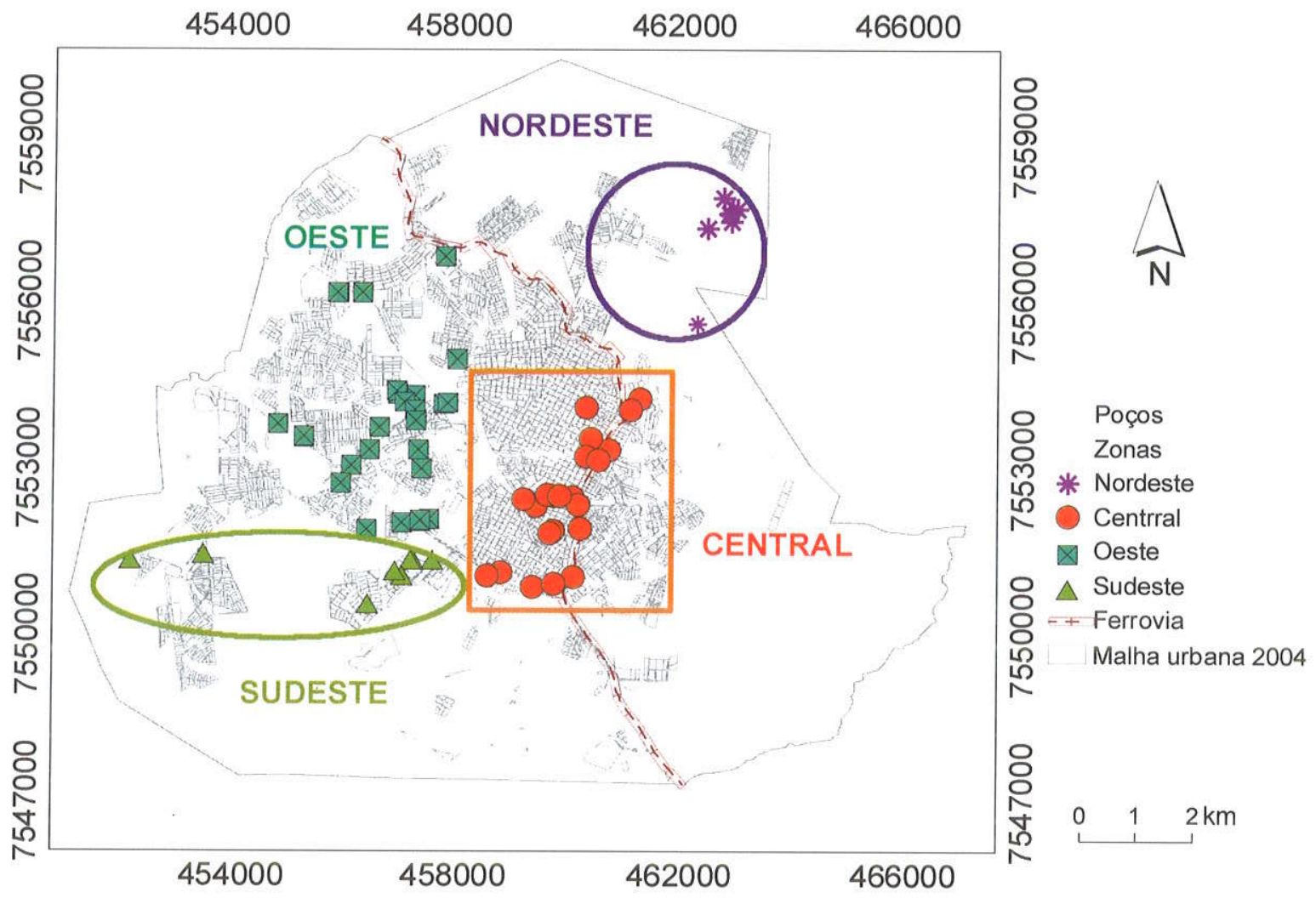

Figura 6.12 Localização das zonas urbanas e dos poços com análises pré-existentes (2005-2009.

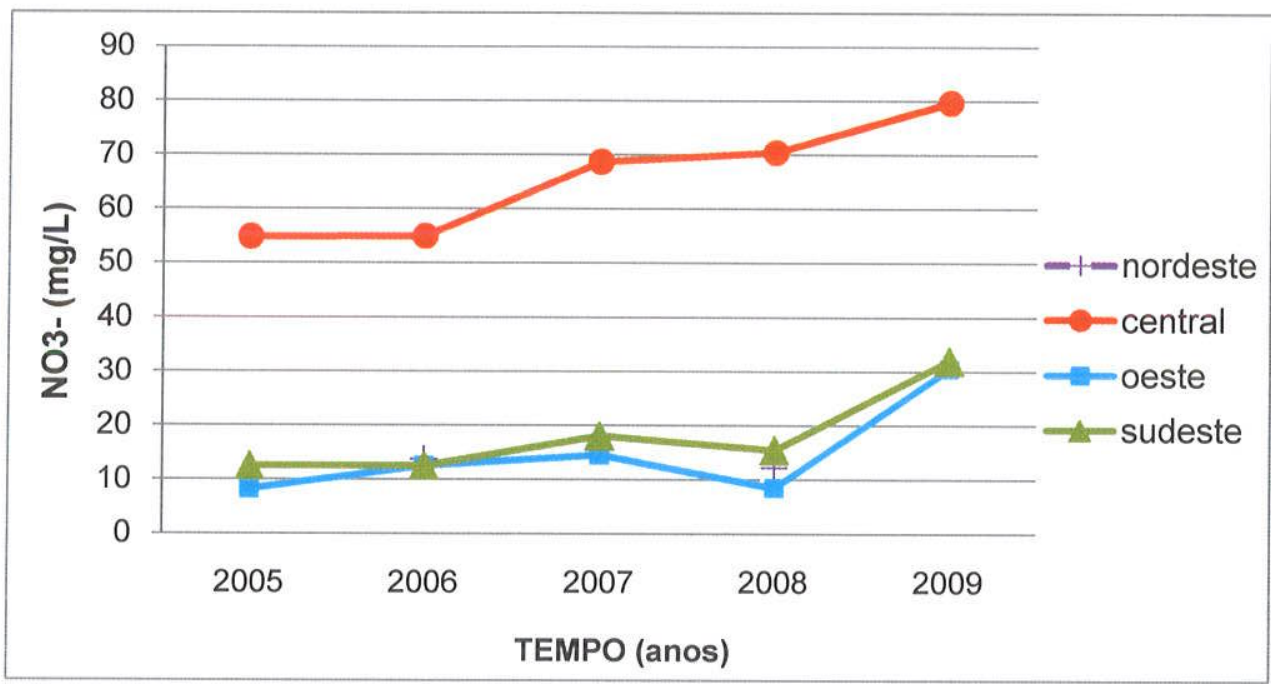

Figura 6.13 Variação temporal nas concentrações de nitrato ao longo do tempo (2005-2009. 


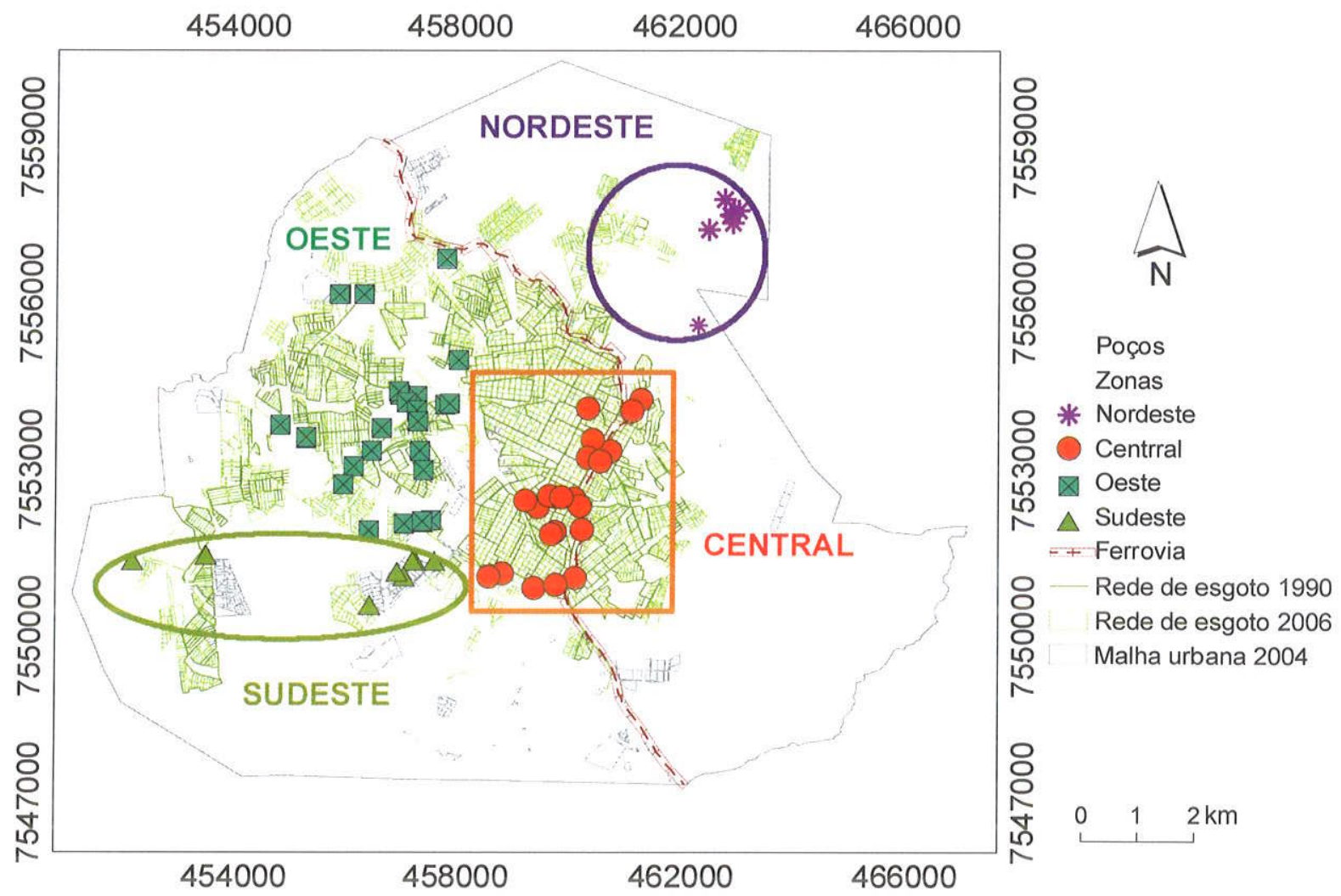

Figura 6.14 Localização das zonas urbanas, redes de esgoto e poços com análises pretéritas na área urbana de Presidente Prudente.

\subsubsection{Concentrações de nitrato a partir das campanhas recentes}

As análises químicas das duas campanhas de amostragem (dezembro 2009 e junho-julho 2010) indicaram variações nas concentrações de nitrato durante as estações úmida e seca (figura 6.15). Em relação à distribuição das mesmas por zonas, notou-se que, dos 22 poços amostrados, 45\% (10 poços) localizam-se na zona central da cidade, com concentrações de nitrato entre 6,80 e 204,00 mg/L NO${ }^{-}$ (estação úmida) e 7,10 a $111,00 \mathrm{mg} / \mathrm{L} \mathrm{NO}_{3}{ }^{-}$(estação seca).

Da mesma forma, identificou-se menores concentrações de nitrato nas quatro zonas da área urbana durantes a estação seca (figura 6.16). A zona central destacase por apresentar as maiores concentrações, com média de $71,76 \mathrm{mg} / \mathrm{L} \mathrm{NO}_{3}{ }^{-}$ (estação úmida) e 52,01 mg/L NO${ }_{3}^{-}$(estação seca). A zona nordeste mostrou valores médios de $47,93 \mathrm{mg} / \mathrm{L}$ a $41,57 \mathrm{mg} / \mathrm{L}$ para a primeira e segunda campanha, respectivamente. Salienta-se, contudo, que muito poucos dados foram considerados 
nesta zona (três poços) (anexo VII). Em outras zonas, os valores médios de nitrato foram de 17,42 a 25,44 mg/L $\mathrm{NO}_{3}{ }^{-}$na zona oeste e de 22,00 a 29,50 mg/L na zona sudeste (figura 6.16).

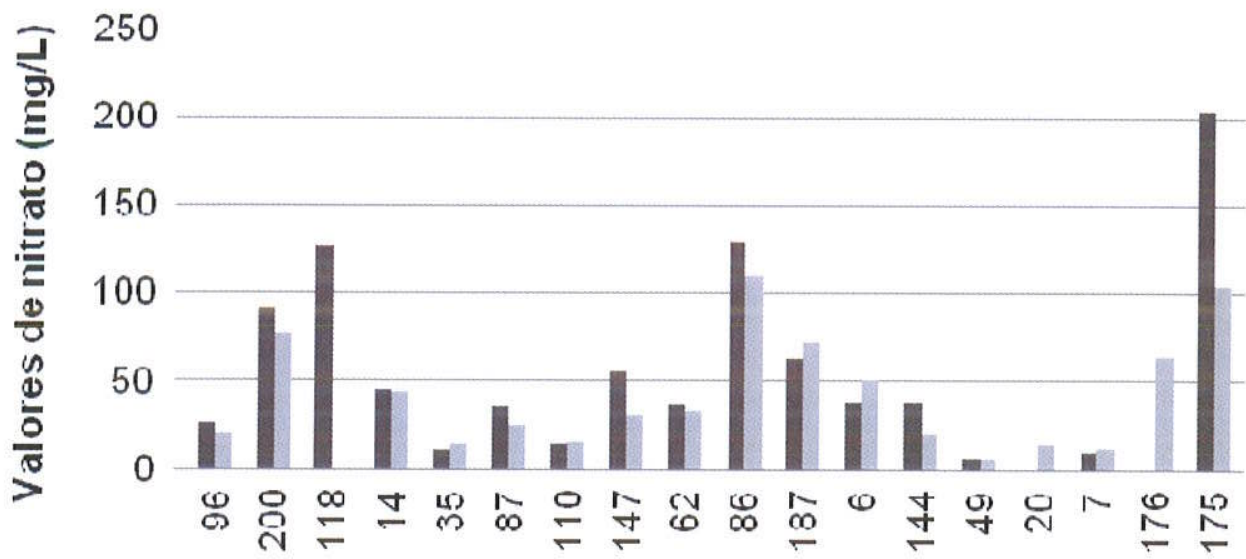

- Período de chura

Período de estiagem

Poços amostrados

Figura 6.15 Variações do nitrato nas duas campanhas de amostragem

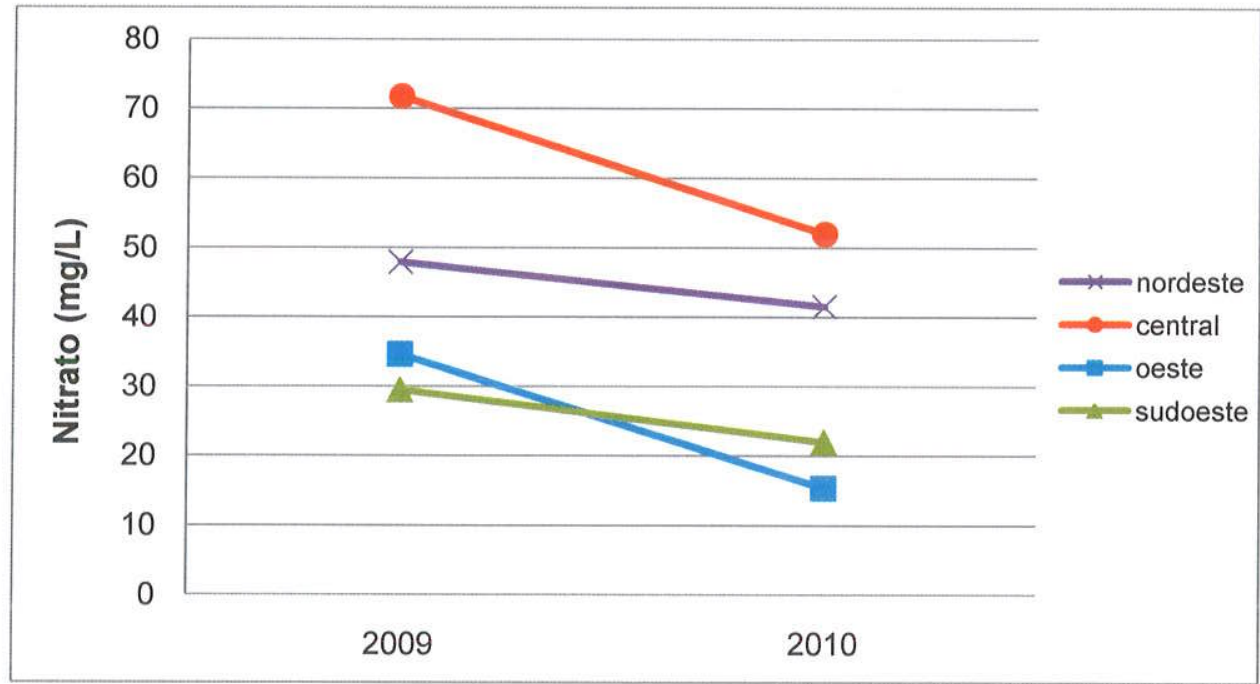

Figura 6.16 Variação temporal de nitrato nos poços rasos durante as estações úmida e seca.

As maiores concentrações de nitrato foram encontradas em poços rasos, cujos filtros são mais superficiais (figura 6.17). Nos poços profundos, menores 
concentrações de nitrato são observadas, comparativamente à média dos rasos (tabela 6.11).

As diminuições de uma estação para outra podem ser explicadas pela recarga do aquifero com águas não contaminadas e assim diluição da pluma contaminante. Outra variação não analisada neste estudo é que as estações úmida e seca alteram o regime de explotação dos poços e maiores diluições, ocasionadas pelos maiores regimes de bombeamento.

Tabela 6.11 Estatística dos valores de nitrato, condutividade elétrica e cloreto analisado em laboratório para as amostras dos poços rasos (dezembro 2009 e junho-julho 2010).

\begin{tabular}{|c|c|c|c|c|c|c|c|}
\hline \multicolumn{2}{|c|}{ Poços < $150 \mathrm{~m}$} & \multicolumn{3}{|c|}{$\begin{array}{c}\text { Estação úmida } \\
1^{\text {ra }} \text { campanha }(\text { dez, 2009) }\end{array}$} & \multicolumn{3}{|c|}{$\begin{array}{c}\text { Estação seca } \\
2^{\text {da }} \text { campanha (julho, 2010) }\end{array}$} \\
\hline Poços & $\begin{array}{l}\text { Prof. } \\
\text { (m) }\end{array}$ & $\begin{array}{c}\mathrm{NO}_{3}^{-} \\
(\mathrm{mg} / \mathrm{L})\end{array}$ & $\frac{C E}{(\mu S / \mathrm{cm})}$ & $\begin{array}{c}\mathrm{Cl}^{-} \\
(\mathrm{mg} / \mathrm{L})\end{array}$ & $\begin{array}{c}\mathrm{NO}_{3}{ }^{\prime \prime} \\
(\mathrm{mg} / \mathrm{L})\end{array}$ & $\begin{array}{c}C E \\
(\mu S / \mathrm{cm})\end{array}$ & $\begin{array}{c}\mathrm{Cl}^{-} \\
(\mathrm{mg} / \mathrm{L})\end{array}$ \\
\hline 96 & 60 & 27 & 110.5 & 3.8 & 21 & 101.1 & 3.3 \\
\hline 200 & 68 & 91 & 280 & 24 & 78 & 300 & 26 \\
\hline 118 & 70 & 127 & 451.0 & 49.0 & $N R$ & $N R$ & 21.0 \\
\hline 14 & 78 & 45 & 381 & 65 & 44 & 348 & 50 \\
\hline 35 & 100 & 11 & 255 & 4.6 & 14 & 281 & 14 \\
\hline 87 & 100 & 36 & 361 & 25 & 26 & 359 & 26 \\
\hline 110 & 100 & 14 & 750 & 37 & 16 & 701 & 39 \\
\hline 62 & 100 & 37 & 291.3 & 18.0 & 33.0 & 198.3 & 20.0 \\
\hline 86 & 100 & 130 & 577.0 & 0.02 & 111.0 & 584.0 & 57.0 \\
\hline 147 & 102 & 57 & 167.8 & 8 & 31 & 149.1 & 31 \\
\hline 187 & 108 & 63 & 352.0 & 30.0 & 72.0 & 368.0 & 41.0 \\
\hline 6 & 110 & 39 & 314.0 & 14.0 & 51.0 & 417.0 & 20.3 \\
\hline 144 & 116.5 & 38 & 291 & 17 & 20 & 260 & 20 \\
\hline 175 & 120 & 204 & 488.0 & 62.0 & 104.0 & 496.0 & 37.0 \\
\hline 20 & 120 & NR & NR & $N R$ & 14.0 & 144.2 & 4.7 \\
\hline 7 & 124 & 10 & 304 & 9.5 & 12 & 288 & 12 \\
\hline 49 & 132 & 6.8 & 205.0 & 3.0 & 7.1 & 184.4 & 2.5 \\
\hline 176 & 132 & NR & NR & NR & 64.0 & 332.0 & NR \\
\hline Mín. & 60 & 6.8 & 110.5 & 0.02 & 7.1 & 101.1 & 2.5 \\
\hline Máx. & 132 & 204 & 750 & 65 & 111 & 701 & 57 \\
\hline Média & & 58.49 & 348.66 & 23.12 & 42.24 & 324.18 & 24.99 \\
\hline D.P & & 54.32 & 158.68 & 20.65 & 32.71 & 159.58 & 15.91 \\
\hline C.V & & 0.93 & 0.46 & 0.89 & 0.77 & 0.49 & 0.64 \\
\hline
\end{tabular}


Tabela 6.12 Estatística dos valores de nitrato, condutividade elétrica e cloreto analisados em laboratório para as amostras dos poços profundos (dezembro 2009 e junho-julho 2010).

\begin{tabular}{|c|c|c|c|c|c|c|c|}
\hline \multicolumn{2}{|c|}{ Poços > $150 \mathrm{~m}$} & \multicolumn{3}{|c|}{$\begin{array}{c}\text { Estação úmida } \\
1^{\text {ra }} \text { campanha (dez, 2009). }\end{array}$} & \multicolumn{3}{|c|}{$\begin{array}{c}\text { Estação seca } \\
2^{\text {da }} \text { campanha (julho, 2010) }\end{array}$} \\
\hline Poços & $\begin{array}{l}\text { Prof. } \\
(\mathrm{m})\end{array}$ & $\begin{array}{l}\mathrm{NO}_{3}^{-} \\
(\mathrm{mg} / \mathrm{L})\end{array}$ & $\begin{array}{c}\mathrm{CE} \\
(\mu \mathrm{S} / \mathrm{cm})\end{array}$ & $\begin{array}{c}\mathrm{Cl}^{-} \\
(\mathrm{mg} / \mathrm{L})\end{array}$ & $\begin{array}{l}\mathrm{NO}_{3}^{-} \\
(\mathrm{mg} / \mathrm{L})\end{array}$ & $\begin{array}{c}\mathrm{CE} \\
(\mu \mathrm{S} / \mathrm{cm})\end{array}$ & $\underset{(\mathrm{mg} / \mathrm{L})}{\mathrm{Cl}^{-}}$ \\
\hline 12 & 200 & 32 & 151.5 & 7.4 & 23 & 218 & 3.4 \\
\hline 146 & 250 & 25 & 402.0 & 46.0 & 10.0 & 370.0 & 21.0 \\
\hline 153 & 217.5 & 7.8 & 254 & 4.4 & 2.7 & 222 & 1.5 \\
\hline 157 & 241 & 0.55 & 331 & 1.4 & NR & NR & NR \\
\hline 159 & 272 & 0.65 & 328 & 1.4 & 1.5 & 369 & 1.5 \\
\hline Mín. & 200 & 0,55 & 151,5 & 1,4 & 1,5 & 218 & 1,5 \\
\hline Máx. & 272 & 32 & 402 & 46 & 23 & 370 & 21 \\
\hline Média & & 13,20 & 293,30 & 12,12 & 9,30 & 294,75 & 6,85 \\
\hline D.P & & 14,49 & 94,99 & 19,10 & 9,88 & 86,33 & 9,48 \\
\hline C.V & & 1,10 & 0,32 & 1,58 & 1,06 & 0,29 & 1,38 \\
\hline
\end{tabular}

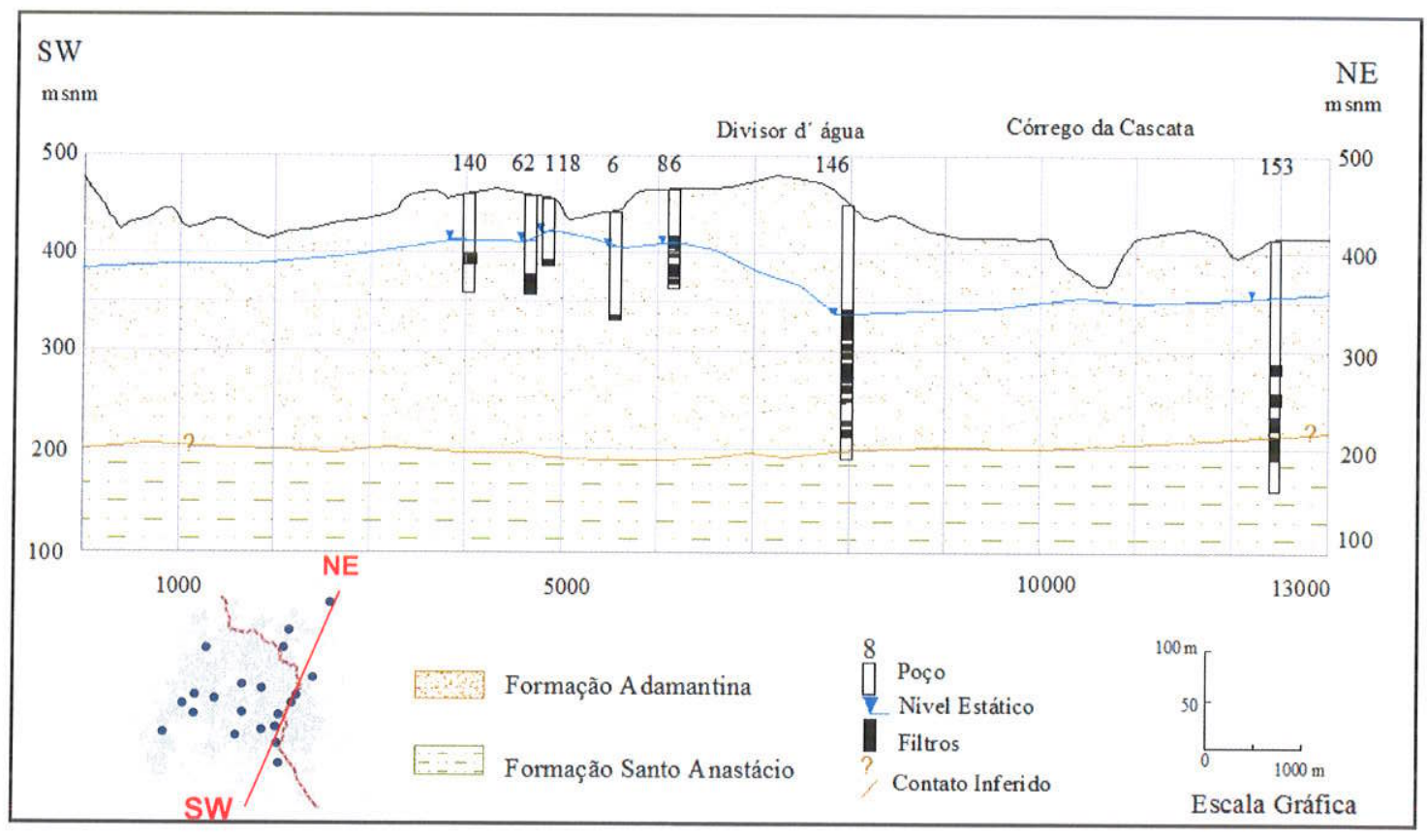

Figura 6.17 Seção dos poços e posicionamento dos filtros.

De acordo as características hidroquímicas evidenciadas neste estudo, faz-se um resumo dos ambientes, tipos de água, íons predominantes e possíveis processos que ocorrem em diferentes profundidades do aquífero (tabela 6.13) 
Tabela 6.13 Resumo das principais características hidrogeoquimicas das águas subterrâneas do SAB em Presidente Prudente.

Águas rasas $(<150 \mathrm{~m}) \quad$ Aguas profundas $(>150 \mathrm{~m})$

\begin{tabular}{|c|c|c|}
\hline Ambiente & Aguas ácidas e meio oxidante & Águas alcalinas e meio oxidante \\
\hline Tipo de água & cloro-nitratada a bicarbonatada cálcica & bicarbonatada sódica \\
\hline Cátions & $\uparrow \mathrm{Ca}^{2+} ; \uparrow \mathrm{Mg}^{2+}>\mathrm{Na}^{+}$e $\mathrm{K}^{+}$ & $\uparrow \mathrm{Na}+\downarrow \mathrm{Ca}^{2+} ; \downarrow \mathrm{Mg}^{2+}$ \\
\hline Ânions & $\mathrm{NO}_{3}{ }^{-}>\mathrm{HCO}_{3}{ }^{-} \mathrm{e \textrm {Cl } ^ { - }}$ & $\uparrow \mathrm{HCO}_{3}^{-} \downarrow \mathrm{NO}_{3} ; \downarrow \mathrm{Cl}^{-}$ \\
\hline $\begin{array}{l}\text { Possiveis } \\
\text { processos }\end{array}$ & $\begin{array}{l}\text { Concentrações de } \mathrm{NO}_{3}, \mathrm{Na}^{+}, \mathrm{Cl}^{-} \\
\text {atribuidos à contaminação antrópica } \\
\text { (fossas, fuga da rede de esgoto). }\end{array}$ & $\begin{array}{c}\text { Baixa concentração de contaminantes (dispersão e } \\
\text { diluição). Possiveis reações de troca catiônica } \\
\text { (diminuição de } \mathrm{Ca}^{2+} \text { e } \mathrm{Mg}^{2+4} \text { e aumento do } \mathrm{Na}^{+} \text {). } \\
\text { Dissolução de minerais carbonáticos, aumento do pH. }\end{array}$ \\
\hline
\end{tabular}

\subsection{Estimativa da carga potencial de nitrato}

\subsubsection{Fontes potenciais de contaminação}

As principais fontes de contaminação de nitrato nas águas subterrâneas na área urbana de Presidente Prudente estão relacionadas à eliminação das águas residuais através de sistemas de saneamento in situ bem como às fugas ou vazamentos das redes de esgotos.

Fazendo-se uma retrospectiva da ocupação urbana em Presidente Prudente pode-se dizer que a cidade nasceu em meados da década de 1930, com os bairros Centro e Vila Marcondes (figura 6.18). A cidade tinha na época 87.400 habitantes (SEADE, 2010), com uma malha urbana de $0,92 \mathrm{~km}^{2}$. O abastecimento de água era feito pelas fontes superficiais e o sistema de saneamento era constituido pelas fossas sépticas e negras. 
Nas décadas posteriores (1950, 1960 e 1970), teve a expansão da cidade para as zonas norte, sul, oeste e leste da ferrovia, considerada como o mais alto ponto topográfico da cidade (Camargo, 2007). Os principais bairros da época eram: Centro, Vila Marcondes, Vila Industrial e Parque Jabaquara (figura 6.18).

O auge da urbanização ocorreu nos anos 80 (taxa de urbanização de 94,74\%), com uma população de 129.260 habitantes (SEADE, 2010). Nesta década foi implantada a rede de esgoto que não atendia $100 \%$ da cidade (figura 6.19 ).

Nos anos 90, o surgimento das áreas residenciais (Parque Residencial Damha I e II, Parque Brasil Novo, Conjunto Ana Jacinta, Bosque) fez com que $87 \%$ do uso do solo fosse destinado a esse fim (Amorim, 2009). A população neste período, já era de 156.900 habitantes (SEADE, 2010). Ainda nesta década, a concessionária de água, SABESP, necessitando de mais água iniciou a perfuração de poços com 11 deles incorporados à rede pública.

A partir dos anos 2000,100\% da população já era atendida pelas redes de água potável e $97 \%$ pela rede coletora de esgoto (SABESP, 2010). Entanto, há bairros onde o sistema de esgoto ainda não chegou tais como: Parque Residencial Damha II, Conjunto Ana Jacinta, Distrito Industrial, Bosque (figura 6.20).

Segundo SABESP (comunicação verbal), aproximadamente $82 \%$ do esgoto coletado recebe tratamento. O restante, $18 \%$, é despejado in natura nos principais córregos da cidade. Este fato ocorre sobretudo na zona leste, onde se localizam o Córrego do Gramado e o Rio Mandaguari, afluente do Rio do Peixe (figura 6.20).

Adicionalmente, a rede de esgoto atual pode apresentar vazamentos, o que contribui com a contaminação do $\mathrm{SAB}$. A má manutenção associada à idade da rede, principalmente em áreas mais antigas, pode ser uma fonte importante de nitrogênio no Aquífero Adamantina. 


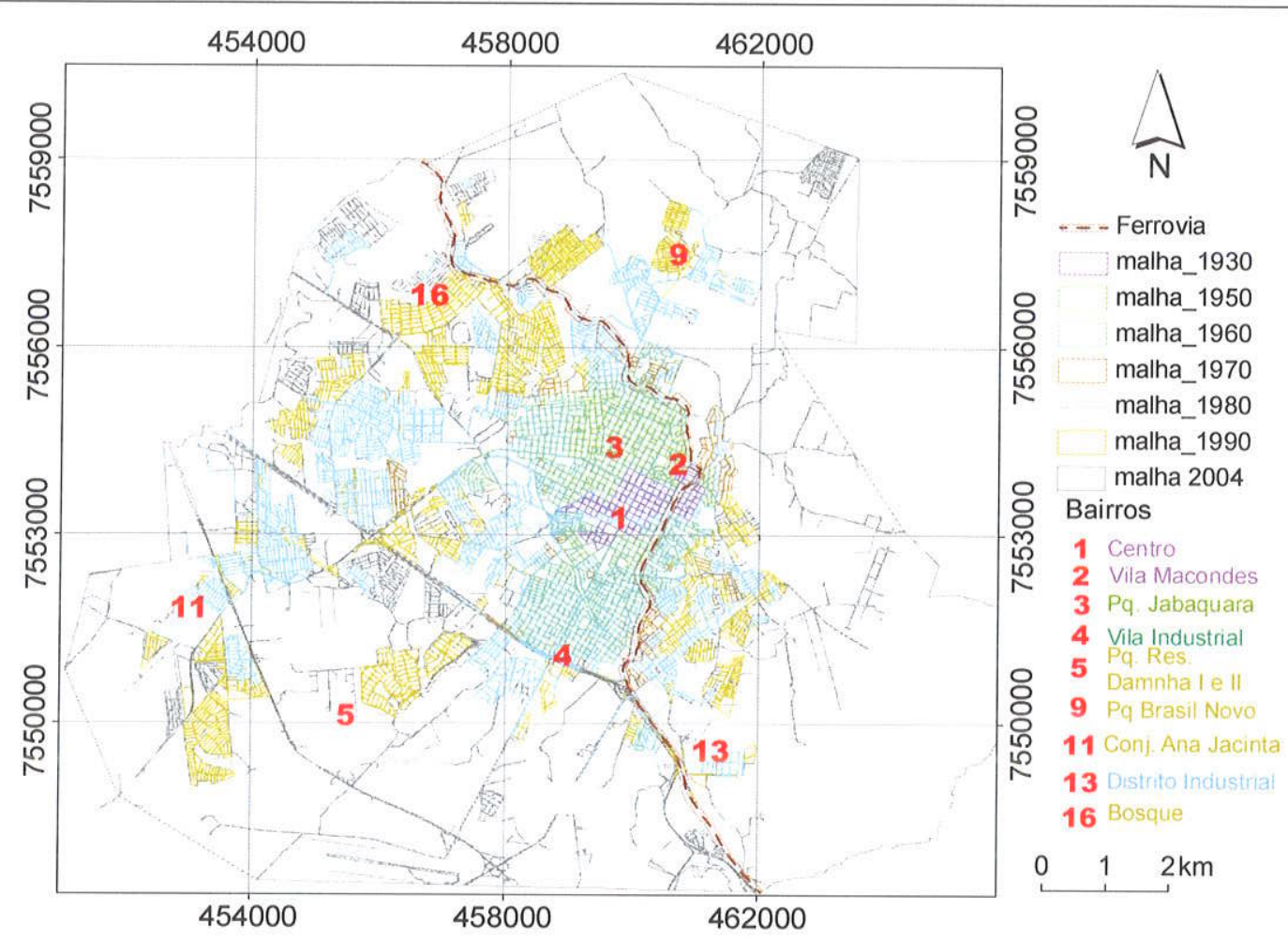

Figura 6.18 Evolução da malha urbana do município de Presidente Prudente (adaptado de Camargo, 2007).

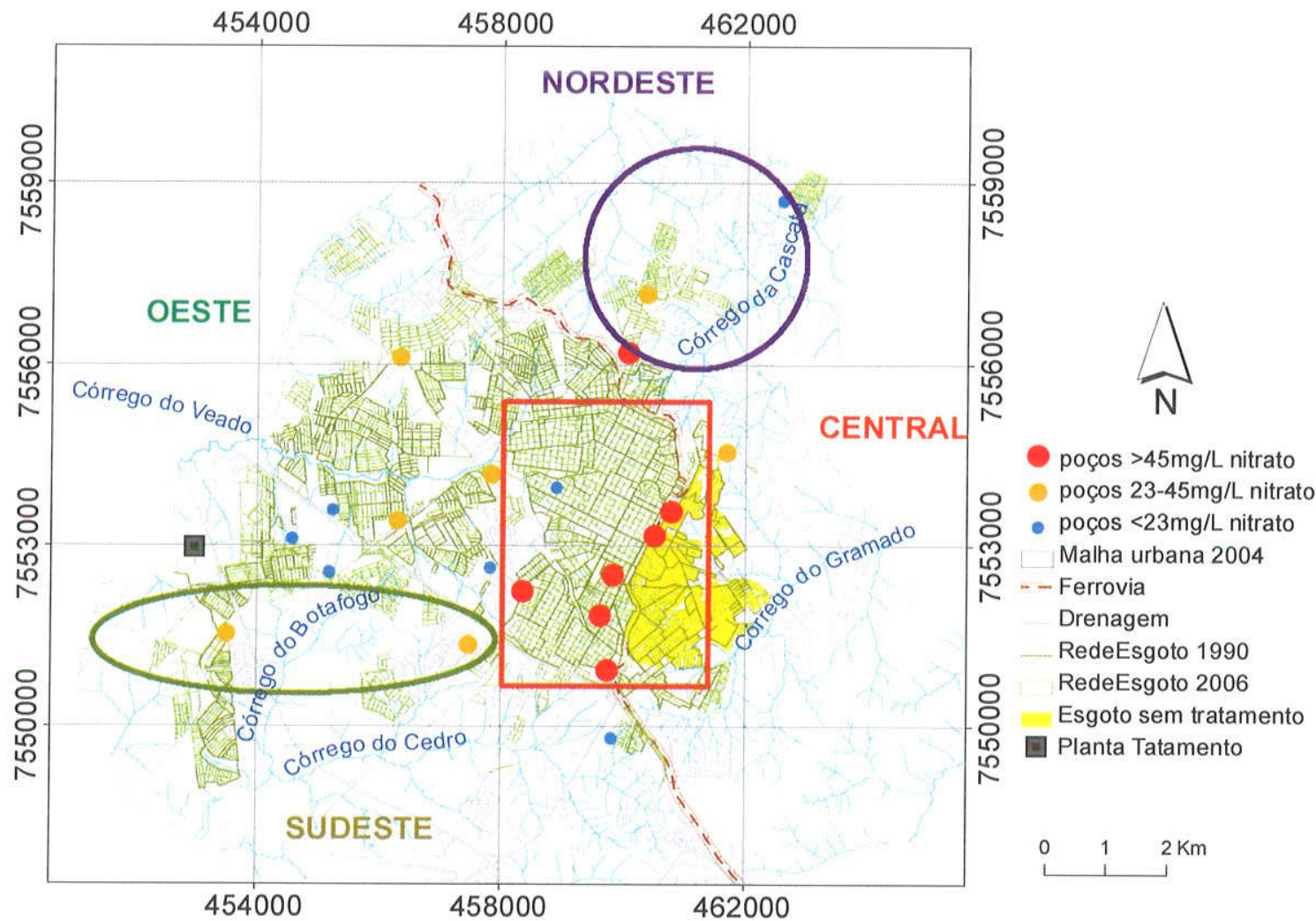

Figura 6.19 Evolução da rede de esgoto no município de Presidente Prudente (adaptado de SABESP, 1990 e 2006). 


\subsubsection{Cálculo semiquantitativo da concentração de nitrato}

Com base na densidade de ocupação urbana, localização e profundidade dos poços, a malha urbana de Presidente Prudente foi dividida em três grupos para o cálculo da concentração de nitrato, através da equação semi quantitativa proposta por Foster \& Hirata (1988). Os grupos considerados foram os seguintes:

a) poços localizados em zonas predominantemente adensadas, com maior quantidade de residências e poucos espaços livres (160 hab/ha);

b) poços localizados em áreas urbanas de média densidade (84hab/ha) com maior ocorrência de espaços livres, em relação ao item anterior;

c) poços localizados em bairros mais novos que ainda estão em processo de ocupação (média 20 hab/ha).

Para as duas campanhas de amostragem, a concentração média de nitrato obtida nas zonas com maior adensamento urbano (160 hab/ha) foi de $94,6 \mathrm{mg} / \mathrm{L}$ de $\mathrm{NO}_{3}{ }^{*}$. A concentração média de nitrato para adensamento urbano intermediário (84hab/ha), por sua vez, foi de $37,2 \mathrm{mg} / \mathrm{L}$ de $\mathrm{NO}_{3}{ }$. Os valores mais elevados foram observados nos poços 200 e 14 (anexo VIII), onde as concentrações excederam o limite de potabilidade. Os poços localizados em áreas com menor adensamento urbano (20 hab/ha), mostraram concentrações menores de nitrato, com média de $14,9 \mathrm{mg} / \mathrm{L}$ de $\mathrm{NO}_{3}{ }^{-}$. O valor mais alto foi obtido no poço $12\left(23,4 \mathrm{mg} / \mathrm{L}\right.$ de $\left.\mathrm{NO}_{3}{ }^{-}\right)$, o qual ultrapassa o valor de alerta definido pela CETESB (anexo VIII).

Nas figuras $6.20,6.21$ e 6.22 observa-se que os valores da carga de nitrato, quantificados pela equação proposta por Foster \& Hirata (1988), são muito semelhantes àqueles medidos em campo nas duas campanhas de amostragem (dezembro 2009; junho-julho 2010).

A figura 6.22 mostra a existência de correlação positiva entre os valores calculados e os valores medidos. Levando-se em conta as concentrações pretéritas de nitrato nos poços amostrados, observou-se que dos 19 poços, só seis $(6,86,110$, $187,175,12$ ) contém análises mais antigas que datam de 2007 (anexo VIII). 


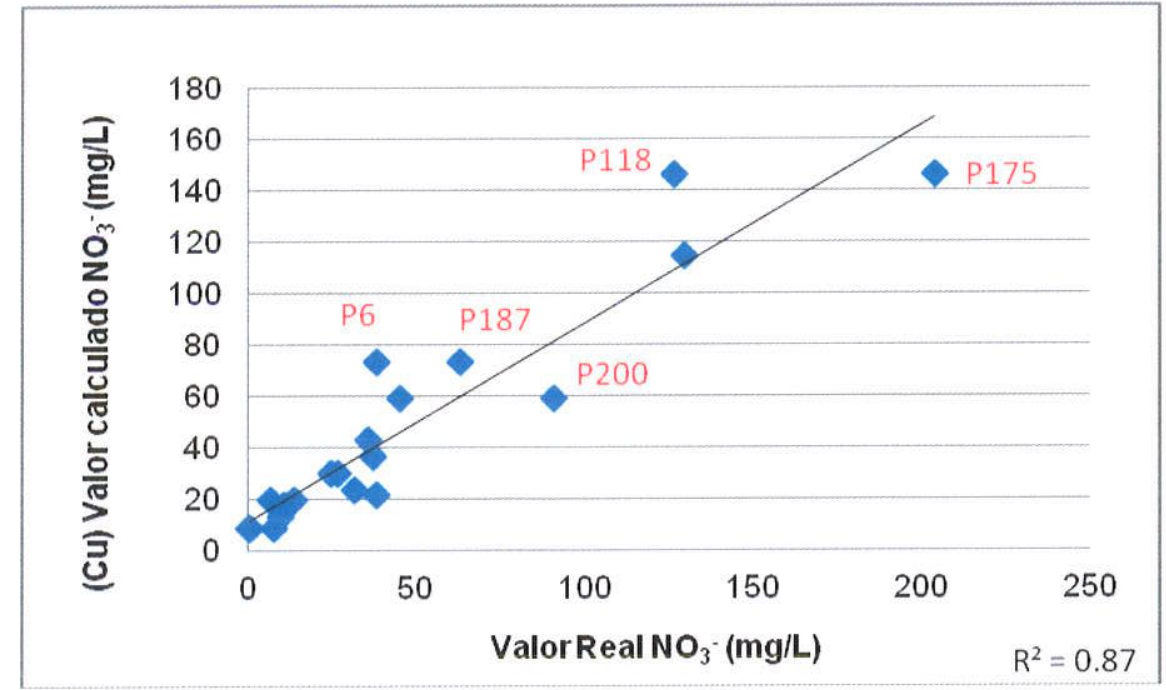

Figura 6.20 Correlação entre as concentrações de nitrato medidas em campo e as calculadas semiquantitativamente (Cu) (dezembro 2009).

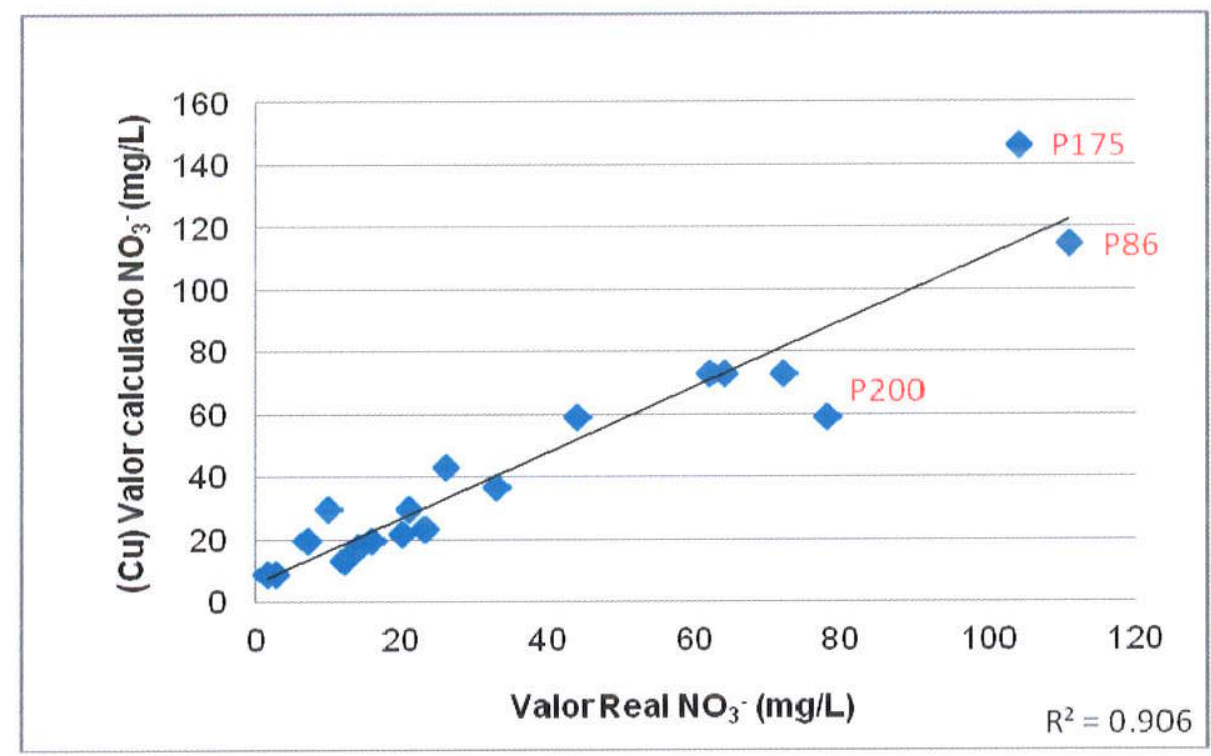

Figura 6.21 Correlação entre as concentrações medidas em campo e as calculadas semiquantitativamente (Cu) (junho-julho 2010). 


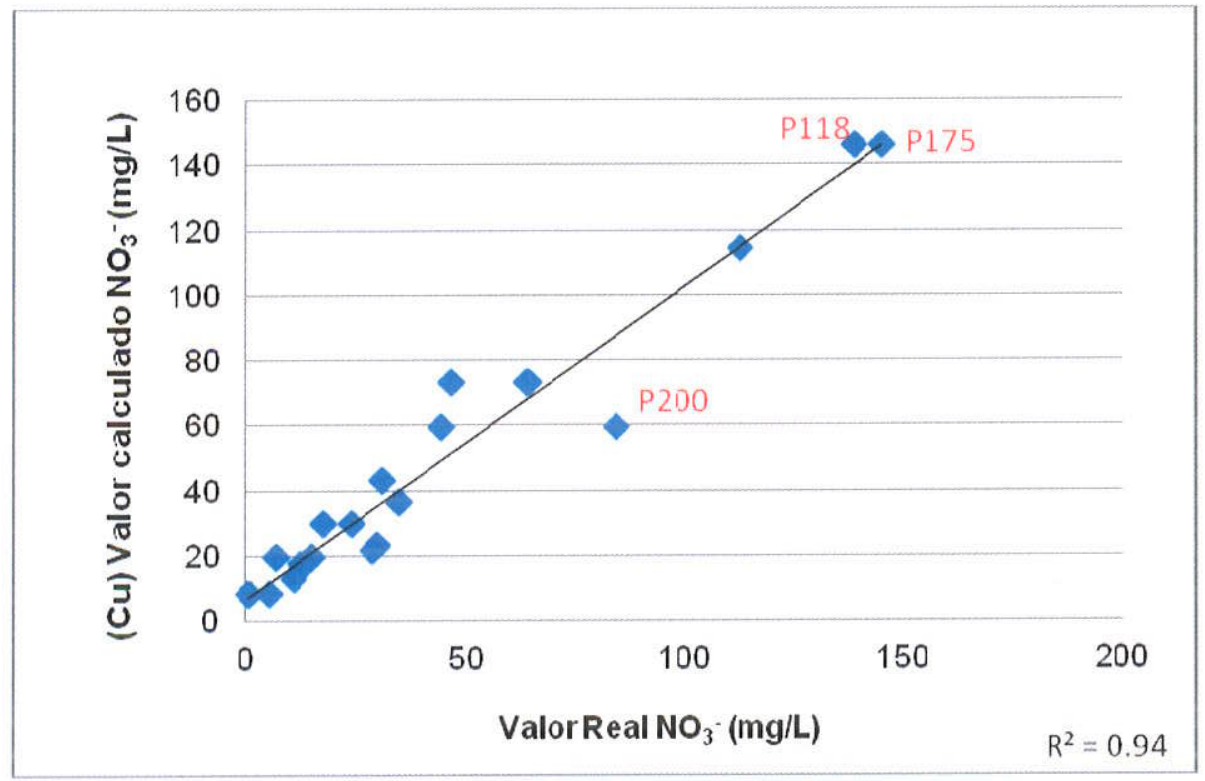

Figura 6.22 Correlação entre as concentrações de nitrato medidas em campo e as calculadas semiquantitativamente (Cu), para as análises pretéritas (2007).

As figuras 6.23a a 6.23e mostram as relações entre as variáveis de densidade da ocupação, localização e profundidade dos poços (bairros antigos ou novos; poços rasos e profundos), expansão da malha urbana (entre 1920 e 2004) e em relação à concentração de nitrato (alta, média e baixa). As figuras 6.23 a e c apresentam as concentrações de nitrato determinadas nas duas campanhas de amostragem. Entretanto, nas figuras $6.23 \mathrm{~b}$ e d consideraram-se as concentrações da carga de nitrato, quantificadas através da equação proposta por Foster \& Hirata (1988).

Nessas figuras é visível que na área urbana, os poços com maiores concentrações de nitrato correspondem àqueles situados em áreas de altas densidades populacionais. Estas relações são perceptíveis ao longo da expansão da malha urbana. Este fato é observado em todas as figuras, tanto as que consideraram as concentrações determinadas em campo (figura 6.23a e 6.23c) como nas quantificadas pela equação semi-quantitativa (figura 6.23b, 6.23d) e as reportadas pelas análises pré-existentes (figura 6.23 e). 

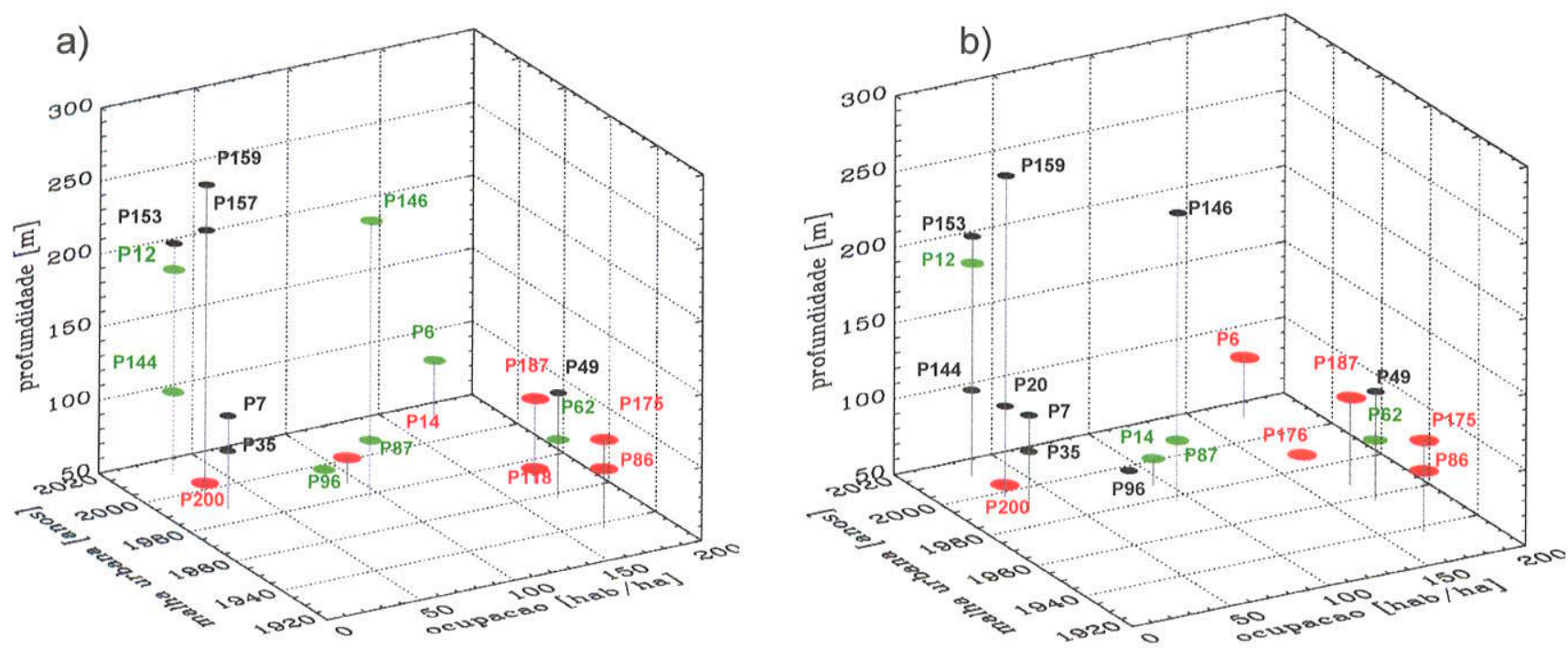

c)

d)

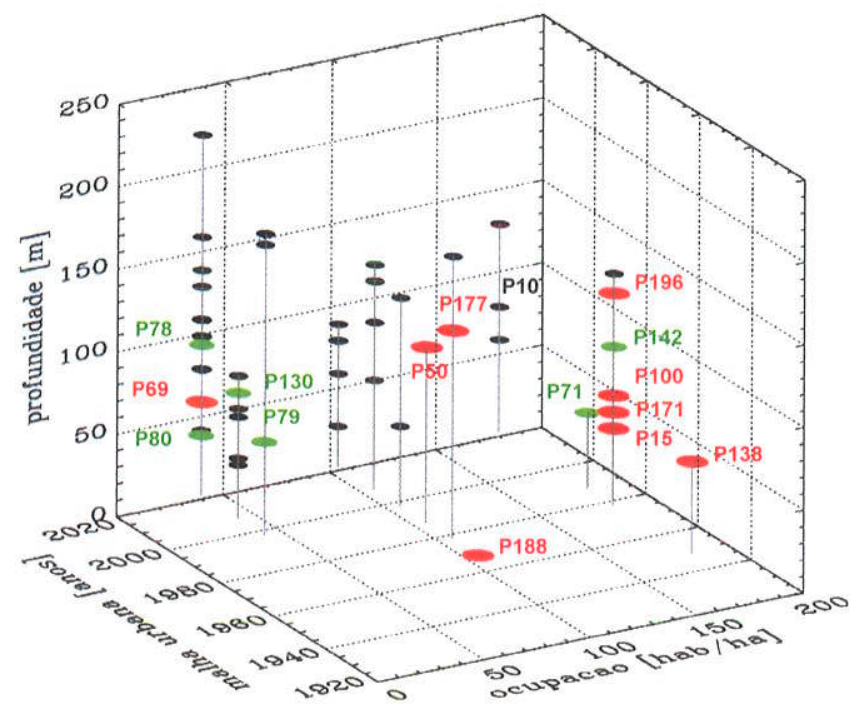

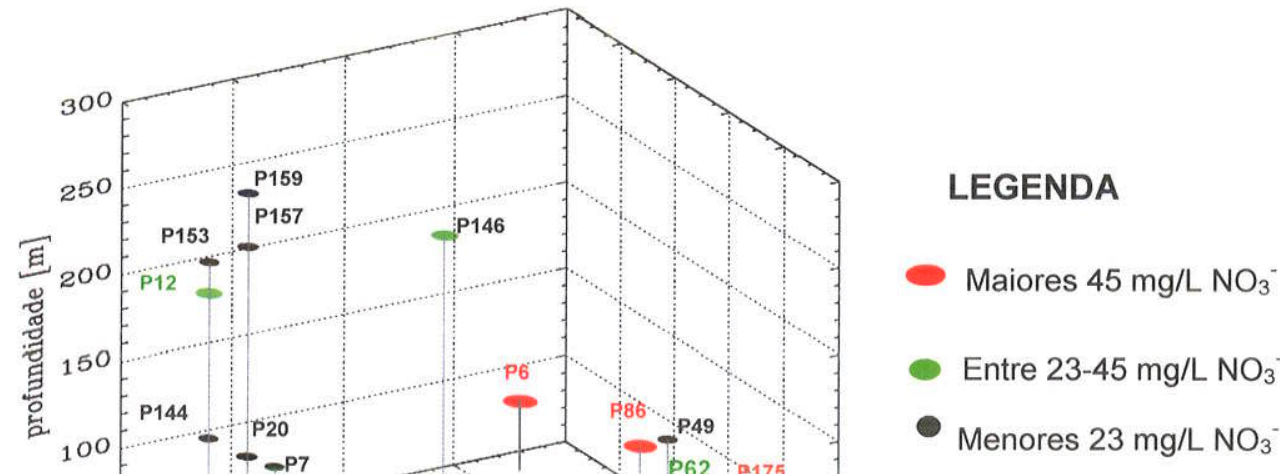

P49 Número do poço

Figura 6.23 Concentrações de nitrato: a) medidas em campo (2009), b) medidas em campo (2010); c) calculadas para as duas campanhas (Cu); d) valor médio das análises preexistentes (2007-2009) e) calculadas para as análises pré-existentes $(\mathrm{Cu})$ 


\subsubsection{Determinação da zona de captura nos poços}

A delimitação da ZOC neste trabalho foi realizada mediante dois métodos: a) raio fixo calculado (RFC), definido através do tempo de trânsito de 50 dias e, b) método de Wyssling (Merino et al., 1991).

As informações necessárias para a aplicação das duas metodologias foram: vazão do poço, nível estático e características médias do aquífero (condutividade hidráulica, velocidade do fluxo, gradiente hidráulico, porosidade efetiva e espessura saturada) (anexo IX).

Dos cadastros dos poços estimou-se que das 198 captações extraem aproximadamente $584 \mathrm{~m}^{3} / \mathrm{h}\left(5,1 \times 10^{6} \mathrm{~m}^{3} / \mathrm{ano}\right)$ de água, com valores mínimos e máximos de $0,62 \mathrm{~m}^{3} / \mathrm{h}$ e $26 \mathrm{~m}^{3} / \mathrm{h}$, respectivamente. Em geral, os valores mínimos de vazão correspondem aos poços rasos, enquanto que os máximos pertencem aos poços de maior profundidade (figura 6.24; tabela 6.12).

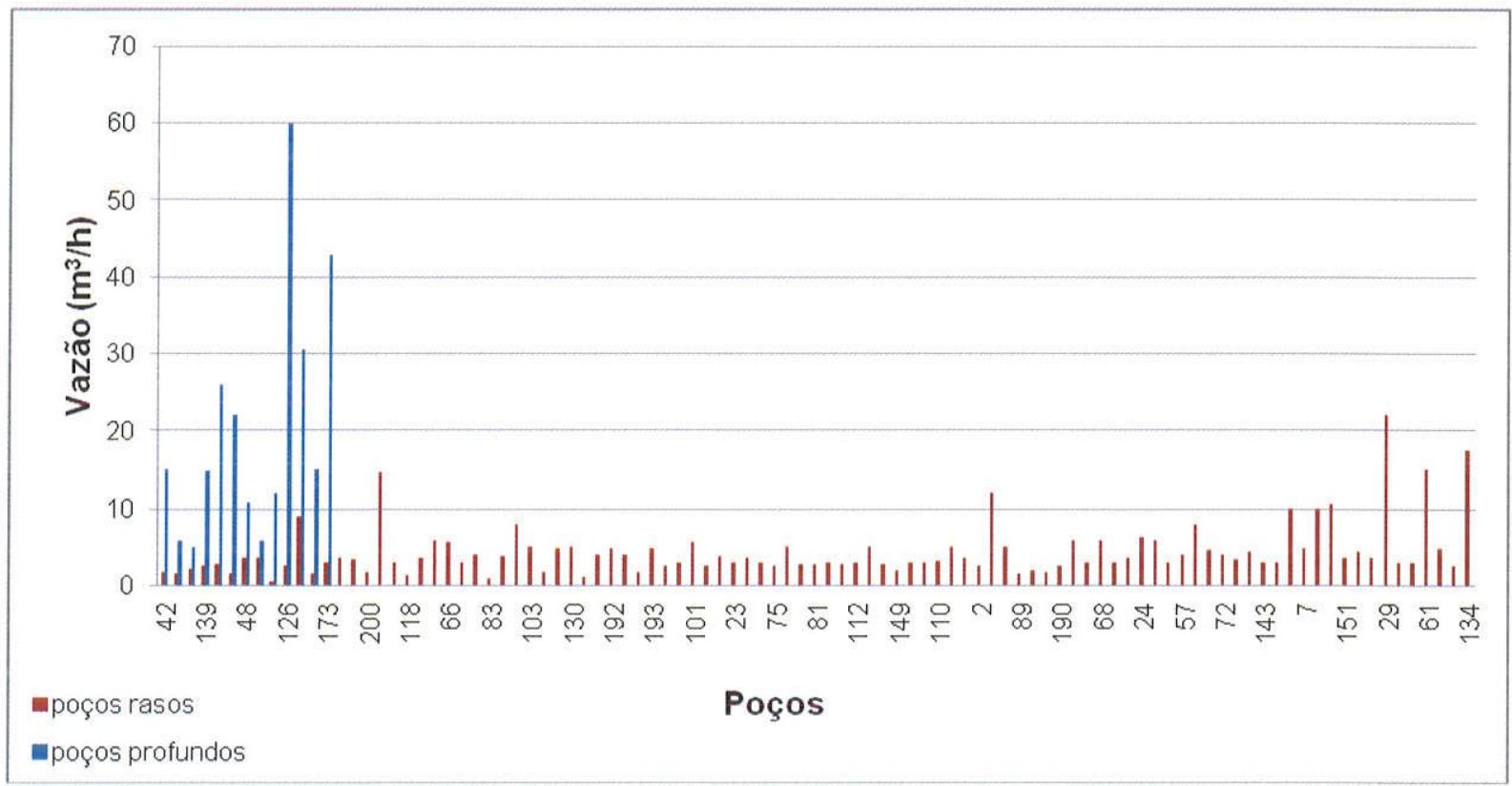

Figura 6.24 Vazões dos poços rasos e profundos na área urbana de Presidente Prudente. 
Tabela 6.14 Estatistica básica e comparação dos raios fixos calculados para os poços cadastrados na área urbana de Presidente Prudente.

\begin{tabular}{|c|c|c|c|c|c|c|c|c|}
\hline \multicolumn{6}{|c|}{ Parâmetros hidrogeológicos } & \multirow{2}{*}{$\begin{array}{c}\begin{array}{c}\text { Método } \\
\text { RFC }\end{array} \\
r(m)\end{array}$} & \multicolumn{2}{|c|}{$\begin{array}{l}\text { Método } \\
\text { Wissling }\end{array}$} \\
\hline $\begin{array}{l}\text { Poços } \\
\text { rasos }\end{array}$ & $\begin{array}{c}Q \\
\left(m^{3} / h\right)\end{array}$ & $b(m)$ & $n_{e f}$ & $\begin{array}{c}k \\
(\mathrm{~m} / \mathrm{h})\end{array}$ & $\mathrm{i}$ & & $\mathrm{So}(\mathrm{m})$ & $\mathrm{Su}(\mathrm{m})$ \\
\hline Mín. & 0,62 & 14,58 & 0,15 & 0,70 & 0,02 & 5,81 & 8,78 & 4,35 \\
\hline Máx. & 36,60 & 108,00 & 0,15 & 0,70 & 0,02 & 37,87 & 41,69 & 37,26 \\
\hline Média & 4,79 & 60,00 & 0,15 & 0,70 & 0,02 & 13,60 & 16,48 & 12,04 \\
\hline D.P & 5,08 & 21,51 & & & & 4,83 & 5,26 & 5,26 \\
\hline $\begin{array}{l}\text { Poços } \\
\text { profundos }\end{array}$ & $\begin{array}{c}\mathrm{Q} \\
\left(\mathrm{m}^{3} / \mathrm{h}\right)\end{array}$ & $b(m)$ & $n_{\text {ef }}$ & $\begin{array}{c}k \\
(\mathrm{~m} / \mathrm{h})\end{array}$ & $\mathrm{i}$ & $r(m)$ & So(m) & $\mathrm{Su}(\mathrm{m})$ \\
\hline Mín. & 5 & 82 & 0,15 & 0,70 & 0,02 & 10,88 & 13,55 & 9,11 \\
\hline Máx. & 26 & 130 & 0,15 & 0,70 & 0,02 & 22,92 & 21,89 & 17,45 \\
\hline Média & 14,23 & 110,48 & 0,15 & 0,70 & 0,02 & 17,55 & 17,49 & 13,06 \\
\hline D.P & 7,79 & 20,23 & & & & 4,82 & 3,02 & 3,02 \\
\hline
\end{tabular}

Tabela 6.15 Comparação entre os raios fixos calculados para os poços amostrados na área urbana de Presidente Prudente.

\begin{tabular}{ccccccccccc}
\multicolumn{1}{c}{ Parâmetros hidrogeológicos } & \multicolumn{3}{c}{$\begin{array}{c}\text { Método } \\
\text { RFC }\end{array}$} & $\begin{array}{c}\text { Método } \\
\text { Wissling }\end{array}$ \\
\hline Poço & $\begin{array}{c}\text { Prof. } \\
(\mathrm{m})\end{array}$ & $\begin{array}{c}\mathrm{Q} \\
\left(\mathrm{m}^{3} / \mathrm{h}\right)\end{array}$ & $\mathrm{b}(\mathrm{m})$ & nef & $\begin{array}{c}\mathrm{k} \\
(\mathrm{m} / \mathrm{h})\end{array}$ & $\mathrm{i}$ & $\mathrm{r}$ & So(m) & Su(m) \\
\hline 96 & 60 & 3,6 & 25 & 0,15 & 0,7 & 0,02 & 19,15 & 14,08 & 9,65 \\
200 & 68 & 1,8 & 42 & 0,15 & 0,7 & 0,02 & 10,45 & 16,73 & 12,30 \\
118 & 70 & 1,44 & 36 & 0,15 & 0,7 & 0,02 & 10,09 & 18,33 & 13,89 \\
14 & 78 & 6 & 49 & 0,15 & 0,7 & 0,02 & 17,66 & 17,79 & 13,36 \\
35 & 100 & 2,93 & 77 & 0,15 & 0,7 & 0,02 & 9,84 & 13,55 & 9,11 \\
87 & 100 & 3 & 72 & 0,15 & 0,7 & 0,02 & 10,30 & 21,89 & 17,45 \\
110 & 100 & 3,2 & 80 & 0,15 & 0,7 & 0,02 & 10,09 & 20,78 & 16,34 \\
147 & 102 & 12 & 42 & 0,15 & 0,7 & 0,02 & 26,97 & 10,73 & 6,30 \\
62 & 100 & 5 & 56 & 0,15 & 0,7 & 0,02 & 15,08 & 17,24 & 12,80 \\
86 & 100 & 3,6 & 45 & 0,15 & 0,7 & 0,02 & 14,27 & 22,94 & 18,50 \\
6 & 110 & 6 & 74 & 0,15 & 0,7 & 0,02 & 14,37 & 13,55 & 9,11 \\
144 & 116.5 & 3 & 51 & 0,15 & 0,7 & 0,02 & 12,24 & 18,33 & 13,89 \\
49 & 132 & 4,5 & 70 & 0,15 & 0,7 & 0,02 & 12,79 & 16,02 & 11,59 \\
20 & 120 & 3 & 60 & 0,15 & 0,7 & 0,02 & 11,28 & 30,04 & 25,61 \\
7 & 124 & 4,9 & 96 & 0,15 & 0,7 & 0,02 & 11,40 & 17,16 & 12,72 \\
176 & 132 & 3,6 & 97 & 0,15 & 0,7 & 0,02 & 9,72 & 14,77 & 10,34 \\
175 & 120 & 10 & 90 & 0,15 & 0,7 & 0,02 & 10,30 & 14,77 & 10,34 \\
\hline Mín. & 60 & 1,44 & 25 & & & & 9,72 & 10,73 & 6,30 \\
Máx. & 132 & 12,00 & 97 & & & & 26,97 & 30,04 & 25,61 \\
Média & 101 & 4,56 & 62 & & & & 13,30 & 17,57 & 13,14 \\
D.P & 22,39 & 2,75 & 22 & & & & 4,51 & 4,51 & 4,51 \\
\hline
\end{tabular}

So $(m)$ : distância a montante; Su $(\mathrm{m})$ : distância a jusante. Distâncias correspondentes a um tempo de trânsito t 
Tabela 6.16 Comparação entre os raios fixos calculados para os poços profundos amostrados na área urbana de Presidente Prudente.

\begin{tabular}{|c|c|c|c|c|c|c|c|c|}
\hline \multicolumn{6}{|c|}{ Parâmetros hidrogeologicos } & \multirow{2}{*}{$\begin{array}{l}\text { Método } \\
\text { do RFC } \\
r(\mathrm{~m})\end{array}$} & \multicolumn{2}{|c|}{$\begin{array}{l}\text { Método } \\
\text { Wissling }\end{array}$} \\
\hline Poço & $\stackrel{Q}{Q}\left(\mathrm{~m}^{3} / \mathrm{h}\right)$ & $\begin{array}{c}b \\
(m)\end{array}$ & nef & $\begin{array}{c}k \\
(\mathrm{~m} / \mathrm{h})\end{array}$ & $i$ & & $\mathrm{So}(\mathrm{m})$ & $\mathrm{Su}(\mathrm{m})$ \\
\hline 12 & 6 & 155 & 0,15 & 0,7 & 0,019 & 9,93 & 14,08 & 9,65 \\
\hline 146 & 15 & 139 & 0,15 & 0,7 & 0,019 & 16,58 & 16,73 & 12,30 \\
\hline 153 & 11,92 & 167 & 0,15 & 0,7 & 0,019 & 13,48 & 18,33 & 13,89 \\
\hline 157 & 60 & 167 & 0,15 & 0,7 & 0,019 & 30,25 & 17,79 & 13,36 \\
\hline 159 & 43 & 185 & 0,15 & 0,7 & 0,019 & 24,33 & 13,55 & 9,11 \\
\hline 158 & 30,47 & 181 & 0,15 & 0,7 & 0,019 & 20,70 & 21,89 & 17,45 \\
\hline Min. & 1,44 & 25 & & & & 9,72 & 10,73 & 6,30 \\
\hline Máx. & 12,00 & 97 & & & & 26,97 & 30,04 & 25,61 \\
\hline Média & 4,56 & 62 & & & & 13,30 & 17,57 & 13,14 \\
\hline D.P & 2,75 & 22 & & & & 4,51 & 4,51 & 4,51 \\
\hline
\end{tabular}

Pode-se dizer também que, não existe correlação entre a contaminação por nitrato nos poços e as áreas delimitadas na ZOC. Por exemplo, nos poços 86 e 87 (poços rasos, localizados em diferentes zonas) os raios são muito similares (16,07 e $11,13 \mathrm{~m}$ ), embora as concentrações de nitrato sejam diferentes (tabela 6.15). $\mathrm{O}$ mesmo ocorre com os poços profundos 146 e 153 (tabela 6.16; figura 6.27).

Ao se comparar as ZOC definidas mediante as duas metodologias, foi possível notar que os raios apresentam valores semelhantes porque consideram o mesmo tempo de trânsito de 50 dias (tabela 6.15 e 6.16).

As figuras 6.25 e 6.26 apresentam raios fixos calculados conforme os métodos RFC e Wyssling para um tempo de trânsito de 50 dias. Considerou-se nestes casos, um exagero de 10x no valor do RFC visto que os valores calculados säo muito pequenos para se observar nas figuras 6.25 e 6.26 . 


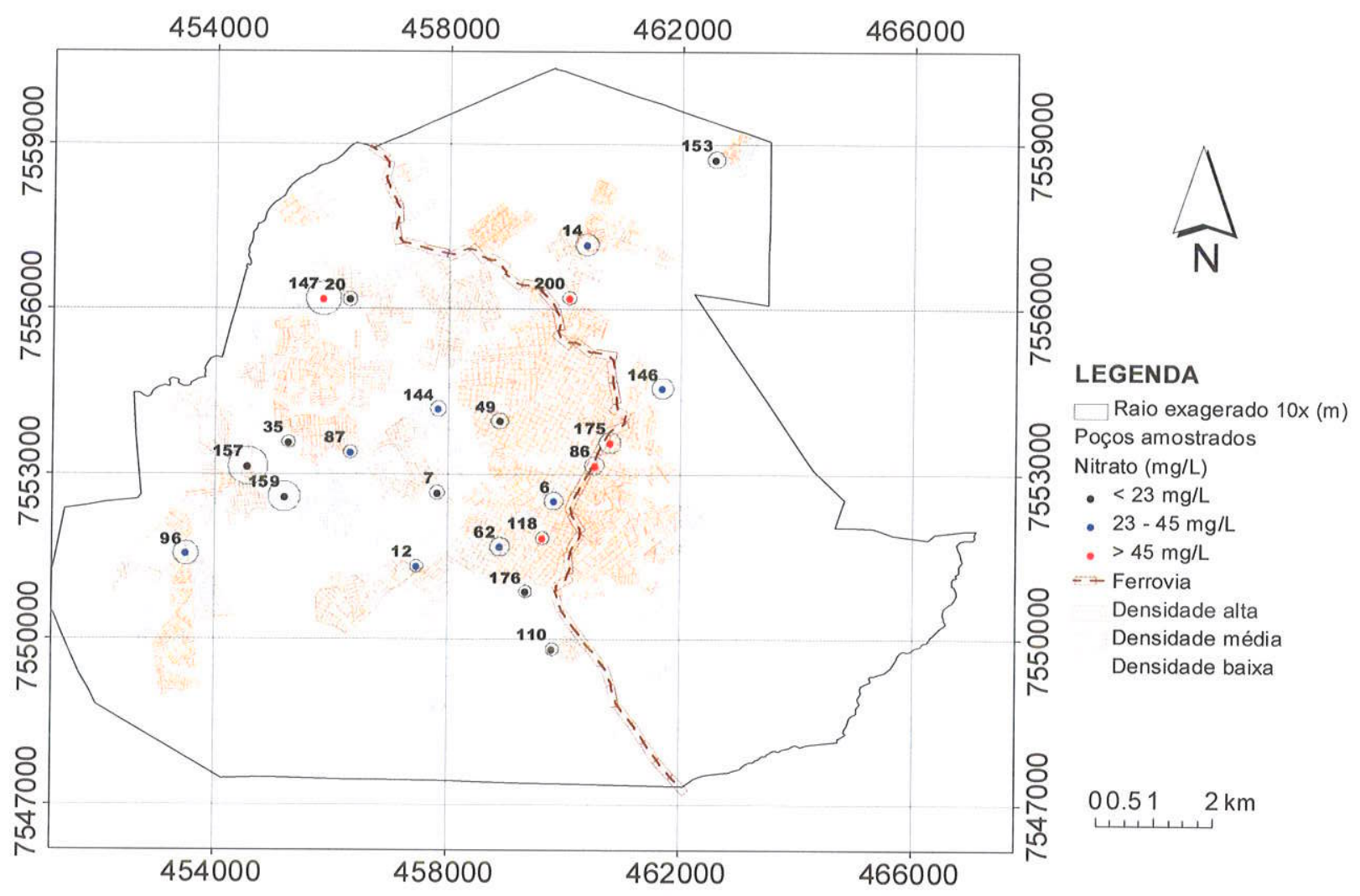

Figura 6.25 Raio fixo calculado para os poços amostrados na área urbana de Presidente Prudente.

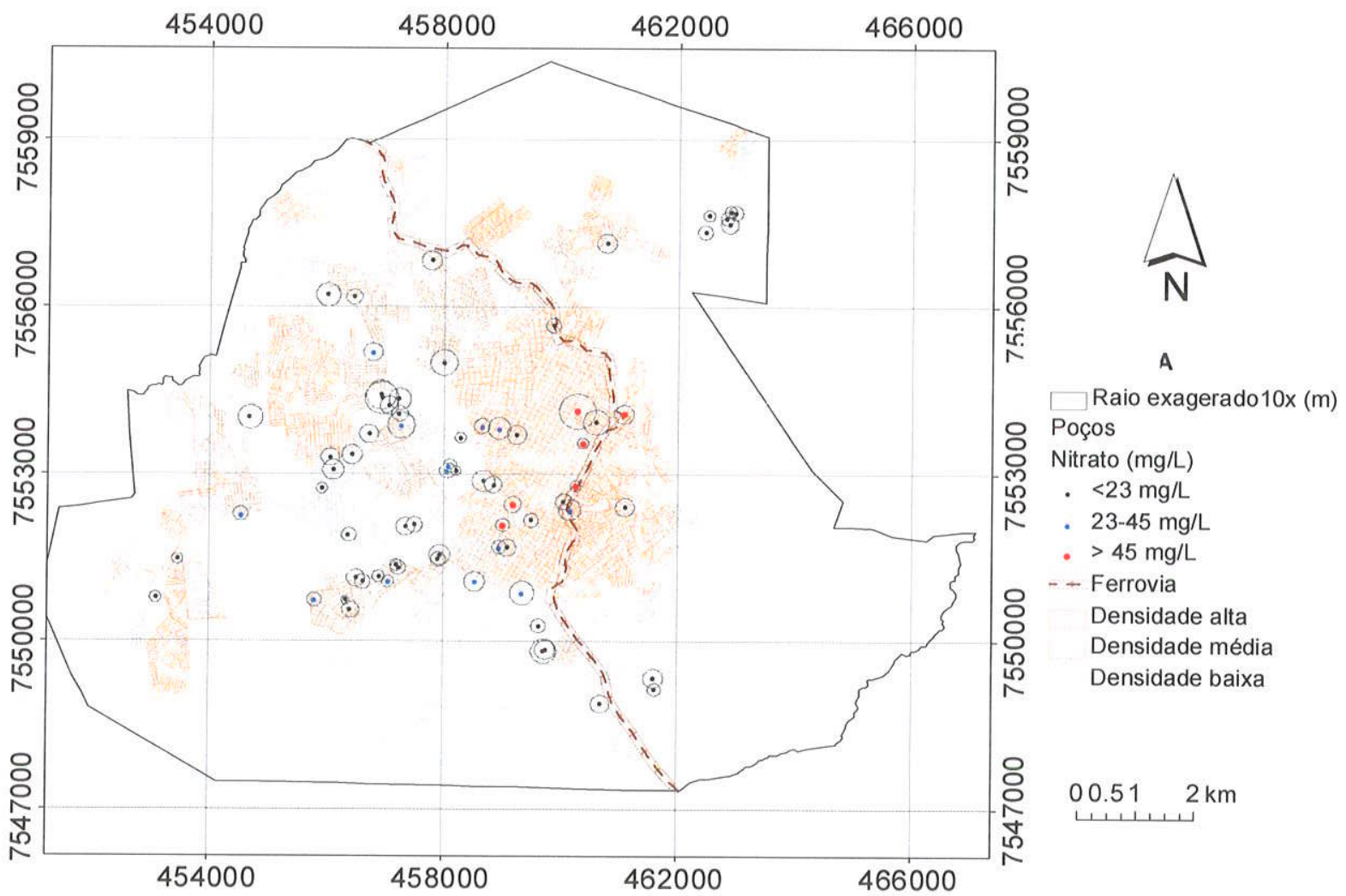

Figura 6.26 Raio fixo calculado para os poços da área urbana de Presidente Prudente. 


\subsection{Zoneamento das áreas potenciais de contaminação de nitrato}

Na área urbana de Presidente Prudente foi possível identificar a ocorrência de três zonas sensiveis à contaminação por nitrato denominadas $A, B$ e $C$ descritas a seguir (figuras 6.27 e 6.28 ):

(A) Zonas com problemas de nitrato ou potencialmente contaminadas: zonas que possuem as malhas urbanas mais antigas (1930-1950), com alta densidade urbana (120 hab/ha) e poços rasos que apresentam altas concentrações de nitrato $(>45$ $\mathrm{mg} / \mathrm{L}$ de $\mathrm{NO}_{3}{ }^{-}$). Tais poços localizam-se em bairros antigos como Centro, Vila Marcondes, Vila Industrial que contaram com rede pública de esgoto a partir dos anos 80s;

(B) Zonas com possiveis problemas de nitrato: apresentam densidade urbana média (84 hab/ha) e poços com concentrações de nitrato intermediárias, de "alerta" (entre $23 \mathrm{mg} / \mathrm{L}$ e $45 \mathrm{mg} / \mathrm{L}$ de $\mathrm{NO}_{3}{ }^{-}$). Tais poços situam-se em bairros relativamente novos como: Parque Residencial Dahma I e II, Jardim Maracanã, Jardim das Rosas. A rede de esgoto nestes locais existe a partir do ano 2000.

(C) Zonas sem problemas de nitrato ou não contaminadas: possuem baixa densidade urbana (20 hab/ha), com presença de poços profundos com concentrações de nitrato baixas $\left(<23 \mathrm{mg} / \mathrm{L}\right.$ de $\left.\mathrm{NO}_{3}{ }^{-}\right)$. Os poços localizam-se em bairros novos como Cerqueira César, Parque Brasil Novo, Novo Oeste, Conjunto Ana Jacinta, Vila Nova Prudente, Distrito Industrial, Parque Cervantes 2, Jardim São Luiz e Bosque). Tais locais contam com sistema de saneamento, implementado desde sua criação, a partir do ano 2000. 

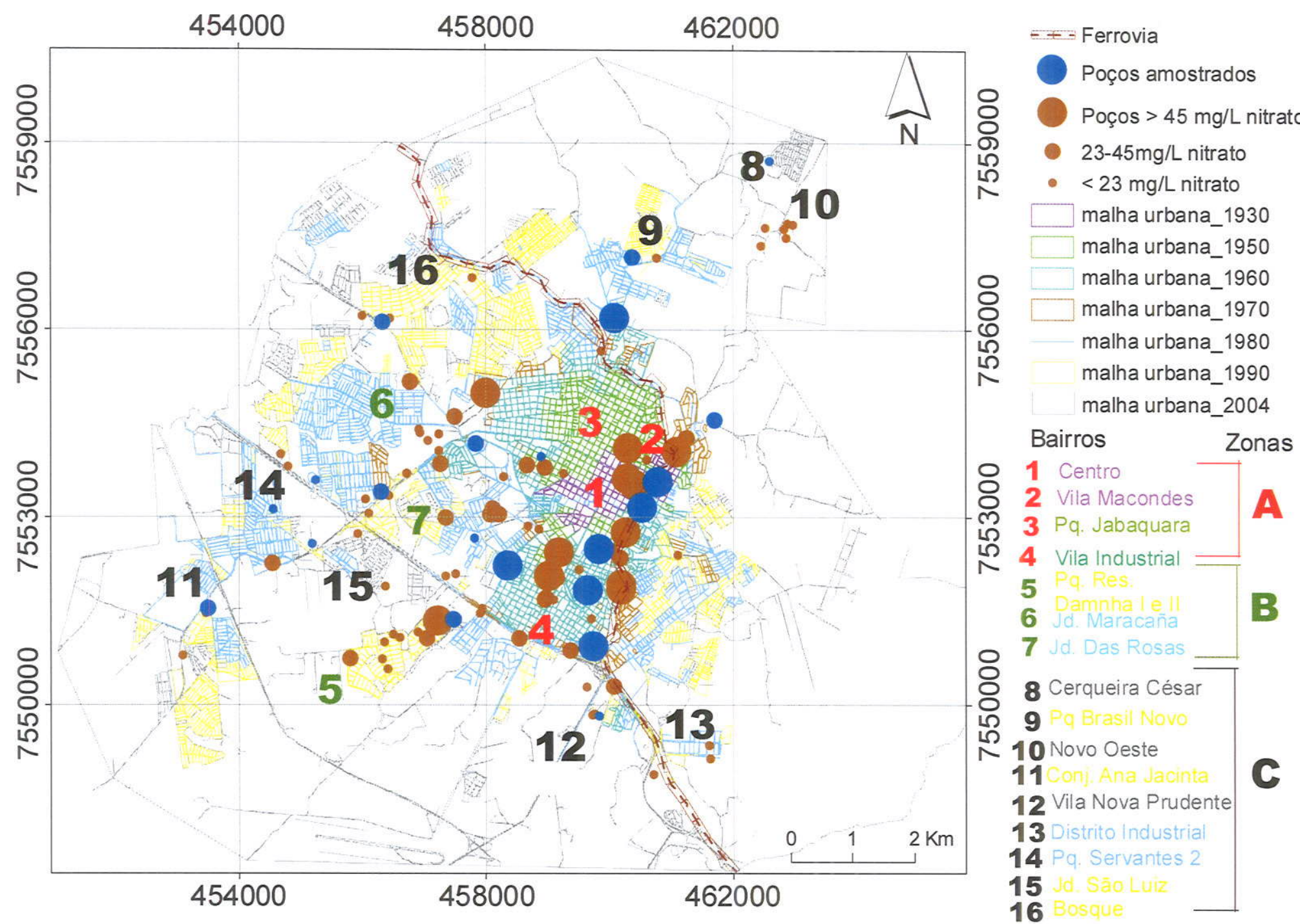

Figura 6.27 Expansão urbana e distribuição dos poços amostrados nas zonas A, B e C (adaptado de Camargo, 2007). 

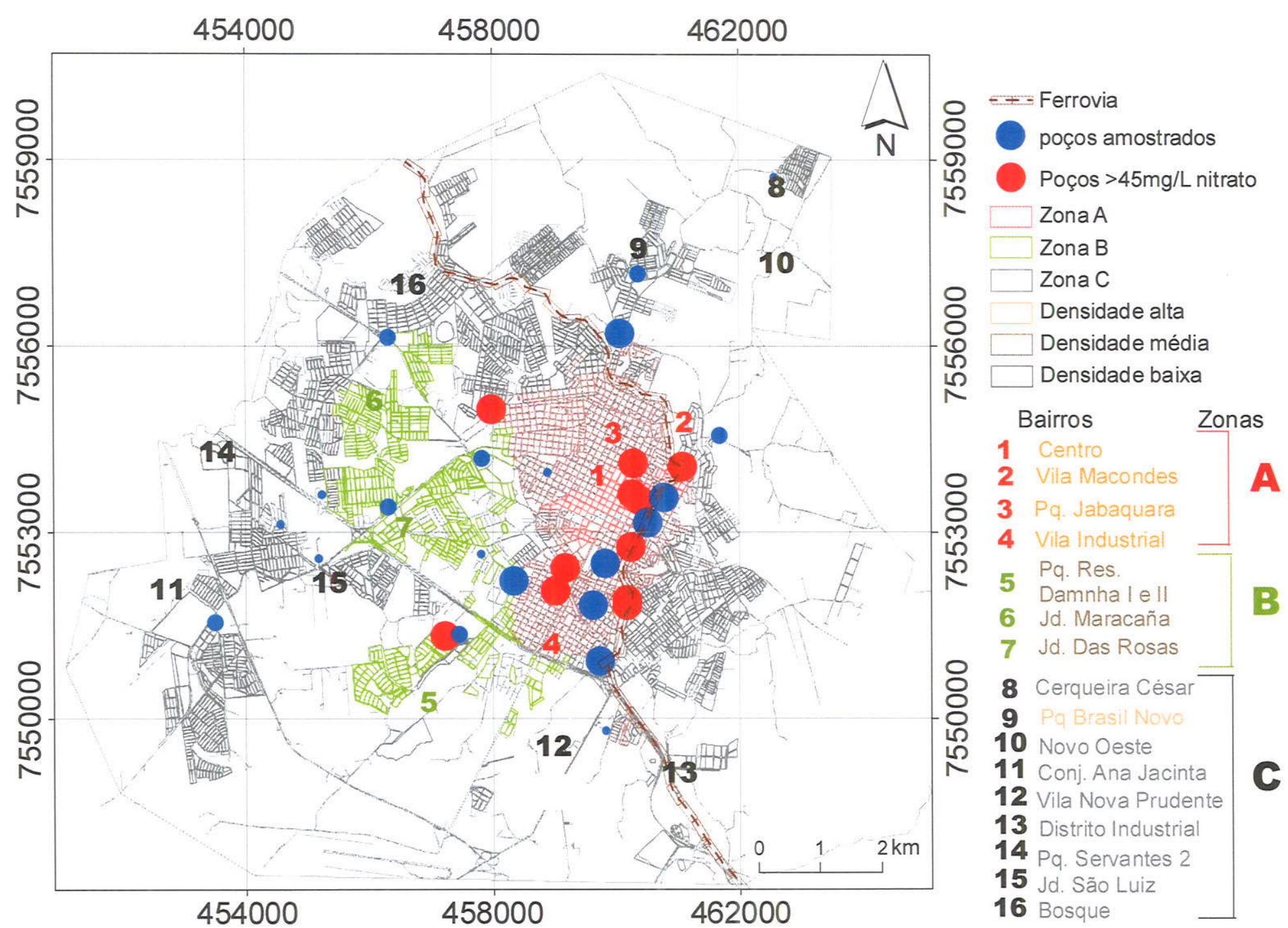

Figura 6.28 Zoneamento das áreas potenciais de contaminação por nitrato para a área urbana de Presidente Prudente 


\section{CONCLUSÕES}

As águas subterrâneas na área de estudo estão representadas pelo $S A B$, que é de tipo livre, de porosidade primária, composto principalmente pelos aquíferos Adamantina e Santo Anastácio. A recarga ocorre pela infiltração da água de chuva, que é influenciada pela morfologia da área, tendo como direções preferenciais as regiões oeste e sudoeste e deságue nos córregos do Veado, Cedro e Botafogo. Há igualmente recarga associada à ocupação urbana, como atestam os focos de contaminação. A partir dos resumos dos testes de bombeamento determinou-se que - Aquífero Adamantina tem uma condutividade hidráulica média de 0,7 m/dia, coincidente com as litologias de sedimentos arenosos permeáveis. Gradiente hidráulico médio de $1,9 \%$ e velocidade do fluxo de 0,15 a $0,46 \mathrm{~m} / \mathrm{dia}$. O Aquífero Santo Anastácio possui parâmetros hidrogeológicos similares com condutividade hidráulica média de $0,7 \mathrm{~m} /$ dia, gradiente hidráulico médio de $1,9 \%$ e velocidade do fluxo de 0,14 a $0,15 \mathrm{~m} / \mathrm{dia}$.

O estudo da hidroquímica das águas subterrâneas no SAB em Presidente Prudente indicou a ocorrência de dois tipos hidroquímicos predominantes. $O$ primeiro, as águas cloro-nitratadas a bicarbonatadas cálcicas, nas porções mais rasas (poços até $150 \mathrm{~m}$ ) do aquífero. Os valores de $\mathrm{pH}$ encontram-se entre 5,54 e 8,39 e os de Eh entre 394,50 e $575,60 \mathrm{mV}$, o que sugere águas ácidas em meio oxidante. As elevadas concentrações de nitrato e cloreto sugerem contaminação das águas subterrâneas associadas ao esgoto doméstico.

O segundo tipo corresponde às águas bicarbonatadas sódicas, localizadas em maior profundidade (>150 m). Os valores de pH encontram-se entre 6,02 e 9,53 e os de Eh entre 323,90 e $507,60 \mathrm{mV}$. A diminuição nas concentrações de cálcio (até $0,88 \mathrm{mg} / \mathrm{L})$ e de magnésio $(0,09 \mathrm{mg} / \mathrm{L})$ sugere possivel ocorrência de reações de troca catiônica nestas porções do aquifero. Detectaram-se também baixas concentrações de nitrato e cloreto. 
A avaliação das análises químicas de 2005 a 2009 mostraram que $15 \%$ das captações apresentaram valores de nitrato acima dos limites de potabilidade (Portaria 518/04). Observou-se também que as maiores concentrações de nitrato encontram-se na região central da cidade (zona central), variando de 55 a $80 \mathrm{mg} / \mathrm{L}$, tanto nos poços rasos $(<150 \mathrm{~m})$ como nos profundos $(>150 \mathrm{~m})$. Essa zona abrange os bairros mais antigos da cidade, a partir dos quais se iniciou o processo de expansão urbana, na década dos anos 30 .

Com base nas análises químicas das duas campanhas de amostragem (dezembro 2009 e junho-jutho2010) notaram-se variações das concentrações de nitrato a curto prazo. Dos 22 poços amostrados 45\% (10 poços) localizam-se na

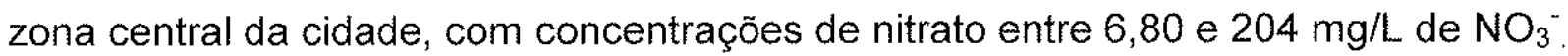
Nas outras zonas, as concentrações variam de 2,70 a 78,00 mg/L de $\mathrm{NO}_{3}{ }^{-}$na zona nordeste; 0,65 a $57,00 \mathrm{mg} / \mathrm{L}$ na zona oeste; e 21,00 a $32,00 \mathrm{mg} / \mathrm{L}$ na zona sudeste.

Em relação à profundidade dos poços, observou-se que as maiores concentrações de nitrato foram encontradas nos poços rasos que tem os filtros posicionados nas zonas mais superficiais do aquífero. Isto sugere uma estratificação do problema de poluição de nitrato nas águas subterrâneas do aquífero na cidade.

De acordo com as principais características evidenciadas neste estudo conclui-se que há três zonas sensiveis à contaminação por nitrato na área urbana de Presidente Prudente: A) Zonas com problemas de nitrato ou potencialmente contaminadas $\left(>45 \mathrm{mg} / \mathrm{L}\right.$ de $\left.\mathrm{NO}_{3}{ }^{-}\right)$, relacionadas às áreas urbanas mais antigas (1930-1950), com uma alta densidade urbana (120 hab/ha). B) Zonas com possiveis problemas de nitrato (entre $23 \mathrm{mg} / \mathrm{L}$ e $45 \mathrm{mg} / \mathrm{L}$ de $\mathrm{NO}_{3}{ }^{-}$), catalogadas a áreas com bairros relativamente novos (<30 anos) e densidade urbana média ( $84 \mathrm{hab} / \mathrm{ha}$ ). C) Zonas sem problemas de nitrato ou não contaminadas ( $<45 \mathrm{mg} / \mathrm{L}$ de $\mathrm{NO}_{3}{ }^{-}$) relacionadas a áreas mais novas, com baixa densidade urbana (20hab/ha). 
Os resultados desta pesquisa demonstraram que a expansão territorial urbana de Presidente Prudente ocasionou uma forte mudança no ciclo hidrológico local em função do aumento da densidade urbana, uso intensivo dos sistemas de saneamento in situ, cobertura incompleta das redes coletoras de esgoto (implantada somente a partir dos anos 80 ), falta de manutenção e vazamentos das mesmas. Tais alterações aumentaram a carga contaminante de nitrato no subsolo e, por conseguinte, a contaminação das águas subterrâneas.

\section{RECOMENDAÇÕES}

Com intuito de contribuir com a preservação dos recursos hídricos subterrâneos, são propostas recomendações segundo o zoneamento proposto:

(A) Nas zonas com problemas de nitrato ou potencialmente contaminadas é recomendável:

i) avaliar a real necessidade do uso dos poços tubulares ou rasos no abastecimento público ou privado e induzir aos usuários ao uso da água pública;

ii) fechar o poço contaminado e furar outro poço mais profundo para evitar a captação das águas mais superficiais;

iii) induzir, através de campanhas, que usuários privados monitorem os seus poços regularmente e busquem auxilio técnico na interpretação dos dados e ações protetoras;

Nas zonas com possiveis problemas de nitrato (B) ou não contaminadas (C); é recomendável:

i) monitoramento anual dos parâmetros definidos na Portaria 518/2004 e a cada seis meses, medição de cloreto, nitrato, condutividade elétrica e pH.

Ficou provado que a instalação de rede de esgoto prévia à urbanização pode reduzir a contaminação do aquífero. Assim, para evitar novas contaminações, o crescimento urbano da cidade deve ser antecedido da instalação da rede de esgoto. 
Ademais, a concessionária pública de água e esgoto deve procurar ligações clandestinas de esgotos que não atendam às normas, bem como banir o uso de sistemas de saneamentos in situ nas áreas urbanas. 


\section{REFERÊNCIAS BIBLIOGRÁFICAS}

ABREU, D.S. Formação histórica de uma cidade pionera paulista: Presidente Prudente. Presidente Prudente. Faculdade de Filosofía Ciencias e Letras, 1972, $339 p$.

ALMEIDA, M.A; STEIN, D.P.; MELO, M.S.;BISTRICHI, C.A.; PONÇANO, W.L; HUASI, Y.; ALMEIDA, F.F.M. Geologia do oeste paulista e áreas fronteiriças dos estado do Mato Grosso do Sul e Paraná. In: CONGRESSO BRASILEIRO DE GEOLOGIA, 31, 1980, Balneário de Camburiú. Anais: Balneário de Camburiú: SBG. V5, p 2799 2812, 1980.

ALVES DE LIMA, M.L.; PARAGUASSU, C.A.; REIS DE MELO, H.J.; BATISTA, F.S.; Aplicação de métodos geoestadísticos para mapeamento de área de risco em saúde pública no município de Porto Velho-RO. Vita ET Sanitas, Trindade/60. V2, ก.02, 2008 .

AMERICAN PUBLIC HEALTH ASSOCIATION. Standard Methods for the Examination of Water and Wastewater, $19^{\mathrm{a}}$ ed. Washington DC, American Water Works Association and Water Environment Federation. 1268p.1998.

AMORIM, M.C. O clima urbano de Presidente Prudente. São Paulo: FFLCH/USP, 2000. $374 p$.

AMORIN, M. T. Análise ambiental e qualidade de vida na cidade de Presidente Prudente. Presidente Prudente: Faculdade de Ciências e Tecnologia, 1993.

APPELO, C.A.J. and POSTMA. D. Geochemistry, groundwater and pollution Balkema, Rotterdam. 1993.

ASSOCIAÇÃO BRASILEIRA DE NORMAS TÉCNICAS- ABNT. Tanque séptico, fossa séptica. 15 p NBR 229SET 1993.

BARCHA, S.F. Aspectos geológicos e provincias hidrogeológicas da Formação Bauru na região norte-ocidental do Estado de São Paulo. São José do Rio Preto: Universidade Estadual Paulista, 1980. 
BARISON, M.R. Estudo hidrogeoquímico na Porção Meridional do Sistema Aquifero Bauru no Estado de São Paulo. 2003. 153 p. Tese de Doutorado, Instituto de Geociências e Ciências Exatas, Universidade Estadual Paulista, Rio Claro, 2003.

BARRIOS, N. A. Z., SANT'ANNA NETO, J. L. A circulação atmosférica no extremo oeste paulista. Boletim climatológico, Presidente Prudente, v.1, n.1, p.8-9, março 1996.

BERENICE, A.M.; \& HIRATA, R. Evolução da contaminação por nitrato em aquíferos urbanos: Estudo de caso em Urânia (SP). 2010, 127 p. Dissertação de Mestrado, Instituto de Geociências, Universidade de São Paulo, São Paulo: 2010.

BERTOLO, R.A; HIRATA, R. Monitoramento da zona não saturada: um estudo da hidráulica e hidroquímica na estação experimental de Urânia, São Paulo, Brasil: In: CONGRESSO MUNDIAL INTEGRADO DE ÁGUAS SUBTERRÂNEAS. 1. Fortaleza: ABAS, 2000.

BERTOLO, R. A. Hidrodinâmica e hidrogeoquímica da zona não saturada do aquífero Adamantina em Urânia (SP). São Paulo, 218p. (Tese-Doutorado) Instituto de Geociências, Universidade de São Paulo, 2001.

BERTOLO, R.A.; MARCOLAN, L.N.O.; BOUROTTE, C.L.M. Relações Água-Rocha e Hidrogeoquímica do Cromo na Água Subterrânea de Poços de Monitoramento Multiniveis de Urânia, SP, Brasil. Ravista do Instituto de geociências-USP, v.9, n.2, p. 47-62., 2009.

BOUROTTE, C.; BERTOLO, R.; ALMODÓVAR, M.; HIRATA, R. Natural Occurrence of Hexavalent Chromium in a Sedimentary Aquifer in Urânia, State of São Paulo, Brazil. Anais da Academia Brasileira de Ciências, v.81, n.2. 227-242 p. 2009.

CAGNON, F.A. Origem e Hidroquímica do nitrato nas Águas Subterrâneas do Aquífero Adamantina em Urânia, SP. 2003. Dissertação de Mestrado, Instituto de Geociências, Universidade de São Paulo, São Paulo: 2003. 
CAMARGO, C.E.S.QQualidade Ambiental Urbana em Presidente Prudente/SP. Presidente Prudente, 2007.149p. Dissertação de Mestrado, Departamento de Geografia, Universidade Estadual Paulista. 2007.

CAMPOS, H.C.N.S. Contribuição ao estudo hidrogeoquímico do grupo Bauru no estado de Sào Paulo 1987. 105 p. Dissertação de Mestrado, Instituto de Geociências, Universidade de São Paulo, São Paulo, 1987.

CAMPOS, H.C.N.S. Caracterização e cartografia das províncias hidrogeoquímicas do estado de São Paulo. 1993. 177p.Tese de Doutorado, Instituto de Geociências, Universidade de São Paulo, São Paulo. 1993.

CANTER, L.W. Nitrate and pesticides in ground water: an analysis of a computer based literature research. In: Ground Water Quality and Agricultural Practices. Edited by: Deborah M. Fairchild. Lewis Publishers. pp. 153-174. 1990.

CARVALHO, B. de A. Glossário de Saneamento e Ecologia. Rio de Janeiro. Associação Brasileira de Engenharia Sanitária e Ambiental, 1981 apud MINARI, B. H. Influência do Uso de Sistema de Saneamento In Situ na Qualidade de Poços Rasos e Profundos. Tese de Mestrado em Infra-estrutura Aeronáutica-Instituto de Aeronáutica, São José dos Campos. 2007. 211p.

CAVALCANTE DE LIMA, J.; PEDROSA, V. de A.; ROCHA, W.J.S. Avaliação da concentração de nitrato nas águas subterrâneas no bairro do Farol, em Maceió-Alagoas. In: IX SIMPÓSIO DE RECURSOS HÍDRICOS DO NORDESTE, 1 $20 \mathrm{p}, 2003$.

CAVALHEIRO, M.G. O processo de cheia em bacias hidrográficas urbanas. Trabalho de conclusão de curso (TCC), 2008. Faculdade de Engenharia Cons. Algacyr Munhoz Meader. Tecnologia em Saneamento Ambiental. Universidade do Oeste Paulista Presidente Prudente-SP, 2008. 63 p.

COELHO, R.O. Estudo hidroquímico e isotópico do Aquífero Bauru, sudoeste do estado de São Paulo. 1996. 103 p. Dissertação de Mestrado, Instituto de Geociências, Universidade de São Paulo, São Paulo, 1996. 
CONSTANTINO, J.D.M.F. Hidrogeología Aplicada. Editorial Félix Valera. El Veado, C. de la Habana, Cuba, 1999. ISBN:959-258-066-99, 453 p.

COMPANHIA ESTADUAL DE TECNOLOGIA DE SANEAMENTO AMBIENTAL.Fossa séptica. Série Manuais/Secretaria do Meio Ambiente. São Paulo; CETESB; 1989. 20 p.

COMPANHIA ESTADUAL DE TECNOLOGIA DE SANEAMENTO AMBIENTAL. Relatório de Qualidade das Águas Subterrâneas do Estado de São Paulo. São Paulo.Relatório técnico.São Paulo: CETESB, 1994. 95 p.

COMPANHIA ESTADUAL DE TECNOLOGIA DE SANEAMENTO AMBIENTAL. Relatório de Qualidade das Águas Subterrâneas do Estado de São Paulo. São Paulo.Relatório técnico.São Paulo: CETESB, 1997. 106 p.

COMPANHIA DE TECNOLOGIA DE SANEAMENTO AMBIENTAL. Relatório para Solos e Águas Subterrâneas no Estado de São Paulo. Coord. Dorothy C.P. Casarini. São Paulo, CETESB. 73 p, 2000.

COMPANHIA ESTADUAL DE TECNOLOGIA DE SANEAMENTO AMBIENTAL. Poluição das Águas Subterrâneas no Estado de São Paulo no periodo 2004 2006. Relatório técnico.São Paulo: CETESB, 2007.Série Relatórios/Secretaria de Estado do Meio Ambiente, ISSN 0103-4101.119 p.

COMPANHIA DE SANEAMENTO BÁSICO DO ESTADO DE SÃO PAULO-SABESP. Programa do controle e redução de perdas. Diretoria de Distribuição, 2009.

COMPANHIA DE SANEAMENTO BÁSICO DO ESTADO DE SÃO PAULO-SABESP. Coleta e tratamento de esgoto no Município de Presidente Prudente, 2006.

CUSTODIO, E.; LLAMAS, M.R. Hidrologia subterránea. $2^{\mathrm{a}}$ ed. Barcelona: Ediciones: Omega, 1976. 2v. 2350 p.

DEPARTAMENTO DE ÁGUAS E ENERGIA ELÉTRICA- DAEE. Estudo de águas subterrâneas: região administrativa 6, Ribeirão Preto-SP, São Paulo: Geopesquisadora-Tahal, 1974. 2v. 
DRAKE, V.M.; BAUDER, J.W.. Ground water nitrate-nitrogen trends in relation to urban development, Helena Montana, 1971-2003. Ground Water Monitoring and Remediation, v. 25, n. 2, p. 118-130. 2005.

IKUTA, F.A.; A cidade e as águas: Expansão territorial urbana e a ocupação dos fundos de vales em Presidente Prudente-SP. 2003. Dissertação de Mestrado, Faculdade de Ciências e Tecnologia. Universidade Estadual Paulista, Presidente Prudente, 2003. $191 \mathrm{p}$.

IRITANI, M.A.; EZAKI, S. Roteironorientativo para delimitação de área de proteção de poço. Secretaria do Meio Ambiente/Instituto Geológico. Cadernos do Projeto Ambiental Estratégico Aquíferos. $1^{a}$ edição, n.2, 2010. 48 p.

INSTITUTO BRASILEIRO DE GEOGRAFIA E ESTATÍSTICA. Censo demográfico do Brasil. URL: hto:/Wwm boe gov brlcidadesavtopwindow.tm. Acesso em dezembro de 2009.

INSTITUTO DE PESQUISAS TECNOLÓGICAS. Mapa geológico do Estado de São Paulo, escala 1:500.000. São Paulo, IPT, 2v, 1981.

FEITOSA, F.A.C.; MANOEL FILHO, J. Hidrogeologia: conceitos e aplicações. Fortaleza: CPRM, LABHID-UFPE, 2000. 391p.

FOSTER, S.\& HIRATA, R. Grounwater pollution risk assessment: A methodology using available data. World/Pan American Health OrganizationCEPIS Technical Report, Lima Perú, 83pp. 1988.

FOSTER, S.; LAWRENCE, A.; MORRIS B. Grounwater in urban development: Assesing management needs and formulating policy strategies. World Bank Technical Document. No 390, 55. 1998.

FOSTER, S. S. D., LAWRENCE, A. R. y MORRIS, B. L. 2001. El agua subterránea en el desarrollo urbano: evaluación de las necesidades de gestión y formulación de estrategias. Documento Técnico del Banco Mundial 390. 2001.

FREEZE, R. A.; CHERRY, J. A. (1979). Groundwater. Englewood Cliffs, PrenticeHall. 604 p. 
FUNDAÇÃO SISTEMA ESTADUAL DE ANÁLISE DE DADOS - SEADE (1981). São Paulo em Dados. Disponivel em: htr:/hww seade gov brlcgibin/lnocvos/spd ksh). Acesso em: outubro de 2010.

GIAFFERIS, G.; OLIVEIRA, $E$. Investigação da qualidade das águas subterrâneas do município de Bauru. In: XIV CONGRESSO BRASILEIRO DE ÁGUAS SUBTERRÂNEAS, curitiba, 2006. Anais Curitiba, ABAS. (CD-ROM).

GIAFFERIS, G; OLIVEIRA, E. Gestão da qualidade das águas subterrâneas do município de Bauru-SP. In: XVII SIMPÓSIO BRASILEIRO DE RECURSOS HÍDRICOS, São Paulo, 2007. Anais São Paulo, ABRH. (CD-ROM).

GODOY M.T.; BOIN, M.; SANAIOTTI, D.; SILVA, J. Contaminação das Águas Subterrâneas por nitrato em Presidente Prudente- SP, Brasil. Adolfo Lutz , v63, n.2, p. 208-214, 2004.

GUTIERREZ; A. S. A Hidroquímica do SAB na cidade de Urânia-SP. 1999. Projeto de iniciação científica. 45 p., 1999. Instituto de Geocieências, Universidade de São Paulo, São Paulo: 1999.

HIRATA, R. Fundamentos e estratégia de proteção e controle da qualidade das águas subterrâneas. Estudo de casos no estado de São Paulo. São Paulo: Instituto de Geocieências, Universidade de São Paulo, São Paulo IGc/USP. 1994.

HIRATA, R.C.A \& NUNES DA SILVA, A. Mapa hidrogeólogico da Bacia do Alto Tietê. In: Macedo A. (coord) Banco de Dados Espaciais da Bacia do Alto Tietê. LIG_IGc-USP, São Paulo (disponivel em meio digital, no site: hto:lloeologicioc.usp.br), 1999.

HIRATA, R. Estudo da Contaminação por nitrato no Distrito de Tibiriçá, Bauru. Departamento de água energia e esgoto/Instituto de Geocieências, Universidade de São Paulo, DAEE/IGc-USP, 2000.

HOUNSLOW, A. W. Water quality data: analysis and interpretation. Boca Raton, CRC Press/Lewis Publishers. 397 p, 1994.

HYPOLITO, R. Alcalinidade-Metodologia para determinação em campo. Revista Analytica junho/julho, 2008. No 35. 52-61 p. 
JEON, C.H. Effect of land use and urbanization on hidrochemistry and contamination of groundwater from Taejon area, Korea. J. Hydrol. 253,194-210. 2001.

KEENEY, D. R. Sources of nitrate to groundwater. Nitrogen management and groundwater protection. Developments in Agricultural and Managed-forest Ecology, v. 21, p. $23-34.1989$.

KÖPPEN, W. Climatología: con un estudio de los climas de la Tierra. F. de Cultura. México. 478pp. 1948.

LIMA, A.A. \& BRAGA, A.C. Hidrogeologia do Sistema Aquífero Bauru no município de São José do Rìo Preto (SP). 2004, 82p. Dissertação de Mestrado, Instituto de Geociências e Ciências Exatas, Universidade Estadual Paulista, Rio Claro, 2004.

MALANER, C.H. Recarga de aquífero em área urbana: estudo de caso de Urânia (SP). 2010. Dissertação de Mestrado, Instituto de Geociências, Universidade de São Paulo IGc/USP, São Paulo, 2010.

MORENO, L., MARTINEZ, C, López, J.A., Navarrete, P. Guía metodológica para la elaboración de perímetros de protección de captaciones de aguas subterráneas. Instituto Tecnológico Geominero de España (IGME), Madrid, 1991.

MILESKI, M.M. Qualidade de vida nas proximidades das antigas e atuais áreas de disposição final de resíduoas sólidos em Presidente Prudente-SP. Bacharelado curso de Geografia. Faculdade de Cieências e Tecnologia. Universidade Estadual Paulista. Presidente Prudente. 179 p.2006.

MINISTÉRIO DA SAÚDE. Portaria 518, de 25 de março de 2004. 1994. Estabelece os procedimentos e responsabilidades relativos ao controle e vigilância da qualidade da água para consumo humano e seu padrão de potabilidade.

MUCHIMBANE, A.D. (2010) Estudo dos indicadores de contaminação das águas subterrâneas por sistemas de saneamento in situ Distrito Urbano 4, cidade de Maputo-Moçambique. Dissertação de Mestrado. Instituto de Geociências, Universidade de São Paulo, 2010. 
PAULA E SILVA, F. \& CAVAGUTI, N. Nova caracterização estratigráfica e tectónica do Mesozoico na cidade de Bauru-SP. Revista Geociências, v13, n.1, p. 83-99, 1999.

PAULA E SILVA, F.; KIANG, C.; CAETANO-CHANG, M. Hidroestratigrafia do Grupo Bauru (K) no Estado de São Paulo. Águas Subterrâneas, v19, n.2, p. 19-32, 2005.

PAYNE, W.J. Reduction of nitrogenous oxides by microorganisms. Bacteriological, 1973. Reviews, v. 37, n. 4, pp. 409-452.

PERROTA, M. M.; SALVADOR, E.D.; LOPES, R.C.; D'AGOSTINO, L.Z.; PERUFFO, N.; GOMEZ, S.D.; SACHS, L.L.B.; MEIRA, V.T.; LACERDA FILHO, J. V. Mapa Geológico do Estado de São Paulo, escala 1:750.000. São Paulo: Programa Levantamentos Geológicos Básicos do Brasil, Companhia de Pesquisa de Resursos Minerais, 2005.

PIVELI, RP \& KATO, M.T. Qualidade das águas e poluição: aspectos físicoquímicos. São Paulo: ABES- Associação Brasileira de Engenharia Sanitária e Ambiental. 2006.

PIPER, A.M. A Graphic Procedure in the Geochemical Interpretation of Water Analysis. Trans. Am. Geophysical Union. 25:911-923. 1944.

REYNOLDS-VARGAS, J.; FRAILE, J.; HIRATA R. Trends in nitrate concentrações and determination of their origin using idotopes (180 and $15 \mathrm{~N}$ ) in groundwater of the wester Central Valley, Costa Rica. A Journal of the Human Environment, v35, n5 p.229-236, 2006.

ROCHA, G.A.; BERTACHINI, C.; CAMPOS, H.C.N.S. \& CAIXETA, J.B. Tentativa de zoneamento das características hidráulicas e hidroquimicas do aquífero Bauru. In: ENCONTRO DE GEOLOGIA E HIDROGEOLOGIA: O Grupo Bauru no Estado de São Paulo, 1., Atas... São Paulo: SBG/ABAS, 1982.

ROSS, J.L.S. Geomorfologia: ambiente e planejamento. 2. ed. São Paulo:Contexto, 1991. 82p.

SCHOELLER, H. Les eaux souterraines. Paris: Masson \& Cie., 1962. 642p. 
SILVA, S.R. Caracterização Hidrogeoquímica dos sistemas Aquíferos Bauru e Guarani no Município de Bauru. 2009. 113 p. Tese de Mestrado, Instituto de Geociências e Ciências Exatas, Universidade Estadual Paulista, Rio Claro, 2009.

SPOSITO, M.E.B. O chão em Presidente Prudente: A lógica da expansão territorial urbana. 1983, 230p. Dissertação de Mestrado, Instituto de Geociências e Ciências Exatas, Universidade Estadual Paulista, Rio Claro, 1983.

STARR R.C. AND R.W. GILLHAM. Denitrification and Organic Carbon Availability in Two Aquifers. Ground Water, 1993. 31:934-947.

STRADIOTO, M.R. Hidroquímica e aspectos diagenéticos do Sistema Aquífero Bauru na região sudoeste do Estado de São Paulo. 2007. 103 p. Dissertação de Mestrado, Instituto de Geociências e Ciências Exatas, Universidade Estadual Paulista, Rio Claro, 2007.

STRAHLER, A. N. Quantitative analysis of watershed geomorphology. Transactions of American Geophysical Union. New Haven, v. 38. p 913-920. 1957.

SUHOGUSOFF, A.V. Mimização de impactos nos recursos hídricos causados por sistemas de saneamento in situ: estudo piloto em Parelheiros - São Paulo (SP) Tese de Doutorado. Instituto de Geociências, Universidade de São Paulo, São Paulo: 2010.

TUCCI, C.E.M. Águas urbanas In: Carlos Eduardo M. Tucci, Juan Carlos Bertoni. (orgs). Inundações urbanas na América do Sul. Porto Alegre: ABRH, 2003.

UNITED STATES ENVIRONMENTAL PROTECTION AGENCY. Pratical guide for Groundwater Sampling. URL hto:/Www epa gov/swerust/catprecow pof, 1985.

VARNIER, C.O efeito do nitrogênio proveniente de sistemas de saneamento in situ na qualidade das águas subterrâneas em aquíferos livres e rasos . 2001, 150 p.. Dissertação de Mestrado, Instituto de Geociências, Universidade de São Paulo, São Paulo: 2001.

VARNIER, C.Comportamento do nitrogênio em uma fossa negra desativada na zona não-saturada do Aquífero Adamantina em Urânia (São Paulo, Brasil). 
2007, 144 p.. Tese de Doutorado, Instituto de Geociências, Universidade de São Paulo, São Paulo: 2007.

WAKIDA, F.T. and LERNER, D.N. Non-agricultural sources of groundwater nitrate: a review and case study. Water Research 39, 3-16. 2005.

WILHELM, S.; SCHIFF, S.; CHERRY, J. Biogeochemical evolution of domestic waste in septic systems: Conceptual Model. Ground Water, v.32, n.6, p. 905-916 WORLD HEALTH ORGANISATION (WHO). Environmental health information. URL. http// www who org. Accesado em 2009.

WORLD HEALTH ORGANISATION (WHO). Guidelines for Drinking Water Quality (2 nd ed., v2). Health Criteria and Other Supporting Information. Word Health Organization. Geneva. P 313-324. 2009.

$X U, \quad Y ;$ BAKER, L.A.; JOHNSON, P.C. Trends in ground water nitrate contamination in the Phoenix, Arizona Region. Ground Water Monitoring and Remediation, v. 27, n. 2, p. 49-56. 2007.

Lu,Y.; Tang,Ch.; Chen, J; Sakura, Y. Impact of septic tank systems on local groundwater quality and water supply in the Pearl River Delta, China: case study. HYDROLOGICAL PROCESSES. Hydrol. Process. 22, 443-450 (2008). Published online 30 July 2007 in Wiley InterScience (www.interscience.wiley.com) DOI: $10.1002 /$ hyp. 6617.

ZILBERBRAND, M.; ROSENTHAL, E.; SHACHNAI, E. Impact of urbanization on hydrochemical evolution of groundwater and unsatured-zone gas composition in the coastal city of Tel Aviv, Israel. Journal of Contaminant Hydrology, n.50, pp. $175-208,2001$. 
ANEXO I.- Cadastro dos poços 
Cadastro dos poços na área urbana de Presidente Prudente

\begin{tabular}{|c|c|c|c|c|c|c|c|c|c|c|}
\hline \multirow[t]{2}{*}{ Poço } & \multicolumn{3}{|c|}{ Localização } & \multirow{2}{*}{$\begin{array}{l}\text { Cota } \\
\text { (m) }\end{array}$} & \multirow[t]{2}{*}{ Data Perf. } & \multirow{2}{*}{$\begin{array}{l}\text { Prof. } \\
\text { (m) }\end{array}$} & \multirow{2}{*}{$\begin{array}{l}\mathrm{NE} \\
(\mathrm{m})\end{array}$} & \multirow{2}{*}{$\begin{array}{c}Q \\
m^{3} / h\end{array}$} & \multirow{2}{*}{$\begin{array}{l}\text { P. Filtro } \\
\text { (m) }\end{array}$} & \multirow[t]{2}{*}{ Uso } \\
\hline & UTME & UTMN & Bairro & & & & & & & \\
\hline 1 & 452678 & 7551398 & Pq. Castelo Branco & 377 & 1985 & 78 & 29 & 6 & 1,5 a 3 & NR \\
\hline 2 & 458099 & 7553142 & Jardim João Paulo II & 439 & $03 / 2001$ & 102 & 41 & 2.5 & 1,5 a 3 & $N R$ \\
\hline 3 & 464928 & 7556206 & Sete Copas & 398 & 2001 & 148 & 48.1 & 17.2 & $\begin{array}{l}1,19 a \\
2,42\end{array}$ & I \\
\hline 4 & 465041 & 7557053 & Sete Copas & 402 & $23 / 06 / 1905$ & 150 & 56 & 20 & NR & NR \\
\hline 5 & 460825 & 7553575 & Vila Marcondes & 465 & 1970 & 120 & 49.3 & 6.75 & NR & NR \\
\hline 6 & 459826 & 7552512 & Vila São Jorge & 475 & 14/10/1997 & 110 & 36 & 6 & 1,5 a 3 & NR \\
\hline 7 & 457813 & 7552662 & NR & 450 & NR & 124 & 28 & 4.88 & & NR \\
\hline 8 & 455798 & 7550746 & Res. Damha ॥ & 405 & $04 / 2003$ & 160 & 31 & 6 & 1,5 & NR \\
\hline 9 & 456419 & 7553340 & Jardim Cambuy & 399 & $19 / 11 / 1999$ & 60 & 30 & 2.8 & NR & NR \\
\hline 10 & 459180 & 7552450 & Jardim Paulistano & 405 & $10 / 2004$ & 100 & 39.6 & 3.86 & 1,5 a 3 & NR \\
\hline 11 & 463548 & 7554503 & União & 429 & $>15 a$ & 90 & 31 & 1.6 & NR & NR \\
\hline 12 & 457466 & 7551329 & Pq Res. Damha I & 461 & $\sim 1999$ & 200 & 45 & 6 & 1,5 a 3 & $\mathrm{NR}$ \\
\hline 13 & 456413 & 7550569 & $\mathrm{PqR}$ & 435 & 20 & 110 & 32 & 5 & & NR \\
\hline 14 & 460370 & 7557168 & Pq Castelo Branco & 528 & 1985 & 78 & 29 & 6 & 1,5 a 3 & $R$ \\
\hline 15 & 460284 & 7554120 & Bosque & 426 & 1990 & 70 & 22 & 14.5 & 2 a 3 & NR \\
\hline 16 & 452154 & 7551354 & Res. Anita Ti & 480 & 17/07/1999 & 120 & 51 & 5.6 & 1,5 a 3 & NR \\
\hline 17 & 461897 & 7547867 & Zona Rural & 473 & NR & 150 & 33.3 & 9.05 & 1,5 a 3 & NR \\
\hline 18 & 460766 & 7557148 & $\mathrm{PqB}$ & 482 & 2002 & 81 & 34 & 4 & & NR \\
\hline 19 & 459867 & 7555662 & Jardir & 466 & $4 / 03$ & 120 & 46 & 3.6 & & NR \\
\hline 20 & 456287 & 7556168 & Maracana & 456 & 1986 & 120 & 60 & 3 & 1,5 a 3 & $R$ \\
\hline 21 & 454535 & 7552274 & Jardi & 474 & 07/1998 & 60 & 27 & 1.6 & $N R$ & JR \\
\hline 22 & 454500 & 7552305 & Jard & 436 & $05 / 1$ & 60 & 27 & 1.6 & NR & NR \\
\hline 23 & 458952 & 7551690 & Bon & 435 & $08 / 2$ & 100 & 32 & 3 & 1,5 a 3 & NR \\
\hline 24 & 456709 & 7553713 & Jardi & 412 & $08 / 07$ & 120 & 43 & 6.3 & 1 a 1,5 & NR \\
\hline 25 & 458651 & 7553852 & Vila & 415 & 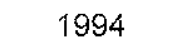 & 90 & 41 & 2.6 & & NR \\
\hline 26 & 457054 & 7554222 & Jard & 397 & 19 & 120 & 44 & 6 & & IR \\
\hline 27 & 457146 & 7554256 & Jardi & 393 & 196 & 120 & 42 & 9 & 1,5 a 3 & S \\
\hline 28 & 457237 & 7554338 & Jard & 389 & 196 & 130 & 42 & 10 & 1,5 a 3 & IS \\
\hline 29 & 456926 & 7554357 & Jard & 404 & 200 & 140 & 54 & 22 & 1,5 a 3 & NR \\
\hline 30 & 456918 & 7554410 & Jardi & 410 & 200 & 190 & 64 & 26 & 1,5 a 3 & IR \\
\hline 31 & 453084 & 7550778 & Char & 434 & 2000 & 84 & 24 & 1.8 & NR & NR \\
\hline 32 & 458680 & 7552871 & Jard & 420 & & 130 & 35 & 10.6 & $1-2,5$ & D \\
\hline 33 & 457369 & 551020 & $\mathrm{PqF}$ & 457 & 20 & 70 & 28 & 3.6 & & $R$ \\
\hline 34 & 456353 & 7550987 & $\mathrm{PqF}$ & NR & $04 / 2$ & 100 & 18 & 3.6 & 1,5 a 3,0 & D \\
\hline 35 & 455252 & 7553578 & Jardi & 480 & $16 / 0$ & 100 & 23 & 2.93 & 1,5 a 3,0 & AP \\
\hline 36 & 455252 & 7553563 & Jardim Jequitibás & 419 & $16 / 03 / 1999$ & 100 & 81.3 & 1.76 & 1,5 a 3,0 & I/S \\
\hline 37 & 458847 & 552803 & Vila Glória & 434 & $>15$ anos & 100 & 55 & 3 & NR & NR \\
\hline 38 & 415461 & 577757 & Vila & 452 & & 60 & 9 & 4.2 & 1,5 a 3,0 & s \\
\hline 39 & 462818 & 557587 & $\mathrm{Ch}$ & 42 & 200 & 120 & 44 & 3 & 1,5 a 3,0 & $\mathrm{D}$ \\
\hline 40 & 460049 & 555645 & Jard & NR & N & NR & NR & 0.15 & NR & $\mathrm{R}$ \\
\hline 41 & 462951 & 557541 & Cent & 41 & 200 & 120 & 30 & 3 & 1,5 a 3,0 & NR \\
\hline 42 & 459151 & 7552042 & Jardim & NR & 198 & 20 & 5.42 & 1.8 & & I/S \\
\hline 43 & 463835 & 7544664 & Distr Ind do Espigäo & 464 & 09/2005 & 101 & 41.5 & 6.5 & 1,5 a 3 & NR \\
\hline 44 & 462731 & 7557508 & Chácaras N. Oeste & NR & 2001 & 86 & 32 & 2 & & D \\
\hline 45 & 53684 & 7550651 & Conj Ma & 390 & $09 / 2005$ & 100 & 36 & 6 & 1,5 a 3 & NR \\
\hline 47 & 5547 & 553608 & Cent & $N R$ & 1987 & 100 & 26 & 5 & 1,5 a 3 & D \\
\hline 48 & 0603 & 553922 & & 463 & 23/01/1999 & 60 & 36 & 3.6 & & D \\
\hline 49 & 58889 & 7553968 & Vila Santa Hele & 463 & 1985 & 132 & 62 & 4.5 & 1,5 a 3 & 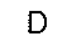 \\
\hline 50 & 459600 & 7552534 & Centro & 455 & 1972 & 150 & 48 & 5 & 1,5 a 3 & D \\
\hline 51 & 456655 & 7548580 & Quinta das Flores & NR & $01 / 2004$ & 120 & 80 & 2.5 & 1,5 & D \\
\hline
\end{tabular}

Contianuação... 


\begin{tabular}{|c|c|c|c|c|c|c|c|c|c|c|}
\hline \multirow[t]{2}{*}{ Poço } & \multicolumn{3}{|c|}{ Localização } & \multirow{2}{*}{$\begin{array}{l}\text { Cota } \\
(\mathrm{m})\end{array}$} & \multirow{2}{*}{$\begin{array}{l}\text { Data } \\
\text { Perf. }\end{array}$} & \multirow{2}{*}{$\begin{array}{l}\text { Prof. } \\
\text { (m) }\end{array}$} & \multirow{2}{*}{$\begin{array}{l}\text { NE } \\
\text { (m) }\end{array}$} & \multirow{2}{*}{$\begin{array}{c}Q \\
\mathrm{~m}^{3} / \mathrm{h}\end{array}$} & \multirow{2}{*}{$\begin{array}{l}\text { P.Filtro } \\
\text { (m) }\end{array}$} & \multirow[t]{2}{*}{ Uso } \\
\hline & UTME & UTMN & Bairro & & & & & & & \\
\hline 52 & 462261 & 7555623 & Rural & 434 & +20 anos & 150 & 24 & 14.5 & NR & $1 / S$ \\
\hline 53 & 457071 & 7554584 & Frigorificos & 420 & NR & 150 & NR & 18 & 1 a 3 & $1 / S$ \\
\hline 54 & 457021 & 7554739 & Frigorificos & 420 & NR & NR & NR & 27 & 1 a 3 & I/S \\
\hline 55 & 457100 & 7554180 & NR & 355 & NR & 180 & 79.5 & 33 & 1 a 3 & US \\
\hline 56 & 462514 & 7557636 & Chácaras N.Oeste & 403 & 2003 & 140 & 44 & 3 & 1,5 a 3 & $D$ \\
\hline 57 & 462865 & 7557478 & Chácaras N.Oeste & 422 & 2001 & 120 & 60 & 4 & NR & $\mathrm{D}$ \\
\hline 58 & 456250 & 7546165 & Zona Rural & 430 & NR & 100 & 21 & 4.8 & NR & $\mathrm{D}$ \\
\hline 59 & 456250 & 7546165 & Aeroporto & 430 & NR & 100 & 32.2 & 2,76 & 1,5 a 3 & $S$ \\
\hline 60 & 461433 & 7547935 & Zona Rural & 449 & $\sim 1980$ & 80 & 33.3 & 7 & 1,5 a 3 & NR \\
\hline 61 & 454690 & 7554009 & Jardim Jequitibás & $N R$ & NR & 150 & 42 & 15 & 1,5 a 3 & $\mathrm{D}$ \\
\hline 62 & 458902 & 7551686 & Jardim Bongiovani & 486 & $06 / 1996$ & 100 & 44.4 & 5 & 1,5 a 3 & $D$ \\
\hline 63 & 458959 & 7551718 & Jardim Bongiovani & $\mathrm{NR}$ & $06 / 12 / 1991$ & 120 & 60 & 8 & 1,5 a 3 & $D$ \\
\hline 64 & 459500 & 7552164 & Vila Foglia & 459 & 1993 & 120 & 20 & 4.58 & 1,5 a 3 & $\mathrm{D}$ \\
\hline 65 & 459400 & 7552332 & Vila Foglia & 449 & NR & 120 & 32 & 8 & 1,5 a 3 & $\mathrm{D}$ \\
\hline 66 & 460273 & 7553630 & Centro & NR & NR & 80 & 24 & 5.7 & NR & $S$ \\
\hline 67 & 460508 & 7554638 & Jardim Aviação & 449 & 05/06/1989 & 153 & 36.7 & 7.2 & 1,5 a 3 & $\mathrm{D}$ \\
\hline 68 & 459088 & 7551672 & Jardim Biongiovani & 447 & $\sim 1988$ & 116 & 33.3 & 6 & 1,5 a 3 & $D$ \\
\hline 69 & 457222 & 7551355 & Parque Res. Damhal & NR & 2004 & 80 & 28 & 3 & 1,5 a 3 & $\mathrm{D}$ \\
\hline 70 & 465948 & 7555149 & Aeroporto & NR & $08 / 2001$ & 100 & 50 & 2 & 1,5 a 3 & $D$ \\
\hline 71 & 459725 & 7552515 & Jardim Paulistano & 465 & 1982 & 120 & NR & 6 & 1,5 a 3 & $D$ \\
\hline 72 & 459633 & 7550280 & BRO Memória & 487 & $02 / 2005$ & 120 & 36 & 4 & 1,5 a 3 & NR \\
\hline 73 & 457340 & 7551120 & Parque Res. Dahma I & 450 & $03 / 2005$ & 120 & 60 & 5 & 1,5 a 3 & NR \\
\hline 74 & 461603 & 7549338 & Distrito Industrial & 453 & $\sim 1994$ & 80 & 34 & 4 & 1,5 a 3 & 1 \\
\hline 75 & 457181 & 7551360 & Parque Res. Damha I & 449 & $10 / 2005$ & 100 & 13 & 2.7 & NR & D \\
\hline 76 & 457343 & 7552049 & Jardim São Luiz & 414 & 1988 & 100 & 36 & 5 & 1,5 a 3 & $\mathrm{D}$ \\
\hline 77 & 460936 & 7568814 & Timburi & 460 & $16 / 08 / 2001$ & 110 & 30 & 3.5 & NR & $\mathrm{CA}$ \\
\hline 78 & 462726 & 7557902 & Chácara Novo Oeste & NR & $\mathrm{NR}$ & 115 & NR & NR & NR & D \\
\hline 79 & 457043 & 7551070 & Parque Res. Damha I & 449 & $09 / 2005$ & 100 & 11 & 2.8 & NR & $D$ \\
\hline 80 & 459351 & 7550867 & Vila Formosa & 471 & $08 / 2000$ & 60 & 33 & 3.6 & 1,5 a 3 & $D$ \\
\hline 81 & 456886 & 7551158 & Parque Res. Damha I & 445 & $11 / 2005$ & 100 & 16 & 2.9 & NR & $\mathrm{D}$ \\
\hline 82 & 455385 & 7552578 & Jardim Itaipu & 410 & $+30 a$ & 80 & 30 & 3.6 & NR & NR \\
\hline 83 & 456322 & 7550736 & Parque Res. Damha & 433 & $07 / 06 / 2000$ & 80 & 12 & 0.9 & NR & $\mathrm{D}$ \\
\hline 84 & 457046 & 7555006 & Jardim Maracanã & 423 & $<1970$ & 120 & 38 & 10 & 1,5 a 3 & I/S \\
\hline 85 & 457046 & 7555006 & Jardim Maracanã & 423 & $\sim 1992$ & 150 & 52 & 28 & 1,5 a 3 & I/S \\
\hline 86 & 460521 & 7553161 & Vila Nova & 489 & NR & 100 & 55 & 3.6 & 1,5 a 3 & NR \\
\hline 87 & 456308 & 7553395 & JardimMonte Alto & 397 & NR & 100 & 28 & 3 & 1,5 a 3 & NR \\
\hline 88 & 456054 & 7553294 & Jardim Monte Alto & 400 & NR & 150 & 87.1 & 4.8 & 1,5 a 3 & NR \\
\hline 89 & 458200 & 7553056 & Jardim João Paulo ll & 425 & $06 / 2002$ & 110 & 41 & 1.6 & 1,5 a 3 & $\mathrm{D}$ \\
\hline 90 & 457350 & 7553000 & JardimCinquentenário & NR & NR & 90 & 28 & 3 & $\mathrm{NR}$ & NR \\
\hline 91 & 457298 & 7553351 & Jardim Icaray & 424 & NR & 125 & NR & 10 & 1 a 3 & I/S \\
\hline 92 & 459870 & 7555286 & Jardim Aviação & NR & 1975 & 110 & 29 & 4 & 1,5 a 3 & $D$ \\
\hline 93 & 460058 & 7552500 & Vila SãoJorge Centro & 465 & 2000 & 150 & 107 & 2.6 & 1,5 a 3 & NR \\
\hline 94 & 457903 & 7551467 & Jd Alto da Boa Vista & 470 & $15 / 06 / 2000$ & 80 & 6 & 3.8 & 1,5 a 3 & $\mathrm{D}$ \\
\hline 95 & 460260 & 7552780 & Jd Quincentenario & 465 & $\sim 2002$ & 60 & 36.7 & 0.62 & NR & NR \\
\hline 96 & 453503 & 7551557 & Dist ind Ana Jacinta & 437 & $08 / 2006$ & 60 & 35 & 3.6 & 1,5 a 3 & $1 / S$ \\
\hline 97 & 456023 & 7556109 & Esquema & 473 & $22 / 06 / 1991$ & 262 & 82 & 4.83 & 1,5 a 3 & I \\
\hline 98 & 459701 & 7551369 & Jardim Bongiovani & NR & $10 / 09 / 1998$ & 100 & 36 & 3 & 1,5 a 3 & $\mathrm{D}$ \\
\hline 100 & 460184 & 7551851 & Vila Industrial & NR & +10 anos & 80 & 22 & 8 & NR & $S$ \\
\hline 101 & 457768 & 7556835 & Bosque & 284 & NR & 90 & 28 & 5.6 & 1,5 a 3 & $\mathrm{D}$ \\
\hline 102 & 456498 & 7551129 & Parque Res. Damha & 420 & $09 / 04 / 2000$ & 63 & 15 & 3.5 & NR & $D$ \\
\hline 103 & 456771 & 7555182 & Jardim Maracanã & 435 & 2001 & 80 & 20 & 5 & NR & NR \\
\hline 104 & 459725 & 7549825 & Vila Nova Prudente & 487 & $02 / 2005$ & 180 & 80 & 14.8 & 1,5 a 3 & 1 \\
\hline 105 & 459750 & 7549850 & Vila Nova Prudente & 440 & $02 / 1997$ & 200 & 81.6 & 10.8 & 1,5 a 3 & 1 \\
\hline 106 & 452876 & 7553694 & Zona Rural & 449 & $02 / 1982$ & 140 & 40 & 8 & 1,5 a 3 & 1 \\
\hline
\end{tabular}


Contianuação...

\begin{tabular}{|c|c|c|c|c|c|c|c|c|c|c|}
\hline Doço & UTME & $\begin{array}{l}\text { Loc } \\
\text { UTMN }\end{array}$ & $\begin{array}{r}\text { alização } \\
\text { Bairro } \\
\end{array}$ & $\begin{array}{l}\text { Cota } \\
\text { (m) }\end{array}$ & Data Perf. & $\begin{array}{l}\text { Prof. } \\
\text { (m) }\end{array}$ & $\begin{array}{l}\text { NE } \\
(\mathrm{m})\end{array}$ & $m^{3} / h$ & $\begin{array}{l}\text { P.Filtro } \\
(\mathrm{m})\end{array}$ & Uso \\
\hline 107 & 452840 & 7553670 & Zona Rural & 422 & $02 / 1998$ & 220 & 83.5 & 30.2 & 1,5 a 3 & 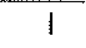 \\
\hline 108 & 462449 & 7557346 & Chácaras N.Oeste & 399 & 01/1996 & 80 & 44 & 1.7 & NR & 8 \\
\hline 109 & 456613 & 7551067 & Cond Res Damha I & 449 & $08 / 2000$ & 48 & 18 & 1.6 & 1,5 a 3 & R \\
\hline 110 & 459820 & 7549819 & Trevo Rodoviário & 450 & $04 / 2000$ & 100 & 20 & 7.2 & 1,5 a 3 & \\
\hline 111 & 457223 & 7551319 & Residencial Damha I & 461 & NR & 100 & 44 & 2.8 & 1,5 a 3 & NR \\
\hline 112 & 462820 & 7557620 & Chácaras N. Oeste & NR & 2001 & 100 & 44 & 3.1 & 1,5 a 3 & \\
\hline 113 & 460064 & 7550287 & Vila Nova Prudente & NR & 1997 & 120 & 40 & 3.5 & 1,5 a 3 & $N R$ \\
\hline 114 & 459114 & 7551877 & Jardim Bongiovani & 440 & 02/09/1993 & 100 & NR & 8 & NR & $\mathrm{D}$ \\
\hline 115 & 458093 & 7551206 & Vila Formosa & 440 & 1981 & 110 & NR & 8 & NR & D \\
\hline 116 & 458094 & 7551293 & Vila Formosa & 440 & 10/10/1994 & 50 & NR & 4 & NR & D \\
\hline 117 & 457497 & 7552084 & Jardim São Luiz & 476 & NR & 160 & 72 & 5 & 1 a 3 & \\
\hline 118 & 459638 & 7551843 & Vila Industrial & 461 & $08 / 1975$ & 70 & 33.6 & 1.44 & 1,5 a 3 & D \\
\hline 119 & 454788 & 7553820 & PQ. Res. Servantes 2 & NR & $06 / 2$ & 100 & 44 & 5 & 1,5 a 3 & D \\
\hline 120 & 454750 & 7557432 & Limoeiro & 432 & 05/1996 & 40 & 21 & 3 & 1,5 a 3 & IRR \\
\hline 121 & 460700 & 7548880 & Distrito Industrial & 420 & 2001 & 120 & 60 & 4.5 & $N R$ & I \\
\hline 122 & 454535 & 7552274 & Jardim Itaipu & 474 & 07/1998 & 60 & 27 & 1.6 & NKK & NR \\
\hline 123 & 454500 & 7552305 & Jardim Itaipu & 436 & $05 /$ & 60 & 27 & 1.6 & NR & NR \\
\hline 124 & 457238 & 7554075 & Centro & 398 & $10 /$ & 72 & 12 & 3.6 & 1,5 a 3 & NR \\
\hline 125 & 457481 & 7554620 & Jardim Eldorado & NR & $08 / 2$ & 144 & 45 & 3 & 1,5 a 3 & NR \\
\hline 126 & 459247 & 7553699 & Vila Santa Helena & 445 & 06 & 60 & 30 & 2.6 & NR & D \\
\hline 127 & 461101 & 7552402 & Jardim São Pedro & 415 & $07 / 1998$ & 50 & 24 & 2.1 & $N$ & NR \\
\hline 128 & 458945 & 7553812 & Vila & 435 & $04 / 08 / 2004$ & 80 & 39 & 4.8 & 1,5 a 2 & NR \\
\hline 129 & 458777 & 7551140 & Vila I & 456 & 1997 & 60 & 14 & 7.3 & 1,5 a 3 & D \\
\hline 130 & 458535 & 7551070 & Vila Formo & 453 & NR & 80 & 27 & 5 & NR & NR \\
\hline 131 & 455915 & 7552735 & Parc & 436 & $05 / 2$ & 110 & 36.7 & 1.96 & 1,5 a 3 & 1 \\
\hline 132 & 461622 & 7549139 & Distrit & 432 & $05 / 1$ & 115 & 38 & 3 & & 1 \\
\hline 133 & 463704 & 7547883 & Zone & 409 & $06 / 2$ & 80 & 22 & 3.22 & & D \\
\hline 134 & 457990 & 7554990 & Jardim & 395 & 05/07/1988 & 150 & 45 & 17.5 & t a 1,5 & NR \\
\hline 135 & 458862 & 7548824 & Recantc & 400 & NR & 60 & 6 & 9 & NR & D \\
\hline 136 & 462970 & 7557688 & Chác & 418 & 2001 & 100 & 41 & 2.9 & 1,5 a 3 & D \\
\hline 137 & 453462 & 7551465 & Con & 439 & $\mathrm{NF}$ & 110 & 42.3 & 1.7 & 1,5 a 3 & NR \\
\hline 138 & 460380 & 7553546 & Cen & 456 & $\mathrm{~N}$ & 80 & 37.1 & 1.2 & 1,5 a 3 & NR \\
\hline 139 & 456103 & 7553063 & Jardir & 426 & $04 /$ & 56 & 30 & 2.6 & NR & NR \\
\hline 140 & 459413 & 7551113 & Vila F & NR & 198 & 100 & 46 & 3 & 1,5 a 3 & NR \\
\hline 141 & 457142 & 7551436 & Parque Res $D$ & 452 & $10 / 2005$ & 100 & 17 & 2.6 & NR & $D$ \\
\hline 142 & 461242 & 7554280 & Vila Furquim & NR & 1988 & 70 & 35 & 3 & 1,5 a 3 & D \\
\hline 143 & 458057 & 553059 & Jardim Esplar & 452 & $19 / 03 / 1966$ & 120 & 68 & 3 & 1,5 a 3 & D \\
\hline 144 & 457827 & 554187 & Centro & 426 & 1989 & 117 & 65.9 & 3 & 1 a 2 & NR \\
\hline 145 & 457260 & 7553870 & Jardim c & 403 & $N R$ & 195 & 65 & 22 & 1,5 a 2,5 & $\mathrm{R}$ \\
\hline 146 & 461690 & 7554564 & Parque & 428 & $20 / 11 /$ & 250 & 111 & 15 & 1,5 a 3 & NR \\
\hline 147 & 455833 & 7556180 & Parque & 447 & $18 / 12 / 1$ & 102 & 60 & 12 & NR & IRR \\
\hline 148 & 464617 & 7550244 & Terras de Imoplan & 448 & $>4$ anos & 60 & 25 & 4.5 & NR & NR \\
\hline 149 & 462887 & 7557706 & Chácaras N.Oeste & 420 & $N R$ & 100 & 45 & 2 & NR & $D$ \\
\hline 150 & 458720 & 7548077 & Aeropo & 460 & int 1985 & 144 & 63 & 3 & 1,5 a 3 & 1 \\
\hline 151 & 456443 & 7556176 & Marace & 443 & 1985 & 130 & 65 & 3.67 & 1,5 a 3 & D \\
\hline 152 & 456289 & 7556172 & Marace & 456 & 1979 & 120 & 50 & 6 & 1,5 a 3 & NR \\
\hline 153 & 462589 & 7558719 & Sede & 444 & NR & 218 & 51 & 11.9 & NR & $\mathrm{AP}$ \\
\hline 154 & 454400 & 7561100 & NR & 480 & $13 / 03 / 1986$ & 201 & 87.9 & 22 & NR & $A P$ \\
\hline 155 & 454150 & 7555400 & NR & 400 & 18/05/1986 & NR & 50.1 & 20 & 1 a 2 & AP \\
\hline 156 & 454670 & 7556820 & Sede & 400 & NR & 229 & 68.5 & 50 & NR & $A P$ \\
\hline 157 & 454563 & 7553135 & Sede & 404 & 23/01/1992 & 214 & 74 & 60 & NR & $A P$ \\
\hline 158 & 454550 & 7553100 & & 420 & $30 / 01 / 1992$ & 241 & 60 & 30.5 & NR & AP \\
\hline 159 & 455184 & & Sao J & 430 & 18/12/1992 & 272 & 87.4 & 43 & NR & $A P$ \\
\hline 60 & 1300 & 55950 & Sede & 400 & NR & 206 & 64.2 & 8 & NR & AP \\
\hline
\end{tabular}


Conclusão....

\begin{tabular}{|c|c|c|c|c|c|c|c|c|c|c|}
\hline Poço & UTME & $\begin{array}{l}\text { Loca } \\
\text { UTMN }\end{array}$ & $\begin{array}{r}\text { alização } \\
\text { Bairro }\end{array}$ & $\begin{array}{c}\text { Cota } \\
\text { (m) }\end{array}$ & Data Perf. & $\begin{array}{l}\text { Prof. } \\
(\mathrm{m})\end{array}$ & $\begin{array}{l}N E \\
(m)\end{array}$ & $\begin{array}{c}Q \\
m^{3} / h\end{array}$ & $\begin{array}{l}\text { P.Filtro } \\
\text { (m) }\end{array}$ & $\boldsymbol{j} \mathbf{s}$ \\
\hline 161 & 460900 & 7555950 & NR & 400 & 15/12/1992 & 207 & 75.7 & 46.6 & $1 \mathrm{a} 2$ & NR \\
\hline 162 & 455350 & 7551500 & NR & 440 & 11/03/1993 & 244 & 72 & 38.6 & 1 a 2 & NR \\
\hline 163 & 459900 & 7556800 & NR & 430 & 18/11/1992 & 230 & 90.2 & 42 & 1 a 2 & NR \\
\hline 164 & 459700 & 7557500 & NR & 400 & 24/11/1992 & 199 & 62 & 56.5 & 1 a 2 & $N R$ \\
\hline 165 & 460123 & 7553715 & Centro & NR & 1986 & 130 & 48 & 8 & 1,5 a 3 & D \\
\hline 166 & 460142 & 7553747 & Centro & 451 & $05 / 2008$ & 150 & 50.1 & 5.6 & 1,5 a 3 & NR \\
\hline 167 & 458087 & 7552452 & Bongiovani & NR & NR & 180 & NR & 28 & 1 a 3 & NR \\
\hline 168 & 457933 & 7552356 & Bongiovani & NR & NR & 210 & NR & 30 & 1 a 3 & NR \\
\hline 169 & 459012 & 7552079 & Jardim Bongiovani & 438 & $>10$ anos & 90 & 28 & 2.5 & $N R$ & NR \\
\hline 170 & 456375 & 7551900 & Jardim Santa Fé & 460 & 1996 & 60 & 27 & 1.6 & 1 a 3 & I/S \\
\hline 171 & 461081 & 7554069 & Vila Furquim & 487 & 1994 & 80 & 34 & 4 & 1,5 a 3 & NR \\
\hline 172 & 459959 & 7552487 & Vila São Jorge & 454 & 08/1986 & 60 & 8 & 1.53 & 1,5 a 3 & JR \\
\hline 173 & 457935 & 7551545 & Jardim Cambuy & 443 & 06/01/1998 & 60 & 30 & 3 & 1 a 1,5 & NR \\
\hline 174 & 464295 & 7549104 & Distrito Industrial & 346 & $05 / 1983$ & 160 & 46 & 9.5 & 1,5 a 3 & NR \\
\hline 175 & 460785 & 7553574 & Vila Marcondes & 460 & NR & 120 & 30 & 10 & NR & 1/S \\
\hline 176 & 459351 & 7550867 & Cidade Universitária & 471 & 08/2006 & 60 & 35 & 3.6 & 1,5 a 3 & NR \\
\hline 177 & 460078 & 7551065 & Jardim Santa Helena & $\mathrm{NR}$ & 1975 & 130 & 40 & 5 & 2 a 3 & D \\
\hline 178 & 459038 & 7555287 & Pq. São Judas Tadeu & 440 & $15 / 03 / 1986$ & 141 & NR & 5 & 1,5 a 3 & D \\
\hline 179 & 459985 & 7553860 & Centro & & 1990 & 100 & 24 & 11 & 1,5 a 3 & D \\
\hline 180 & 465063 & 7556648 & Sete Copas & 360 & 1995 & 80 & NR & 6 & NR & 1 \\
\hline 181 & 464944 & 7556277 & Sete Copas & 390 & 2002 & 120 & NR & 6 & NR & 1 \\
\hline 182 & 457014 & 7552036 & Jardim Satélite & 451 & $N R$ & 164 & 85 & 10 & 1 a 3 & $\mathrm{R}$ \\
\hline 183 & 459194 & 7548155 & Bairro & $N R$ & 1975 & 160 & 85 & 8 & 1 a 3 & D \\
\hline 184 & 458967 & 7551956 & Jardim Bongiovani & 458 & NR & 60 & 15 & 3 & $N R$ & 1 \\
\hline 185 & 459760 & 7553638 & Vila Ocidental & 449 & 1984 & 120 & 36 & 4 & $\cdot 1$ a 3 & D \\
\hline 186 & 460714 & 7553130 & Vila Marc & 500 & 05/05/1995 & 119 & 50 & 10.7 & 2,5 a 3 & AP \\
\hline 187 & 459735 & 7550942 & Vila Industrial & 466 & NR & 108 & NR & 5.1 & NR & D \\
\hline 188 & 460698 & 7553342 & Vila Marcondes & $\mathrm{NR}$ & NR & 24 & 20 & 1 & NR & D \\
\hline 189 & 458308 & 7553540 & Jardim Marupiara & 419 & 1987 & 30 & & 0.43 & NR & D \\
\hline 190 & 458284 & 7553646 & Jardim Marupiara & 451 & $11 / 2005$ & 110 & 18 & 2.5 & 1,5 a 3 & D \\
\hline 191 & 459847 & 7550178 & Aeroporto & 460 & 1985 & 144 & 63 & 3 & 1,5 a 3 & 1 \\
\hline 192 & 460162 & 7552354 & Vila Brasil & 455 & 1994 & 80 & 36 & 4.8 & NR & D \\
\hline 193 & 455999 & 7556213 & Jd Novo Bongiovani & 449 & $02 / 05 / 1996$ & 86 & 50 & 4.8 & 1,5 a 3 & D \\
\hline 194 & 457182 & 7554075 & Jardim c & $N R$ & $02 / 1$ & 60 & 11 & 3 & NR & \\
\hline 195 & 472921 & 7581855 & Amelióp & 372 & $08 / 1995$ & 172 & 25 & 11 & 1,5 a 3 & I/S \\
\hline 196 & 460187 & 7551932 & Vila Industrial & NR & 1986 & 152 & 70 & 15 & 1,5 a 3 & D \\
\hline 197 & 456715 & 7553922 & NR & NR & NR & 180 & 63 & 18 & 1 a 3 & 1 \\
\hline 198 & 456601 & 7553740 & NR & NR & $\mathrm{NF}$ & 190 & $N R$ & 18 & 1 a 3 & 1 \\
\hline 199 & 450223 & 7547539 & Jardir & NR & NR & 250 & 41 & 27 & 1,5 a 3 & 1 \\
\hline 200 & 460074 & 7556195 & Jabaquara & 472 & 1989 & 68 & 26 & 1.8 & NR & D \\
\hline 201 & 455953 & 7555964 & Esquema & 466 & $02 / 12 / 1987$ & 242 & 112 & 5.63 & 1,5 a 3,0 & 1 \\
\hline 202 & 458035 & 7551199 & Vila Formose & 463 & 1981 & 110 & 35 & 8 & NR & $N R$ \\
\hline 203 & 473103 & 7581779 & Ameliópolis & 382 & $12 / 2003$ & 170 & 28 & 20 & 1,5 a 3,0 & I/S \\
\hline 204 & 452741 & 7554796 & Limoeiro & 407 & 123 & NR & NR & NR & NR & NR \\
\hline 205 & 456737 & 7547393 & Aeroporto & NR & NR & 45 & NR & NR & NR & $N R$ \\
\hline 206 & 453090 & 7554819 & Limoeiro & $\mathrm{NR}$ & NR & 123 & NR & NR & NR & NR \\
\hline 207 & 458456 & 7552431 & Bongic & NR & NR & 160 & NR & NR & NR & $\mathrm{NR}$ \\
\hline 208 & 458476 & 7552327 & Bongiov & NR & $N R$ & 150 & NR & NR & NR & NR \\
\hline 209 & 449714 & 7556649 & Zona rural & NR & NR & 170 & NR & NR & NR & $N R$ \\
\hline 210 & 449041 & 7557699 & Zona rural & $N R$ & NR & 80 & NR & NR & NR & $N R$ \\
\hline 211 & 453723 & 7553829 & Limoeiro & NR & $23 / 10 / 1995$ & 261 & NR & $N R$ & NR & NR \\
\hline 212 & 453884 & 7554008 & Limoeiro & $N R$ & NR & 120 & NR & NR & NR & NR \\
\hline
\end{tabular}


ANEXO II Parâmetros Hidrogeológicos 
Parâmetros Hidrogeológicos

\begin{tabular}{cccccccc}
\hline $\begin{array}{c}\text { Poços } \\
\text { rasos }\end{array}$ & $\begin{array}{c}\text { NE } \\
(\mathbf{m})\end{array}$ & $\begin{array}{c}\mathbf{b} \\
(\mathbf{m})\end{array}$ & $\begin{array}{c}\mathbf{s} \\
(\mathbf{m})\end{array}$ & $\begin{array}{c}\mathbf{q} \\
(\mathbf{l} / \mathbf{s} / \mathbf{m})\end{array}$ & $\mathbf{A}$ & $\begin{array}{c}\mathbf{T} \\
\left(\mathbf{m}^{2} / \mathrm{dia}\right)\end{array}$ & $\begin{array}{c}\mathrm{K} \\
(\mathbf{m} / \mathrm{dia})\end{array}$ \\
\hline 9 & 30 & 60 & 21 & 0,48 & 81 & 43,85 & 0,46 \\
176 & 35 & 60 & 13 & 1,00 & 83 & 89,12 & 0,94 \\
118 & 33,62 & 70 & 13 & 0,69 & 83 & 61,79 & 0,65 \\
142 & 35 & 70 & 14 & 0,76 & 83 & 67,99 & 0,72 \\
14 & 29 & 78 & 28 & 0,77 & 83 & 75,60 & 0,80 \\
60 & 33,27 & 80 & 18,7 & 1,33 & 85 & 126,22 & 1,33 \\
138 & 37,12 & 80 & 20,99 & 0,21 & 80 & 18,56 & 0,20 \\
169 & 28 & 90 & 11 & 0,98 & 81 & 84,43 & 0,89 \\
87 & 28 & 100 & 49 & 0,22 & 80 & 24,06 & 0,25 \\
35 & 81,3 & 80 & 11 & 0,58 & 82 & 50,28 & 0,53 \\
86 & 55 & 100 & 13 & 0,99 & 83 & 88,83 & 0,94 \\
98 & 36 & 60 & 28 & 0,39 & 81 & 36,89 & 0,39 \\
119 & 44 & 80 & 25 & 0,72 & 82 & 68,47 & 0,72 \\
76 & 36 & 100 & 11,94 & 0,83 & 83 & 73,56 & 0,78 \\
6 & 36 & 110 & 37 & 0,58 & 82 & 60,06 & 0,63 \\
131 & 36,65 & 80 & 56,75 & 0,11 & 80 & 12,57 & 0,13 \\
137 & 42,31 & 110 & 38,37 & 0,16 & 80 & 16,07 & 0,17 \\
144 & 65,92 & 116,5 & 23,93 & 0,45 & 81 & 42,12 & 0,45 \\
20 & 60 & 120 & 15 & 1,73 & 86 & 161,99 & 1,71 \\
65 & 32 & 120 & 34 & 0,85 & 83 & 86,39 & 0,91 \\
51 & 80 & 120 & 28 & 0,47 & 81 & 44,82 & 0,47 \\
7 & 28 & 104 & 85 & 0,21 & 80 & 31,08 & 0,33 \\
49 & 62 & 132 & 60 & 0,27 & 80 & 32,26 & 0,34 \\
61 & 42 & 150 & 66 & 0,82 & 83 & 106,55 & 1,13 \\
\hline Min. & 28,00 & 60,00 & 11,00 & 0,11 & 80,00 & 12,57 & 0,13 \\
Máx. & 81,30 & 150,00 & 85,00 & 1,73 & 86,00 & 161,99 & 1,71 \\
Média & 42,76 & 94,60 & 30,07 & 0,65 & 81,92 & 62,65 & 0,66 \\
D.P. & 15,95 & 24,40 & 19,99 & 0,39 & 1,64 & 36,45 & 0,39 \\
\hline & & & & & & & \\
\hline
\end{tabular}

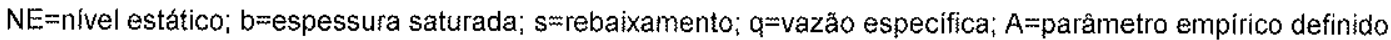
experimenta!mente em função da vazão especifica; $T=$ transmissividade; $K=$ condutividade hidráulica.

Mín.=minimo; Máx =máximo; $D P=$ desviação padrão 
ANEXO III Poços Amostrados 


\begin{tabular}{|c|c|c|c|c|c|c|c|c|c|c|}
\hline Poço & Amostra & Endereço & Bairro & Zona & $\begin{array}{c}\text { Data } \\
\text { análise }\end{array}$ & $x$ & $Y$ & $\begin{array}{c}\text { Cota } \\
(\mathrm{m})\end{array}$ & $\begin{array}{l}\text { Prof. } \\
(\mathrm{m})\end{array}$ & Uso \\
\hline 96 & 96 & Rua Vicente Mele, 771 & Dist ind Ana Jacinta & Sudoeste & $23 / 12 / 2009$ & 453503 & 7551557 & 437 & 60 & $1 / S$ \\
\hline *176 & 176 & Avenida da Saudade, 1.215 & Cidade Universitária & Centro & $01 / 07 / 2010$ & 458345 & 7552240 & 490 & 60 & NR \\
\hline 200 & 200 & Rua Alvino Gomes Teixeira, 2749 & Parque Jabaquara & Nordeste & $23 /\{2 / 2009$ & 460074 & 7556195 & 472 & 68 & D \\
\hline *118 & 118 & Rua Nações Unidas, 395 & Vila Industrial & Centro & $23 / 12 / 2009$ & 459638 & 7551843 & 461 & 70 & D \\
\hline 14 & 14 & Rod. Raimundo Maisolini, s/n $\mathrm{n}^{\circ} \mathrm{km} 03$ & Pq Castelo Branco & Nordeste & $23 / 12 / 2009$ & 460370 & 7557168 & 528 & 78 & $\mathrm{R}$ \\
\hline 35 & 35 & Av Jucelino K. de Oliveira, 105 -Rod. Rap Tav km570 & Jardim Jequitibás & Oeste & 23/12/2009 & 455252 & 7553578 & 480 & 100 & AP \\
\hline 62 & 62 & Rua Manoel Espinhosa, 195 & Jardim Bongiovani & Centro & $23 / 12 / 2009$ & 458902 & 7551686 & 486 & 100 & $\mathrm{D}$ \\
\hline $86 d$ & 86 & Rua Doutor José Foz, 613 & Vila Nova & Centro & $23 / 12 / 2009$ & 460521 & 7553161 & 489 & 100 & NR \\
\hline 87 & 87 & Rua Joaquim Pereira Paixão, 207 & JardimMonte Alto & Oeste & $23 / 12 / 2009$ & 456308 & 7553395 & 397 & 100 & NR \\
\hline $110 d$ & 110 & Rod. Assis Chateaubriand, S/N, KM 455.1 & Trevo Rodoviário & Centro & $23 / 12 / 2009$ & 459820 & 7549819 & 450 & 100 & 1 \\
\hline $\begin{array}{l}147 \\
187\end{array}$ & $\begin{array}{l}147 \\
187\end{array}$ & $\begin{array}{l}\text { Rod. Arthur Bolgues Filho, } 585 \\
\text { Rua Campestre, } 500\end{array}$ & $\begin{array}{l}\text { Parque Res. Carandá } \\
\text { Vila Industrial }\end{array}$ & $\begin{array}{l}\text { Oeste } \\
\text { Centro }\end{array}$ & $\begin{array}{l}23 / 12 / 2009 \\
23 / 12 / 2009\end{array}$ & $\begin{array}{l}455833 \\
459735\end{array}$ & $\begin{array}{l}7556180 \\
7550942\end{array}$ & $\begin{array}{l}447 \\
466\end{array}$ & $\begin{array}{l}102 \\
108\end{array}$ & $\underset{D}{\mathrm{IRR}}$ \\
\hline $6 t$ & 6 & R Siqueira Campos, 1545 & Vila São Jorge & Centro & $23 / 12 / 2009$ & 459826 & 7552512 & 475 & 110 & NR \\
\hline 144 & 144 & Av. Manoel Goulart, 2.881 & Centro & Oeste & $23 / 12 / 2009$ & 457827 & 7554187 & 426 & 116.5 & NR \\
\hline $175 \mathrm{dt}$ & $175 / 0$ & Rua Marechal Floriano Peixoto, $420 / 478$ & Vila Marcondes & Oeste & 23/12/2009 & 460785 & 7553574 & 460 & 120 & iS \\
\hline $175 \mathrm{rt}$ & $175 / 0$ & Rua Marechal Floriano Peixoto, $420 / 478$ & Vila Marcondes & Oeste & $23 / 12 / 2009$ & 460785 & 7553574 & 460 & 120 & I/S \\
\hline+20 & $20-2 c$ & Av. Salim Farah Maluf, 2370 & Maracaná & Oeste & $01 / 07 / 2010$ & 456309 & 7556126 & 453 & 120 & NR \\
\hline 7 & 7 & $R$ José Bongiovani, 1595 & NR & Oeste & 23/12/2009 & 457813 & 7552662 & 450 & 124 & NR \\
\hline 49 & 49 & Rua Rui Barbosa, 1.736 & Vila Santa Helena & Oeste & 23/12/2009 & 458889 & 7553968 & 463 & 132 & $D$ \\
\hline 84 & 84 & Av. Salim Farah Maluf, 780 & Jardim Maracanã & Oeste & $23 / 12 / 2009$ & 457046 & 7555006 & 423 & 150 & I/S \\
\hline 85 & 85 & Av. Salim Farah Maluf, 780 & Jardim Maracanä & Oeste & $30 / 06 / 2010$ & 457246 & 7555283 & 404 & 150 & $1 / S$ \\
\hline 12 & 12 & Av Vereador Aurelino Alves Coutinho, 2.400 & Pq Res. Damha I & Sudoeste & $23 / 12 / 2009$ & 457466 & 7551329 & 461 & 200 & NR \\
\hline 153 & 153 & Bairro Quilômetro Sete & Sede & Nordeste & $23 / 12 / 2009$ & 462589 & 7558719 & 444 & 217.5 & AP \\
\hline 157 & 157 & Margem direita do afluentedireito Córrego Limoeiro & Sede & Oeste & $23 / 12 / 2009$ & 454563 & 7553135 & 404 & 241 & $\mathrm{AP}$ \\
\hline $146 t$ & 146 & Avenida Ibraim Nobre, 585 & Parque Furquim & Centro & $23 / 12 / 2009$ & 461690 & 7554564 & 428 & 250 & $N R$ \\
\hline *159 & 159 & Capela São Joäo & São João & Oeste & $23 / 12 / 2009$ & 455184 & 7552583 & 430 & 272 & $A P$ \\
\hline
\end{tabular}

*Poços amostrados só na primeira campanha; +poços amostrados só na segunda campanha; d poços com duplicata; $t$ poços amostradios em diferentes tempos ( $t=0, t=6$ e $t=24$ horas); $r$ poços 
ANEXO IV. Resultados dos parâmetros físico-químicos

INSTITUTO DE GEOCIÉNCIAS - USP

- BIBLIOTECA-

TS151 
Resultados das análises efetuadas em campo nos periodos de dezembro, 20093 e junho-julho, 2010 para poços menores o iguais a $150 \mathrm{~m}$

\begin{tabular}{|c|c|c|c|c|c|c|c|c|c|c|c|c|c|c|c|}
\hline Poços & $\begin{array}{l}\text { Prof. } \\
\text { (m) }\end{array}$ & $\begin{array}{c}\mathrm{pH} \\
(2009)\end{array}$ & $\begin{array}{c}\mathrm{pH} \\
(2010)\end{array}$ & $\begin{array}{c}\mathrm{pH} \\
\text { (Média) }\end{array}$ & $\begin{array}{l}\mathrm{T}\left({ }^{\circ} \mathrm{C}\right) \\
(2009)\end{array}$ & $\begin{array}{l}\mathrm{T}\left({ }^{\circ} \mathrm{C}\right) \\
(2010)\end{array}$ & $\begin{array}{l}\mathrm{T}\left({ }^{0} \mathrm{C}\right) \\
(2009)\end{array}$ & $\begin{array}{l}\mathrm{T}\left({ }^{\circ} \mathrm{C}\right) \\
(2010)\end{array}$ & $\begin{array}{l}T\left({ }^{\circ} \mathrm{C}\right) \\
\text { (Média) }\end{array}$ & $\begin{array}{c}C E \\
(\mu \mathrm{S} / \mathrm{cm}) \\
(2009)\end{array}$ & $\begin{array}{c}\text { CE } \\
(\mu S / \mathrm{cm}) \\
(2010)\end{array}$ & $\begin{array}{c}\mathrm{CE} \\
\text { ( } \mu \mathrm{S} / \mathrm{cm}) \\
\text { (Média) }\end{array}$ & $\begin{array}{c}\text { Eh } \\
(\mathrm{mV}) \\
(2009)\end{array}$ & $\begin{array}{c}\text { Eh } \\
(\mathrm{mV}) \\
(2010)\end{array}$ & $\begin{array}{c}\text { Eh } \\
\text { (mV) } \\
\text { (Média) }\end{array}$ \\
\hline 96 & 60 & 5.82 & 5.72 & 5.77 & 25.9 & 25.7 & & 25.30 & 25.63 & 110.5 & 101.10 & 105.8 & 488.1 & 543.00 & \\
\hline 176 & 60 & 5.87 & & 5.87 & 25.00 & 27.10 & & & 26.05 & 332.00 & & 332 & 482.50 & & 482.5 \\
\hline 200 & 68 & 5.64 & 5.54 & 5.59 & 26.6 & 27.7 & 23.60 & 25.40 & 25.825 & 280 & 300.00 & 290 & 484.6 & 510.40 & 497.5 \\
\hline 118 & 70 & 5.89 & & 5.89 & 24.6 & 24.7 & & & 24.65 & 451 & & 451 & 486.4 & & 486.4 \\
\hline 14 & 78 & 6.19 & 6.12 & 6.16 & 25.3 & 25.4 & 25.00 & 24.70 & 25.1 & 381 & 348.00 & 364.5 & 394.5 & 446.50 & \\
\hline 35 & 100 & 8.14 & 7.39 & 7.76 & 25.6 & 25.5 & 27.20 & 27.90 & 26.55 & 255 & 281.00 & 268 & 408.4 & 406.50 & 407.45 \\
\hline 62 & 100 & 6.51 & 6.06 & 6.29 & 24.8 & & 25.00 & 24.40 & 24.73 & 291.3 & 198.30 & & 463 & 516.80 & \\
\hline 86 & 100 & 6.53 & 6.39 & 6.46 & 24.5 & 24.7 & 24.30 & 24.60 & 24.525 & 577 & 584.00 & 580.5 & 429.5 & 485.50 & 457.5 \\
\hline 87 & 100 & 6.8 & 7.18 & 6.99 & 25.8 & 25.9 & 24.10 & 25.60 & 25.35 & 361 & 359.00 & 360 & 418.5 & 448.30 & 433.4 \\
\hline 110 & 100 & 7.11 & 6.96 & 7.04 & & 24.5 & 25.00 & & 24.75 & 750 & 701.00 & 725.5 & 501 & 500.00 & 500.5 \\
\hline 147 & 102 & 6.1 & 5.74 & 5.92 & 24.8 & 24.6 & & 25.10 & 24.83 & 167.8 & 149.10 & 158.45 & 493 & 540.60 & \\
\hline 187 & 108 & 5.83 & 5.94 & 5.89 & 24.4 & 24.5 & 22.80 & 23.70 & 23.85 & 352 & 368.00 & 360 & 575.6 & 489.10 & \\
\hline 6 & 110 & 7.07 & 7.07 & 7.07 & 24.3 & 24.4 & 24.3 & 24.30 & 24.325 & 314 & 417.00 & & 410 & 495.60 & \\
\hline 144 & 116.5 & 6.96 & 8.39 & 7.68 & 25.5 & 25.3 & 25.00 & 25.90 & 25.425 & 291 & 260.00 & & 466.5 & 505.00 & \\
\hline 20 & & & 6.16 & 6.16 & & & & 25.60 & 25.60 & & 144.20 & 144.2 & & 530.90 & 530.9 \\
\hline 175 & 120 & 6.27 & 5.94 & 6.11 & 24.3 & 24.4 & 21.70 & 23.10 & 23.375 & 488 & 496.00 & 492 & 420 & 471.00 & \\
\hline 7 & 124 & 7.1 & 4.31 & & 25.1 & 24.9 & & 26.20 & 25.40 & 304 & 288.00 & & 499.4 & 489.70 & 494.55 \\
\hline 49 & 132 & 6.6 & 6.49 & 6.55 & 24.9 & 24.8 & & 25.20 & 24.97 & 205 & 184.40 & & 532.4 & 400.00 & \\
\hline 85 & 150 & 7.55 & & 7.55 & & 24.10 & & & 24.10 & 256 & & & 433.30 & & 433.3 \\
\hline Mín. & & 5.64 & 4.31 & 5.59 & 24.30 & 24.10 & 21.70 & 23.10 & 23.38 & 110.50 & 101.10 & 105.80 & 394.50 & 400.00 & 407.45 \\
\hline Máx. & & 8.14 & 8.39 & 7.76 & 26.60 & 27.70 & 27.20 & 27.90 & 26.55 & 750.00 & 701.00 & 725.50 & 575.60 & 543.00 & 530.90 \\
\hline Média & & 6.55 & 6.34 & 6.48 & 25.09 & 25.19 & 24.36 & 25.13 & 25.00 & 342.59 & 323.69 & 356.30 & 465.93 & 486.18 & 472.40 \\
\hline
\end{tabular}


Resultados das análises efetuadas em campo nos periodos de dezembro, 20093 e junho-julho, 2010 para poços maiores a $150 \mathrm{~m}$

\begin{tabular}{|c|c|c|c|c|c|c|c|c|c|c|c|c|c|c|c|}
\hline Poços & $\begin{array}{l}\text { Prof. } \\
\text { (m) }\end{array}$ & $\begin{array}{c}\mathrm{pH} \\
(2009)\end{array}$ & $\begin{array}{c}\mathrm{pH} \\
(2010)\end{array}$ & $\begin{array}{c}\mathrm{pH} \\
\text { (Média) }\end{array}$ & $\begin{array}{l}T\left({ }^{0} \mathrm{C}\right) \\
(2009)\end{array}$ & $\begin{array}{l}T\left({ }^{0} \mathrm{C}\right) \\
(2010)\end{array}$ & $\begin{array}{l}\mathrm{T}\left({ }^{\mathrm{C}} \mathrm{C}\right) \\
(2009)\end{array}$ & $\begin{array}{l}T\left({ }^{\circ} \mathrm{C}\right) \\
(2010)\end{array}$ & $\begin{array}{c}T\left({ }^{\circ} \mathrm{C}\right) \\
\text { (Média) }\end{array}$ & $\begin{array}{c}C E \\
(\mu \mathrm{C} / \mathrm{cm}) \\
(2009)\end{array}$ & $\begin{array}{c}C E \\
(\mu \mathrm{S} / \mathrm{cm}) \\
(2010)\end{array}$ & $\begin{array}{c}C E \\
(\mu S / c m) \\
\text { (Média) }\end{array}$ & $\begin{array}{c}\text { Eh } \\
(\mathrm{mV}) \\
(2009)\end{array}$ & $\begin{array}{c}\text { Eh } \\
\text { (mV) } \\
(2010)\end{array}$ & $\begin{array}{c}\text { Eh } \\
\text { (mVV) } \\
\text { (Média) }\end{array}$ \\
\hline 153 & 217.5 & 9.08 & 9.18 & 9.13 & 24.2 & 24 & 25.00 & 23.50 & 24.175 & 254 & 222.00 & 238 & 387.1 & 430.20 & 408.65 \\
\hline 157 & 241 & 9.53 & & 9.53 & 26.6 & 26.3 & & & 26.45 & 331 & & 331 & 397.7 & & 397.7 \\
\hline 159 & 272 & 9.33 & 6.97 & & 25.4 & 25.3 & 25.00 & 24.50 & 25.05 & 328 & 369.00 & 348.5 & 415 & 456.40 & 435.7 \\
\hline Min. & & 9.08 & 6.97 & 9.13 & 24.20 & 24.00 & 25.00 & 23.50 & 24.18 & 254.00 & 222.00 & 238.00 & 387.10 & 430.20 & 397.70 \\
\hline Máx. & & 9.53 & 9.18 & 9.53 & 26.60 & 26.30 & 25.00 & 24.50 & 26.45 & 331.00 & 369.00 & 348.50 & 415.00 & 456.40 & 435.70 \\
\hline Média & & 9.31 & 8.08 & 9.33 & 25.40 & 25.20 & 25.00 & 24.00 & 25.23 & 304.33 & 295.50 & 305.83 & 399.93 & 443.30 & 414.02 \\
\hline D.P & & 2.53 & 2.53 & 2.53 & 2.53 & 2.53 & 2.53 & 2.53 & 8.38 & 8.38 & 8.38 & 201.19 & 201.19 & 201.19 & 160.32 \\
\hline C.V & & 0.30 & 0.30 & 0.30 & 0.30 & 0.30 & 0.30 & 0.30 & 0.33 & 0.33 & 0.33 & 0.61 & 0.61 & 0.61 & 0.37 \\
\hline
\end{tabular}

Min.- Valor mínimo; Máx.- Valor máximo; D. P.- Desvio Padrão; C. V. - Coefíciente de variaçāo 
Resultados das análises químicas dos poços amostrados na primeira campanha de amostragem (15a26/12/2009)

\begin{tabular}{|c|c|c|c|c|c|c|c|c|c|c|c|c|c|c|}
\hline Poços & $\begin{array}{l}\text { Alcalinidade } \\
\text { Total (mg/L) }\end{array}$ & $\begin{array}{c}\mathrm{NH}_{4}^{+} \\
(\mathrm{mg} / \mathrm{L})\end{array}$ & $\begin{array}{c}\text { Nit } \\
\text { Org } \\
(\mathrm{mg} / \mathrm{L})\end{array}$ & $\begin{array}{c}\text { Nit } \\
\text { Total } \\
\text { (mg/L) }\end{array}$ & $\begin{array}{c}\mathrm{Na}^{+} \\
(\mathrm{mg} / \mathrm{L})\end{array}$ & $\begin{array}{c}\mathrm{K}^{+} \\
(\mathrm{mg} / \mathrm{L})\end{array}$ & $\begin{array}{c}\mathrm{Mg}^{2+} \\
(\mathrm{mg} / \mathrm{L})\end{array}$ & $\begin{array}{c}\mathrm{Ca}^{2+} \\
(\mathrm{mg} / \mathrm{L})\end{array}$ & $\begin{array}{c}\mathrm{Fe}^{2+} \\
(\mathrm{mg} / \mathrm{L})\end{array}$ & $\begin{array}{c}\mathrm{SiO}_{2} \\
(\mathrm{mg} / \mathrm{L})\end{array}$ & $\begin{array}{c}\mathrm{Cl}^{-} \\
(\mathrm{mg} / \mathrm{L})\end{array}$ & $\begin{array}{c}\mathrm{NO}_{2}^{-} \\
(\mathrm{mg} / \mathrm{L})\end{array}$ & $\begin{array}{c}\mathrm{NO}_{3}^{-} \\
(\mathrm{mg} / \mathrm{L})\end{array}$ & $\begin{array}{c}\mathrm{SO}_{4}{ }^{2} \\
(\mathrm{mg} / \mathrm{L})\end{array}$ \\
\hline 6 & 108 & 0.02 & 0.02 & 8.8 & 14 & 7.6 & 9.2 & 67 & 0.005 & 30 & 14 & 0.02 & 39 & 0.06 \\
\hline 7 & 119 & 0.02 & 0.02 & 2.3 & 8.9 & 2.4 & 6.9 & 38 & 0.005 & 46 & 9.5 & 0.02 & 10 & 0.8 \\
\hline 12 & 40 & 0.02 & 0.02 & 7.2 & 5.5 & 3.8 & 3.9 & 2.8 & 0.26 & 30 & 7.4 & 0.02 & 32 & 0.18 \\
\hline 14 & 73 & 0.02 & 0.02 & 10 & 6.8 & 4.2 & 6.2 & 50 & 0.025 & 35 & 65 & 0.02 & 45 & 2.9 \\
\hline 35 & 112 & 0.02 & 0.02 & 2.5 & 45 & 1.1 & 1.8 & 9.1 & 0.005 & 26 & 4.6 & 0.02 & 11 & 1.26 \\
\hline 49 & 94 & 0.02 & 0.02 & 1.5 & 10 & 2.4 & 4.2 & 21 & 0.005 & 49 & 3 & 0.02 & 6.8 & 0.13 \\
\hline 62 & 42 & 0.02 & 0.02 & 8.4 & 8 & 4.1 & 3.7 & 20 & 0.005 & 36 & 18 & 0.02 & 37 & 0.06 \\
\hline 86 & 82 & 0.02 & 0.02 & 29 & 10 & 2.9 & 6.5 & 36 & 0.005 & 46 & 0.02 & 0.02 & 130 & 1 \\
\hline 87 & 169 & 0.02 & 0.02 & 8.1 & 16 & 2.7 & 8.4 & 41 & 0.005 & 49 & 25 & 0.02 & 36 & 2.2 \\
\hline 96 & 27 & 0.02 & 0.02 & 6.2 & 3.8 & 3.1 & 2.4 & 8.1 & 0.005 & 32 & 3.8 & 0.02 & 27 & 0.48 \\
\hline 110 & 272 & 0.02 & 0.02 & 3.2 & 173 & 4.8 & 26 & 93 & 0.005 & 51 & 37 & 0.02 & 14 & 12 \\
\hline 118 & 23 & 0.02 & 0.02 & 29 & 9.2 & 7.7 & 9.7 & 43 & 0.005 & 28 & 49 & 0.02 & 127 & 0.15 \\
\hline 144 & 109 & 0.02 & 0.02 & 8.5 & 7.3 & 2.3 & 6.8 & 33 & 0.005 & 45 & 17 & 0.02 & 38 & 1.23 \\
\hline 147 & 43 & 0.02 & 0.02 & 13 & 4.9 & 3.5 & 2.9 & 18 & 0.005 & 32 & 8 & 0.02 & 57 & 0.49 \\
\hline 153 & 119 & 0.02 & 0.02 & 1.8 & 45 & 0.38 & 1.6 & 5.9 & 0.005 & 23 & 4.4 & 0.02 & 7.8 & 2.4 \\
\hline 157 & 165 & 0.02 & 0.02 & 0.12 & 67 & 0.096 & 0.086 & 0.88 & 0.005 & 21 & 1.4 & 0.02 & 0.55 & 0.23 \\
\hline 158 & 163 & 0.02 & 0.02 & 0.08 & 65 & 0.095 & 0.084 & 0.89 & 0.005 & 21 & 1.3 & 0.02 & 0.37 & 0.24 \\
\hline 159 & 172 & 0.02 & 0.02 & 0.15 & 66 & 0.29 & 1.2 & 4.6 & 0.005 & 22 & 1.4 & 0.02 & 0.65 & 0.29 \\
\hline $175 / 0$ & 82 & 0.02 & 0.02 & 46 & 9.8 & 5.3 & 7.9 & 62 & 0.005 & 31 & 62 & 0.02 & 204 & 0.67 \\
\hline $175 /$ ro & 41 & 0.02 & 0.02 & 3.2 & 9.9 & 5.4 & 7.9 & 63 & 0.005 & 31 & 123 & 0.02 & 14 & 0.15 \\
\hline 187 & 52 & 0.02 & 0.02 & 14 & 6.5 & 5.8 & 7.6 & 33 & 0.005 & 28 & 30 & 0.02 & 63 & 0.09 \\
\hline 200 & 24 & 0.02 & 0.02 & 21 & 12 & 11 & 8.1 & 12 & 0.005 & 32 & 24 & 0.02 & 91 & 0.02 \\
\hline $146 / 0$ & 170 & 0.02 & 0.02 & 5.6 & 17 & 3.1 & 4.8 & 55 & 0.005 & 32 & 46 & 0.02 & 25 & 5 \\
\hline
\end{tabular}


Resultados das análises químicas dos poços amostrados na segunda campanha de amostragem (28/06/2010 a 01/07/2010)

\begin{tabular}{|c|c|c|c|c|c|c|c|c|c|c|c|c|c|c|}
\hline Poços & $\begin{array}{l}\text { Alcalinidade. } \\
\text { Total (mg/L) }\end{array}$ & $\begin{array}{c}\mathrm{NH}_{4}^{+} \\
(\mathrm{mg} / \mathrm{L})\end{array}$ & $\begin{array}{c}\text { Nitr } \\
\text { Orgânico } \\
\text { (mg/L) }\end{array}$ & $\begin{array}{c}\text { Nitr } \\
\text { Total } \\
\text { (mg/L) }\end{array}$ & $\begin{array}{c}\mathrm{Na}^{+} \\
(\mathrm{mg} / \mathrm{L})\end{array}$ & $\begin{array}{c}\mathrm{K}^{+} \\
(\mathrm{mg} / \mathrm{L})\end{array}$ & $\begin{array}{c}\mathrm{Mg}^{2+} \\
(\mathrm{mg} / \mathrm{L})\end{array}$ & $\begin{array}{c}\mathrm{Ca}^{2+} \\
(\mathrm{mg} / \mathrm{L})\end{array}$ & $\begin{array}{c}\mathrm{Fe}^{2+} \\
(\mathrm{mg} / \mathrm{L})\end{array}$ & $\begin{array}{c}\mathrm{SiO}_{2} \\
(\mathrm{mg} / \mathrm{L})\end{array}$ & $\begin{array}{c}\mathrm{Cr} \\
(\mathrm{mg} / \mathrm{L})\end{array}$ & $\begin{array}{c}\mathrm{NO}_{2}^{-} \\
(\mathrm{mg} / \mathrm{L})\end{array}$ & $\begin{array}{c}\mathrm{NO}_{3}^{-} \\
(\mathrm{mg} / \mathrm{L})\end{array}$ & $\begin{array}{l}\mathrm{SO}_{4}{ }^{2-} \\
(\mathrm{mg} / \mathrm{L})\end{array}$ \\
\hline 7 & 50 & 0.02 & 0.02 & 2.71 & 10 & 2.9 & 6.2 & 38 & 0.005 & 77 & 11 & 0.02 & 12 & 2.3 \\
\hline 12 & 49 & 0.02 & 0.02 & 5.2 & 21 & 2.9 & 2.7 & 15 & 0.005 & 43 & 3.4 & 0.02 & 23 & 0.24 \\
\hline 14 & 44 & 0.02 & 0.02 & 9.94 & 8 & 4.3 & 5.1 & 49 & 0.005 & 58 & 50 & 0.02 & 44 & 5.8 \\
\hline 20 & 100 & 0.02 & 0.02 & 3.16 & 5.5 & 3.1 & 2.3 & 16 & 0.005 & 49 & 4.7 & 0.02 & 14 & 0.03 \\
\hline 35 & 49 & 0.02 & 0.02 & 3.16 & 28 & 2.8 & 3.6 & 22 & 0.005 & 53 & 5.6 & 0.02 & 14 & 2.4 \\
\hline 49 & 27 & 0.02 & 0.02 & 1.6 & 12 & 2.4 & 3.6 & 19 & 0.005 & 81 & 2.5 & 0.02 & 7.1 & 0.22 \\
\hline 62 & 58 & 0.02 & 0.02 & 7.45 & 9.4 & 3.8 & 3.1 & 20 & 0.005 & 56 & 20 & 0.02 & 33 & 0.05 \\
\hline 86 & 73 & 0.02 & 0.02 & 25.07 & 19 & 8.2 & 7.5 & 59 & 0.005 & 45 & 57 & 0.02 & 111 & 2.6 \\
\hline 87 & 106 & 0.02 & 0.02 & 5.87 & 16 & 2.9 & 6.8 & 36 & 0.005 & 73 & 10 & 0.02 & 26 & 0.37 \\
\hline 96 & 78 & 0.02 & 0.02 & 4.74 & 11 & 2.8 & 2.1 & 7.6 & 0.005 & 45 & 3.3 & 0.02 & 21 & 0.02 \\
\hline 110 & 35 & 0.02 & 0.02 & 3.61 & 22 & 5.4 & 14 & 88 & 0.005 & 88 & 39 & 0.02 & 16 & 22 \\
\hline 144 & 39 & 0.02 & 0.02 & 4.52 & 8.5 & 2.4 & 5.8 & 31 & 0.005 & 71 & 10 & 0.02 & 20 & 1.1 \\
\hline 146 & 62 & 0.02 & 0.02 & 2.26 & 17 & 3.2 & 4.2 & 52 & 0.005 & 62 & 21 & 0.02 & 10 & 2 \\
\hline 147 & 103 & 0.02 & 0.02 & 7 & 5.9 & 3.4 & 2.3 & 15 & 0.005 & 45 & 5.2 & 0.02 & 31 & 0.02 \\
\hline 153 & 100 & 0.02 & 0.02 & 0.61 & 51 & 0.43 & 1.2 & 6.2 & 0.005 & 32 & 1.5 & 0.02 & 2.7 & 0.7 \\
\hline 159 & 132 & 0.02 & 0.02 & 0.34 & 52 & 1.7 & 6.1 & 30 & 0.005 & 47 & 3.3 & 0.02 & 1.5 & 1.2 \\
\hline 176 & 103 & 0.02 & 0.02 & 14.46 & 21 & 7.9 & 5.3 & 25 & 0.005 & 30 & 37 & 0.02 & 64 & 4.5 \\
\hline 187 & 83 & 0.02 & 0.02 & 16.26 & 8.2 & 6.9 & 6.8 & 30 & 0.005 & 37 & 41 & 0.02 & 72 & 0.06 \\
\hline 200 & 50 & 0.02 & 0.02 & 17.62 & 15 & 14 & 7.1 & 8.1 & 0.005 & 47 & 26 & 0.02 & 78 & 0.02 \\
\hline $175 / 0$ & 76 & 0.02 & 0.02 & 23.49 & 16 & 5.5 & 6.5 & 52 & 0.005 & 45 & 37 & 0.02 & 104 & 0.2 \\
\hline $175 / \mathrm{ro}$ & 89 & 0.02 & 0.02 & 6.1 & 12 & 5.6 & 6.5 & 55 & 0.005 & 47 & 111 & 0.02 & 27 & 0.02 \\
\hline $6 / 0$ & 68 & 0.02 & 0.02 & 14.01 & 8.7 & 3.4 & 6.2 & 46 & 0.005 & 73 & 24 & 0.02 & 62 & 0.15 \\
\hline
\end{tabular}


Comparação dos parâmetros de alcalinidade determinadas em campo e laboratório para a primeira campanha de amostragem

\begin{tabular}{ccccc}
\hline Poços & $\begin{array}{c}\text { Alcalinidade } \\
\text { Total (lab.) } \\
\text { (mg/L) }\end{array}$ & $\begin{array}{c}\text { Alcalinidade } \\
\text { Total } \\
\text { (campo) } \\
\text { (mg/L) }\end{array}$ & $\begin{array}{c}\text { \% erro } \\
\text { laboratório }\end{array}$ & $\begin{array}{c}\text { \% erro } \\
\text { campo }\end{array}$ \\
\hline 96 & 27 & 31.11 & 12.64 & 16.19 \\
200 & 24 & 22.22 & 11.82 & 11.14 \\
118 & 23 & 32.22 & 4.72 & 7.02 \\
14 & 73 & 56.66 & 8.92 & 4.77 \\
35 & 112 & 13.33 & 0.29 & 61.35 \\
62 & 42 & 47.22 & 5.60 & 8.21 \\
86 & 82 & 112.21 & 13.90 & 21.13 \\
87 & 169 & 216.65 & 14.71 & 23.58 \\
110 & 272 & 386.64 & 34.92 & 21.85 \\
147 & 43 & 51.11 & 16.63 & 20.37 \\
187 & 52 & 75.55 & 3.56 & 11.03 \\
6 & 108 & 134.99 & 21.25 & 13.66 \\
144 & 109 & 136.10 & 12.15 & 19.56 \\
175 & 82 & 98.33 & 21.69 & 23.95 \\
7 & 119 & 208.87 & 1.52 & 22.69 \\
49 & 94 & 118.88 & 5.04 & 15.66 \\
12 & 40 & 46.11 & 30.87 & 34.30 \\
153 & 119 & 35.37 & 5.64 & 40.76 \\
157 & 165 & 65.69 & 6.10 & 36.93 \\
146 & 170 & 215.54 & 13.59 & 21.41 \\
159 & 172 & 45.48 & 4.32 & 53.71 \\
\hline
\end{tabular}


Comparação dos parâmetros de alcalinidade determinadas em campo e laboratório para a segunda campanha de amostragem

\begin{tabular}{ccccc}
\hline Poços & $\begin{array}{c}\text { Alcalinidade } \\
\text { Total (lab.) } \\
\text { (mg/L) }\end{array}$ & $\begin{array}{c}\text { Alcalinidade } \\
\text { Total } \\
\text { (campo) } \\
\text { (mg/L) }\end{array}$ & $\begin{array}{c}\text { \% erro } \\
\text { laboratório }\end{array}$ & $\begin{array}{c}\text { \% erro } \\
\text { campo }\end{array}$ \\
\hline 96 & 78 & 25.86 & 28.75 & 7.47 \\
176 & 103 & 39.06 & 20.34 & 2.62 \\
200 & 50 & 14.60 & 18.69 & 5.40 \\
118 & & & & \\
14 & 44 & 67.99 & 3.28 & 3.87 \\
35 & 49 & 124.93 & 30.99 & 4.43 \\
62 & 58 & 37.22 & 12.39 & 2.28 \\
86 & 73 & 84.09 & 3.30 & 5.51 \\
87 & 106 & 147.82 & 4.99 & 7.95 \\
110 & 35 & 321.13 & 45.04 & 10.76 \\
147 & 103 & 39.54 & 35.74 & 5.74 \\
187 & 83 & 29.14 & 21.13 & 5.66 \\
6 & 68 & 104.24 & 3.66 & 7.02 \\
144 & 39 & 109.09 & 27.13 & 6.72 \\
20 & 100 & 53.17 & 28.72 & 4.25 \\
175 & 76 & 80.21 & 3.39 & 4.37 \\
7 & 50 & 136.72 & 30.53 & 5.98 \\
49 & 27 & 95.89 & 42.94 & 7.11 \\
12 & 49 & 83.39 & 14.85 & 4.43 \\
153 & 100 & 112.32 & 11.33 & 0.95 \\
157 & & & & \\
146 & 62 & 169.75 & 29.79 & 5.39 \\
159 & 132 & 222.70 & 21.47 & 3.29 \\
\hline & & & & \\
\hline
\end{tabular}


ANEXO V. Confiabilidade dos resultados analíticos 
Erros obtidos pelo balanço iônico dos resultados das análises da primeira campanha de amostragem, considerando a alcalinidade de laboratório

\begin{tabular}{|c|c|c|c|c|c|c|c|c|c|c|c|c|c|}
\hline $\begin{array}{l}\text { Poços } \\
<150 \mathrm{~m}\end{array}$ & $\begin{array}{c}\mathrm{HCO}_{3}^{-} \\
\text {(meq/L) }\end{array}$ & $\begin{array}{c}\mathrm{NH}^{+} \\
\text {(meq/L) }\end{array}$ & $\underset{\text { (meq/L) }}{\mathrm{Na}^{+}}$ & $\begin{array}{c}\mathrm{K}^{+} \\
(\mathrm{meq} / \mathrm{L})\end{array}$ & $\underset{(\mathrm{meq} / \mathrm{L})}{\mathrm{Mg}^{2+}}$ & $\begin{array}{c}\mathrm{Ca}^{2+} \\
(\mathrm{meq} / \mathrm{L})\end{array}$ & $\begin{array}{c}\mathrm{Fe}^{2+} \\
(\mathrm{meq} / \mathrm{L})\end{array}$ & $\begin{array}{c}\mathrm{Cl}^{-} \\
\text {(meq/L) }\end{array}$ & $\begin{array}{c}\mathrm{NO}_{3}^{-} \\
\text {(meqill) }\end{array}$ & $\begin{array}{c}\mathrm{SO}_{4} \\
\text { (meq/L) }\end{array}$ & $\begin{array}{c}\text { Soma } \\
\text { ânions }\end{array}$ & $\begin{array}{l}\text { Soma } \\
\text { cátions }\end{array}$ & $\%$ erro \\
\hline 96 & 0.54 & 0.001 & 0.17 & 0.08 & 0.20 & 0.40 & 0.0002 & 0.11 & 0.44 & 0.01 & 1.09 & 0.85 & 12.64 \\
\hline 200 & 0.48 & 0.001 & 0.52 & 0.28 & 0.67 & 0.60 & 0.0002 & 0.68 & 1.47 & 0.00 & 2.62 & 2.07 & 11.82 \\
\hline 118 & 0.46 & 0.001 & 0.40 & 0.20 & 0.80 & 2.14 & 0.0002 & 1.38 & 2.05 & 0.00 & 3.89 & 3.54 & 4.72 \\
\hline 14 & 1.46 & 0.001 & 0.30 & 0.11 & 0.51 & 2.49 & 0.0009 & 1.83 & 0.73 & 0.06 & 4.08 & 3.41 & 8.92 \\
\hline 35 & 2.24 & 0.001 & 1.96 & 0.03 & 0.15 & 0.45 & 0.0002 & 0.13 & 0.18 & 0.03 & 2.57 & 2.59 & 0.29 \\
\hline 62 & 0.84 & 0.001 & 0.33 & 0.10 & 0.30 & 1.00 & 0.0002 & 0.51 & 0.60 & 0.00 & 1.95 & 1.74 & 5.60 \\
\hline 86 & 1.64 & 0.001 & 0.43 & 0.07 & 0.53 & 1.80 & 0.0002 & 0.00 & 2.10 & 0.02 & 3.76 & 2.84 & 13.90 \\
\hline 87 & 3.38 & 0.001 & 0.70 & 0.07 & 0.69 & 2.04 & 0.0002 & 0.70 & 0.58 & 0.05 & 4.71 & 3.50 & 14.71 \\
\hline 110 & 5.44 & 0.001 & 7.52 & 0.12 & 2.14 & 4.64 & 0.0002 & 1.04 & 0.23 & 0.25 & 6.96 & 14.42 & 34.92 \\
\hline 147 & 0.86 & 0.001 & 0.21 & 0.09 & 0.24 & 0.90 & 0.0002 & 0.23 & 0.92 & 0.01 & 2.01 & 1.44 & 16.63 \\
\hline 187 & 1.04 & 0.001 & 0.28 & 0.15 & 0.63 & 1.65 & 0.0002 & 0.85 & 1.02 & 0.00 & 2.90 & 2.70 & 3.56 \\
\hline 6 & 2.16 & 0.001 & 0.61 & 0.19 & 0.76 & 3.34 & 0.0002 & 0.39 & 0.63 & 0.00 & 3.18 & 4.90 & 21.25 \\
\hline 144 & 2.18 & 0.001 & 0.32 & 0.06 & 0.56 & 1.65 & 0.0002 & 0.48 & 0.61 & 0.03 & 3.30 & 2.58 & 12.15 \\
\hline 175 & 1.64 & 0.001 & 0.43 & 0.14 & 0.65 & 3.09 & 0.0002 & 1.75 & 3.29 & 0.01 & 6.69 & 4.31 & 21.69 \\
\hline 7 & 2.38 & 0.001 & 0.39 & 0.06 & 0.57 & 1.90 & 0.0002 & 0.27 & 0.16 & 0.02 & 2.83 & 2.91 & 1.52 \\
\hline 49 & 1.88 & 0.001 & 0.42 & 0.06 & 0.35 & 1.05 & 0.0002 & 0.08 & 0.11 & 0.00 & 2.08 & 1.88 & 5.04 \\
\hline \multicolumn{14}{|l|}{$\begin{array}{l}\text { Poços } \\
>150 \mathrm{~m}\end{array}$} \\
\hline 12 & 0.8 & 0.001 & 0.24 & 0.10 & 0.32 & 0.14 & 0.0093 & 0.21 & 0.52 & 0.00 & 1.53 & 0.81 & 30.87 \\
\hline 153 & 2.38 & 0.001 & 1.96 & 0.01 & 0.13 & 0.29 & 0.0002 & 0.12 & 0.13 & 0.05 & 2.68 & 2.39 & 5.64 \\
\hline 157 & 3.3 & 0.001 & 2.91 & 0.00 & 0.01 & 0.04 & 0.0002 & 0.04 & 0.01 & 0.00 & 3.35 & 2.97 & 6.10 \\
\hline $146 / 0$ & 3.4 & 0.001 & 0.74 & 0.08 & 0.40 & 2.74 & 0.0002 & 1.30 & 0.40 & 0.10 & 5.20 & 3.96 & 13.59 \\
\hline 159 & 3.44 & 0.001 & 2.87 & 0.01 & 0.10 & 0.23 & 0.0002 & 0.04 & 0.01 & 0.01 & 3.50 & 3.21 & 4.32 \\
\hline
\end{tabular}


Erros obtidos pelo balanço iônico dos resultados das análises da primeira campanha de amostragem, considerando a alcalinidade de campo

\begin{tabular}{|c|c|c|c|c|c|c|c|c|c|c|c|c|c|}
\hline $\begin{array}{l}\text { Poços } \\
<150 \mathrm{~m}\end{array}$ & $\begin{array}{c}\mathrm{HCO}_{3}{ }^{-} \\
\text {(meq/L) }\end{array}$ & $\begin{array}{c}\mathrm{NH}^{+} \\
\text {meq/L) }\end{array}$ & $\underset{(\text { meq/L) }}{\mathrm{Na}^{+}}$ & $\begin{array}{c}\mathrm{K}^{+} \\
(\mathrm{meq} / \mathrm{L})\end{array}$ & $\begin{array}{c}\mathrm{Mg}^{2+} \\
(\mathrm{meq} / \mathrm{L})\end{array}$ & $\begin{array}{c}\mathrm{Ca}^{2+} \\
\text { (meq/L) }\end{array}$ & $\begin{array}{c}\mathrm{Fe}^{2+} \\
(\mathrm{meq} / \mathrm{L})\end{array}$ & $\begin{array}{c}\mathrm{Cl}^{-} \\
\text {(meq/L) }\end{array}$ & $\begin{array}{c}\mathrm{NO}_{3}{ }^{-} \\
(\mathrm{meq} / \mathrm{L})\end{array}$ & $\underset{\text { (meq/L) }}{\mathrm{SO}_{4}}$ & $\begin{array}{l}\text { Soma } \\
\text { ânions }\end{array}$ & $\begin{array}{c}\text { Soma } \\
\text { cátions }\end{array}$ & $\%$ erro \\
\hline 96 & 0.62 & 0.001 & 0.17 & 0.08 & 0.20 & 0.40 & 0.0002 & 0.11 & 0.44 & 0.01 & 1.17 & 0.85 & 16.19 \\
\hline 200 & 0.44 & 0.001 & 0.52 & 0.28 & 0.67 & 0.60 & 0.0002 & 0.68 & 1.47 & 0.00 & 2.59 & 2.07 & 11.14 \\
\hline 118 & 0.64 & 0.001 & 0.40 & 0.20 & 0.80 & 2.14 & 0.0002 & 1.38 & 2.05 & 0.00 & 4.08 & 3.54 & 7.02 \\
\hline 14 & 1.13 & 0.001 & 0.30 & 0.11 & 0.51 & 2.49 & 0.0009 & 1.83 & 0.73 & 0.06 & 3.75 & 3.41 & 4.77 \\
\hline 35 & 0.27 & 0.001 & 1.96 & 0.03 & 0.15 & 0.45 & 0.0002 & 0.13 & 0.18 & 0.03 & 0.64 & 2.59 & 61.35 \\
\hline 62 & 0.94 & 0.001 & 0.33 & 0.10 & 0.30 & 1.00 & 0.0002 & 0.51 & 0.60 & 0.00 & 2.05 & 1.74 & 8.21 \\
\hline 86 & 2.24 & 0.001 & 0.43 & 0.07 & 0.53 & 1.80 & 0.0002 & 0.00 & 2.10 & 0.02 & 4.36 & 2.84 & 21.13 \\
\hline 87 & 4.33 & 0.001 & 0.70 & 0.07 & 0.69 & 2.04 & 0.0002 & 0.70 & 0.58 & 0.05 & 5.66 & 3.50 & 23.58 \\
\hline 110 & 7.73 & 0.001 & 7.52 & 0.12 & 2.14 & 4.64 & 0.0002 & 1.04 & 0.23 & 0.25 & 9.25 & 14.42 & 21.85 \\
\hline 147 & 1.02 & 0.001 & 0.21 & 0.09 & 0.24 & 0.90 & 0.0002 & 0.23 & 0.92 & 0.01 & 2.18 & 1.44 & 20.37 \\
\hline 187 & 1.51 & 0.001 & 0.28 & 0.15 & 0.63 & 1.65 & 0.0002 & 0.85 & 1.02 & 0.00 & 3.37 & 2.70 & 11.03 \\
\hline 6 & 2.70 & 0.001 & 0.61 & 0.19 & 0.76 & 3.34 & 0.0002 & 0.39 & 0.63 & 0.00 & 3.72 & 4.90 & 13.66 \\
\hline 144 & 2.72 & 0.001 & 0.32 & 0.06 & 0.56 & 1.65 & 0.0002 & 0.48 & 0.61 & 0.03 & 3.84 & 2.58 & 19.56 \\
\hline 175 & 1.97 & 0.001 & 0.43 & 0.14 & 0.65 & 3.09 & 0.0002 & 1.75 & 3.29 & 0.01 & 7.02 & 4.31 & 23.95 \\
\hline 7 & 4.18 & 0.001 & 0.39 & 0.06 & 0.57 & 1.90 & 0.0002 & 0.27 & 0.16 & 0.02 & 4.62 & 2.91 & 22.69 \\
\hline 49 & 2.38 & 0.001 & 0.42 & 0.06 & 0.35 & 1.05 & 0.0002 & 0.08 & 0.11 & 0.00 & 2.57 & 1.88 & 15.66 \\
\hline \multicolumn{14}{|l|}{$\begin{array}{l}\text { Poços } \\
>150 \mathrm{~m}\end{array}$} \\
\hline 12 & 0.92 & 0.001 & 0.24 & 0.10 & 0.32 & 0.14 & 0.0093 & 0.21 & 0.52 & 0.00 & 1.65 & 0.81 & 34.30 \\
\hline 153 & 0.71 & 0.001 & 1.96 & 0.01 & 0.13 & 0.29 & 0.0002 & 0.12 & 0.13 & 0.05 & 1.01 & 2.39 & 40.76 \\
\hline 157 & 1.31 & 0.001 & 2.91 & 0.00 & 0.01 & 0.04 & 0.0002 & 0.04 & 0.01 & 0.00 & 1.37 & 2.97 & 36.93 \\
\hline $146 / 0$ & 4.31 & 0.001 & 0.74 & 0.08 & 0.40 & 2.74 & 0.0002 & 1.30 & 0.40 & 0.10 & 6.11 & 3.96 & 21.41 \\
\hline 159 & 0.91 & 0.001 & 2.87 & 0.01 & 0.10 & 0.23 & 0.0002 & 0.04 & 0.01 & 0.01 & 0.97 & 3.21 & 53.71 \\
\hline
\end{tabular}

16.19 Valores superiores ac erro máximo permitido $(>10 \%)$ 
Erros obtidos pelo balanço iônico dos resultados das análises da segunda campanha de amostragem, considerando a alcalinidade de laboratório

\begin{tabular}{|c|c|c|c|c|c|c|c|c|c|c|c|c|c|c|c|}
\hline $\begin{array}{l}\text { Poços } \\
<150 \mathrm{~m}\end{array}$ & $\begin{array}{c}\mathrm{HCO}_{3}^{-} \\
(\mathrm{meq} / \mathrm{L})\end{array}$ & $\begin{array}{c}\mathrm{NH}^{+} \\
\text {(lab.) } \\
\text { (meq/L) }\end{array}$ & $\underset{\text { (meq/L) }}{\mathrm{Na}^{+}}$ & $\begin{array}{c}\mathrm{K}^{+} \\
\text {(meq/L) }\end{array}$ & $\begin{array}{c}\mathrm{Mg}^{2+} \\
(\mathrm{meq} / \mathrm{L})\end{array}$ & $\begin{array}{c}\mathrm{Ca}^{2+} \\
\text { (meq/L) }\end{array}$ & $\begin{array}{c}\mathrm{Fe}^{2+} \\
(\mathrm{meq} / \mathrm{L})\end{array}$ & $\begin{array}{c}\mathrm{Cl}^{-} \\
\text {(meq/L) }\end{array}$ & $\begin{array}{c}\mathrm{NO}_{3}^{-} \\
\text {(meq/L) }\end{array}$ & $\underset{(\mathrm{meq} / \mathrm{L})}{\mathrm{SO}_{4}}$ & $\begin{array}{l}\text { Soma } \\
\text { cátions }\end{array}$ & $\begin{array}{l}\text { Soma } \\
\text { ânions }\end{array}$ & $\begin{array}{l}\text { Soma } \\
\text { cátions }\end{array}$ & $\begin{array}{l}\text { Soma } \\
\text { ânions }\end{array}$ & $\begin{array}{c}\% \\
\text { erro }\end{array}$ \\
\hline 96 & 1.56 & 0.001 & 0.48 & 0.07 & 0.17 & 0.38 & 0.0001 & 0.09 & 0.34 & 0.0004 & 1.10 & 0.95 & 1.10 & 1.99 & 28.75 \\
\hline 176 & 2.06 & 0.001 & 0.91 & 0.20 & 0.44 & 1.25 & 0.0001 & 1.04 & 1.03 & 0.0938 & 2.80 & 2.95 & 2.80 & 4.23 & 20.34 \\
\hline 200 & 1 & 0.001 & 0.65 & 0.36 & 0.58 & 0.45 & 0.0001 & 0.73 & 1.26 & 0.0004 & 2.05 & 2.28 & 2.05 & 2.99 & 18.69 \\
\hline 14 & 0.88 & 0.001 & 0.36 & 0.11 & 0.42 & 2.44 & 0.0001 & 1.41 & 0.71 & 0.1208 & 3.33 & 3.60 & 3.33 & 3.12 & 3.28 \\
\hline 35 & 0.98 & 0.001 & 1.22 & 0.07 & 0.30 & 1.10 & 0.0001 & 0.16 & 0.23 & 0.0500 & 2.68 & 2.93 & 2.68 & 1.41 & 30.99 \\
\hline 62 & 1.16 & 0.001 & 0.41 & 0.10 & 0.26 & 1.00 & 0.0001 & 0.56 & 0.53 & 0.0010 & 1.76 & 1.84 & 1.76 & 2.26 & 12.39 \\
\hline 87 & 2.12 & 0.001 & 0.70 & 0.07 & 0.56 & 1.80 & 0.0001 & 0.28 & 0.42 & 0.0077 & 3.13 & 3.67 & 3.13 & 2.83 & 4.99 \\
\hline 110 & 0.7 & 0.001 & 0.96 & 0.14 & 1.15 & 4.39 & 0.0001 & 1.10 & 0.26 & 0.4583 & 6.64 & 8.24 & 6.64 & 2.51 & 45.04 \\
\hline 86 & 1.46 & 0.001 & 0.83 & 0.21 & 0.62 & 2.94 & 0.0001 & 1.61 & 1.79 & 0.0542 & 4.60 & 5.13 & 4.60 & 4.91 & 3.30 \\
\hline 147 & 2.06 & 0.001 & 0.26 & 0.09 & 0.19 & 0.75 & 0.0001 & 0.15 & 0.50 & 0.0004 & 1.28 & 1.44 & 1.28 & 2.71 & 35.74 \\
\hline 187 & 1.66 & 0.001 & 0.36 & 0.18 & 0.56 & 1.50 & 0.0001 & 1.15 & 1.16 & 0.0013 & 2.59 & 2.90 & 2.59 & 3.98 & 21.13 \\
\hline $6 / 0$ & 1.36 & 0.001 & 0.38 & 0.09 & 0.51 & 2.29 & 0.0001 & 0.68 & 1.00 & 0.0031 & 3.27 & 3.76 & 3.27 & 3.04 & 3.66 \\
\hline 144 & 0.78 & 0.001 & 0.37 & 0.06 & 0.48 & 1.55 & 0.0001 & 0.28 & 0.32 & 0.0229 & 2.46 & 2.81 & 2.46 & 1.41 & 27.13 \\
\hline 20 & 2 & 0.001 & 0.24 & 0.08 & 0.19 & 0.80 & 0.0001 & 0.13 & 0.23 & 0.0006 & 1.31 & 1.42 & 1.31 & 2.36 & 28.72 \\
\hline $175 / 0$ & 1.52 & 0.001 & 0.70 & 0.14 & 0.53 & 2.59 & 0.0001 & 1.04 & 1.68 & 0.0042 & 3.97 & 4.33 & 3.97 & 4.24 & 3.39 \\
\hline 7 & 1 & 0.001 & 0.43 & 0.07 & 0.51 & 1.90 & 0.0001 & 0.31 & 0.19 & 0.0479 & 2.92 & 3.29 & 2.92 & 1.55 & 30.53 \\
\hline 49 & 0.54 & 0.001 & 0.52 & 0.06 & 0.30 & 0.95 & 0.0001 & 0.07 & 0.11 & 0.0046 & 1.83 & 2.11 & 1.83 & 0.73 & 42.94 \\
\hline \multicolumn{16}{|l|}{$\begin{array}{l}\text { Poços } \\
>150 \mathrm{~m}\end{array}$} \\
\hline 12 & 0.98 & 0.001 & 0.91 & 0.07 & 0.22 & 0.75 & 0.0001 & 0.10 & 0.37 & 0.0050 & 1.96 & 2.14 & 1.96 & 1.45 & 14.85 \\
\hline 153 & 2 & 0.001 & 2.22 & 0.01 & 0.10 & 0.31 & 0.0001 & 0.04 & 0.04 & 0.0146 & 2.64 & 2.59 & 2.64 & 2.10 & 11.33 \\
\hline 146 & 1.24 & 0.001 & 0.74 & 0.08 & 0.35 & 2.59 & 0.0001 & 0.59 & 0.16 & 0.0417 & 3.76 & 4.19 & 3.76 & 2.03 & 29.79 \\
\hline 159 & 2.64 & 0.001 & 2.26 & 0.04 & 0.50 & 1.50 & 0.0001 & 0.09 & 0.02 & 0.0250 & 4.30 & 4.60 & 4.30 & 2.78 & 21.47 \\
\hline
\end{tabular}

21.47 Valores superiores ao erro máximo permitido $(>10 \%)$ 
Erros obtidos pelo balanço iônico dos resultados das análises da segunda campanha de amostragem, considerando a alcalinidade de campo

\begin{tabular}{|c|c|c|c|c|c|c|c|c|c|c|c|c|c|c|}
\hline $\begin{array}{l}\text { POçOS } \\
<150 \mathrm{~m}\end{array}$ & $\begin{array}{c}\mathrm{HCO}_{3}^{-} \\
(\text {meq } / \mathrm{L})\end{array}$ & $\begin{array}{c}\mathrm{CO}_{3}{ }^{2-} \\
(\mathrm{meq} / \mathrm{L})\end{array}$ & $\begin{array}{c}\mathrm{NH}^{+} \\
(\mathrm{meq} / \mathrm{L})\end{array}$ & $\begin{array}{c}\mathrm{Na}^{+} \\
(\mathrm{meq} / \mathrm{L})\end{array}$ & $\begin{array}{c}\mathrm{K}^{+} \\
\text {(meq/L) }\end{array}$ & $\begin{array}{c}\mathrm{Mg}^{2+} \\
(\text { meq/L) }\end{array}$ & $\begin{array}{c}\mathrm{Ca}^{2+} \\
(\text { meq/L) }\end{array}$ & $\begin{array}{c}\mathrm{Fe}^{2+} \\
(\mathrm{meq} / \mathrm{L})\end{array}$ & 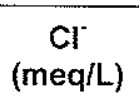 & $\begin{array}{c}\mathrm{NO}_{3}^{-} \\
(\mathrm{meq} / \mathrm{L})\end{array}$ & $\underset{(\mathrm{meq} / \mathrm{L})}{\mathrm{SO}_{4}}$ & $\begin{array}{l}\text { Soma } \\
\text { anions }\end{array}$ & $\begin{array}{l}\text { Soma } \\
\text { cátions }\end{array}$ & $\%$ erro \\
\hline 96 & 0.52 & 0.00 & 0.001 & 0.48 & 0.07 & 0.17 & 0.38 & 0.0001 & 0.09 & 0.34 & 0.0004 & 0.95 & 1.10 & 7.47 \\
\hline 176 & 0.78 & 0.00 & 0.001 & 0.91 & 0.20 & 0.44 & 1.25 & 0.0001 & 1.04 & 1.03 & 0.0938 & 2.95 & 2.80 & 2.62 \\
\hline 200 & 0.29 & 0.00 & 0.001 & 0.65 & 0.36 & 0.58 & 0.45 & 0.0001 & 0.73 & 1.26 & 0.0004 & 2.28 & 2.05 & 5.40 \\
\hline 14 & 1.36 & 0.00 & 0.001 & 0.36 & 0.11 & 0.42 & 2.44 & 0.0001 & 1.41 & 0.71 & 0.1208 & 3.60 & 3.33 & 3.87 \\
\hline 35 & 2.50 & 0.00 & 0.001 & 1.22 & 0.07 & 0.30 & 1.10 & 0.0001 & 0.16 & 0.23 & 0.0500 & 2.93 & 2.68 & 4.43 \\
\hline 62 & 0.74 & 0.00 & 0.001 & 0.41 & 0.10 & 0.26 & 1.00 & 0.0001 & 0.56 & 0.53 & 0.0010 & 1.84 & 1.76 & 2.28 \\
\hline${ }^{*} 86$ & 1.68 & 0.00 & 0.001 & 0.83 & 0.21 & 0.62 & 2.94 & 0.0001 & 1.61 & 1.79 & 0.0542 & 5.13 & 4.60 & 5.51 \\
\hline 87 & 2.96 & 0.00 & 0.001 & 0.70 & 0.07 & 0.56 & 1.80 & 0.0001 & 0.28 & 0.42 & 0.0077 & 3.67 & 3.13 & 7.95 \\
\hline$* 110$ & 6.42 & 0.00 & 0.001 & 0.96 & 0.14 & 1.15 & 4.39 & 0.0001 & 1.10 & 0.26 & 0.4583 & 8.24 & 6.64 & 10.76 \\
\hline 147 & 0.79 & 0.00 & 0.001 & 0.26 & 0.09 & 0.19 & 0.75 & 0.0001 & 0.15 & 0.50 & 0.0004 & 1.44 & 1.28 & 5.74 \\
\hline 187 & 0.58 & 0.00 & 0.001 & 0.36 & 0.18 & 0.56 & 1.50 & 0.0001 & 1.15 & 1.16 & 0.0013 & 2.90 & 2.59 & 5.66 \\
\hline 6 & 2.08 & 0.00 & 0.001 & 0.38 & 0.09 & 0.51 & 2.29 & 0.0001 & 0.68 & 1.00 & 0.0031 & 3.76 & 3.27 & 7.02 \\
\hline 144 & 2.18 & 0.00 & 0.001 & 0.37 & 0.06 & 0.48 & 1.55 & 0.0001 & 0.28 & 0.32 & 0.0229 & 2.81 & 2.46 & 6.72 \\
\hline 20 & 1.06 & 0.00 & 0.001 & 0.24 & 0.08 & 0.19 & 0.80 & 0.0001 & 0.13 & 0.23 & 0.0006 & 1.42 & 1.31 & 4.25 \\
\hline 175 & 1.60 & 0.00 & 0.001 & 0.70 & 0.14 & 0.53 & 2.59 & 0.0001 & 1.04 & 1.68 & 0.0042 & 4.33 & 3.97 & 4.37 \\
\hline 7 & 2.73 & 0.00 & 0.001 & 0.43 & 0.07 & 0.51 & 1.90 & 0.0001 & 0.31 & 0.19 & 0.0479 & 3.29 & 2.92 & 5.98 \\
\hline 49 & 1.92 & 0.00 & 0.001 & 0.52 & 0.06 & 0.30 & 0.95 & 0.0001 & 0.07 & 0.11 & 0.0046 & 2.11 & 1.83 & 7.11 \\
\hline \multicolumn{15}{|l|}{$\begin{array}{l}\text { POÇOS } \\
>150 \mathrm{~m}\end{array}$} \\
\hline 12 & 1.67 & 0.00 & 0.001 & 0.91 & 0.07 & 0.22 & 0.75 & 0.0001 & 0.10 & 0.37 & 0.0050 & 2.14 & 1.96 & 4.43 \\
\hline 153 & 2.25 & 0.24 & 0.001 & 2.22 & 0.01 & 0.10 & 0.31 & 0.0001 & 0.04 & 0.04 & 0.0146 & 2.59 & 2.64 & 0.95 \\
\hline 146 & 3.39 & 0.00 & 0.001 & 0.74 & 0.08 & 0.35 & 2.59 & 0.0001 & 0.59 & 0.16 & 0.0417 & 4.19 & 3.76 & 5.39 \\
\hline 159 & 4.45 & 0.00 & 0.001 & 2.26 & 0.04 & 0.50 & 1.50 & 0.0001 & 0.09 & 0.02 & 0.0250 & 4.60 & 4.30 & 3.29 \\
\hline
\end{tabular}


Resultados das análises dos poços em amostras duplicatas

Primeira campanha de amostragem, dezembro 2009

\begin{tabular}{|c|c|c|c|c|c|c|c|c|c|c|c|c|c|c|c|c|c|}
\hline Poços & $\begin{array}{c}\text { STD } \\
\text { (mg/L) }\end{array}$ & $\begin{array}{c}\mathrm{COD} \\
\text { (mg/L) }\end{array}$ & $\begin{array}{c}\text { Alcalinidade } \\
\text { Total (lab.) } \\
\text { (mg/L) }\end{array}$ & $\begin{array}{l}\mathrm{HCO}_{3}{ }^{-} \\
(\mathrm{mg} / \mathrm{L})\end{array}$ & $\begin{array}{c}\mathrm{NH}^{+} \\
(\mathrm{mg} / \mathrm{L})\end{array}$ & $\begin{array}{c}\mathrm{Nit} \\
\text { Org } \\
\text { (mg/L) }\end{array}$ & $\begin{array}{c}\text { Nit } \\
\text { Total } \\
\text { (mg/L) }\end{array}$ & $\begin{array}{c}\mathrm{Na}^{+} \\
(\mathrm{mg} / \mathrm{L})\end{array}$ & $\begin{array}{c}K^{+} \\
(m g / L)\end{array}$ & $\begin{array}{c}\mathrm{Mg}^{2+} \\
(\mathrm{mg} / \mathrm{L})\end{array}$ & $\begin{array}{c}\mathrm{Ca}^{2+} \\
(\mathrm{mg} / \mathrm{L})\end{array}$ & $\begin{array}{c}\mathrm{Fe}^{2+} \\
(\mathrm{mg} / \mathrm{L})\end{array}$ & $\underset{(\mathrm{mg} / \mathrm{L})}{\mathrm{SiO}_{2}}$ & $\begin{array}{c}\mathrm{Cl}^{-} \\
(\mathrm{mg} / \mathrm{L})\end{array}$ & $\underset{(\mathrm{mg} / \mathrm{L})}{\mathrm{NO}_{2}^{-}}$ & $\begin{array}{c}\mathrm{NO}_{3} \\
(\mathrm{mg} / \mathrm{L})\end{array}$ & $\begin{array}{l}\mathrm{SO}_{4}{ }^{2-} \\
(\mathrm{mg} / \mathrm{L})\end{array}$ \\
\hline 157 & 331 & 0.5 & 165 & 201.3 & 0.02 & 0.02 & 0.12 & 67 & 0.096 & 0.086 & 0.88 & 0.005 & 21 & 1.4 & 0.02 & 0.55 & 0.23 \\
\hline $157-1$ & 331 & 0.5 & 163 & 198.86 & 0.02 & 0.02 & 0.08 & 65 & 0.095 & 0.084 & 0.89 & 0.005 & 21 & 1.3 & 0.02 & 0.37 & 0.24 \\
\hline 175 & & 0.5 & 82 & 100.04 & 0.02 & 0.02 & 46 & 9.8 & 5.3 & 7.9 & 62 & 0.005 & 31 & 62 & 0.02 & 204 & 0.67 \\
\hline $175-1$ & & 0.5 & 49 & 59.78 & 0.02 & 0.02 & 44 & 9.9 & 5.2 & 7.9 & 58 & 0.005 & 31 & 60 & 0.02 & 195 & 0.54 \\
\hline
\end{tabular}

Segunda campanha de amostragem, junho-julho 2010

\begin{tabular}{|c|c|c|c|c|c|c|c|c|c|c|c|c|c|}
\hline Poços & $\begin{array}{c}\mathrm{NH}^{+} \\
(\mathrm{mg} / \mathrm{L})\end{array}$ & $\begin{array}{c}\text { Nitr } \\
\text { Orgânico } \\
\text { (mg/L) }\end{array}$ & $\begin{array}{c}\text { Nitr } \\
\text { Total } \\
\text { (mg/L) }\end{array}$ & $\underset{(\mathrm{mg} / \mathrm{L})}{\mathrm{Na}^{+}}$ & $\underset{(m g / L)}{K^{+}}$ & $\begin{array}{c}\mathrm{Mg}^{2+} \\
(\mathrm{mg} / \mathrm{L})\end{array}$ & $\begin{array}{c}\mathrm{Ca}^{2+} \\
(\mathrm{mg} / \mathrm{L})\end{array}$ & $\begin{array}{l}\mathrm{Fe}^{2+} \\
(\mathrm{lab} .) \\
(\mathrm{mg} / \mathrm{L})\end{array}$ & $\begin{array}{c}\mathrm{SiO}_{2} \\
(\mathrm{mg} / \mathrm{L})\end{array}$ & $\underset{(\mathrm{mg} / \mathrm{L})}{\mathrm{Cl}^{-}}$ & $\begin{array}{c}\mathrm{NO}_{2}{ }^{-} \\
(\mathrm{mg} / \mathrm{L})\end{array}$ & $\begin{array}{c}\mathrm{NO}_{3}^{-} \\
(\mathrm{mg} / \mathrm{L})\end{array}$ & $\underset{(\mathrm{mg} / \mathrm{L})}{\mathrm{SO}_{4}}$ \\
\hline 86 & 0.02 & 0.02 & 25.07 & 19 & 8.2 & 7.5 & 59 & 0.005 & 45 & 57 & 0.02 & 111 & 2.6 \\
\hline 486 & 0.02 & 0.02 & 0.02 & 52 & 0.28 & 0.61 & 4.1 & 0.005 & 37 & 3.3 & 0.02 & 3.9 & 0.52 \\
\hline 110 & 0.02 & 0.02 & 3.61 & 22 & 5.4 & 14 & 88 & 0.005 & 88 & 39 & 0.02 & 16 & 22 \\
\hline 310 & 0.02 & 0.02 & 3.39 & 23 & 5.5 & 14 & 89 & 0.005 & 88 & 39 & 0.02 & 15 & 22 \\
\hline
\end{tabular}


ANEXO VI. Análises químicas de nitrato preexistentes 
Análises químicas preexistentes no período compreendido entre 2005-2009. Zona Centro

\begin{tabular}{|c|c|c|c|c|c|}
\hline Poço & Bairro & Prof. (m) & Data análise & $\mathrm{N}-\mathrm{NO}_{3}{ }^{-}(\mathrm{mg} / \mathrm{L})$ & $\mathrm{NO}_{3}{ }^{-}(\mathrm{mg} / \mathrm{L})$ \\
\hline 65 & vila foglia & 120 & $31 / 10 / 2005$ & 2.00 & 8.86 \\
\hline 80 & vila formosa & 60 & $15 / 12 / 2005$ & 8.70 & 38.54 \\
\hline 188 & vila marcondes & 24 & $24 / 11 / 2005$ & 26.41 & 117.00 \\
\hline Mín. & & & & 2.00 & 8.86 \\
\hline Máx. & & & & 26.41 & 117.00 \\
\hline Média & & & & 12.37 & 54.80 \\
\hline D. P. & & & & 12.61 & 55.87 \\
\hline 71 & jardim paulistano & 120 & $13 / 06 / 2006$ & 6.46 & 28.62 \\
\hline 171 & fila furquim & 80 & $14 / 03 / 2006$ & 23.90 & 105.88 \\
\hline 142 & vila furquim & 70 & $06 / 02 / 2006$ & 6.82 & 30.21 \\
\hline Mín. & & & & 6.46 & 28.62 \\
\hline Máx. & & & & 23.90 & 105.88 \\
\hline Média & & & & 12.39 & 54.90 \\
\hline D.P & & & & 9.97 & 44.15 \\
\hline 50 & centro & 150 & 04/07/2007 & 10.70 & 47.40 \\
\hline 93 & centro, vila são jorge & 150 & $11 / 04 / 2007$ & 6.87 & 10.5 \\
\hline 177 & jardim santa helena & 130 & $14 / 08 / 2007$ & 22.00 & 97.46 \\
\hline 175 & vila marcondes & 120 & $13 / 04 / 2007$ & 24.40 & 108.09 \\
\hline 187 & vila industrial & 118 & $06 / 02 / 2007$ & 12.92 & 57.24 \\
\hline 6 & vila são jorge & 100 & 03/04/2007 & 9.11 & 40.34 \\
\hline 86 & vila nova & 100 & $22 / 02 / 2007$ & 22.00 & 97.46 \\
\hline 138 & centro & 80 & $10 / 04 / 2007$ & 20.50 & 90.82 \\
\hline 192 & vila brasil & 80 & $27 / 03 / 2007$ & 5.36 & 12.14 \\
\hline 15 & bosque & 70 & $22 / 02 / 2007$ & 22.00 & 97.46 \\
\hline 15 & bosque & 70 & $16 / 04 / 2007$ & 21.71 & 96.18 \\
\hline 129 & vila formosa & 60 & $16 / 08 / 2007$ & 15.72 & 69.64 \\
\hline Mín. & & & & 5.36 & 10.50 \\
\hline Máx. & & & & 24.40 & 108.09 \\
\hline Média & & & & 16.11 & 68.73 \\
\hline D. P. & & & & 6.83 & 34.71 \\
\hline 196 & vila indusrial & 152 & $24 / 07 / 2008$ & 31.80 & 140.87 \\
\hline 10 & jdm paulistano & 100 & $30 / 09 / 2008$ & 2.62 & 11.61 \\
\hline 86 & vila nova & 100 & $14 / 06 / 2008$ & 1 & 4.43 \\
\hline 118 & vila industrial & 70 & $04 / 08 / 2008$ & 36.80 & 163.02 \\
\hline 130 & vila formosa & 80 & $31 / 01 / 2008$ & 7.33 & 32.47 \\
\hline Mín. & & & & 1.00 & 4.43 \\
\hline Máx. & & & & 36.80 & 163.02 \\
\hline Média & & & & 11.94 & 70.48 \\
\hline D. P. & & & & 16.79 & 75.49 \\
\hline 6 & vila são jorge & 110 & $23 / 12 / 2009$ & 8.80361 & 39.0 \\
\hline 187 & vila industrial & 108 & $23 / 12 / 2009$ & 14.22 & 63 \\
\hline 86 & vila nova & 100 & $23 / 12 / 2009$ & 29.35 & 130.0 \\
\hline 110 & trevo rodoviário & 100 & $23 / 12 / 2009$ & 3.16 & 14 \\
\hline 171 & fila furquim & 80 & $30 / 01 / 2009$ & 33.03 & 146.32 \\
\hline 118 & vila industrial & 70 & $23 / 12 / 2009$ & 28.67 & 127 \\
\hline 80 & vila formosa & 60 & $26 / 01 / 2009$ & 8.69 & 38.50 \\
\hline Mín. & & & & 3.16 & 14.00 \\
\hline Máx. & & & & 33.03 & 146.32 \\
\hline Média & & & & 17.99 & 79.69 \\
\hline D. P. & & & & 12.07 & 53.47 \\
\hline
\end{tabular}

Mín.- Valor mínimo; Máx.- Valor máximo; D. P.- Desvio Padrão. 127=valores de concentrações máximas acima do limite permitido; $38.50=$ valores entre 23 e $45 \mathrm{mg} / \mathrm{L}$ de nitrato 
Análises quimicas preexistentes no periodo compreendido entre 2005-2009. Zona Sudeste

\begin{tabular}{|c|c|c|c|c|c|}
\hline Poço & Bairro & $\begin{array}{l}\text { Prof. } \\
\text { (m) }\end{array}$ & $\begin{array}{l}\text { Data } \\
\text { análise }\end{array}$ & $\begin{array}{l}\mathrm{N} \sim \mathrm{NO}_{3}{ }^{-} \\
(\mathrm{mg} / \mathrm{L})\end{array}$ & $\begin{array}{l}\mathrm{NO}_{3}^{-} \\
(\mathrm{mg} / \mathrm{L})\end{array}$ \\
\hline 12 & parque damhal & 200 & $18 / 11 / 2005$ & 6.00 & 26.6 \\
\hline 13 & parque damha II & 110 & $30 / 11 / 2005$ & 1.00 & 4.43 \\
\hline Min. & & & & 1.00 & 4.43 \\
\hline Máx. & & & & 6.00 & 26.58 \\
\hline Média & & & & 2.83 & 12.55 \\
\hline D.P. & & & & 2.75 & 12.20 \\
\hline Poço & Bairro & $\begin{array}{l}\text { Prof. } \\
\text { (m) }\end{array}$ & $\begin{array}{l}\text { Data } \\
\text { análise }\end{array}$ & $\begin{array}{l}\mathrm{N} \cdot \mathrm{NO}_{3}{ }^{-} \\
(\mathrm{mg} / \mathrm{L})\end{array}$ & $\begin{array}{l}\mathrm{NO}_{3}^{-} \\
(\mathrm{mg} / \mathrm{L})\end{array}$ \\
\hline 12 & jd alto de boa vista & 200 & $05 / 07 / 2006$ & 0.09 & 0.41 \\
\hline 12 & jd alto de boa vista & 200 & $05 / 07 / 2006$ & 0.35 & 1.57 \\
\hline 105 & vila nova prudente & 180 & $05 / 07 / 2006$ & 1.42 & 6.30 \\
\hline 105 & vila nova prudente & 180 & $05 / 07 / 2006$ & 1.41 & 6.23 \\
\hline 105 & vila nova prudente & 180 & $05 / 07 / 2006$ & 1.50 & 6.65 \\
\hline 13 & parque damha II & 110 & $30 / 03 / 2006$ & 2.01 & 8.90 \\
\hline 69 & parque damhal & 80 & 24/05/2006 & 15.86 & 70.26 \\
\hline Min. & & & & 0.00 & 0.01 \\
\hline Máx. & & & & 15.86 & 70.26 \\
\hline Média & & & & 2.83 & 12.54 \\
\hline D.P. & & & & 5.32 & 23.55 \\
\hline Poço & Bairro & $\begin{array}{l}\text { Prof. } \\
\text { (m) }\end{array}$ & $\begin{array}{l}\text { Data } \\
\text { análise }\end{array}$ & $\begin{array}{l}\mathrm{N}-\mathrm{NO}_{3} \\
(\mathrm{mg} / \mathrm{L})\end{array}$ & $\begin{array}{l}\mathrm{NO}_{3}^{-} \\
(\mathrm{mg} / \mathrm{L})\end{array}$ \\
\hline 16 & residencial anita tiezzi & 120 & $17 / 01 / 2007$ & 0.05 & 0.22 \\
\hline 75 & parque damha & 100 & $11 / 01 / 2007$ & 2.99 & 13.25 \\
\hline 79 & parque damha I & 100 & $11 / 01 / 2007$ & 6.18 & 27.38 \\
\hline 81 & parque damba I & 100 & $11 / 01 / 2007$ & 3.22 & 14.26 \\
\hline Min. & & & & 0.05 & 0.22 \\
\hline Máx. & & & & 7.93 & 35.13 \\
\hline Média & & & & 4.07 & 18.05 \\
\hline D. P. & & & & 3.06 & 13.54 \\
\hline Poço & Bairro & $\begin{array}{l}\text { Prof. } \\
\text { (m) }\end{array}$ & $\begin{array}{l}\text { Data } \\
\text { análise }\end{array}$ & $\begin{array}{l}\mathrm{N}_{-N O_{3}} \\
(\mathrm{mg} / \mathrm{L})\end{array}$ & $\begin{array}{l}\mathrm{NO}_{3}{ }^{-} \\
(\mathrm{mg} / \mathrm{L})\end{array}$ \\
\hline 13 & parque damha ll & 110 & $22 / 07 / 2008$ & 2.73 & 12.09 \\
\hline 13 & parque damha II & 110 & $22 / 07 / 2008$ & 4.32 & 19.12 \\
\hline Min. & & & & 2.73 & 12.09 \\
\hline Máx. & & & & 4.32 & 19.12 \\
\hline Média & & & & 3.49 & 15.47 \\
\hline D. P. & & & & 0.80 & 3.52 \\
\hline 12 & parque damha I & 200 & $23 / 12 / 2009$ & 7.22 & 32 \\
\hline
\end{tabular}

Mín.- Valor mínimo; Máx.- Valor máximo; D. P.- Desvio Padräo. 127=valores de concentrações máximas acima do limite permitido; $8.60 .$. valores entre 23 e $45 \mathrm{mg} / \mathrm{L}$ de nitrato 
Análises químicas preexistentes no período compreendido entre 2005-2009. Zona Oeste

\begin{tabular}{|c|c|c|c|c|c|}
\hline Poço & Bairro & Prof. (m) & Data análise & $\mathrm{N}-\mathrm{NO}_{3}{ }^{-}(\mathrm{mg} / \mathrm{L})$ & $\mathrm{NO}_{3}{ }^{-}(\mathrm{mg} / \mathrm{L})$ \\
\hline 28 & Jd santa eliza & 130 & $06 / 03 / 2005$ & 0.51 & 2.26 \\
\hline 29 & jd santa eliza & 130 & $06 / 03 / 2005$ & 0.79 & 3.50 \\
\hline 30 & jd santa eliza & 130 & $06 / 03 / 2005$ & 0.37 & 1.64 \\
\hline 26 & jd santa eliza & 120 & $11 / 03 / 2005$ & 1.4 & 6.20 \\
\hline 119 & pq. servantes 2 & 100 & $03 / 11 / 2005$ & 3.4 & 15.06 \\
\hline 119 & pq. servantes 3 & 100 & $25 / 11 / 2005$ & 5 & 22.15 \\
\hline 101 & bosque & 90 & $16 / 08 / 2005$ & 1.6 & 7.09 \\
\hline Min. & & & & 0.37 & 1.64 \\
\hline Máx. & & & & 5.00 & 22.15 \\
\hline $\begin{array}{l}\text { Média } \\
\text { D. P. }\end{array}$ & & & & $\begin{array}{l}1.87 \\
1.72 \\
\end{array}$ & $\begin{array}{l}8.27 \\
7.61 \\
\end{array}$ \\
\hline 134 & jd das rosas & 150 & $09 / 08 / 2006$ & 1.5 & 6.65 \\
\hline 134 & $\mathrm{jd}$ das rosas & 150 & $05 / 09 / 2006$ & 1.1 & 4.87 \\
\hline 144 & centro-oeste & 116.5 & $09 / 03 / 2006$ & 5.9 & $20: 4$ \\
\hline Mín. & & & & 1.10 & 4.87 \\
\hline Máx. & & & & 5.90 & 26.14 \\
\hline Média & & & & 2.83 & 12.55 \\
\hline D. P. & & & & 2.66 & 11.80 \\
\hline 198 & jó cica & 250 & $16 / 11 / 2007$ & 0.36 & 1.59 \\
\hline 117 & jd são luiz & 160 & $22 / 08 / 2007$ & 0.42 & 1.86 \\
\hline 15 & Jd Satélite & 164 & $21 / 08 / 2007$ & 0.42 & 1.86 \\
\hline 91 & jd icaray & 125 & $05 / 07 / 2007$ & 0.01 & 0.04 \\
\hline 20 & jd maracanã & 120 & $13 / 02 / 2007$ & 10.07 & 44.61 \\
\hline 20 & jd maracanä & 120 & $19 / 09 / 2007$ & 13.05 & 57.81 \\
\hline 147 & pq. carandá & 102 & $20 / 06 / 2007$ & 0.1 & 0.44 \\
\hline 119 & pq.servantes 2 & 100 & $27 / 06 / 2007$ & 4.92 & था \\
\hline 90 & jd cinquentenário & 90 & $19 / 06 / 2007$ & 5.36 & हौ॰ \\
\hline 124 & centro & 72 & $08 / 08 / 2007$ & 1.04 & 4.62 \\
\hline 9 & jd cambuhy & 60 & $10 / 01 / 2007$ & 0.05 & 0.22 \\
\hline 170 & jd santa fe & 60 & $10 / 01 / 2007$ & 2.36 & 10.45 \\
\hline 139 & jd cambuy & 56 & $22 / 06 / 2007$ & 4.44 & 19.71 \\
\hline Min. & & & & 0.01 & 0.04 \\
\hline Máx. & & & & 13.05 & 57.81 \\
\hline $\begin{array}{l}\text { Média } \\
\text { D. P. }\end{array}$ & & & & $\begin{array}{l}3.28 \\
4.20 \\
\end{array}$ & $\begin{array}{r}14.53 \\
18.62 \\
\end{array}$ \\
\hline 145 & jd das rosas & 195 & $01 / 02 / 2008$ & 0.42 & 1.86 \\
\hline 151 & jd maracana & 130 & $17 / 06 / 2008$ & 2.92 & 12.94 \\
\hline 20 & jd maracana & 120 & $14 / 08 / 2008$ & 3.0 & 13.29 \\
\hline 131 & pq. cedral & 110 & $20 / 10 / 2008$ & 2.3 & 10.19 \\
\hline 76 & jư sãoluiz & 101 & $23 / 07 / 2008$ & 0.919 & 4.07 \\
\hline Min. & & & & 0.42 & 1.86 \\
\hline Máx. & & & & 13.05 & 13.29 \\
\hline $\begin{array}{l}\text { Média } \\
\text { D.P. }\end{array}$ & & & & $\begin{array}{l}1.91 \\
1.18 \\
\end{array}$ & $\begin{array}{l}8.47 \\
5.22 \\
\end{array}$ \\
\hline 144 & centro-oeste & 117 & $23 / 12 / 2009$ & 8.58 & 88 \\
\hline 147 & pq. carandá & 102 & $23 / 12 / 2009$ & 12.87 & 57 \\
\hline 118 & pq servantes 2 & 100 & $22 / 01 / 2009$ & 4.90 & $21 \%$ \\
\hline 35 & centro-oeste & 100 & $23 / 12 / 2009$ & 2.48 & 11 \\
\hline Mín. & & & & 2.48 & 11 \\
\hline Máx. & & & & 12.86 & 57 \\
\hline $\begin{array}{l}\text { Média } \\
\text { D. P. }\end{array}$ & & & & $\begin{array}{l}7.21 \\
4.53\end{array}$ & $\begin{array}{l}31.93 \\
20.07\end{array}$ \\
\hline
\end{tabular}

Mín.- Valor mínimo; Máx.- Valor máximo; D. P.- Desvio Padrão, 127=valores de concentrações máximas acima do limite permitido; 98 s. valores entre 23 e $45 \mathrm{mg} / \mathrm{L}$. de nitrato 
Análises químicas preexistentes no periodo compreendido entre 2005-2009. Zona Nordeste

\begin{tabular}{|c|c|c|c|c|c|}
\hline Poço & Bairro & $\begin{array}{l}\text { Prof. } \\
\text { (m) }\end{array}$ & $\begin{array}{l}\text { Data } \\
\text { análise }\end{array}$ & $\begin{array}{l}\mathrm{N}-\mathrm{NO}_{3}{ }^{-} \\
(\mathrm{mg} / \mathrm{L})\end{array}$ & $\begin{array}{l}\mathrm{NO}_{3}^{-} \\
(\mathrm{mg} / \mathrm{L})\end{array}$ \\
\hline 39 & novoeste & 120 & $07 / 11 / 2006$ & 3.44 & 15.22 \\
\hline 57 & novoeste & 120 & $07 / 10 / 2006$ & 4.12 & 18.24 \\
\hline 78 & novoeste & 115 & $11 / 10 / 2006$ & 6.30 & 27.88 \\
\hline 112 & novoeste & 100 & $11 / 10 / 2006$ & 2.09 & 9.26 \\
\hline 136 & novoeste & 100 & $16 / 08 / 2006$ & 2.84 & 12.58 \\
\hline 149 & novoeste & 100 & $23 / 08 / 2006$ & 1.80 & 7.97 \\
\hline 108 & novoeste & 80 & $17 / 08 / 2006$ & 1.15 & 5.09 \\
\hline Mín. & & & & 1.15 & 5.09 \\
\hline Máx. & & & & 6.30 & 27.89 \\
\hline Média & & & & 3.10 & 13.75 \\
\hline D.P. & & & & 1.73 & 7.66 \\
\hline 52 & novoeste & 150 & $06 / 05 / 2008$ & 2.76 & 12.24 \\
\hline
\end{tabular}

Mín.- Valor mínimo; Máx.- Valor máximo; D. P.. Desvio Padrăo. 127=valores de concentraçóes máximas acima do limite permitido; 3860 valores entre 23 e $45 \mathrm{mg} / \mathrm{L}$ de nitrato 
ANEXO VII. Análises químicas separadas por zonas 
Resultados das análises quimicas dos poços amostrados dezembro 2009 e junho-julho 2011. Zona Centro

\begin{tabular}{|c|c|c|c|c|c|c|c|c|c|c|c|c|c|c|c|c|c|c|}
\hline & 2009 & 2010 & 2009 & 2010 & 2009 & 2010 & 2009 & 2010 & 2009 & 2010 & 2009 & 2010 & 2009 & 2010 & 2009 & 2010 & & \\
\hline Poço & $\begin{array}{c}\mathrm{NO}_{3}^{-} \\
(\mathrm{mg} / \mathrm{L})\end{array}$ & $\begin{array}{c}\mathrm{NO}_{3}^{-} \\
(\mathrm{mg} / \mathrm{L})\end{array}$ & $\begin{array}{c}C E \\
(\mu S / \mathrm{cm})\end{array}$ & $\begin{array}{c}C E \\
(\mu \mathrm{S} / \mathrm{cm})\end{array}$ & $\begin{array}{c}\mathrm{Na}^{4} \\
(\mathrm{mg} / \mathrm{L})\end{array}$ & $\begin{array}{c}\mathrm{Na}^{+} \\
(\mathrm{mg} / \mathrm{L})\end{array}$ & $\begin{array}{c}\mathrm{K}^{+} \\
(\mathrm{mg} / \mathrm{L})\end{array}$ & $\begin{array}{c}\mathrm{K}^{+} \\
(\mathrm{mg} / \mathrm{L})\end{array}$ & $\begin{array}{c}\mathrm{Mg}^{2+} \\
(\mathrm{mg} / \mathrm{L})\end{array}$ & $\begin{array}{c}\mathrm{Mg}^{2+} \\
(\mathrm{mg} / \mathrm{L})\end{array}$ & $\begin{array}{c}\mathrm{Ca}^{2+} \\
(\mathrm{mg} / \mathrm{L})\end{array}$ & $\begin{array}{c}\mathrm{Ca}^{2+} \\
(\mathrm{mg} / \mathrm{L})\end{array}$ & $\begin{array}{c}\mathrm{Cl}^{-} \\
(\mathrm{mg} / \mathrm{L})\end{array}$ & $\begin{array}{c}\mathrm{Cl}^{-} \\
(\mathrm{mg} / \mathrm{L})\end{array}$ & $\begin{array}{l}\mathrm{SO}_{4}{ }^{2-} \\
(\mathrm{mg} / \mathrm{L})\end{array}$ & $\begin{array}{l}\mathrm{SO}_{4}{ }^{2-} \\
(\mathrm{mg} / \mathrm{L})\end{array}$ & $\begin{array}{c}Q \\
\left(m^{3} / h\right)\end{array}$ & $\begin{array}{l}\text { Prof. } \\
\text { (m) }\end{array}$ \\
\hline 118 & 127 & & 451.0 & & 9.2 & & 7.7 & & 9.7 & & 43.0 & 52.0 & 49.0 & 21.0 & 0.2 & 2.0 & 1.44 & 70 \\
\hline 110 & 14 & 16.0 & 750.0 & 701.0 & 173.0 & 22.0 & 4.8 & 5.4 & 26.0 & 14.0 & 93.0 & 88.0 & 37.0 & 39.0 & 12.0 & 14.0 & & 100 \\
\hline 62 & 37 & 33.0 & 291.3 & 198.3 & 7.6 & 9.4 & 4.1 & 3.8 & 3.7 & 3.1 & 20.0 & 20.0 & 18.0 & 20.0 & 0.1 & 0.1 & 5 & 100 \\
\hline 86 & 130 & 111.0 & 577.0 & 584.0 & 10.0 & 19.0 & 2.9 & 8.2 & 6.5 & 7.5 & 36.0 & 59.0 & 0.02 & 57.0 & 1.0 & 0.1 & 3.6 & 100 \\
\hline 187 & 63 & 72.0 & 352.0 & 368.0 & 6.5 & 8.2 & 5.8 & 6.9 & 7.6 & 6.8 & 33.0 & 30.0 & 30.0 & 41.0 & 0.1 & 4.5 & 5.1 & 108 \\
\hline 6 & 39 & 51.0 & 314.0 & 417.0 & 14.0 & 9.9 & 7.6 & 3.3 & 9.2 & 6.1 & 67.0 & 41.3 & 14.0 & 20.3 & 0.1 & 0.1 & 6 & 110 \\
\hline 175 & 204 & 104.0 & 488.0 & 496.0 & 9.8 & 16.0 & 5.3 & 5.5 & 7.9 & 6.5 & 62.0 & 52.0 & 62.0 & 37.0 & 0.7 & 0.2 & 10 & 120 \\
\hline 49 & 6.8 & 7.1 & 205.0 & 184.4 & 9.7 & 12.0 & 2.4 & 2.4 & 4.2 & 3.6 & 21.0 & 19.0 & 3.0 & 2.5 & 0.1 & 2.6 & 4.5 & 132 \\
\hline 146 & 25 & 10.0 & 402.0 & 370.0 & 17.0 & 17.0 & 3.1 & 3.2 & 4.8 & 4.2 & 55.0 & 52.0 & 46.0 & 21.0 & 5.0 & 0.2 & 15 & 250 \\
\hline 176 & & 64.0 & & 332.0 & & 21.0 & & 7.9 & & 5.3 & & 25.0 & & & & 0.2 & 3.6 & 132 \\
\hline Min. & 6.80 & 7.10 & 205.00 & 184.40 & 6.50 & 8.20 & 2.40 & 2.40 & 3.70 & 3.10 & 20.00 & 19.00 & 0.02 & 2.50 & 0.06 & 0.05 & 1.44 & 70 \\
\hline Máx. & 204.00 & 111.00 & 750.00 & 701.00 & 173.00 & 22.00 & 7.70 & 8.20 & 26.00 & 14.00 & 93.00 & 88.00 & 62.00 & 57.00 & 12.00 & 14.00 & 15.00 & 250 \\
\hline Média & 71.76 & 52.01 & 425.59 & 405.63 & 28.53 & 14.94 & 4.86 & 5.18 & 8.84 & 6.34 & 47.78 & 43.83 & 28.78 & 28.76 & 2.13 & 2.40 & & \\
\hline D.P & 67.11 & 39.00 & 165.01 & 168.59 & 54.27 & 5.23 & 1.94 & 2.14 & 6.78 & 3.24 & 23.82 & 21.39 & 21.52 & 16.12 & 4.03 & 4.34 & & \\
\hline C. V. & 0.94 & 0.75 & 0.39 & 0.42 & 1.90 & 0.35 & 0.40 & 0.41 & 0.77 & 0.51 & 0.50 & 0.49 & 0.75 & 0.56 & 1.89 & 1.81 & & \\
\hline
\end{tabular}


Resultados das análises quimicas dos poços amostrados dezembro 2009 e junho-julho 2011. Zona Oeste

\begin{tabular}{|c|c|c|c|c|c|c|c|c|c|c|c|c|c|c|c|c|c|c|}
\hline & 2009 & 2010 & 2008 & 2010 & 2009 & 2010 & 2009 & 2010 & 2009 & 2010 & 2009 & 2010 & 2009 & 2010 & 2009 & 2010 & & \\
\hline Poço & $\begin{array}{c}\mathrm{NO}_{3}^{-} \\
(\mathrm{mg} / \mathrm{L})\end{array}$ & $\begin{array}{c}\mathrm{NO}_{3}^{-} \\
(\mathrm{mg} / \mathrm{L})\end{array}$ & $\begin{array}{c}C E \\
(\mu \mathrm{S} / \mathrm{cm})\end{array}$ & $\begin{array}{c}\text { CE } \\
(\mu \mathrm{S} / \mathrm{cm})\end{array}$ & $\begin{array}{c}\mathrm{Na}^{+} \\
(\mathrm{mg} / \mathrm{L})\end{array}$ & $\begin{array}{c}\mathrm{Na}^{+} \\
(\mathrm{mg} / \mathrm{L})\end{array}$ & $\begin{array}{c}\mathrm{K}^{+} \\
(\mathrm{mg} / \mathrm{L})\end{array}$ & $\begin{array}{c}\mathrm{K}^{+} \\
(\mathrm{mg} / \mathrm{L})\end{array}$ & $\begin{array}{c}\mathrm{Mg}^{2+} \\
(\mathrm{mg} / \mathrm{L})\end{array}$ & $\begin{array}{c}\mathrm{Mg}^{2+} \\
(\mathrm{mg} / \mathrm{L})\end{array}$ & $\begin{array}{c}\mathrm{Ca}^{2+} \\
(\mathrm{mg} / \mathrm{L})\end{array}$ & $\begin{array}{c}\mathrm{Ca}^{2+} \\
(\mathrm{mg} / \mathrm{L})\end{array}$ & $\begin{array}{c}\mathrm{Cl}^{-} \\
(\mathrm{mg} / \mathrm{L})\end{array}$ & $\begin{array}{c}\mathrm{Cl}^{-} \\
(\mathrm{mg} / \mathrm{L})\end{array}$ & $\begin{array}{c}\mathrm{SO}_{4}{ }^{2} \\
(\mathrm{mg} / \mathrm{L})\end{array}$ & $\begin{array}{c}\mathrm{SO}_{4}{ }^{2-} \\
(\mathrm{mg} / \mathrm{L})\end{array}$ & $\begin{array}{c}Q \\
\left(\mathrm{~m}^{3} / \mathrm{h}\right)\end{array}$ & $\begin{array}{c}\text { Prof. } \\
(\mathrm{m})\end{array}$ \\
\hline 35 & 11 & 14 & 255 & 281 & 45 & 28 & 1.1 & 2.8 & 1.8 & 3.6 & 9.1 & 22 & 4.6 & 14 & 1.26 & 2.4 & 2.93 & 100 \\
\hline 87 & 36 & 26 & 361 & 359 & 16 & 16 & 2.7 & 2.8 & 8.4 & 6.8 & 41 & 36 & 25 & 26 & 2.2 & 0.37 & 3 & 100 \\
\hline 147 & 57 & 31 & 167.8 & 149.1 & 4.9 & 5.9 & 3.5 & 3.4 & 2.9 & 2.3 & 18 & 15 & 8 & 31 & 0.49 & 0.02 & 12 & 102 \\
\hline 144 & 38 & 20 & 291 & 260 & 7.3 & 8.5 & 2.3 & 2.4 & 6.8 & 5.8 & 33 & 31 & 17 & 20 & 1.23 & 1.1 & 3 & 116.5 \\
\hline 7 & 10 & 12 & 304 & 288 & 8.9 & 10 & 2.4 & 2.9 & 6.9 & 6.2 & 38 & 38 & 9.5 & 12 & 0.8 & 2.3 & 4.9 & 124 \\
\hline 159 & 0.65 & 1.5 & 328 & 369 & 66 & 52 & 0.29 & 1.7 & 1.2 & 6.1 & 4.6 & 30 & 1.4 & 1.5 & 0.29 & 1.2 & 43 & 272 \\
\hline Min. & 0.65 & 1.50 & 167.80 & 149.10 & 4.90 & 5.90 & 0.29 & 1.70 & 1.20 & 2.30 & 4.60 & 15.00 & 1.40 & 1.50 & 0.29 & 0.02 & 2.93 & 100 \\
\hline Máx. & 57.00 & 31.00 & 361.00 & 369.00 & 66.00 & 52.00 & 3.50 & 3.40 & 8.40 & 6.80 & 41.00 & 38.00 & 25.00 & 31.00 & 2.20 & 2.40 & 43.00 & 272 \\
\hline Média & 25.44 & 17.42 & 284.47 & 284.35 & 24.68 & 20.07 & 2.05 & 2.68 & 4.67 & 5.13 & 23.95 & 28.67 & 10.92 & 17.42 & 1.05 & 1.23 & & \\
\hline D.P & 21.57 & 10.58 & 67.31 & 79.56 & 25.05 & 17.52 & 1.16 & 0.58 & 3.06 & 1.77 & 15.49 & 8.71 & 8.68 & 10.58 & 0.69 & 0.97 & & \\
\hline C.V. & 0.85 & 0.61 & 0.24 & 0.28 & 1.01 & 0.87 & 0.57 & 0.22 & 0.66 & 0.34 & 0.65 & 0.30 & 0.79 & 0.61 & 0.66 & 0.79 & & \\
\hline
\end{tabular}


Resultados das análises quimicas dos poços amostrados dezembro 2009 e junho-julho 2011. Zona Sudeste

\begin{tabular}{|c|c|c|c|c|c|c|c|c|c|c|c|c|c|c|c|c|c|c|}
\hline & 2009 & 2010 & 2009 & 2010 & 2009 & 2010 & 2009 & 2010 & 2009 & 2010 & 2009 & 2010 & 2009 & 2010 & 2009 & 2010 & & \\
\hline Poços & $\begin{array}{c}\mathrm{NO}_{3} \\
(\mathrm{mg} / \mathrm{L})\end{array}$ & $\begin{array}{c}\mathrm{NO}_{3}^{-} \\
(\mathrm{mg} / \mathrm{L})\end{array}$ & $\begin{array}{c}\mathrm{CE} \\
(\mu \mathrm{S} / \mathrm{cm})\end{array}$ & $\underset{(\mu \mathrm{S} / \mathrm{cm})}{\mathrm{CE}}$ & $\underset{(\mathrm{mg} / \mathrm{L})}{\mathrm{Na}^{+}}$ & $\underset{(\mathrm{mg} / \mathrm{L})}{\mathrm{Na}^{+}}$ & $\underset{(\mathrm{mg} / \mathrm{L})}{\mathrm{K}^{+}}$ & $\underset{(\mathrm{mg} / \mathrm{L})}{\mathrm{K}^{+}}$ & $\begin{array}{c}\mathrm{Mg}^{2+} \\
(\mathrm{mg} / \mathrm{L})\end{array}$ & $\underset{(\mathrm{mg} / \mathrm{L})}{\mathrm{Mg}^{2+}}$ & $\begin{array}{c}\mathrm{Ca}^{2+} \\
(\mathrm{mg} / \mathrm{L})\end{array}$ & $\begin{array}{c}\mathrm{Ca}^{2+} \\
(\mathrm{mg} / \mathrm{L})\end{array}$ & $\underset{(\mathrm{mg} / \mathrm{L})}{\mathrm{Cl}^{-}}$ & $\underset{(\mathrm{mg} / \mathrm{L})}{\mathrm{Cl}}$ & $\begin{array}{l}\mathrm{SO}_{4}{ }^{2-} \\
(\mathrm{mg} / \mathrm{L})\end{array}$ & $\begin{array}{l}\mathrm{SO}_{4}{ }^{2-} \\
(\mathrm{mg} / \mathrm{L})\end{array}$ & $\left(\mathrm{m}^{\frac{Q}{3}} / \mathrm{h}\right)$ & $\begin{array}{c}\text { Prof. } \\
\text { (m) }\end{array}$ \\
\hline 96 & 27 & 21 & 110.5 & 101.1 & 3.8 & 11 & 3.1 & 2.8 & 2.4 & 2.1 & 8.1 & 7.6 & 3.8 & 3.3 & 0.48 & 0.02 & 3.6 & 60 \\
\hline 12 & 32 & 23 & 151.5 & 218 & 5.5 & 21 & 3.8 & 2.9 & 3.9 & 2.7 & 2.8 & 15 & 7.4 & 3.4 & 0.18 & 0.24 & 6 & 200 \\
\hline Min. & 27.00 & 21.00 & 110.50 & 101.10 & 3.80 & 11.00 & 3.10 & 2.80 & 2.40 & 2.10 & 2.80 & 7.60 & 3.80 & 3.30 & 0.18 & 0.02 & 3.60 & 60 \\
\hline Máx. & 32.00 & 23.00 & 151.50 & 218.00 & 5.50 & 21.00 & 3.80 & 2.90 & 3.90 & 2.70 & 8.10 & 15.00 & 7.40 & 3.40 & 0.48 & 0.24 & 6.00 & 200 \\
\hline Média & 29.50 & 22.00 & 131.00 & 159.55 & 4.65 & 16.00 & 3.45 & 2.85 & 3.15 & 2.40 & 5.45 & 11.30 & 5.60 & 3.35 & 0.33 & 0.13 & & \\
\hline D.P & 3.54 & 1.41 & 28.99 & 82.66 & 1.20 & 7.07 & 0.49 & 0.07 & 1.06 & 0.42 & 3.75 & 5.23 & 2.55 & 0.07 & 0.21 & 0.16 & & \\
\hline C.V. & 0.12 & 0.06 & 0.22 & 0.52 & 0.26 & 0.44 & 0.14 & 0.02 & 0.34 & 0.18 & 0.69 & 0.46 & 0.45 & 0.02 & 0.64 & 1.20 & & \\
\hline
\end{tabular}

Resultados das análises quimicas dos poços amostrados dezembro 2009 e junho-julho 2011. Zona Nordeste

\begin{tabular}{|c|c|c|c|c|c|c|c|c|c|c|c|c|c|c|c|c|c|c|}
\hline & 2009 & 2010 & 2009 & 2010 & 2009 & 2010 & 2009 & 2010 & 2009 & 2010 & 2009 & & 2009 & 2010 & 2009 & 2010 & & \\
\hline Poço & $\begin{array}{c}\mathrm{NO}_{3}{ }^{-} \\
(\mathrm{mg} / \mathrm{L})\end{array}$ & $\begin{array}{c}\mathrm{NO}_{3}{ }^{-} \\
\text {(mg/L) }\end{array}$ & $\begin{array}{c}C E \\
(\mu \mathrm{S} / \mathrm{cm})\end{array}$ & $\begin{array}{c}C E \\
(\mu S / \mathrm{cm})\end{array}$ & $\begin{array}{c}\mathrm{Na}^{+} \\
(\mathrm{mg} / \mathrm{L})\end{array}$ & $\begin{array}{c}\mathrm{Na}^{+} \\
(\mathrm{mg} / \mathrm{L})\end{array}$ & $\begin{array}{c}\mathrm{K}^{+} \\
(\mathrm{mg} / \mathrm{L})\end{array}$ & $\begin{array}{c}\mathrm{K}^{+} \\
(\mathrm{mg} / \mathrm{L})\end{array}$ & $\begin{array}{c}\mathrm{Mg}^{2+} \\
(\mathrm{mg} / \mathrm{L})\end{array}$ & $\begin{array}{c}\mathrm{Mg}^{2+} \\
(\mathrm{mg} / \mathrm{L})\end{array}$ & $\begin{array}{c}\mathrm{Ca}^{2+} \\
(\mathrm{mg} / \mathrm{L})\end{array}$ & $\begin{array}{c}\mathrm{Ca}^{2+} \\
(\mathrm{mg} / \mathrm{L})\end{array}$ & $\begin{array}{c}\mathrm{Cl}^{-} \\
(\mathrm{mg} / \mathrm{L})\end{array}$ & $\begin{array}{c}\mathrm{Cl}^{-} \\
(\mathrm{mg} / \mathrm{L})\end{array}$ & $\begin{array}{l}\mathrm{SO}_{4}^{2-} \\
(\mathrm{mg} / \mathrm{L})\end{array}$ & $\begin{array}{c}\mathrm{SO}_{4}{ }^{2} \\
(\mathrm{mg} / \mathrm{L})\end{array}$ & $\begin{array}{c}\mathrm{Q} \\
\left(\mathrm{m}^{3} / \mathrm{h}\right)\end{array}$ & $\begin{array}{c}\text { Prof. } \\
\text { (m) }\end{array}$ \\
\hline 200 & 91 & 78 & 280 & 300 & 12 & 15 & 11 & 14 & 8.1 & 7.1 & 12 & 9.1 & 24 & 26 & 0.02 & 0.02 & 1.8 & 68 \\
\hline 14 & 45 & 44 & 381 & 348 & 6.8 & 8.2 & 4.2 & 4.3 & 6.2 & 5.1 & 50 & 49 & 65 & 50 & 2.9 & 5.8 & 6 & 78 \\
\hline 153 & 7.8 & 2.7 & 254 & 222 & 45 & 51 & 0.38 & 0.43 & 1.6 & 1.2 & 5.9 & 6.2 & 4.4 & 1.5 & 2.4 & 0.7 & 11.92 & 217.5 \\
\hline Min. & 7.80 & 2.70 & 254.00 & 222.00 & 6.80 & 8.20 & 0.38 & 0.43 & 1.60 & 1.20 & 5.90 & 6.20 & 4.40 & 1.50 & 0.02 & 0.02 & 1.80 & 68 \\
\hline Máx. & 91.00 & 78.00 & 381.00 & 348.00 & 45.00 & 51.00 & 11.00 & 14.00 & 8.10 & 7.10 & 50.00 & 49.00 & 65.00 & 50.00 & 2.90 & 5.80 & 11.92 & 218 \\
\hline Média & 47.93 & 41.57 & 305.00 & 290.00 & 21.27 & 24.73 & 5.19 & 6.24 & 5.30 & 4.47 & 22.63 & 21.43 & 31.13 & 25.83 & 1.77 & 2.17 & & \\
\hline D.P & 41.68 & 37.71 & 67.09 & 63.59 & 20.72 & 23.00 & 5.38 & 6.99 & 3.34 & 3.00 & 23.90 & 23.92 & 30.92 & 24.25 & 1.54 & 3.16 & & \\
\hline C.V. & 0.87 & 0.91 & 0.22 & 0.22 & 0.97 & 0.93 & 1.04 & 1.12 & 0.63 & 0.67 & 1.06 & 1.12 & 0.99 & 0.94 & 0.87 & 1.45 & & \\
\hline
\end{tabular}


ANEXO VIII. Cálculo semiquantivo da concentração de nitrato 
Cálculo semiquantitativo a partir dos poços amostrados nas duas campanhas de amostragem.

\begin{tabular}{|c|c|c|c|c|c|c|c|c|c|c|c|c|}
\hline Poşo & $\begin{array}{l}\begin{array}{l}\text { Prof } \\
\text { (m) }\end{array} \\
\end{array}$ & $\begin{array}{l}\text { Malha } \\
\text { urbana }\end{array}$ & $\begin{array}{l}\text { ocup. } \\
\text { (hab/ha) }\end{array}$ & $\begin{array}{c}\mathrm{NO}_{3}^{-} \\
(2009) \\
\end{array}$ & $\begin{array}{l}\mathrm{NO}_{3}{ }^{-} \\
(2010)\end{array}$ & $\begin{array}{l}\mathrm{Cu} \mathrm{NO}_{3}{ }^{-} \\
(\mathrm{mg} / \mathrm{L})\end{array}$ & $\begin{array}{c}a \\
(\mathrm{Kg} / \mathrm{cap} / \mathrm{a})\end{array}$ & $\begin{array}{c}\text { A } \\
\text { (hab/ha) }\end{array}$ & fu & $\begin{array}{c}U \\
\text { (L/cap/d) }\end{array}$ & $\begin{array}{c}1 \\
\mathrm{~mm} / \mathrm{a}\end{array}$ & Zona \\
\hline 176 & 60 & 1980 & 160 & & 64 & 73.07 & 4 & 160 & 0.3 & 150 & 300 & \multirow{10}{*}{ 总 } \\
\hline 118 & 70 & 1960 & 160 & 127 & & 146.14 & 4 & 160 & 0.6 & 150 & 300 & \\
\hline 6 & 100 & 2004 & 160 & 38 & 62 & 73.07 & 4 & 160 & 0.3 & 150 & 300 & \\
\hline 62 & 100 & 1950 & 160 & 37 & 33 & 36.54 & 2 & 160 & 0.3 & 150 & 300 & \\
\hline 86 & 100 & 1930 & 160 & 130 & 111 & 114.48 & 4 & 160 & 0.47 & 150 & 300 & \\
\hline 110 & 100 & 2004 & 160 & 14 & 16 & 19.75 & 2 & 84 & 0.2 & 150 & 300 & \\
\hline 187 & 118 & 1960 & 160 & 63 & 72 & 73.07 & 4 & 160 & 0.3 & 150 & 300 & \\
\hline 175 & 120 & 1930 & 160 & 204 & 104 & 146.14 & 4 & 160 & 0.6 & 150 & 300 & \\
\hline 49 & 132 & 1950 & 160 & 6.8 & 7.1 & 19.75 & 2 & 84 & 0.2 & 150 & 300 & \\
\hline 146 & 250 & 1970 & 84 & 25 & 10 & 29.63 & 2 & 84 & 0.3 & 150 & 300 & \\
\hline 200 & 68 & 1990 & 20 & 91 & 78 & 59.25 & 4 & 84 & 0.3 & 150 & 300 & \multirow{3}{*}{$\begin{array}{l}\dot{0} \\
\text { ơ } \\
\frac{0}{2}\end{array}$} \\
\hline 14 & 78 & 1980 & 84 & 45 & 44 & 59.26 & 4 & 84 & 0.3 & 150 & 300 & \\
\hline 153 & 218 & 2004 & 20 & 7.8 & 2.7 & 8.69 & 2 & 20 & 0.2 & 150 & 300 & \\
\hline 96 & 60 & 1990 & 84 & 27 & 21 & 29.63 & 3 & 84 & 0.2 & 150 & 300 & \multirow{2}{*}{ के } \\
\hline 12 & 200 & 2004 & 20 & 32 & 23 & 23.45 & 4 & 20 & 0.27 & 150 & 300 & \\
\hline 35 & 100 & 1980 & 20 & 11 & 14 & 17.37 & 4 & 20 & 0.2 & 150 & 300 & \multirow{7}{*}{$\begin{array}{l}\frac{w}{5} \\
\stackrel{w}{0} \\
\end{array}$} \\
\hline 87 & 100 & 1970 & 84 & 36 & 26 & 42.96 & 3 & 84 & 0.29 & 150 & 300 & \\
\hline 144 & 117 & 2004 & 20 & 38 & 20 & 21.72 & 4 & 20 & 0.25 & 150 & 300 & \\
\hline 20 & 120 & 1990 & 20 & & 14 & 17.37 & 4 & 20 & 0.2 & 150 & 300 & \\
\hline 7 & 124 & 1980 & 20 & 10 & 12 & 13.03 & 3 & 20 & 0.2 & 150 & 300 & \\
\hline 157 & 241 & 1990 & 20 & 0.55 & & 8.69 & 2 & 20 & 0.2 & 150 & 300 & \\
\hline 159 & 272 & 1990 & 20 & 0.65 & 1.5 & 8.69 & 2 & 20 & 0.2 & 150 & 300 & \\
\hline
\end{tabular}


Cálculo semiquantitativo a partir dos poços com análises químicas preexistentes no período compreendido entre 2005-2009.

\begin{tabular}{|c|c|c|c|c|c|c|c|c|c|c|c|c|}
\hline Poço & $\begin{array}{l}\text { Prof. } \\
(\mathrm{m})\end{array}$ & $\begin{array}{l}\text { Malha } \\
\text { urbana }\end{array}$ & $\begin{array}{l}\text { Ocup. } \\
\text { (hab/ha) }\end{array}$ & $\begin{array}{l}\text { Rede } \\
\text { de } \\
\text { esgoto }\end{array}$ & $\begin{array}{c}\mathrm{NO}_{3}^{-} \\
\text {média } \\
\text { (mg/L) }\end{array}$ & $\begin{array}{c}\mathrm{Cu} \\
\mathrm{NO}_{3}^{-} \\
(\mathrm{mg} / \mathrm{L})\end{array}$ & $\begin{array}{c}\mathrm{a} \\
(\mathrm{Kg} / \mathrm{cap} / \mathrm{a})\end{array}$ & $\begin{array}{c}\text { A } \\
\text { (hab/ha) }\end{array}$ & $\mathrm{fu}$ & $\begin{array}{c}U \\
\text { (L/cap/d) }\end{array}$ & $\begin{array}{c}1 \\
(\mathrm{~mm} / \mathrm{a})\end{array}$ & Zona \\
\hline 188 & 24 & 1950 & 84 & 1990 & 117.00 & 118.51 & 4 & 84 & 0.6 & 150 & 300 & \multirow{17}{*}{ 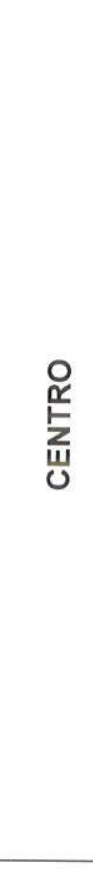 } \\
\hline 80 & 60 & 2004 & 20 & 2006 & 38.54 & 44.44 & 3 & 84 & 0.3 & 150 & 300 & \\
\hline 142 & 70 & 1970 & 160 & 1990 & 30.21 & 44.44 & 3 & 84 & 0.3 & 150 & 300 & \\
\hline 15 & 70 & 1960 & 160 & 1990 & 96.82 & 97.43 & 4 & 160 & 0.4 & 150 & 300 & \\
\hline 171 & 80 & 1960 & 160 & 1990 & 105.88 & 146.14 & 4 & 160 & 0.6 & 150 & 300 & \\
\hline 138 & 80 & 1930 & 160 & 1990 & 90.82 & 97.43 & 4 & 160 & 0.4 & 150 & 300 & \\
\hline 192 & 80 & 2004 & 160 & 1990 & 12.14 & 19.75 & 2 & 84 & 0.2 & 150 & 300 & \\
\hline 130 & 80 & 1980 & 20 & & 32.47 & 44.44 & 3 & 84 & 0.3 & 150 & 300 & \\
\hline 100 & 80 & 1960 & 160 & 1990 & 97.46 & 121.79 & 4 & 160 & 0.5 & 150 & 300 & \\
\hline 169 & 90 & 1960 & 160 & 1990 & 93.03 & 97.43 & 4 & 160 & 0.4 & 150 & 300 & \\
\hline 10 & 100 & 2004 & 160 & 1990 & 11.61 & 29.63 & 2 & 84 & 0.3 & 150 & 300 & \\
\hline 65 & 120 & 1960 & 160 & 1990 & 8.86 & 19.75 & 2 & 84 & 0.2 & 150 & 300 & \\
\hline 71 & 120 & 1960 & 160 & 1990 & 28.62 & 44.44 & 3 & 84 & 0.3 & 150 & 300 & \\
\hline 177 & 130 & 1970 & 84 & 1990 & 97.46 & 98.76 & 4 & 84 & 0.5 & 150 & 300 & \\
\hline 50 & 150 & 1960 & 84 & 1990 & 47.40 & 59.25 & 4 & 84 & 0.3 & 150 & 300 & \\
\hline 93 & 150 & 2004 & 160 & 1990 & 10.50 & 19.75 & 2 & 84 & 0.2 & 150 & 300 & \\
\hline 196 & 152 & 1960 & 160 & 1990 & 140.87 & 146.14 & 4 & 160 & 0.6 & 150 & 300 & \\
\hline 108 & 80 & 2004 & 20 & & 5.09 & 8.69 & 2 & 20 & 0.2 & 150 & 300 & \multirow{11}{*}{ 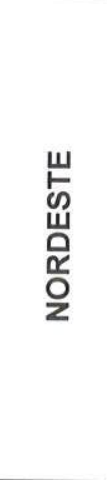 } \\
\hline 112 & 100 & 2004 & 20 & & 9.26 & 13.03 & 3 & 20 & 0.2 & 150 & 300 & \\
\hline 136 & 100 & 2004 & 20 & & 12.58 & 13.03 & 3 & 20 & 0.2 & 150 & 300 & \\
\hline 149 & 100 & 2004 & 20 & & 7.97 & 8.69 & 2 & 20 & 0.2 & 150 & 300 & \\
\hline 112 & 100 & 2004 & 20 & & 9.26 & 13.03 & 3 & 20 & 0.2 & 150 & 300 & \\
\hline 78 & 115 & 2004 & 20 & & 27.89 & 29.63 & 3 & 84 & 0.2 & 150 & 300 & \\
\hline 57 & 120 & 2004 & 20 & & 18.24 & 19.75 & 2 & 84 & 0.2 & 150 & 300 & \\
\hline 39 & 120 & 2004 & 20 & & 15.22 & 19.54 & 3 & 20 & 0.3 & 150 & 300 & \\
\hline 52 & 150 & 2004 & 20 & & 12.24 & 13.03 & 3 & 20 & 0.2 & 150 & 300 & \\
\hline 164 & 199 & 1980 & 20 & & 0.66 & 8.69 & 2 & 20 & 0.2 & 150 & 300 & \\
\hline 160 & 206 & 1980 & 20 & & 15.06 & 19.54 & 3 & 20 & 0.3 & 150 & 300 & \\
\hline
\end{tabular}


Continuação

Cálculo semiquantitativo a partir dos poços com análises químicas preexistentes no periodo compreendido entre 2005-2009.

\begin{tabular}{|c|c|c|c|c|c|c|c|c|c|c|c|c|}
\hline Poço & $\begin{array}{l}\text { Prof. } \\
\text { (m) }\end{array}$ & $\begin{array}{l}\text { Malha } \\
\text { urbana }\end{array}$ & $\begin{array}{c}\text { Ocup. } \\
\text { (hab/ha) }\end{array}$ & $\begin{array}{l}\text { Rede } \\
\text { de } \\
\text { esgoto }\end{array}$ & $\begin{array}{l}\mathrm{NO}_{3}^{-} \\
\text {média } \\
\text { (mg/L) }\end{array}$ & $\begin{array}{c}\mathrm{Cu} \\
\mathrm{NO}_{3}^{-} \\
(\mathrm{mg} / \mathrm{L})\end{array}$ & $\begin{array}{c}\mathrm{a} \\
(\mathrm{Kg} / \mathrm{cap} / \mathrm{a})\end{array}$ & $\begin{array}{c}\text { A } \\
\text { (hab/ha) }\end{array}$ & fu & $\underset{(\mathrm{L} / \mathrm{cap} / \mathrm{d})}{\mathrm{U}}$ & $\begin{array}{c}1 \\
(m m / a)\end{array}$ & Zona \\
\hline 139 & 56 & 1990 & 20 & 1990 & 19.71 & 21.72 & 4 & 20 & 0.25 & 150 & 300 & \multirow{23}{*}{$\begin{array}{l}\frac{w}{5} \\
\text { w } \\
0\end{array}$} \\
\hline 170 & 60 & 2004 & 20 & & 8.31 & 8.69 & 2 & 20 & 0.2 & 150 & 300 & \\
\hline 9 & 60 & 1990 & 20 & 1990 & 6.76 & 8.69 & 2 & 20 & 0.2 & 150 & 300 & \\
\hline 124 & 72 & 1980 & 84 & 1990 & 4.62 & 8.69 & 2 & 20 & 0.2 & 150 & 300 & \\
\hline 193 & 85 & 1990 & 20 & & 1.44 & 8.69 & 2 & 20 & 0.2 & 150 & 300 & \\
\hline 90 & 90 & 1990 & 20 & 1990 & 17.43 & 21.72 & 4 & 20 & 0.25 & 150 & 300 & \\
\hline 101 & 90 & 1990 & 84 & 2006 & 7.09 & 8.69 & 2 & 20 & 0.2 & 150 & 300 & \\
\hline 76 & 100 & 2004 & 20 & & 3.54 & 8.69 & 2 & 20 & 0.2 & 150 & 300 & \\
\hline 119 & 100 & 2004 & 20 & & 18.75 & 19.98 & 4 & 20 & 0.23 & 150 & 300 & \\
\hline 131 & 110 & 1990 & 20 & 2006 & 10.19 & 13.03 & 3 & 20 & 0.2 & 150 & 300 & \\
\hline 24 & 120 & 2004 & 20 & 2006 & 2.22 & 8.69 & 2 & 20 & 0.2 & 150 & 300 & \\
\hline 26 & 120 & 2004 & 20 & & 6.20 & 8.69 & 2 & 20 & 0.2 & 150 & 300 & \\
\hline 91 & 125 & 1990 & 84 & 1990 & 0.04 & 8.69 & 2 & 20 & 0.2 & 150 & 300 & \\
\hline 28 & 130 & 2004 & 20 & & 2.26 & 8.69 & 2 & 20 & 0.2 & 150 & 300 & \\
\hline 29 & 130 & 2004 & 20 & & 3.50 & 8.69 & 2 & 20 & 0.2 & 150 & 300 & \\
\hline 30 & 130 & 2004 & 20 & & 1.64 & 8.69 & 2 & 20 & 0.2 & 150 & 300 & \\
\hline 134 & 150 & 1980 & 84 & 1990 & 4.77 & 8.69 & 2 & 20 & 0.2 & 150 & 300 & \\
\hline 61 & 150 & 2004 & 20 & 2006 & 7.66 & 8.69 & 2 & 20 & 0.2 & 150 & 300 & \\
\hline 53 & 150 & 1990 & 84 & 2006 & 4.43 & 8.69 & 2 & 20 & 0.2 & 150 & 300 & \\
\hline 117 & 160 & 2004 & 20 & & 1.86 & 8.69 & 2 & 20 & 0.2 & 150 & 300 & \\
\hline 15 & 164 & 1960 & 160 & 1990 & 1.86 & 8.69 & 2 & 20 & 0.2 & 150 & 300 & \\
\hline 145 & 195 & 1960 & 84 & 1990 & 1.86 & 19.75 & 2 & 84 & 0.2 & 150 & 300 & \\
\hline 97 & 242 & 2004 & 20 & 2006 & 4.21 & 8.69 & 2 & 20 & 0.2 & 150 & 300 & \\
\hline 109 & 48 & 2004 & 84 & & 8.42 & 8.69 & 2 & 20 & 0.2 & 150 & 300 & \multirow{16}{*}{ 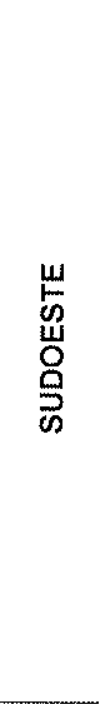 } \\
\hline 135 & 60 & 2004 & 20 & & 10.19 & 13.03 & 2 & 20 & 0.3 & 150 & 300 & \\
\hline 102 & 63 & 2004 & 20 & & 13.29 & 19.75 & 2 & 84 & 0.2 & 150 & 300 & \\
\hline 83 & 80 & 2004 & 20 & & 16.39 & 17.37 & 4 & 20 & 0.2 & 150 & 300 & \\
\hline 69 & 80 & 2004 & 20 & & 70.26 & 79.01 & 4 & 84 & 0.4 & 150 & 300 & \\
\hline 83 & 80 & 2004 & 84 & & 16.39 & 19.75 & 2 & 84 & 0.2 & 150 & 300 & \\
\hline 111 & 100 & 2004 & 84 & & 19.05 & 19.75 & 2 & 84 & 0.2 & 150 & 300 & \\
\hline 34 & 100 & 2004 & 84 & & 8.86 & 13.03 & 2 & 20 & 0.3 & 150 & 300 & \\
\hline 75 & 100 & 2004 & 84 & & 13.25 & 19.75 & 2 & 84 & 0.2 & 150 & 300 & \\
\hline 79 & 100 & 1990 & 20 & & 27.36 & 44.44 & 3 & 84 & 0.3 & 150 & 300 & \\
\hline 81 & 100 & 2004 & 20 & & 14.26 & 19.54 & 3 & 20 & 0.3 & 150 & 300 & \\
\hline 13 & 110 & 2004 & 84 & & 11.14 & 19.75 & 2 & 84 & 0.2 & 150 & 300 & \\
\hline 16 & 120 & 2004 & 20 & & 11.08 & 13.03 & 2 & 20 & 0.3 & 150 & 300 & \\
\hline 137 & 150 & 1990 & 84 & 1990 & 15.19 & 19.54 & 3 & 20 & 0.3 & 150 & 300 & \\
\hline 8 & 160 & 1990 & 84 & 1990 & 6.65 & 8.69 & 2 & 20 & 0.2 & 150 & 300 & \\
\hline 105 & 180 & 2004 & 20 & & 6.39 & 8.69 & 2 & 20 & 0.2 & 150 & 300 & \\
\hline
\end{tabular}

70.26 valores superiores ao limite de potabilidade de nitrato $(>45 \mathrm{mg} / \mathrm{L}) ; \mathrm{k} A \mathrm{~A} .4 \mathrm{~s}$ valores entre $23.45 \mathrm{mg} / \mathrm{L} ; 8.69$ valores $<\mathrm{a}$ 
ANEXO IX Perímetro de proteção dos poços 
Distâncias radiais calculadas para o tempo de trânsito de 50 dias aplicando o método de RFC para os poços rasos amostrados.

\begin{tabular}{|c|c|c|c|c|c|c|c|}
\hline Poço & $\begin{array}{l}\text { Prof. } \\
\text { (m) }\end{array}$ & $\begin{array}{c}Q \\
\left(\mathrm{~m}^{3} / \mathrm{h}\right)\end{array}$ & b & nef & $\begin{array}{c}k \\
(m / h)\end{array}$ & $i$ & $r$ \\
\hline 96 & 60 & 3,6 & 25 & 0,15 & 0,7 & 0,019 & 19,15 \\
\hline 200 & 68 & 1,8 & 42 & 0,15 & 0,7 & 0,019 & 10,45 \\
\hline 118 & 70 & 1,44 & 36 & 0,15 & 0,7 & 0,019 & 10,09 \\
\hline 14 & 78 & 6 & 49 & 0,15 & 0,7 & 0,019 & 17,66 \\
\hline 35 & 100 & 2,93 & 77 & 0,15 & 0,7 & 0,019 & 9,84 \\
\hline 87 & 100 & 3 & 72 & 0,15 & 0,7 & 0,019 & 10,30 \\
\hline 110 & 100 & 3,2 & 80 & 0,15 & 0,7 & 0,019 & 10,09 \\
\hline 147 & 102 & 12 & 42 & 0,15 & 0,7 & 0,019 & 26,97 \\
\hline 62 & 100 & 5 & 56 & 0,15 & 0,7 & 0,019 & 15,08 \\
\hline 86 & 100 & 3,6 & 45 & 0,15 & 0,7 & 0,019 & 14,27 \\
\hline 6 & 110 & 6 & 74 & 0,15 & 0,7 & 0,019 & 14,37 \\
\hline 144 & 116.5 & 3 & 51 & 0,15 & 0,7 & 0,019 & 12,24 \\
\hline 49 & 132 & 4,5 & 70 & 0,15 & 0,7 & 0,019 & 12,79 \\
\hline 20 & 120 & 3 & 60 & 0,15 & 0,7 & 0,019 & 11,28 \\
\hline 7 & 124 & 4,9 & 96 & 0,15 & 0,7 & 0,019 & 11,40 \\
\hline 176 & 132 & 3,6 & 97 & 0,15 & 0,7 & 0,019 & 9,72 \\
\hline 175 & 120 & 10 & 90 & 0,15 & 0,7 & 0,019 & 10,30 \\
\hline Min. & 60 & 1,44 & 25 & & & & 9,72 \\
\hline Máx. & 132 & 12,00 & 97 & & & & 26,97 \\
\hline Média & 101 & 4,56 & 62 & & & & 13,30 \\
\hline D.P & 22,39 & 2,75 & 22 & & & & 4,51 \\
\hline
\end{tabular}

Distâncias radiais calculadas para o tempo de trânsito de 50 dias aplicando o método de RFC para os poços profundos amostrados.

\begin{tabular}{|c|c|c|c|c|c|c|c|}
\hline Poço & $\begin{array}{l}\text { Prof. } \\
\text { (m) }\end{array}$ & $\begin{array}{c}Q \\
\left(\mathrm{~m}^{3} / \mathrm{h}\right)\end{array}$ & b & nef & $\begin{array}{c}k \\
(\mathrm{~m} / \mathrm{h})\end{array}$ & $i$ & $r$ \\
\hline 12 & 200 & 6 & 155 & 0,15 & 0,7 & 0,019 & 9,93 \\
\hline 146 & 250 & 15 & 139 & 0,15 & 0,7 & 0,019 & 16,58 \\
\hline 153 & 217.5 & 11,92 & 167 & 0,15 & 0,7 & 0,019 & 13,48 \\
\hline 157 & 241 & 60 & 167 & 0,15 & 0,7 & 0,019 & 30,25 \\
\hline 159 & 272 & 43 & 185 & 0,15 & 0,7 & 0,019 & 24,33 \\
\hline 158 & 241 & 30,47 & 181 & 0,15 & 0,7 & 0,019 & 20,70 \\
\hline Mín. & 60 & 1,44 & 25 & & & & 9,72 \\
\hline Máx. & 132 & 12,00 & 97 & & & & 26,97 \\
\hline Média & 101 & 4,56 & 62 & & & & 13,30 \\
\hline D.P & 22,39 & 2,75 & 22 & & & & 4,51 \\
\hline
\end{tabular}


Distâncias radiais calculadas para o tempo de trânsito de 50 dias aplicando o método de Wyssling para os poços rasos amostrados.

\begin{tabular}{|c|c|c|c|c|c|c|c|c|c|c|c|c|c|c|c|c|c|}
\hline $\begin{array}{l}\text { Poços } \\
\text { rasos }\end{array}$ & 96 & 200 & 118 & 14 & 35 & 87 & 110 & 147 & 62 & 86 & 6 & 144 & 49 & 20 & 7 & 176 & 175 \\
\hline$Q\left(m^{3} / h\right)$ & 3,6 & 1,8 & 1.44 & 6 & 2,93 & 3 & 3,2 & 12 & 5 & 3,6 & 6 & 3 & 4,5 & 3 & 4,9 & 3,6 & 10 \\
\hline $\mathrm{Q}\left(\mathrm{m}^{3} / \mathrm{d}\right)$ & 86,40 & 43,20 & 34,56 & 144,00 & 70,32 & 72,00 & 76,80 & 288,00 & 120,00 & 86,40 & 144,00 & 72,00 & 108,00 & 72,00 & 117,60 & 86,40 & 240,00 \\
\hline$i$ & 0,02 & 0,02 & 0,02 & 0,02 & 0,02 & 0,02 & 0,02 & 0,02 & 0,02 & 0,02 & 0,02 & 0,02 & 0,02 & 0,02 & 0,02 & 0,02 & 0,02 \\
\hline $\mathrm{K}(\mathrm{m} / \mathrm{d})$ & 0,7 & 0.7 & 0,7 & 0,7 & 0,7 & 0,7 & 0,7 & 0,7 & 0,7 & 0,7 & 0,7 & 0,7 & 0,7 & 0,7 & 0,7 & 0,7 & 0,7 \\
\hline$b(m)$ & 25 & 42 & 36 & 49 & 77 & 72 & 80 & 42 & 56 & 45 & 74 & 51 & 70 & 60 & 96 & 97 & 90 \\
\hline$n_{e}$ & 0,15 & 0,15 & 0,15 & 0,15 & 0,15 & 0,15 & 0,15 & 0,15 & 0,15 & 0,15 & 0,15 & 0,15 & 0,15 & 0,15 & 0,15 & 0,15 & 0,15 \\
\hline $\mathrm{B}(\mathrm{m})$ & 259,85 & 77,34 & 72,18 & 220,96 & 68,67 & 75,19 & 72,18 & 515,57 & 161,12 & 144,36 & 146,31 & 106,15 & 116,00 & 90,23 & 92,11 & 66,97 & 200,50 \\
\hline$B^{\prime}(m)$ & 129,92 & 38,67 & 36,09 & 110,48 & 34,33 & 37,59 & 36,09 & 257,79 & 80,56 & 72,18 & 73,16 & 53,07 & 58,00 & 45,11 & 46,05 & 33,49 & 100,25 \\
\hline $\left.\mathrm{Xo}_{\mathrm{o}} \mathrm{m}\right)$ & 41,36 & 12,31 & 11,49 & 35,17 & 10,93 & 11,97 & 11,49 & 82,06 & 25,64 & 22,98 & 23,29 & 16,89 & 18,46 & 14,36 & 14,66 & 10,66 & 31,91 \\
\hline $\mathrm{Ve}(\mathrm{m} / \mathrm{d})$ & 0,09 & 0,09 & 0,09 & 0,09 & 0,09 & 0,09 & 0,09 & 0,09 & 0,09 & 0,09 & 0,09 & 0,09 & 0,09 & 0,09 & 0,09 & 0,09 & 0,09 \\
\hline$t$ (dias) & 50,00 & 51,00 & 52,00 & 53,00 & 54,00 & 55,00 & 56,00 & 57,00 & 58,00 & 59,00 & 60,00 & 61,00 & 62,00 & 63,00 & 64,00 & 65,00 & 66,00 \\
\hline $\mathrm{I}(\mathrm{m})$ & 4,43 & 4,52 & 4,61 & 4,70 & 4,79 & 4,88 & 4,97 & 5,05 & 5,14 & 5,23 & 5,32 & 5,41 & 5,50 & 5,59 & 5,67 & 5,76 & 5,85 \\
\hline So(m) & 21,49 & 13,05 & 12,85 & 20,68 & 12,90 & 13,51 & 13,45 & 31,44 & 19,01 & $\{8,34$ & 18,62 & 16,49 & 17,26 & 15,76 & 16,04 & 14,33 & 22,47 \\
\hline $\mathrm{Su}(\mathrm{m})$ & 17,06 & 8,53 & 8,24 & 15,98 & 8,11 & 8,64 & 8,48 & 26,38 & 13,87 & 13,11 & 13,30 & 11,08 & 11,76 & 10,18 & 10,37 & 8,57 & 16,62 \\
\hline
\end{tabular}


Distâncias radiais calculadas para o tempo de trânsito de 50 dias aplicando o método de Wyssling para os poços profundos amostrados.

\begin{tabular}{|c|c|c|c|c|c|}
\hline $\begin{array}{l}\text { Poços } \\
\text { profundos }\end{array}$ & 12 & 146 & 153 & 157 & 159 \\
\hline$Q\left(m^{3} / h\right)$ & 6,00 & 15,00 & 11,92 & 60,00 & 43,00 \\
\hline$Q\left(m^{3} / d\right)$ & 144,00 & 360,00 & 286,08 & 1440,00 & 1032,00 \\
\hline$i$ & 0,02 & 0,02 & 0,02 & 0,02 & 0,02 \\
\hline $\mathrm{K}(\mathrm{m} / \mathrm{d})$ & 0,70 & 0,70 & 0,70 & 0,70 & 0,70 \\
\hline$b(m)$ & 155,00 & 138,65 & 166,50 & 167,00 & 184,61 \\
\hline ne & 0,15 & 0,15 & 0,15 & 0,15 & 0,15 \\
\hline$B(m)$ & 69,85 & 195,22 & 129,19 & 648,33 & 420,31 \\
\hline$B^{\prime}(m)$ & 34,93 & 97,61 & 64,59 & 324,16 & 210,16 \\
\hline$X o(m)$ & 11,12 & 31,07 & 20,56 & 103,19 & 66,90 \\
\hline $\operatorname{Ve}(\mathrm{m} / \mathrm{d})$ & 0,09 & 0,09 & 0,09 & 0,09 & 0,09 \\
\hline$t$ (dias) & 50,00 & 51,00 & 52,00 & 53,00 & 54,00 \\
\hline$I(m)$ & 4,43 & 4,52 & 4,61 & 4,70 & 4,79 \\
\hline $\mathrm{So}(\mathrm{m})$ & 12,39 & 19,18 & 16,27 & 33,58 & 27,82 \\
\hline $\mathrm{Su}(\mathrm{m})$ & 7,96 & 14,65 & 11,66 & 28,88 & 23,03 \\
\hline
\end{tabular}


Distâncias radiais calculadas para o tempo de trânsito de 50 dias aplicando o método de RFC e Wyssling para os poços rasos na área urbana de Presidente Prudente.

\begin{tabular}{|c|c|c|c|c|c|c|c|c|}
\hline Poço & $\begin{array}{c}Q \\
\left(\mathrm{~m}^{3} / \mathrm{h}\right)\end{array}$ & b & $n_{\text {ef }}$ & $k(\mathrm{~m} / \mathrm{h})$ & $i$ & $r$ & So $(\mathrm{m})$ & $\mathrm{Su}(\mathrm{m})$ \\
\hline 42 & 1,80 & 14,58 & 0,15 & 0,7 & 0,02 & 17,73 & 20,09 & 15,65 \\
\hline 109 & 1,60 & 30 & 0,15 & 0,7 & 0,02 & 11,65 & 14,08 & 9,65 \\
\hline 127 & 2,10 & 26 & 0,15 & 0,7 & 0,02 & 14,34 & 16,73 & 12,30 \\
\hline 139 & 2,60 & 26 & 0,15 & 0,7 & 0,02 & 15,96 & 18,33 & 13,89 \\
\hline 9 & 2,80 & 30 & 0,15 & 0,7 & 0,02 & 15,42 & 17,79 & 13,36 \\
\hline 21 & 1,60 & 33 & 0,15 & 0,7 & 0,02 & 11,11 & 13,55 & 9,11 \\
\hline 48 & 3,60 & 24 & 0,15 & 0,7 & 0,02 & 19,54 & 21,89 & 17,45 \\
\hline 80 & 3,60 & 27 & 0,15 & 0,7 & 0,02 & 18,43 & 20,78 & 16,34 \\
\hline 95 & 0,62 & 23,35 & 0,15 & 0,7 & 0,02 & 8,22 & 10,73 & 6,30 \\
\hline 126 & 2,60 & 30 & 0,15 & 0,7 & 0,02 & 14,86 & 17,24 & 12,80 \\
\hline 135 & 9,00 & 54 & 0,15 & 0,7 & 0,02 & 20,60 & 22,94 & 18,50 \\
\hline 170 & 1,60 & 33 & 0,15 & 0,7 & 0,02 & 11,11 & 13,55 & 9,11 \\
\hline 173 & 3,00 & 30 & 0,15 & 0,7 & 0,02 & 15,96 & 18,33 & 13,89 \\
\hline 102 & 3,50 & 48 & 0,15 & 0,7 & 0,02 & 13,63 & 16,02 & 11,59 \\
\hline 15 & 14,50 & 48 & 0,15 & 0,7 & 0,02 & 27,74 & 30,04 & 25,61 \\
\hline 142 & 3,00 & 35 & 0,15 & 0,7 & 0,02 & 14,77 & 17,16 & 12,72 \\
\hline 124 & 3,60 & 60 & 0,15 & 0,7 & 0,02 & 12,36 & 14,77 & 10,34 \\
\hline 66 & 5,70 & 56 & 0,15 & 0,7 & 0,02 & 16,10 & 17,93 & 13,49 \\
\hline 69 & 3,00 & 52 & 0,15 & 0,7 & 0,02 & 12,12 & 13,72 & 9,28 \\
\hline 74 & 4,00 & 46 & 0,15 & 0,7 & 0,02 & 14,88 & 15,43 & 11,00 \\
\hline 83 & 0,90 & 68 & 0,15 & 0,7 & 0,02 & 5,81 & 8,78 & 4,35 \\
\hline 94 & 3,80 & 74 & 0,15 & 0,7 & 0,02 & 11,44 & 15,11 & 10,68 \\
\hline 100 & 8,00 & 58 & 0,15 & 0,7 & 0,02 & 18,74 & 20,78 & 16,34 \\
\hline 103 & 5,00 & 60 & 0,15 & 0,7 & 0,02 & 14,57 & 16,95 & 12,52 \\
\hline 108 & 1,70 & 36 & 0,15 & 0,7 & 0,02 & 10,97 & 11,00 & 6,56 \\
\hline 128 & 4,80 & 41 & 0,15 & 0,7 & 0,02 & 17,27 & 16,66 & 12,23 \\
\hline 130 & 5,00 & 53,02 & 0,15 & 0,7 & 0,02 & 15,50 & 16,95 & 12,52 \\
\hline 138 & 1,20 & 42,88 & 0,15 & 0,7 & 0,02 & 8,44 & 9,69 & 5,26 \\
\hline 171 & 4,00 & 46 & 0,15 & 0,7 & 0,02 & 14,88 & 15,43 & 11,00 \\
\hline 192 & 4,80 & 44 & 0,15 & 0,7 & 0,02 & 16,67 & 16,66 & 12,23 \\
\hline 18 & 4,00 & 47 & 0,15 & 0,7 & 0,02 & 14,72 & 15,43 & 11,00 \\
\hline 31 & 1,80 & 60 & 0,15 & 0,7 & 0,02 & 8,74 & 11,23 & 6,80 \\
\hline 193 & 4,80 & 36 & 0,15 & 0,7 & 0,02 & 18,43 & 16,66 & 12,23 \\
\hline 25 & 2,60 & 49 & 0,15 & 0,7 & 0,02 & 11,62 & 12,95 & 8,52 \\
\hline 90 & 3,00 & 62 & 0,15 & 0,7 & 0,02 & 11,10 & 13,72 & 9,28 \\
\hline 101 & 5,60 & 62 & 0,15 & 0,7 & 0,02 & 15,17 & 17,79 & 13,36 \\
\hline 169 & 2,50 & 62 & 0,15 & 0,7 & 0,02 & 10,13 & 12,75 & 8,32 \\
\hline 10 & 3,86 & 60,38 & 0,15 & 0,7 & 0,02 & 12,76 & 15,21 & 10,77 \\
\hline 23 & 3,00 & 68 & 0,15 & 0,7 & 0,02 & 10,60 & 13,72 & 9,28 \\
\hline 34 & 3,60 & 82 & 0,15 & 0,7 & 0,02 & 10,57 & 14,77 & 10,34 \\
\hline 37 & 3,00 & 45 & 0,15 & 0,7 & 0,02 & 13,03 & 13,72 & 9,28 \\
\hline
\end{tabular}


Continuação...

\begin{tabular}{|c|c|c|c|c|c|c|c|c|}
\hline Poço & $\begin{array}{c}Q \\
\left(m^{3} / h\right)\end{array}$ & b & $\mathrm{n}_{\mathrm{ef}}$ & $\mathrm{k}(\mathrm{m} / \mathrm{h})$ & $i$ & $r$ & So $(m)$ & $\mathrm{Su}(\mathrm{m})$ \\
\hline 75 & 2,70 & 87 & 0,15 & 0,7 & 0,02 & 8,89 & 13,15 & 8,72 \\
\hline 76 & 5,00 & 64 & 0,15 & 0,7 & 0,02 & 14,10 & 16,95 & 12,52 \\
\hline 79 & 2,80 & 89 & 0,15 & 0,7 & 0,02 & 8,95 & 13,34 & 8,91 \\
\hline 81 & 2,90 & 84 & 0,15 & 0,7 & 0,02 & 9,38 & 13,53 & 9,10 \\
\hline 98 & 3,00 & 64 & 0,15 & 0,7 & 0,02 & 10,93 & 13,72 & 9,28 \\
\hline 111 & 2,80 & 56 & 0,15 & 0,7 & 0,02 & 11,28 & 13,34 & 8,91 \\
\hline 112 & 3,10 & 56 & 0,15 & 0,7 & 0,02 & 11,87 & 13,90 & 9,47 \\
\hline 119 & 5,00 & 56 & 0,15 & 0,7 & 0,02 & 15,08 & 16,95 & 12,52 \\
\hline 136 & 2,90 & 59 & 0,15 & 0,7 & 0,02 & 11,19 & 13,53 & 9,10 \\
\hline 149 & 2,00 & 55 & 0,15 & 0,7 & 0,02 & 9,62 & 11,69 & 7,26 \\
\hline 2 & 2,50 & 61 & 0,15 & 0.7 & 0,02 & 10,22 & 12,75 & 8,32 \\
\hline 13 & 5,00 & 78 & 0,15 & 0,7 & 0,02 & 12,78 & 16,95 & 12,52 \\
\hline 89 & 1,60 & 69 & 0,15 & 0,7 & 0,02 & 7,68 & 10,75 & 6,32 \\
\hline 131 & 1,96 & 73,35 & 0,15 & 0,7 & 0,02 & 8,25 & 11,60 & 7,17 \\
\hline 137 & 1,70 & 67,69 & 0,15 & 0,7 & 0,02 & 8,00 & 11,00 & 6,56 \\
\hline 190 & 2,50 & 92 & 0,15 & 0,7 & 0,02 & 8,32 & 12,75 & 8,32 \\
\hline 132 & 3,00 & 77 & 0,15 & 0,7 & 0,02 & 9,96 & 13,72 & 9,28 \\
\hline 68 & 6,00 & 82,75 & 0,15 & 0,7 & 0,02 & 13,59 & 18,33 & 13,89 \\
\hline 19 & 3,60 & 74 & 0,15 & 0,7 & 0,02 & 11,13 & 14,77 & 10,34 \\
\hline 24 & 6,30 & 77 & 0,15 & 0,7 & 0,02 & 14,43 & 18,72 & 14,28 \\
\hline 26 & 6,00 & 76 & 0,15 & 0,7 & 0,02 & 14,18 & 18,33 & 13,89 \\
\hline 39 & 3,00 & 76 & 0,15 & 0,7 & 0,02 & 10,03 & 13,72 & 9,28 \\
\hline 57 & 4,00 & 60 & 0,15 & 0,7 & 0,02 & 13,03 & 15,43 & 11,00 \\
\hline 63 & 8,00 & 60 & 0,15 & 0,7 & 0,02 & 18,43 & 20,78 & 16,34 \\
\hline 64 & 4,58 & 100 & 0,15 & 0,7 & 0,02 & 10,80 & 16,33 & 11,90 \\
\hline 72 & 4,00 & 84 & 0,15 & 0,7 & 0,02 & 11,01 & 15,43 & 11,00 \\
\hline 113 & 3,50 & 80 & 0,15 & 0,7 & 0,02 & 10,56 & 14,60 & 10,17 \\
\hline 121 & 4,50 & 60 & 0,15 & 0,7 & 0,02 & 13,82 & 16,21 & 11,78 \\
\hline 143 & 3,00 & 52 & 0,15 & 0,7 & 0,02 & 12,12 & 13,72 & 9,28 \\
\hline 28 & 10,00 & 88 & 0,15 & 0,7 & 0,02 & 17,01 & 22,94 & 18,50 \\
\hline 32 & 10,62 & 95 & 0,15 & 0,7 & 0,02 & 16,87 & 23,56 & 19,13 \\
\hline 151 & 36,60 & 65 & 0,15 & 0,7 & 0,02 & 37,87 & 41,69 & 37,26 \\
\hline 29 & 22,00 & 86 & 0,15 & 0,7 & 0,02 & 25,52 & 32,85 & 28,42 \\
\hline 56 & 3,00 & 96 & 0,15 & 0,7 & 0,02 & 8,92 & 13,72 & 9,28 \\
\hline 125 & 3,00 & 99 & 0,15 & 0,7 & 0,02 & 8,78 & 13,72 & 9,28 \\
\hline 61 & 15,00 & 108 & 0,15 & 0,7 & 0,02 & 18,81 & 27,55 & 23,11 \\
\hline 88 & 4,80 & 62,86 & 0,15 & 0,7 & 0,02 & 13,94 & 16,66 & 12,23 \\
\hline 93 & 2,60 & 43 & 0,15 & 0,7 & 0,02 & 12,41 & 12,95 & 8,52 \\
\hline Min. & 0,62 & 14,58 & 0,15 & 0,70 & 0,02 & 5,81 & 8,78 & 4,35 \\
\hline Máx. & 36,60 & 108,00 & 0,15 & 0,70 & 0,02 & 37,87 & 41,69 & 37,26 \\
\hline Média & 4,79 & 60,00 & 0,15 & 0,70 & 0,02 & 13,60 & 16,48 & 12,04 \\
\hline D.P & 5,08 & 21,51 & 0,00 & bo & 0,00 & 4,83 & 5,26 & 5,26 \\
\hline
\end{tabular}


Distâncias radiais calculadas para o tempo de trânsito de 50 dias aplicando o método de RFC e Wyssling para os poços profundos na área urbana de Presidente Prudente.

\begin{tabular}{|c|c|c|c|c|c|c|c|c|c|c|}
\hline Poço & $\begin{array}{c}Q \\
\left(m^{3} / h\right)\end{array}$ & $\begin{array}{c}Q \\
\left(m^{3} / d\right)\end{array}$ & $t$ (dia) & b & $\mathrm{n}_{\mathrm{ef}}$ & $\begin{array}{c}k \\
(\mathrm{~m} / \mathrm{h})\end{array}$ & $i$ & $r$ & So $(m)$ & $\mathrm{Su}(\mathrm{m})$ \\
\hline 196 & 15 & 360 & 50 & 82 & 0,15 & 0,7 & 0,019 & 21,58 & 20,09 & 15,65 \\
\hline 8 & 6 & 144 & 50 & 129 & 0,15 & 0,7 & 0,019 & 10,88 & 14,08 & 9,65 \\
\hline 117 & 5 & 120 & 50 & 88 & 0,15 & 0,7 & 0,019 & 12,03 & 16,73 & 12,30 \\
\hline 104 & 14,8 & 354,72 & 50 & 99,96 & 0,15 & 0,7 & 0,019 & 19,40 & 18,33 & 13,89 \\
\hline 30 & 26 & 624 & 50 & 126 & 0,15 & 0,7 & 0,019 & 22,92 & 17,79 & 13,36 \\
\hline 145 & 22 & 528 & 50 & 130 & 0,15 & 0,7 & 0,019 & 20,76 & 13,55 & 9,11 \\
\hline 105 & 10,81 & 259,44 & 50 & 118,4 & 0,15 & 0,7 & 0,019 & 15,25 & 21,89 & 17,45 \\
\hline Min. & 5,00 & 120,00 & & 82,00 & & & & 10,88 & 13,55 & 9,11 \\
\hline Máx. & 26,00 & 624,00 & & 130,00 & & & & 22,92 & 21,89 & 17,45 \\
\hline Média & 14,23 & 341,45 & & 110,48 & & & & 17,55 & 17,49 & 13,06 \\
\hline D.P & 7,79 & 187,04 & & 20,23 & & & & 4,82 & 3,02 & 3,02 \\
\hline
\end{tabular}




\section{Errata da figura 3.1}

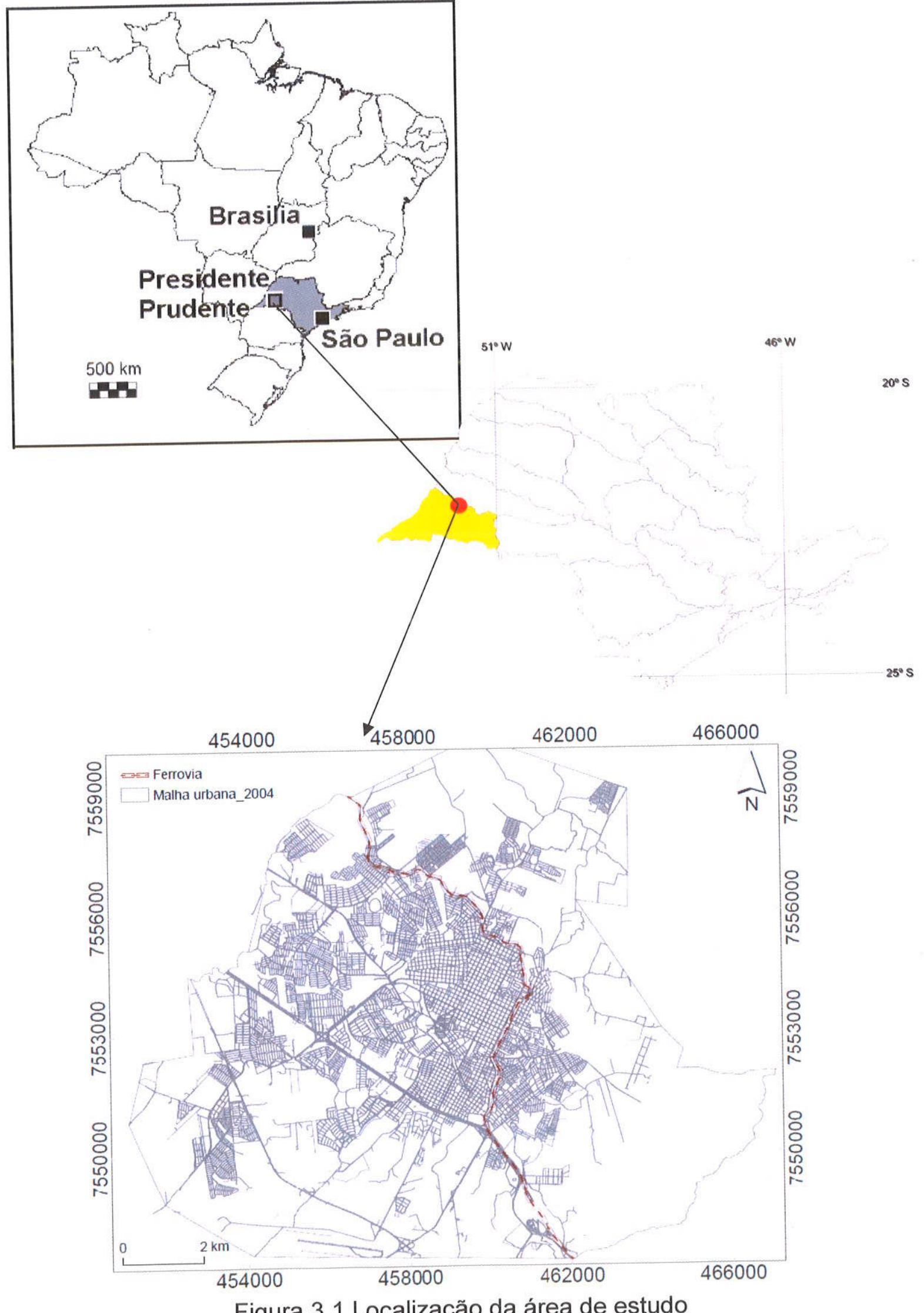

Figura 3.1 Localização da área de estudo 